\title{
The Loma Prieta, California, Earthquake of October 17, 1989-Lifelines
}

\author{
ANSHEL J. SCHIFF, Editor
}

PERFORMANCE OF THE BUILT ENVIRONMENT

Thomas L. Holzer, Coordinator

U.S. GEOLOGICAL SURVEY PROFESSIONAL PAPER 1552-A

Prepared in cooperation with the National Science Foundation
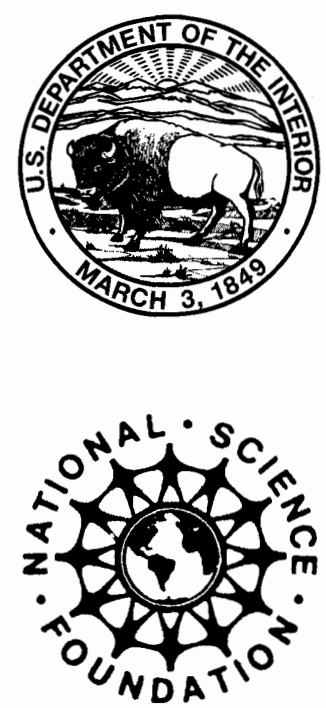

UNITED STATES GOVERNMENT PRINTING OFFICE, WASHINGTON : 1998 


\section{DEPARTMENT OF THE INTERIOR}

BRUCE BABBITT, Secretary

\section{U.S. GEOLOGICAL SURVEY}

\section{Charles G. Groat, Director}

Any use of trade, product, or firm names in this publication is for descriptive purposes only and does not imply endorsement by the U.S. Government

Manuscript approved for publication, August 5, 1997

Text edited by George A. Havach

For sale by the

U.S. Geological Survey

Information Services

Box 25286

Federal Center

Denver, CO 80225 


\section{CONTENTS}

Pages

Introduction

By Anshel J. Schiff

Electrical-power systems-

By Anshel J. Schiff, Sam Swan, and Edward N. Matsuda

Communication systems

By Anshel J. Schiff, Alex Tang, Lawrence F. Wong, and Luis Cusa

Modeling the impact of the earthquake on telecommunication services------ 37

By Michael L. Cohen

The media: Radio, television, and newspapers

By Richard J. Rapaport

Water and wastewater systems

By LeVal Lund, John McLaughlin, Curt Edwards, Gordon Laverty,

Holly Cornell, Alvin R. Guerrero, Michael Cassaro, Andries Godshack,

George Brodt, Donald B. Ballantyne, Ronald Eguchi, Mary Pickett,

Omar Abu-Yasein, Chenwun Lay, Anshel J. Schiff, James R. Blacklock, and

Steven French

Water-distribution system-

By John M. Eidinger

Water- and wastewater-treatment plants-

By William Heuback and Donald B. Ballantyne

Lessons learned by water and wastewater utilities

By Mark Pickett and Gordon L. Laverty

Transportation systems

By Joel Markowitz

Transportation systems-airports-

By Anshel J. Schiff and Luis Cusa

Transportation systems-seaports

By Charles R. Farrar and A. Claude Griffin

Transportation systems-passenger railways and buslines

By Stuart D. Werner and Anshel J. Schiff

Residential natural-gas piping and appliances

By Peter W. McDonough

Repair patterns for the gas-distribution system in San Francisco-

By Douglas G. Honegger 
THE LOMA PRIETA, CALIFORNIA, EARTHQUAKE OF OCTOBER 17, 1989: PERFORMANCE OF THE BUILT ENVIRONMENT

\author{
LIFELINES
}

\title{
INTRODUCTION
}

By Anshel J. Schiff, Precision Measurement Instruments and Stanford University

\section{CONTENTS}

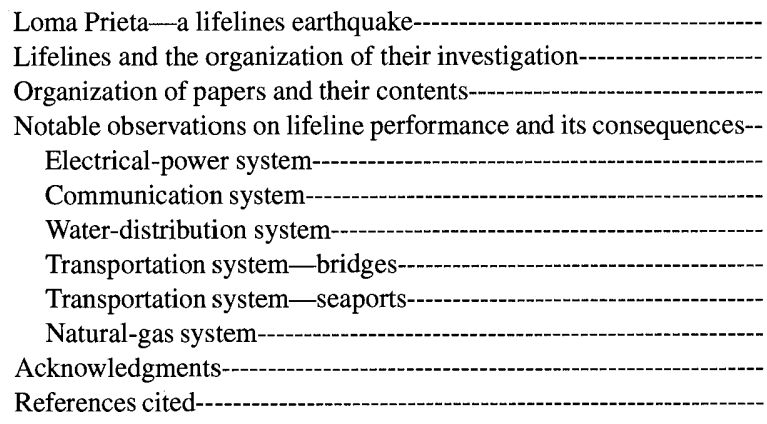

Page

A1

1

2

2

2

3

3

3

3

4

4

4

\section{LOMA PRIETA- A LIFELINES EARTHQUAKE}

To the general public who had their televisions tuned to watch the World Series, the 1989 Loma Prieta earthquake was a lifelines earthquake. It was the images seen around the world of the collapsed Cypress Street viaduct, with the frantic and heroic efforts to pull survivors from the structure that was billowing smoke; the collapsed section of the San Francisco-Oakland Bay Bridge and subsequent home video of a car plunging off the open span; and the spectacular fire in the Marina District of San Francisco fed by a broken gasline. To many of the residents of the San Francisco Bay region, the relation of lifelines to the earthquake was characterized by sitting in the dark because of power outage, the inability to make telephone calls because of network congestion, and the slow and snarled traffic. Had the public been aware of the actions of the engineers and tradespeople working for the utilities and other lifeline organizations on the emergency response and restoration of lifelines, the lifeline characteristics of this earthquake would have been even more significant. Unobserved by the public were the warlike devastation in several electrical-power substations, the $13 \mathrm{mi}$ of gas-distribution lines that had to be replaced in several communities, and the more than 1,200 leaks and breaks in water mains and service connections that had to be excavated and repaired.

Like the 1971 San Fernando, Calif., earthquake, which was a seminal event for activity to improve the earthquake performance of lifelines, the 1989 Loma Prieta earthquake demonstrated that the tasks of preparing lifelines in "earthquake country" were incomplete-indeed, new lessons had to be learned.

\section{LIFELINES AND THE ORGANIZATION OF THEIR INVESTIGATION}

The 14 papers in this chapter describe the earthquake performance of lifelines. Because one major consequence of the disruption of lifelines is its impact on emergency response, many of these papers also discuss the impact of lifeline disruption on the emergency-response communities.

Three additional papers that are related to lifelines appear in other volumes of this series. The first paper (O'Rourke and others, 1992) describes the performance of lifelines in the Marina District; the second paper (Durkin and others, 1994) describes the performance of the Public Safety Answering Point in Santa Cruz County, Calif.; and the third paper (Yashinsky, 1998) describes highway systems.

The postearthquake investigation of lifelines presents several unique problems in comparison with the investigation of, say, a severely damaged building. First, lifelines are spatially distributed systems, and so it is extremely difficult for a single individual to cover an entire system. Second, each lifeline is typically a collection of various facilities, such as buildings or structures, links that interconnect the facilities, and equipment that may function as an integrated whole that is the lifeline. Indeed, some lifelines, such as seaports, are a collection of other lifelines and specialized facilities. The need for specialized knowledge about the construction, operation, interaction, and earthquake performance of structures, equipment, and system operations makes the investigation of lifelines such a challenge. Finally, in reporting on lifeline damage, it is important to do more that count the failures. To apply the lessons that can be learned from earthquake damage, the potential failure modes, the factors that may have contributed to the failures, and the impact of failures on the facility and the lifeline must all be identified. To address these issues, the Earthquake Investigation Committee of the Technical Council on Lifeline Earthquake Engineering (TCLEE) of the American Society of Civil Engineers (ASCE) has developed training materials and conducted training courses for lifeline investigators (Schiff, 1991). 
After an earthquake, lifeline personnel have little time to discuss damage and its impact until service is returned to normal. Many lifeline facilities have controlled access, and for safety reasons, investigators are required to be accompanied by lifeline personnel, and so the investigation puts an added burden on personnel at the facility. Also, the large spatial distribution of lifelines means that it takes time for lifeline personnel to gather and assemble the information necessary to complete a picture of system damage and its impacts. Because of the importance of restoring lifeline functions, the cleanup of damage and the repair of the system starts immediately after the earthquake is over. For some lifelines, such as electrical-power and communication systems, much of the damage can be cleaned up within hours after the earthquake. For lifelines with buried distribution lines, such as water, gas, and sewage systems, a lengthy restoration process may be required in which damaged components must be identified, located, excavated, repaired, and tested. Thus, much of the damage may not be known by the utilities until days or weeks after an earthquake. For this reason, the investigation of lifelines requires an immediate response to observe damage before it is cleared, as well as later followup investigations once an overall picture of system damage and response can be pieced together.

The investigation of these systems was coordinated by the Earthquake Investigation Committee of the TCLEE; the primary coordinators were Anshel J. Schiff and LeVal Lund. Members of the committee, primarily from outside of the San Francisco Bay region, members from the other technical committees of the TCLEE, and others worked on the investigation. Most of the papers in this chapter originally appeared in the preliminary report by Schiff (1990); many of these papers have now been revised to incorporate information gained since they were originally prepared, and additional papers have been added. In general, the first author listed coordinated the collection of data and edited and (or) wrote most of the paper; the other listed authors participated in the investigation and in preparation of the paper.

Information gathered in the confusion of restoration immediately after an earthquake may be incomplete or inaccurate. Because lifeline investigations are typically conducted by professionals who volunteer their services, it is generally impossible to return to all sites to verify information. Although draft reports are sent to utilities for review and correction, discrepancies in the data may arise.

\section{ORGANIZATION OF PAPERS AND THEIR CONTENTS}

The TCLEE has adopted a format for papers describing observations made in a postearthquake investigations of lifelines. In general, the standard format starts with descriptions of the system, of the damage, and, where possible, of potential failure modes and factors that may have contributed to the failures. It continues with an identification of the impact of the damage and with comments on the emergency response and recovery, and concludes with observations and recommendations.

\section{NOTABLE OBSERVATIONS ON LIFELINE PERFORMANCE AND ITS CONSEQUENCES}

No attempt will be made here to summarize the findings of the 11 papers that deal with lifeline performance. Instead, I will highlight those features that stand out because of their uniqueness or importance.

Significantly, many of the major lifelines in the San Francisco Bay region were rather distant from the earthquake epicenter, and the ground motions were generally of moderate magnitude and duration. However, the ground motions in many of these communities from future earthquakes on faults that run through or adjacent to them are expected to be much more severe.

The poor performance of emergency power affected several lifelines and critical facilities, including powerplants, telephone-company central offices, airports, water systems, hospitals, and emergency-operation centers. A broad range of problems with emergency-power systems were observed. Failure modes and recommended practices for emergencypower generators are discussed by Schiff, Swan, and Mastuda (this chapter).

\section{ELECTRICAL-POWER SYSTEM}

The types of electrical-power-system damage observed in the 1989 Loma Prieta earthquake were similar to those observed in previous earthquakes. However, instead of the damage being concentrated at a single substation, in the 1989 Loma Prieta earthquake five substations were damaged. As a result, the high level of redundancy designed into electrical-power networks and into substations was overwhelmed. In most previous earthquakes, the isolated damage at one or two substations could be circumvented, and electrical-powersystem performance was only slightly affected. The relatively good earthquake performance of the electrical-power system in the face of severe, widespread damage is largely attributable to the resourcefulness of utility personnel in working around damaged switchyard equipment.

Damage to transformer bushings can cause extensive, long-term electrical-power disruptions. One factor contributing to the good earthquake performance of the electricalpower system was that damage to transformers was limited. Generally, if a switchyard is severely damaged, temporary powerlines can be routed around the switchyard directly to the transformers, as was done in this earthquake. If large power transformers are damaged, however, power disruption can be much more severe and longer in duration. In the 
earthquake, the damage to transformers was only limited. Three types of transformer damage were observed: Some high-voltage bushings developed oil leaks at the interface between the upper porcelain and the mounting flange, some transformer radiators developed leaks at the upper pipe flanges joining the radiators to the transformer body, and one transformer had an unexplained internal failure. Although costeffective methods for mitigating radiator leaks are available, protecting bushings is more problematic.

The good performance of electrical-power systems in recent California earthquakes may not indicate the performance to be expected in other parts of the United States where older equipment is more prevalent and where earthquakes are expected to affect much larger geographic areas. Recent earthquakes have damaged vulnerable equipment in Western electrical-power systems. As the damaged equipment is typically replaced with more robust equipment and older vulnerable equipment is replaced with more rugged equipment in normal refurbishment, the earthquake ruggedness of Western electrical-power systems is improving. Because electrical-power systems in other parts of the United States have not sustained damaging earthquakes, they lack the seismic enhancement that is associated with new replacement equipment. In addition, the seismic upgrading regularly used by many Western utilities during normal refurbishment is not generally practiced in other parts of the United States. Thus, the earthquake performance of electrical-power systems elsewhere can be expected to be poorer than that observed in California.

\section{COMMUNICATION SYSTEM}

The good earthquake performance of modern communication equipment continues to validate the use of stringent seismic-qualification specifications that include requirements for vibration testing. However, the poor earthquake performance of communication-system emergency power and the severe damage to one tall building housing critical communication equipment indicate significant system vulnerabilities.

Reliable emergency power is needed when commercial power is disrupted. Problems occurred with battery systems and engine generators, although the impact on system performance was minimal in the earthquake. A major communications company has embarked on a $\$ 10$-million retrofit program to add external power hookups for emergency power to critical facilities.

Damage to central-office structures in urban centers can cause widespread, long-term communication-system disruption. These structures need to be periodically evaluated and upgraded. The severe damage from the distant 1989 Loma Prieta earthquake to a large urban central-office building in Oakland that was designed to the then-applicable codes demonstrates communication-system vulnerabilities. Throughout the United States, older central-office structures are still in service. These structures were built to conform to older build- ing codes, many of which had no seismic provisions; and they may have been designed by engineers with limited earthquake experience. Because new equipment commonly occupies only a small fraction of the volume of the older equipment it replaces and severe problems arise in relocating a central office because trunklines are already in place, strong economic incentives exist to continue using the old structures. Although retrofitting older buildings can be costly, because these building may contain equipment worth several billion dollars, a cost-benefit analysis may well justify the additional expense.

\section{WATER-DISTRIBUTION SYSTEM}

The risk of fire after an earthquake requires a careful review of the water-distribution system for fire suppression. Although the United States has been lucky in coping with fires after earthquakes, the 1989 Loma Prieta earthquake provided another warning that appears to have gone unanswered in most communities. For example, in the earthquake, both the regular and special fire-suppression water-distribution systems failed in the Marina District of San Francisco. The favorable wind conditions at the time of the earthquake and the use of a fireboat to provide bay water to fight the fire prevented its spread to adjacent wooden structures and averted a potential disaster. Because San Francisco is one of the few cities in the world with such a double fire-suppression waterdistribution system, this failure suggests that strategies for providing fire-suppression water, other than the normal waterdistribution system, should be considered, particularly in areas where soil liquefaction and ground failure can be expected.

\section{TRANSPORTATION SYSTEM-BRIDGES}

The damage to the San Francisco-Oakland Bay Bridge from this distant earthquake suggests that it and other large bridges elsewhere in the United States which were constructed before earthquake performance was given much consideration may be vulnerable to earthquake damage. The economic impact of severe damage and loss of operation of bridges that do not have nearby alternatives, whether they cross San Francisco Bay or the Mississippi River, will be significant to most communities. The damage to relatively new, freeway-type bridges located far from this earthquake also carries an ominous warning to other parts of the United States.

\section{TRANSPORTATION SYSTEM-SEAPORTS}

Earthquake damage to seaport facilities in the San Francisco Bay region was significant, particularly when the distance from the epicenter is taken into account. Many of these seaport facilities predate the introduction of modern earthquake-damage-mitigation measures in their design and construction; new seaport facilities in seismically active areas 
generally consider earthquake performance in their design. The retrofitting of existing seaport facilities is costly and disruptive to their ongoing operations. However, severe earthquake damage to seaport facilities will impact the local economy, both in the short term, while facilities are being reconstructed, and in the long term, because users establish new shipping patterns. Thus, upgrading seaport facilities can be a sound investment.

\section{NATURAL-GAS SYSTEM}

The widespread use of seismic gas-shutoff valves requires careful review and consideration of a different relight policy. After the earthquake, a week passed before gas service was reestablish for those customers in the Pacific Gas \& Electric Co. service area who had shut off their gas. In Palo Alto, 11 days were required to restore gas service, even though almost no earthquake damage in the community was reported. The types of shutoff valves that are currently available in the United States shut off the gas when triggered by earthquake vibrations, whether a gas leak has occurred or not. The use of such valves should require that users be responsible for relighting their own system, and procedures must be instituted so that users are instructed on how to do so properly.

\section{ACKNOWLEDGMENTS}

This chapter has required not only the voluntary efforts of the authors to seek out the information and prepare the papers, but also the willingness of the many lifeline personnel to meet with the investigators to make their data available, to describe system damage, and to explain its consequences. This cooperation was typically done at a time when the personnel were deeply involved in the recovery process. I gratefully acknowledge the willingness of utility personnel to share their knowledge and data with us.

\section{REFERENCES CITED}

Durkin, M.E., Thiel, C.C., Jr., and Schneider, J.E., 1994, Casualties and emergency medical response, in Tubbesing, S.K., ed., The Loma Prieta, California, earthquake of October 17, 1989-loss estimation and procedures: U.S. Geological Survey Professional Paper 1553-A, p. A9-A38.

O'Rourke, T.D., Pease, J.W., and Stewart, H.E., 1992, Lifeline performance and ground deformation during the earthquake, in O'Rourke, T.D., ed., The Loma Prieta, California, earthquake of October 17, 1989-Marina District: U.S. Geological Survey Professional Paper 1551-F, p. F155-F179.

Schiff, A.J., ed., 1991, Guide to post-earthquake investigation of lifelines: American Society of Civil Engineers, Technical Council on Lifeline Earthquake Engineering Monograph 3, 261 p.

Schiff, A.J., and Lund, LeVal, coordinators, Lifelines, chap. 8 of Benuska, Lee, ed., 1990, Loma Prieta earthquake reconnaissance report: Earthquake Spectra, v. 6, supp. 90-01, p. 239-338.

Yashinsky, Mark, 1998, The Loma Prieta, California, earthquake of October 17, 1989-highway systems: U.S. Geological Survey Professional Paper 1552-B, 191 p. 
THE LOMA PRIETA, CALIFORNIA, EARTHQUAKE OF OCTOBER 17, 1989: PERFORMANCE OF THE BUILT ENVIRONMENT

\author{
LIFELINES
}

\title{
ELECTRICAL-POWER SYSTEMS
}

By Anshel J. Schiff, Precision Measurement Instruments and Stanford University; San Swan, EQE International;

and

Edward N. Matsuda, Pacific Gas \&Electric Co.

\section{CONTENTS}

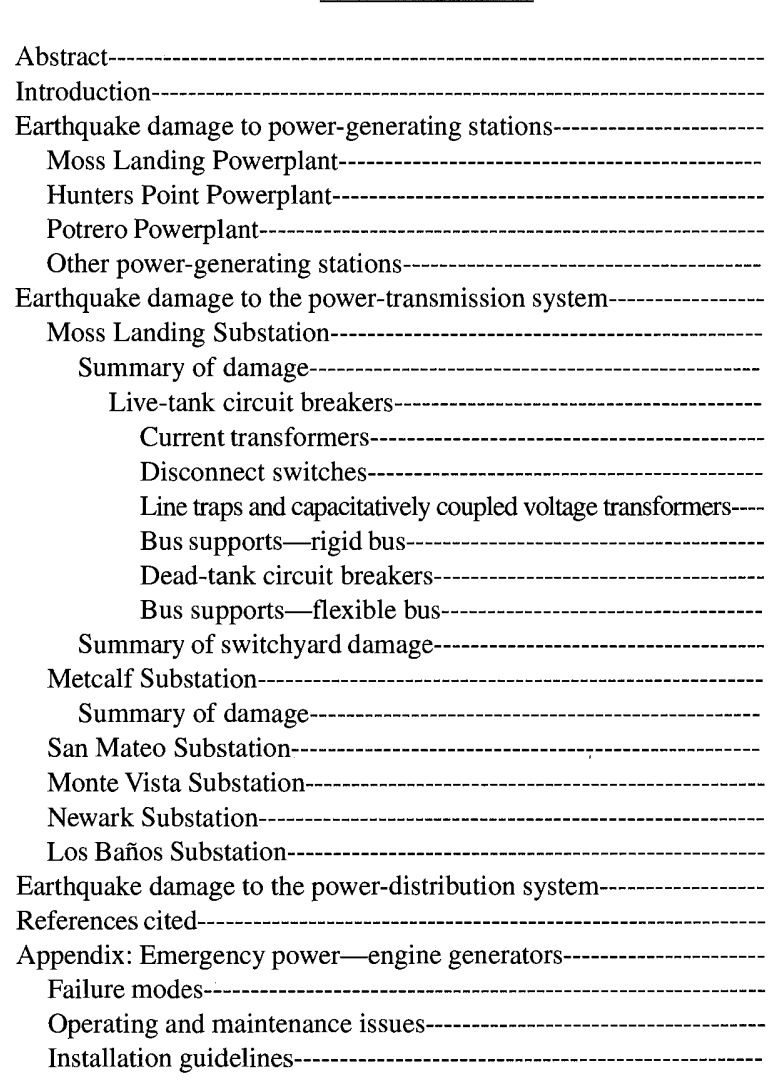

Page

A5

5

7

7

7

7

7

7

8

8

8

10

12

12

\section{ABSTRACT}

The 1989 Loma Prieta earthquake significantly damaged electrical-power facilities and disrupted service in the earthquake-affected area. The Moss Landing, Hunters Point, and Potrero Powerplants went off line. The Moss Landing Powerplant, which was closest to the epicenter, was most heavily damaged. Damage there included minor buckling of the boiler support structure, and failure of a weld at the bottomside wall of a 750,000-gal raw-water-storage tank, which led to loss of the tank contents. In another tank lo- cated in the bottom of the one of the stacks, piping connections failed, and contents were lost. The steel liner in one of the stacks pulled away from the outer stack at about threefourths of its height; the unit could not provide power because the $500-\mathrm{kV}$ switchyard to which it was connected was severely damaged. The powerplants in San Francisco, though only slightly damaged, shut down because of excessive load when power supplied from the peninsula was disrupted.

Five substations were damaged, and three were severely damaged in parts of their 230- and 500-kV switchyards. All the live-tank circuit breakers at ground-shaking sites failed. Current transformers, disconnect switches, and lightning arresters also were significantly damaged. Transformer bushings and radiators were slightly damaged. To restore service, much of the damaged equipment had to be bypassed.

Transmission lines were undamaged. Distribution lines in some areas came into contact with each other and blew fuses or burned through and dropped to the ground.

\section{INTRODUCTION}

The Pacific Gas and Electric Co. (PG\&E) is the primary electrical-power utility in the earthquake-affected area (fig. 1). A few communities, including the cities of Palo Alto, Alameda, and Santa Clara, have their own power-distribution systems, which contract for bulk electrical power delivered over the PG\&E network. In addition, some of these communities have limited power-generating capacity. Many cogeneration plants are also located in the area, most of which are relatively small.

Electrical-power systems can be divided into five major parts: (1) power-generating stations, (2) the power-transmission system, (3) the power-distribution system, (4) control and data-acquisition systems, and (5) ancillary facilities and functions. The function of each of these elements in the operation of the electrical-power system and the functions of the equipment used in the power transmission and distribution systems were described by Schiff (1973).

Three PG\&E power-generating stations are located within the earthquake-affected area. (1) The Moss Landing 
Powerplant, located by Monterey Bay, 8 mi south of Watsonville, has seven units, with a total capacity of about 2,000 MW. (2) The Potrero Powerplant, located by San Francisco Bay, has one 210-MW unit and three 52-MW peaking units; peaking units are typically gas-turbine-powered generators that are used to meet demand during brief periods of very high load. (3) The Hunters Point Powerplant, also located by San Francisco Bay, has three units with a total capacity of about $390 \mathrm{MW}$ and one 52-MW peaking unit. Many other significant power-generating stations outside of the earthquake-affected area supply electrical power to the area through the transmission system.

About 10 cogeneration plants are located in the earthquakeaffected area, ranging in size from 2.4 to $140 \mathrm{MW}$, with a total capacity of about $400 \mathrm{MW}$. These plants are generally built in conjunction with industrial facilities that require large amounts of heat; combining the generation of heat and power can improve overall efficiency.

The PG\&E power-transmission system consists of a $500-\mathrm{kV}$ system that is part of the two a-c Pacific Interties that link the Northwest to southern California. A single 500$\mathrm{kV}$ circuit branches off of the intertie and connects the Tesla Substation to the Los Baños Substation through the Metcalf and Moss Landing Substations. A more extensive 230-kV transmission network provides power to the 60 - and $115-\mathrm{kV}$ subtransmission system that supplies the power-distribution system. A simplified schematic diagram of the power-transmission system in the earthquake-affected area is shown in figure 1.

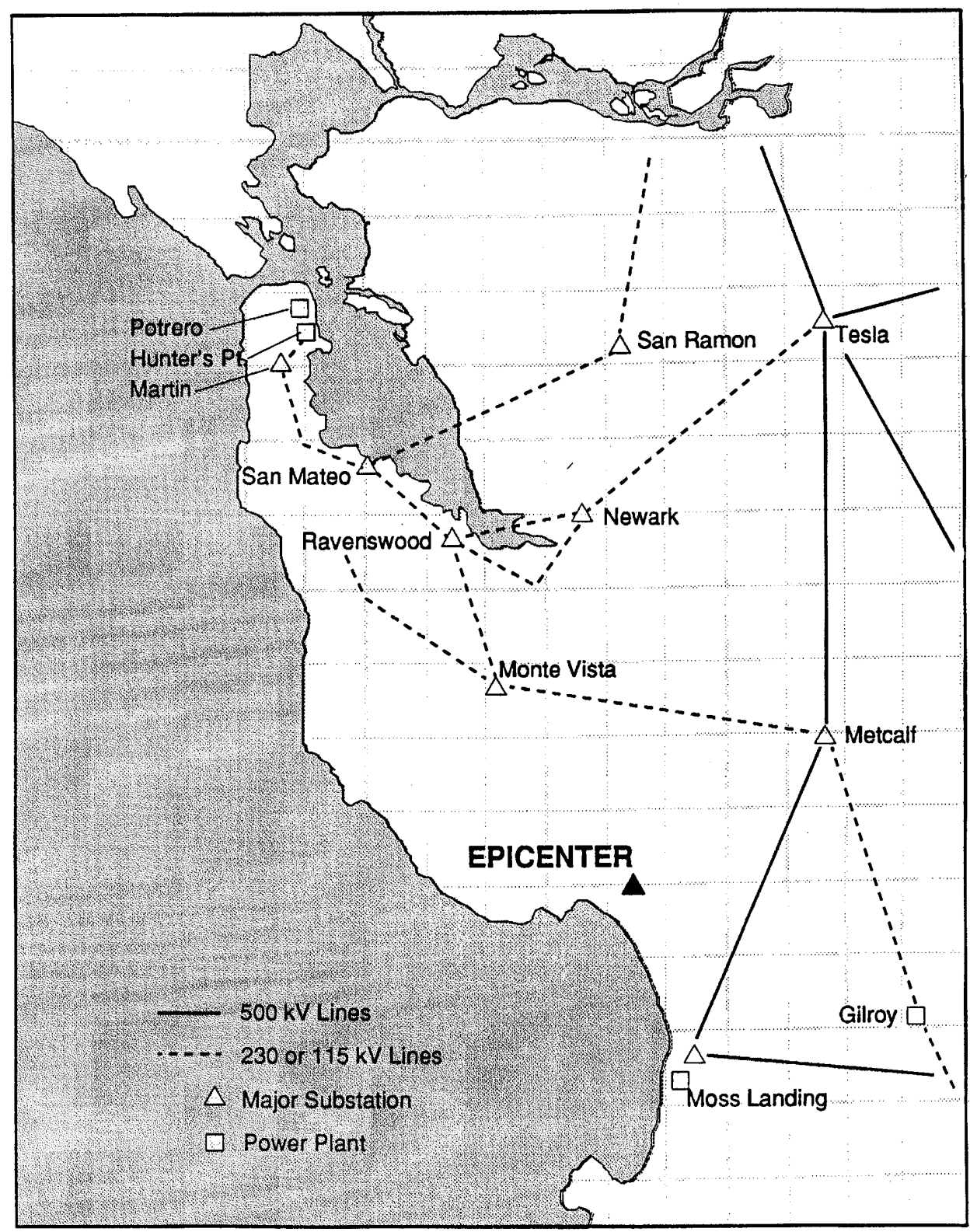

Figure 1.-San Francisco Bay region, showing locations of electrical powerplants and substations. 
The subtransmission system provides power at 60 and $115 \mathrm{kV}$ to distribution substations, which then provide power to feeders operating between 4 and $24 \mathrm{kV}$. One power grid in San Francisco operates at $12 \mathrm{kV}$; this grid is supplied power by the Potrero and Hunters Point Powerplants and from the San Mateo Substation through the Martin Substation (fig. 1). There are also 4- and 21-kV circuits in the city.

To control the electrical-power system and provide protection, an extensive communication system exists that includes microwave links, carrier-frequency communication over the power-transmission lines, leased telephone lines, and commercial telephone lines. Communication is needed among the energy-control center, generating stations, and substations. An energy-control center coordinates power generation throughout the system through its dispatch function. Ancillary facilities include several service centers that stock some spare parts, provide parking for service vehicles, and dispatch service crews who maintain and repair the transmission and distribution systems. Storage depots have larger stores of supplies and store certain types of spare equipment.

To characterize the seismic exposure of the facilities discussed below, we report on the epicentral distance of each facility and the peak ground acceleration recorded near the site. The fault rupture was about $24 \mathrm{mi}$ long, and peak accelerations were sensitive to site conditions.

\section{EARTHQUAKE DAMAGE TO POWER-GENERATING STATIONS}

The three power-generating stations in the earthquakeaffected area are the Moss Landing, Hunters Point, and Potrero Powerplants (fig. 1). For completeness, we summarize below the damage sustained by each station, with emphasis on these stations as parts of a power-distribution system. The damage to industrial equipment in the stations was described by Stepp (1990).

\section{MOSS LANDING POWERPLANT}

The Moss Landing Powerplant is located by Monterey Bay, adjacent to Moss Landing, about 18 mi south of the earthquake epicenter (fig. 1). Damage associated with the Unit 6 steam generator consisted of deformed or broken pipe restraints and pipe hangers, minor leaks in tubes within the boiler, damage to the windbox in the lower part of the boiler near a seismic restraint, a failed bearing on the low-pressure turbine, and damage to a seismic stop on the boiler-support structure. Other damage included the failure of an unanchored 750,000 -gal freshwater-storage tank and failure of pipe couplings on two 750,000-gal distilled-water tanks located in the base of the stacks, which caused a loss of the distilled water. The steel liner in one of the stacks pulled away from the stack at the three-fourths level; the stack was later reinforced with external, circumferential steel bands in this area. Substantial ground settlement occurred in the natural-gas-metering yard, and gas leaks occurred at pipe flanges at a secondary gasmetering station associated with the boiler's gas supply.

The initial estimate of the damage to the Moss Landing Powerplant, not including damage to the switchyard, was $\$ 4.5$ million.

\section{HUNTERS POINT POWERPLANT}

The Hunters Point Powerplant is located on the southeast edge of San Francisco, about $27 \mathrm{mi}$ from the earthquake epicenter (fig. 1). At the time of the earthquake, Units 1 and 2 were operating, and Unit 3 was down for maintenance. Some cracks occurred in the top of the boiler enclosure on Unit 3, and a shear wall was cracked. Minor cracks and spalling of concrete occurred in several places, and a minor leak occurred in a pipe coupling to a water tank.

\section{POTRERO POWERPLANT}

The Potrero Powerplant is about $1 \mathrm{mi}$ north of the Hunters Point Powerplant, about 28 miles from the earthquake epicenter. Bracing in the waterbox was damaged, and the boiler's seismic stops were slightly damaged.

\section{OTHER POWER-GENERATING STATIONS}

Most cogenerating plants in the San Francisco Bay region were undamaged. Two plants were damaged and came back on line 2 days and 12 hours, respectively, after the earthquake. Although many of the 10 cogenerating plants in the earthquake-affected area were located in the region of strong shaking, they were undamaged. How much of the 400-MW capacity of these plants was supplied to the power grid is unknown. Power contributed by cogenerating plants in the Watsonville area played an important part in meeting local demand due to disruption to transmission facilities.

\section{EARTHQUAKE DAMAGE TO THE POWER-TRANSMISSION SYSTEM}

The damage to transmission substations significantly affected the electrical-power system. The Metcalf, Moss Landing, and San Mateo Substations were heavily damaged, whereas the Monte Vista and Newark Substations were less damaged (fig. 1). Live-tank circuit breakers were severely damaged, and transformer radiators developed oil leaks and had damaged bushings. Current transformers failed or developed oil leaks, air disconnect switches were damaged, and transfer buses were damaged. Other reported damage had little effect on system operations. 
In the subsections below, we describe each damaged transmission substation, indicate its seismic exposure, and identify damaged and undamaged equipment. We use the following terminology to describe power connections within substations. The power conductors that connect substation equipment are called buses, of which two types are used: a rigid bus, which is typically made of aluminum pipe; and a flexible bus, which is made of twisted aluminum cable.

\section{MOSS LANDING SUBSTATION}

The Moss Landing Substation is north of and adjacent to the power-generating station, which is about $18 \mathrm{mi}$ southeast of the earthquake epicenter (fig. 1). The nearest strongmotion-recording instrument, which is located in Watsonville, about 8 mi north of Moss Landing, recorded a peak horizontal ground acceleration of $0.39 \mathrm{~g}$; the duration of strong shaking was about $10 \mathrm{~s}$. Within the substation, no evidence of liquefaction, lateral spreading, or differential settlement was observed.

The Moss Landing Substation has 115-, 230-, and 500$\mathrm{kV}$ switchyards; the $115-\mathrm{kV}$ switchyard was damaged.

The general layout of the $500-\mathrm{kV}$ switchyard is shown in figure $2 A$, where a single line is used to describe the three phases of a circuit, each phase consisting of one conductor. Likewise, such pieces of equipment as circuit breakers and transformers are grouped together in threes, with one unit for each phase. The switchyard is configured in a ring, with four Westinghouse $\mathrm{SF}_{6}$-insulated live-tank circuit breakers and one High Voltage Breakers, Inc. (HVB), $\mathrm{SF}_{6}$-insulated dead-tank circuit breaker. Not shown in figure $2 A$ is the current transformer associated with each phase of the live-tank breakers and the capacitatively coupled voltage transformers (CCVT's) associated with each phase of the dead-tank circuit breaker. One circuit is connected to the Metcalf Substation, and one to the Los Baños Substation; one circuit is connected to a bank of 500/230-kV transformers; and two circuits are connected to Moss Landing Powerplant Units 6 and 7. The general layout of the $500-\mathrm{kV}$ switchyard is shown in figure $2 A$, and the general layout of the $230-\mathrm{kV}$ switchyard in figure $2 B$. The switchyard has a segmented-double-bus configuration. All circuit breakers are of the oil type.

\section{SUMMARY OF DAMAGE}

Within the 500-kV switchyard at the Moss Landing Substation, the four live-tank circuit breakers were all severely damaged. Of the 12 current transformers, 10 were severely damaged; and only 17 of the 42 disconnect switches were undamaged. The porcelain supports for one phase of bus 1 failed, causing the rigid bus to fall to the ground. One of the porcelain supports on one phase of bus 2 failed, allowing the bus to sag, but it remained functional. The porcelain members of four CCVT's and two line traps failed. The three phases of the dead-tank circuit breaker, the six nearby disconnect switches, the three CCVT's, and the rigid bus used with the dead-tank circuit breaker were all undamaged, as were the supports for the flexible bus. The six single-phase transformers and the three single-phase 500/230-kV transformers were also undamaged.

Within the $230-\mathrm{kV}$ switchyard, most of the damage was to disconnect switches supported on the $230-\mathrm{kV}$ bus-support structures. The rest of the equipment in the switchyard, including the bulk-oil circuit breakers, was undamaged. A detailed schematic diagram of the $500-\mathrm{kV}$ switchyard is shown in figure 3.

Here, we describe each type of equipment, along with the types of damage it sustained, followed by an overall evaluation of possible interactions. We note that equipment of a given type-for example, disconnect switches-may have been made in different years or by different manufacturers.

\section{LIVE-TANK CIRCUIT BREAKERS}

Four Westinghouse $\mathrm{SF}_{6}$-insulated, seismically strengthened, live-tank circuit breakers were installed in the $500-\mathrm{kV}$ switchyard at the Moss Landing Substation (fig. 1). A similar circuit breaker at the Metcalf Substation is shown in figure 4. The seismically strengthened version of this circuit breaker has posttensioned fiberglass tendons within the interrupterhead-support columns to hold the interrupter head and the column members together. The column consists of four porcelain cylinders, stacked on top of each other and separated by rubberlike gaskets. The non-seismically strengthened circuit breakers have wooden rather than fiberglass tendons. The non-seismically strengthened units have three external diagonal ceramic members connecting the interrupter head to the support structure that were provided to resist wind loads. The three columns are supported on a six-legged steel frame; each leg is anchored by a friction clip held by a 1-in.-diameter cast-in-place bolt, as shown in figure 5. Each circuit-breaker phase is connected to a disconnect switch with rigid bus and to a current transformer.

Two types of circuit-breaker/current-transformer connections were used: flexible-conductor-loop type (fig. 4) and rigid-connection type (fig. 6). The circuit breaker shown in figure 5 is a very flexible loop; the other type is a rigid-bus connection. Item 16 in figure 3 has rigid connections, and all the other live-tank circuit breakers have flexible connections.

All of the 12 phases of the live-tank circuit breakers in the $500-\mathrm{kV}$ switchyard were damaged, 2 phases of item 16 (fig. 3) were removed, and the details of their damage is unknown. All the friction-clip anchors had bent or stretched bolts, allowing the circuit breakers to move. Three types of circuitbreaker failures were noted. In the first type of failure (fig. 6 ), one phase slid off its support pad, and the entire circuit breaker, including its support structure, tipped over (for example, item 13, fig. 3). In the second type of failure (fig. 7), 


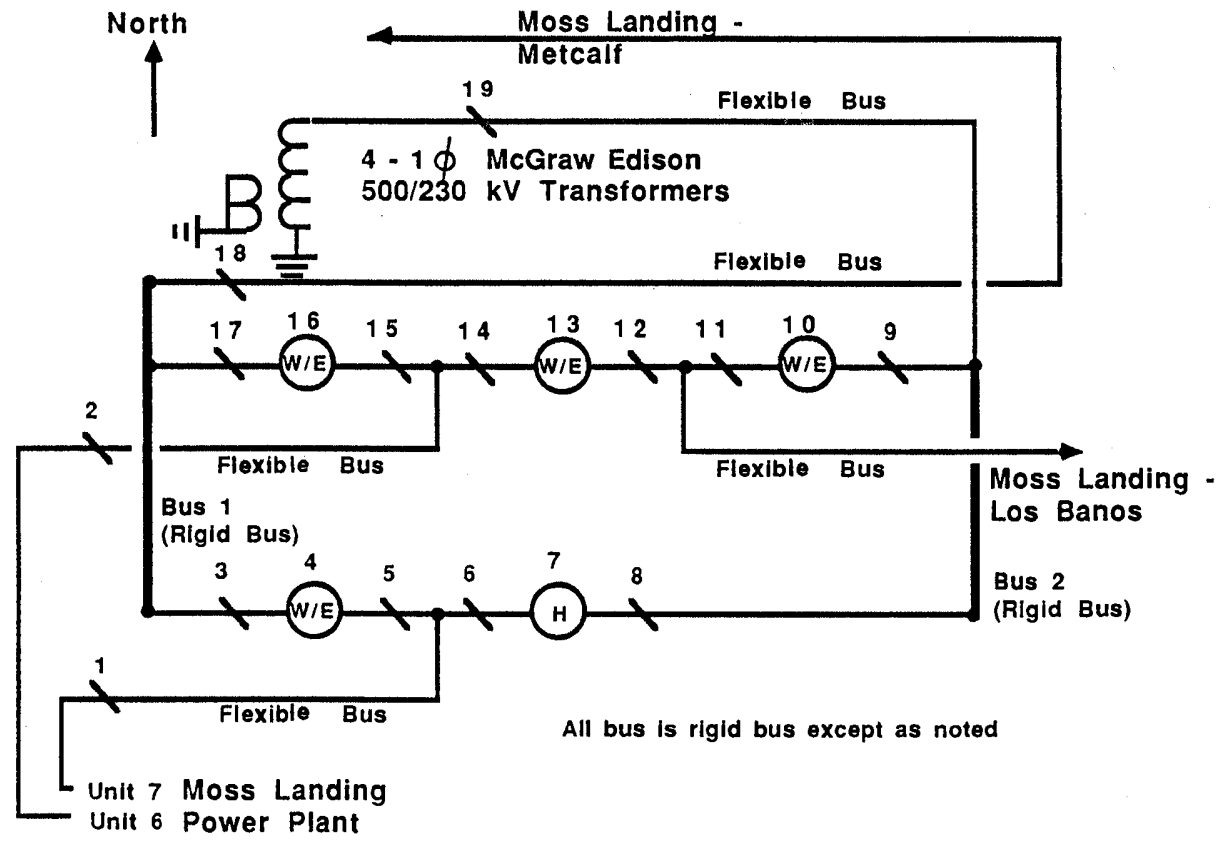

$\boldsymbol{A}$
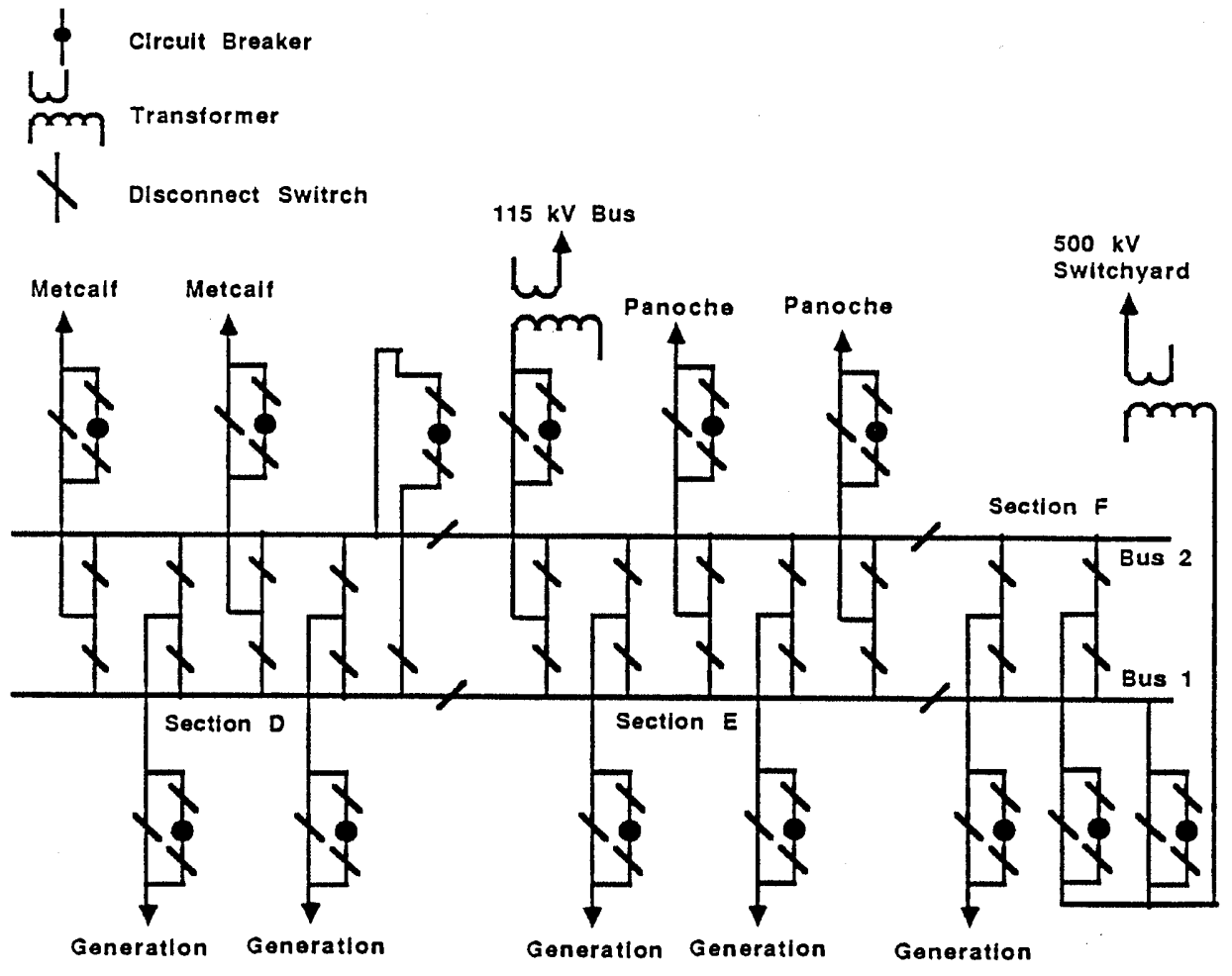

$\boldsymbol{B}$

Figure 2.- One-line diagrams of $500-\mathrm{kV}(A)$ and $230-\mathrm{kV}(B)$ switchyards at the Moss Landing Substation (fig. 1). A single line is used to designate the three phases of each circuit, each phase consisting of one conductor. Likewise, such pieces of equipment as circuit breakers and transformers are grouped together in threes, with one unit for each phase. 
the interrupter-head-support column collapsed, and the interrupter fell to the ground (for example, item 4, fig. 3). In the third type of failure (fig. 8) the support column shattered, but the interrupter head did not fall over (for example, item 10, fig. 3). In other circuit breakers, the support column was cracked but did not shatter. Support columns of this design contain $\mathrm{SF}_{6}$ gas for insulation, and so a crack in the porcelain will generally put the circuit breaker out of service.

Live-tank circuit breakers of this general design - that is, with a heavy interrupter head supported on top of a tall ceramic column-have been damaged in previous earthquakes. The seismically strengthened versions described here performed better than the unstrengthened version. For example, several unstrengthened $500-\mathrm{kV}$ circuit breakers were damaged at the Los Baños Substation in the 1984 Morgan Hill, Calif., earthquake when subjected to a peak acceleration of only about $0.05 \mathrm{~g}$.

\section{CURRENT TRANSFORMERS}

A current transformer is associated with each of the 12 phases of live-tank circuit breakers. Two damaged current transformers associated with live-tank circuit breakers are shown in figure 9 and as item 4 in figure 3 . The support structure has four legs, each secured with a friction clip similar to that shown in figure 5. The current-transformer tank is supported on a "chair" made of channel-shaped structural members, as shown in figure 10. The current transformers are connected to the disconnect switches with a rigid bus and to the circuit breakers as described above; the current transformers shown in figures 8 and 9 are connected with a flexible bus in a looped configuration.

The anchorage of the current transformers did not fail, except for one phase on item 13 in figure 3 . Only 2 of the 12 current transformers at the Moss Landing Substation were

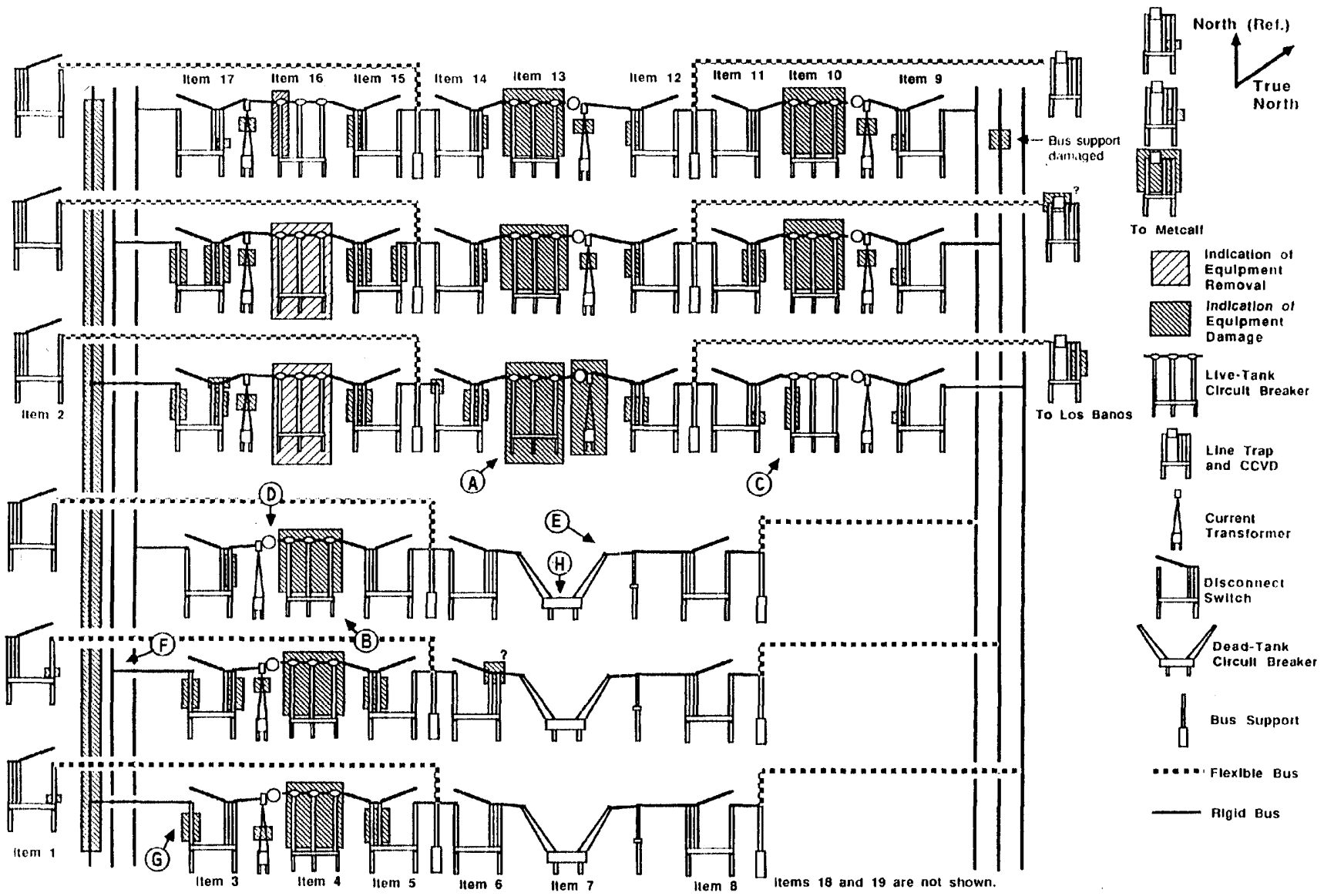

Figure 3.-Schematic diagram of 500-kV switchyard at the Moss Landing Substation (fig. 1), showing locations of damaged and removed equipment and numbered items referred to in text. Equipment shown as undamaged may have required repair that was not obvious from cursory inspection. A, 500-kV circuit breaker (fig. 6); B, interrupter heads on 500-kV live-tank circuit breaker (fig. 7); C, interrupter-headsupport columns on 500-kV circuit breaker (fig. 8); D, 500-kV current transformer (fig. 9); E, support of 500-kV current transformer (fig. 10); F, disconnect switch with rigid bus (fig. 11); G, disconnect switch with flexible bus (fig. 12); H, disconnect switch of channel design (fig. 13). CCVT, capacitatively coupled voltage transformer. 
undamaged. Most current-transformer failures were caused by cracking of the porcelain member in its upper half, as shown in figure 9. Several current transformers folded over at the porcelain break, located at about the three-fourths level. The two current transformers that did not fail had flexible connections to the circuit breakers. In most of the circuit breakers that fell over, the connection between the circuit breaker and the current transformer failed after the current transformer had been severely damaged. A simple analysis of similar current transformers and support structures that was performed after the 1984 Morgan Hill, Calif., earthquake (Schiff, 1985) indicated that the support structure was relatively flexible and that the current transformer had a natural frequency of about $2 \mathrm{~Hz}$.

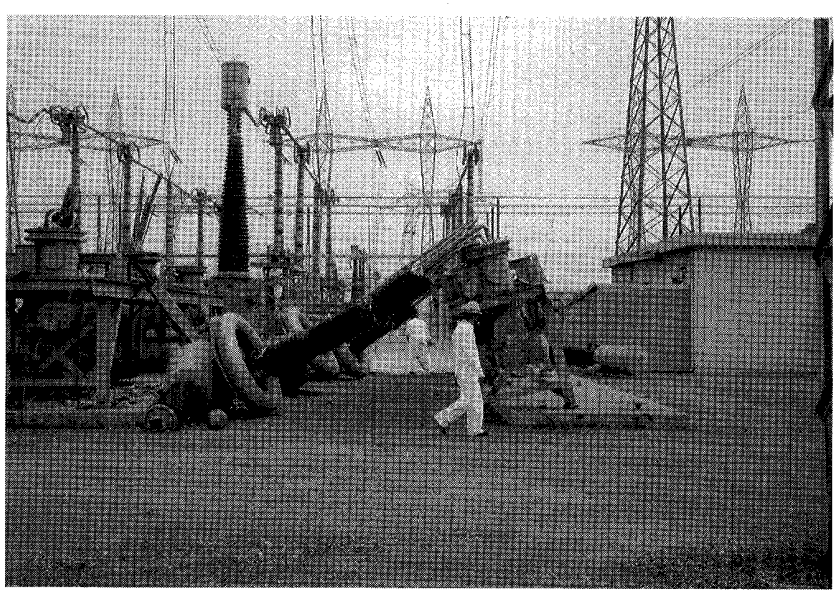

Figure 6.-Overturned 500-kV circuit breaker at the Moss Landing Substation (fig. 1).

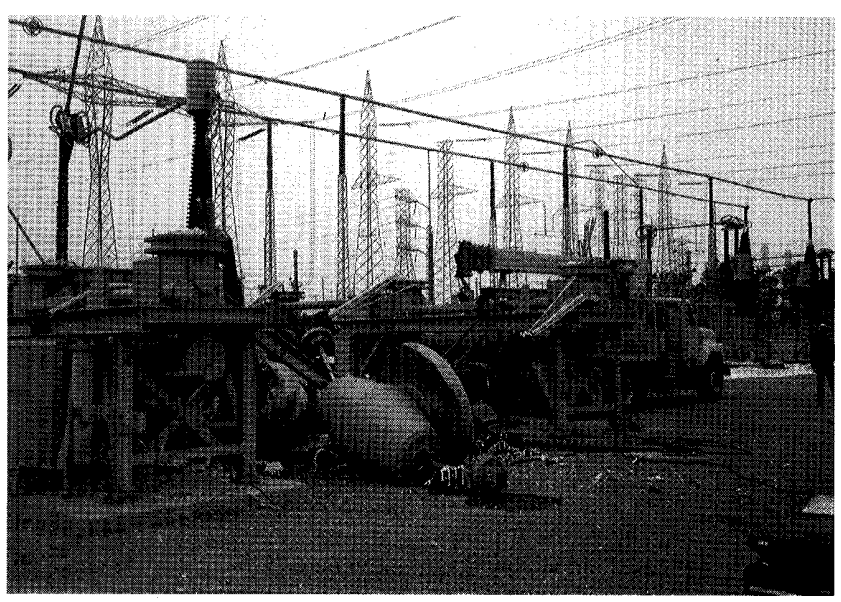

Figure 7.-Fallen interrupter heads on 500-kV live-tank circuit breaker at the Moss Landing Substation (fig. 1).

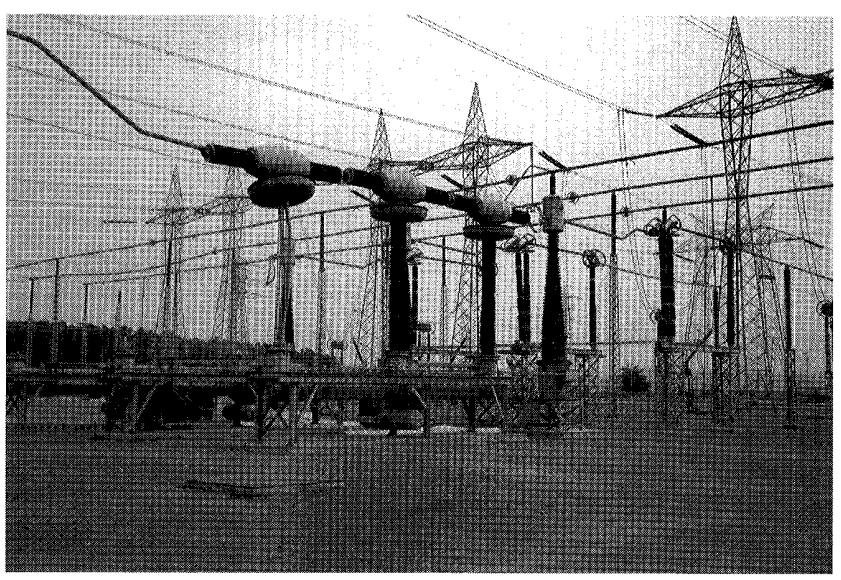

Figure 8.-Shattered interrupter-head-support columns on $500-\mathrm{kV}$ circuit breaker at the Moss Landing Substation (fig. 1).

Figure 5.-Friction-clip anchorage
Moss Landing Substation (fig. 1). 


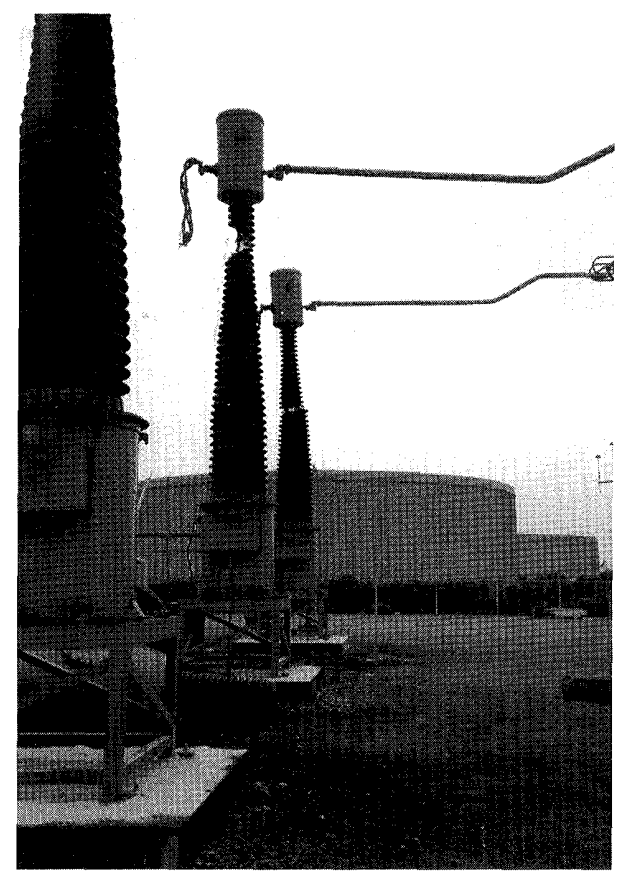

Figure 9.-Damaged 500-kV current transformer at the Moss Landing Substation (fig. 1).

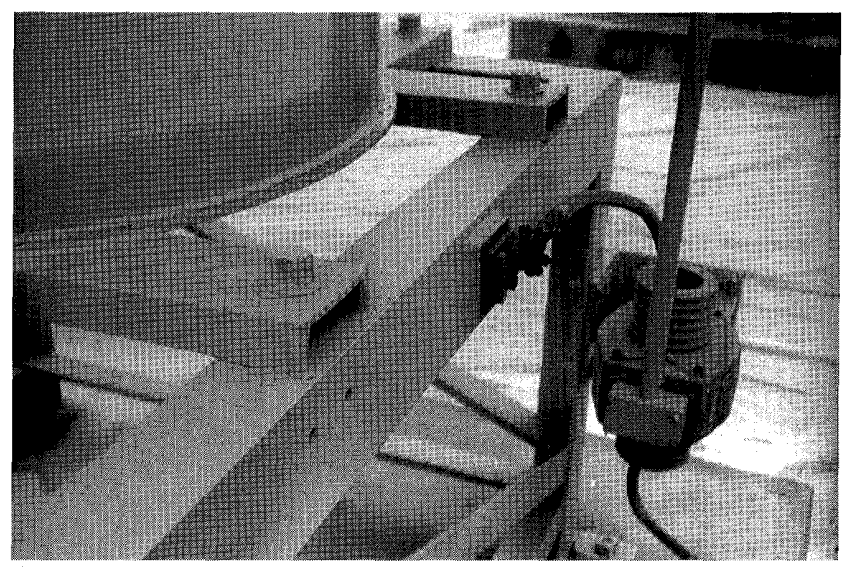

Figure 10.-Detail of damaged 500-kV current transformer (fig. 9) at the Moss Landing Substation (fig. 1).

\section{DISCONNECT SWITCHES}

The disconnect switches are supported on two lattice columns. The switches are of the vertical knifeblade type, in which the knifeblade is supported by two porcelain columns. The knifeblade receiver is supported by a single porcelain column. A disconnect switch is shown on the right side of figure 11, with the knifeblade up. We observed two designs: in one design, the base of the disconnect switch is made of channels; and in the other design, the base is made of a tubular member. Items 1, 2, 6, and 8 in figure 3 were of the tubular design; the lattice structures were anchored with a cast-in-place bolt through a plate at the bottom of each of four legs. Items 1, 2, 18, and 19 in figure 3 were connected with long drops of flexible bus from overhead flexible bus runs, as shown in figure 12 . Three disconnect switches of the channel type are shown in figure 13 (item 3, fig. 3). Of the 12 phases of the tube-type construction, 3 failed; none of these failures is attributable to the failure of adjacent equipment. Of the 24 channel-type disconnect switches, 22 were damaged, but most were adjacent to equipment that had failed and collapsed.

Of the 42 single-phase switches, 25 failed. Four types of failures were noted: (1) in 12 disconnect-switch phases, the outside column that supports the knifeblade failed; (2) in nine disconnect-switch phases, both of the knifeblade-support columns failed; (3) in four disconnect-switch phases, only the knifeblade-receiver column failed; and (4) in five disconnectswitch phases, both the knifeblade-support and knifebladereceiver columns failed. We note that although many of these failures occurred at the bottom of the column, the point of largest cantilever load, many columns failed at other points, suggesting higher modal response. None of the six phases of the disconnect switches of the tubular design associated with dead-tank circuit breakers failed. In figure 11, one of these blades is not aligned with the other two phases, suggesting that it may have been damaged. The two disconnect switches shown in figure 12 (item 1, fig. 3) were also of the tubular design. The knifeblade-receiver columns on the switches failed and are shown hanging from the flexible bus. A similar failure occurred on one phase of a disconnect switch (item 19, not shown in fig. 3). Each of the three phases of the disconnect switch shown in figure 13 illustrates a different type of failure: The unit on the left has lost one of the porcelain columns supporting the knifeblade, the unit in the center has also lost the knifeblade-receiver column, and the unit on the right has just lost the knifeblade-receiver column. Of the 12 disconnect-switch phases that use flexible conductor connections, 3 failed; and of the 30 disconnect-switch phases that use rigid conductor connections, 22 failed.

\section{LINE TRAPS AND CAPACITATIVELY COUPLED VOLTAGE TRANSFORMERS}

Each phase of the two circuits that leave the site has a line trap and CCVT mounted on a single truss-type structure, as shown in figure 14. Each of the four legs is anchored by a castin-place bolt through a plate at the end of each leg. A long flexible bus dropping from an overhead flexible bus forms the bus connections.

The line trap and CCVT failed on one assembly, although it is uncertain which component failed first; the CCVT failed at the base of the porcelain column on three assemblies; and a line trap failed on another assembly. Three failure modes are possible: (1) from inertial loads, possibly compounded by dynamic effects of the devices and their support structures; (2) from the 
dynamic effects of long, flexible cable drops; and (3) from lateral motion of the overhead buses that could apply loads to the connections. Although all of these factors contributed in varying degrees to the failures, it is unclear whether any dominated.

BUS SUPPORTS-RIGID BUS

Two long transfer buses are located along the east and west ends of the 500-kV switchyard at the Moss Landing Sub-

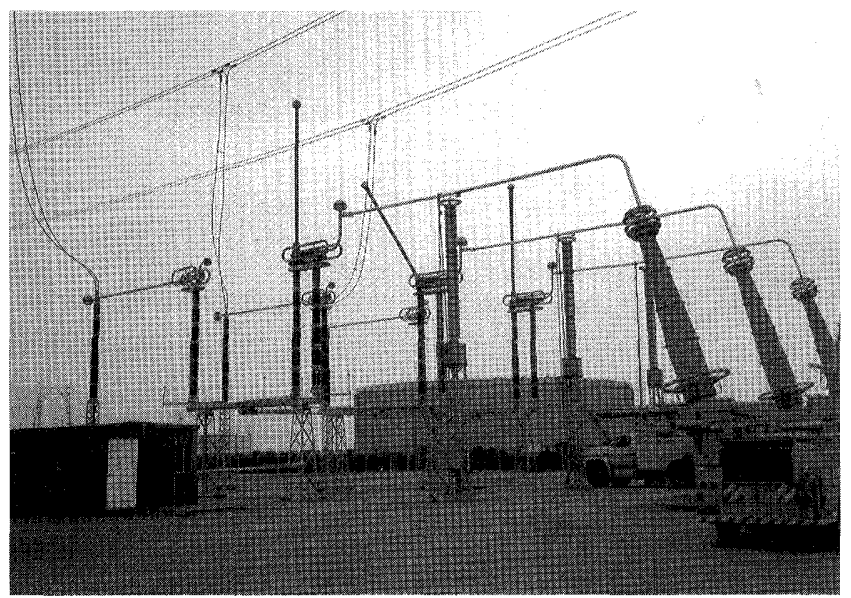

Figure 11.-Disconnect switch with rigid bus at the Moss Landing Substation (fig. 1).

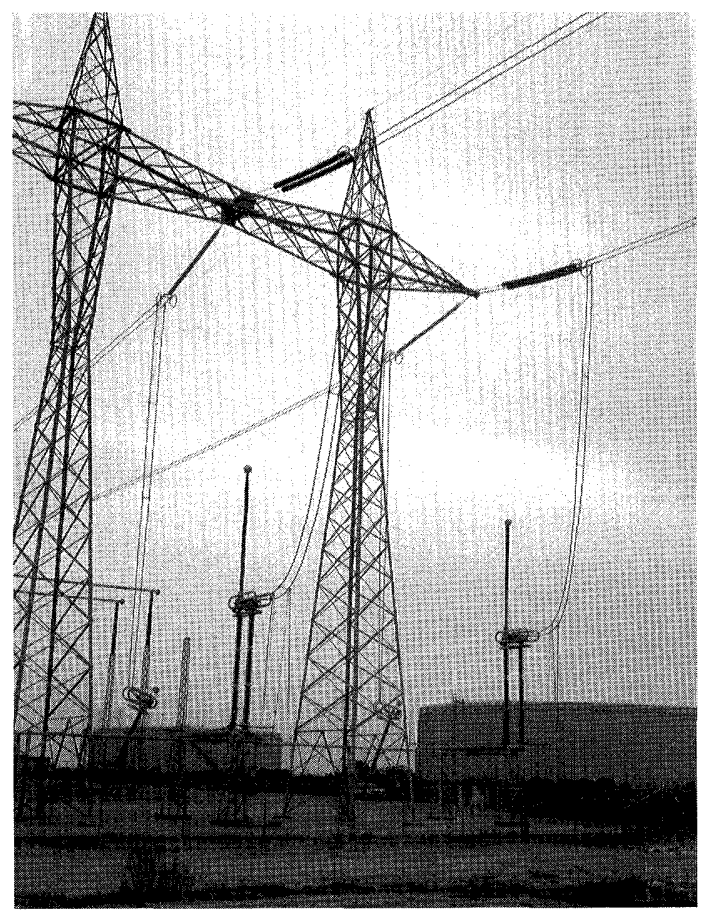

Figure 12.-Disconnect switch with flexible bus at the Moss Landing Substation (fig. 1). station. The bus is supported on lattice structures topped with a post insulator, as shown on the lower left side of figure 12 . Additional isolated bus-support failures occurred between pairs of disconnect switches (items 5 and 6, 11 and 12, 14 and 15 , fig. 3 ).

Two of the three phases of bus 1 are shown in figure 12 . The support column without the post insulator is associated with the failed bus phase. Failure of a single bus support on bus 2 allowed the bus to sag, but the bus remained operational.

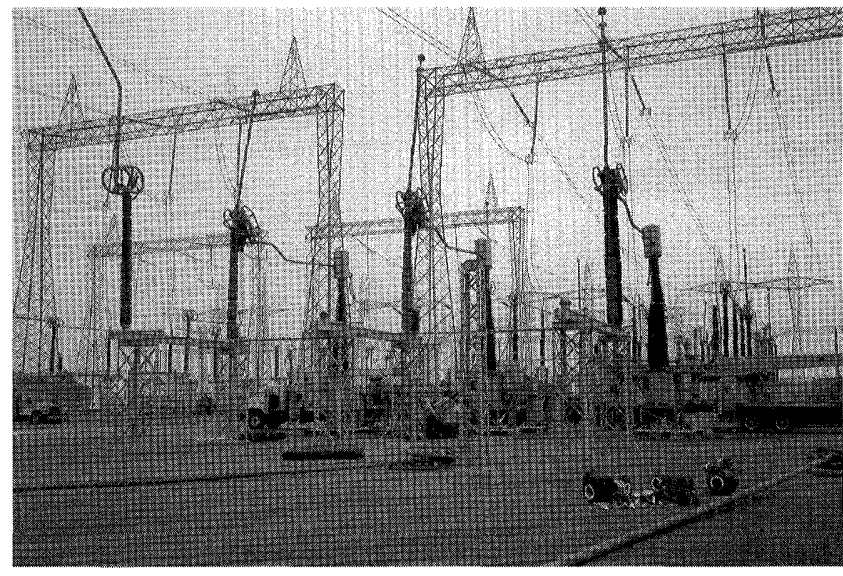

Figure 13.-Disconnect switch of channel design at the Moss Landing Substation (fig. 1).

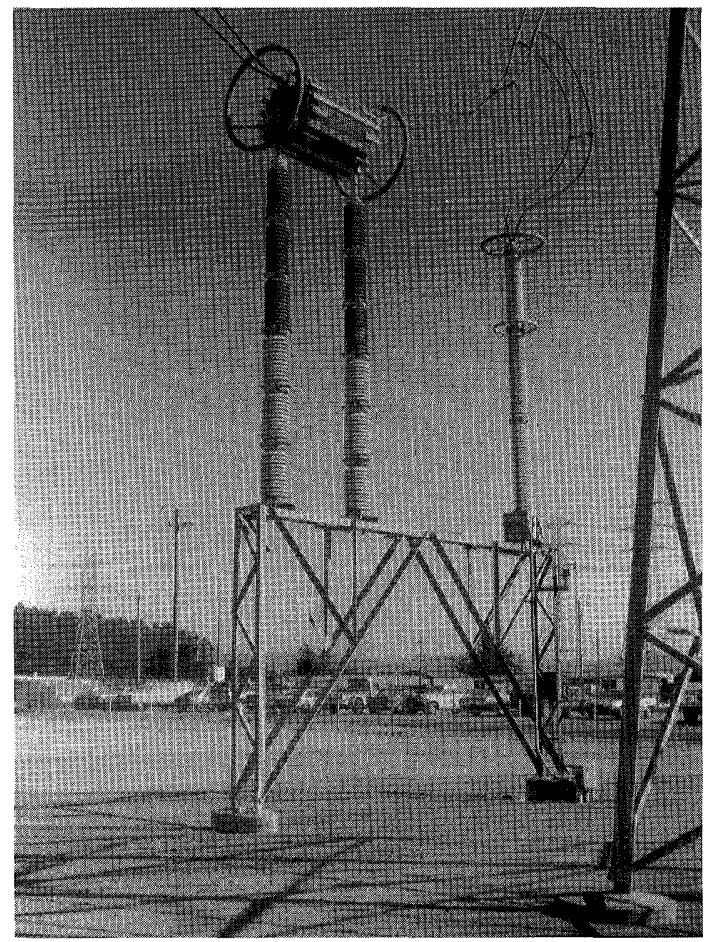

Figure 14.-Line trap and capacitatively coupled voltage transformer on support structure at the Moss Landing Substation (fig. 1). 


\section{METCALF SUBSTATION}

Part of the $\mathrm{HVB} \mathrm{SF}_{6}$-insulated, dead-tank circuit breaker is visible at the right in figure 11. Each of its four legs is welded to a steel embedment, as shown in figure 15 . The circuit breaker is connected by rigid bus to a disconnect switch on one side and to a CCVT on the other; the CCVT is also visible in figure 11. The circuit breakers and all the equipment associated with them were undamaged, with the possible exceptions noted above.

BUS SUPPORTS-FLEXIBLE BUS

The tall, flexible-bus-support structures were undamaged. They are of lattice-type construction and anchored with cast-in-place bolts, as shown in figure 12 .

\section{SUMMARY OF SWITCHYARD DAMAGE}

The 230-kV switchyard at the Moss Landing Substation with bus sections $\mathrm{D}, \mathrm{E}$, and $\mathrm{F}$ is shown in figure $2 B$. On bus 1 , disconnect switches mounted on the buswork of sections D, $\mathrm{E}$, and $\mathrm{F}$ were severely damaged. On bus 2 , the disconnect switches were severely damaged on section $\mathrm{F}$, moderately damaged on section $\mathrm{E}$, and undamaged on section $\mathrm{D}$. The $115-\mathrm{kV}$ switchyard was undamaged.

Any assessment of the interaction of failures must be speculative here because no observers or automatic, seismically triggered video systems were on hand to provide direct accounts or documentation of the sequences in which damage occurred. A review of the pattern of failures indicated in figure 3 suggests that equipment interaction played a role in many, though apparently not all, failures. Observations of the equipment that fell over and that which remained standing suggest that the failure of the live-tank circuit breakers contributed to the damage of other equipment. Components were damaged on six disconnect-switch phases that were not directly attached to circuit breakers.

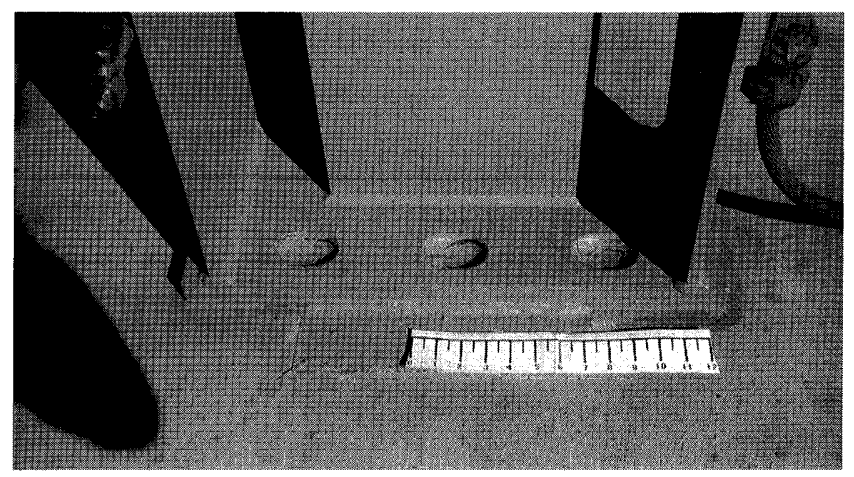

Figure 15.-Detail of welded anchorage on 500-kV dead-tank circuit breaker at the Moss Landing Substation (fig. 1).
The Metcalf Substation is located adjacent to and just west of California Highway 101 and south of Metcalf Road, about 16 mi northeast of the earthquake epicenter (fig. 1). Records obtained about $7 \mathrm{mi}$ southeast and $7 \mathrm{mi}$ west of the substation showed peak ground accelerations of 0.28 and 0.19 $g$, respectively.

The Metcalf Substation has 115-, 230-, and 500-kV switchyards. The general layout of the $500-\mathrm{kV}$ switchyard is shown in figure 16. The switchyard is configured as a ring bus, with three Westinghouse $\mathrm{SF}_{6}$-insulated, seismically strengthened live-tank circuit breakers and one $\mathrm{HVB} \mathrm{SF}_{6}$-insulated dead-tank circuit breaker. There are single-circuit transmission lines connecting it to the Tesla Substation to the north and the Moss Landing Substation to the south (fig. 1). A transmission line goes to each of two $500 / 230-\mathrm{kV}$ transformer banks. The $230-\mathrm{kV}$ switchyard has a segmented double bus, with two transmission circuits to the Newark and Moss Landing Substations and three transmission circuits to the Monte Vista Substation (fig. 1). It supplies two 230/115-kV transformer banks. The $115-\mathrm{kV}$ switchyard was undamaged.

\section{SUMMARY OF DAMAGE}

Within the 500-kV switchyard, all three live-tank circuit breakers were damaged. Five of the nine current transformers associated with the circuit breakers had oil leaks. One phase of a disconnect-switch phase appeared to have been pulled down when the circuit breaker to which it was connected failed. In the two banks of single-phase, 500/230-kV transformers, bank 2 consisted of four single-phase transformers. The spare transformer replaced a transformer with a damage $500-\mathrm{kV}$ bushing flange that was deformed and leaking. Minor radiator leaks occurred. Bank 1 consisted of three single-phase transformers that had severe leaks at flanges which support transformer radiators. In one phase, a $230-\mathrm{kV}$ lightning arrester attached to bank 1 failed and fell to the ground.

In addition, four line traps, five CCVT's, and 23 air disconnect switches were undamaged. An HVB dead-tank circuit breaker was also undamaged and showed no signs of distress. Bus-support structures and rigid buses were undamaged. A schematic diagram of the $500-\mathrm{kV}$ switchyard is shown in figure 17. This diagram shows all major equipment items for each phase and corresponds to the layout in figure 16 . The discussion of the damage to the live-tank circuit breakers at the Moss Landing Substation also applies here. In general, the damage at the Metcalf Substation was less severe. Although friction-clip anchors also failed, the equipment moved only from 2 to $8 \mathrm{in}$. A smaller fraction of interrupterhead-support columns failed than at the Moss Landing Substation. One disconnect-switch phase failed when it was pulled down by a damaged circuit breaker to which it was connected. 


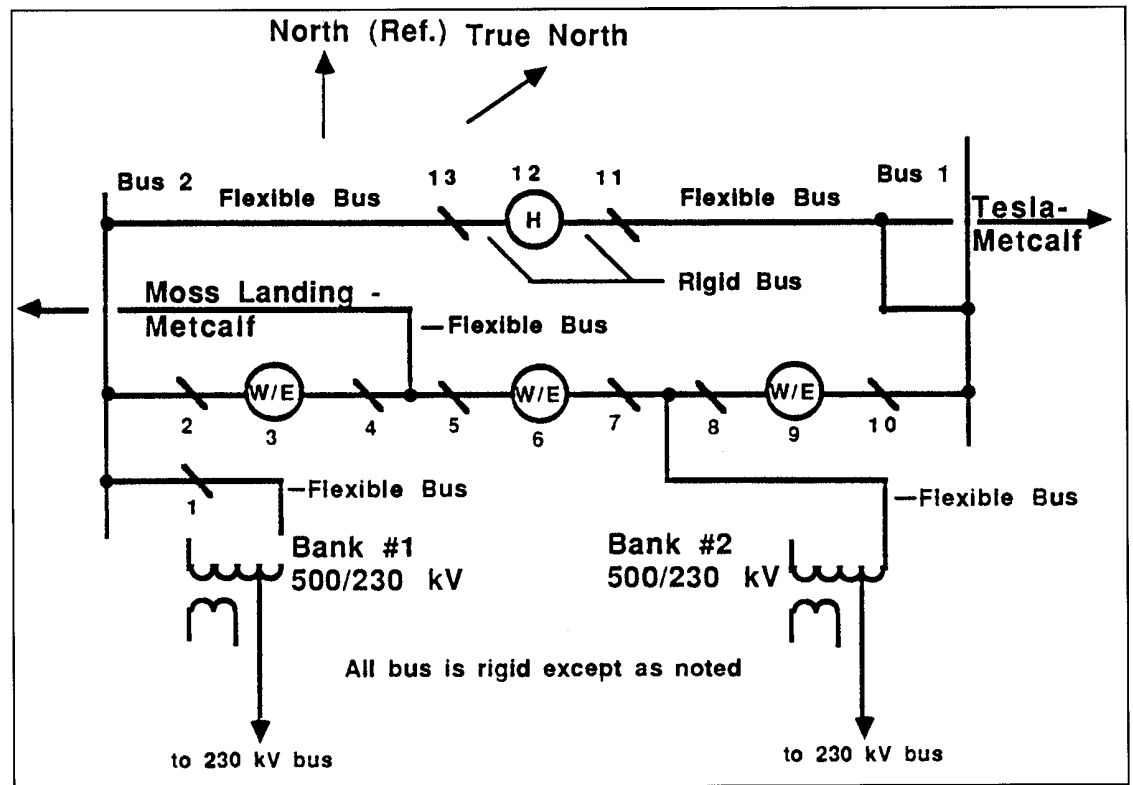

Figure 16.- One-line diagram of 500$\mathrm{kV}$ switchyard at the Metcalf Substation (fig. 1). All buses are rigid except as labeled.

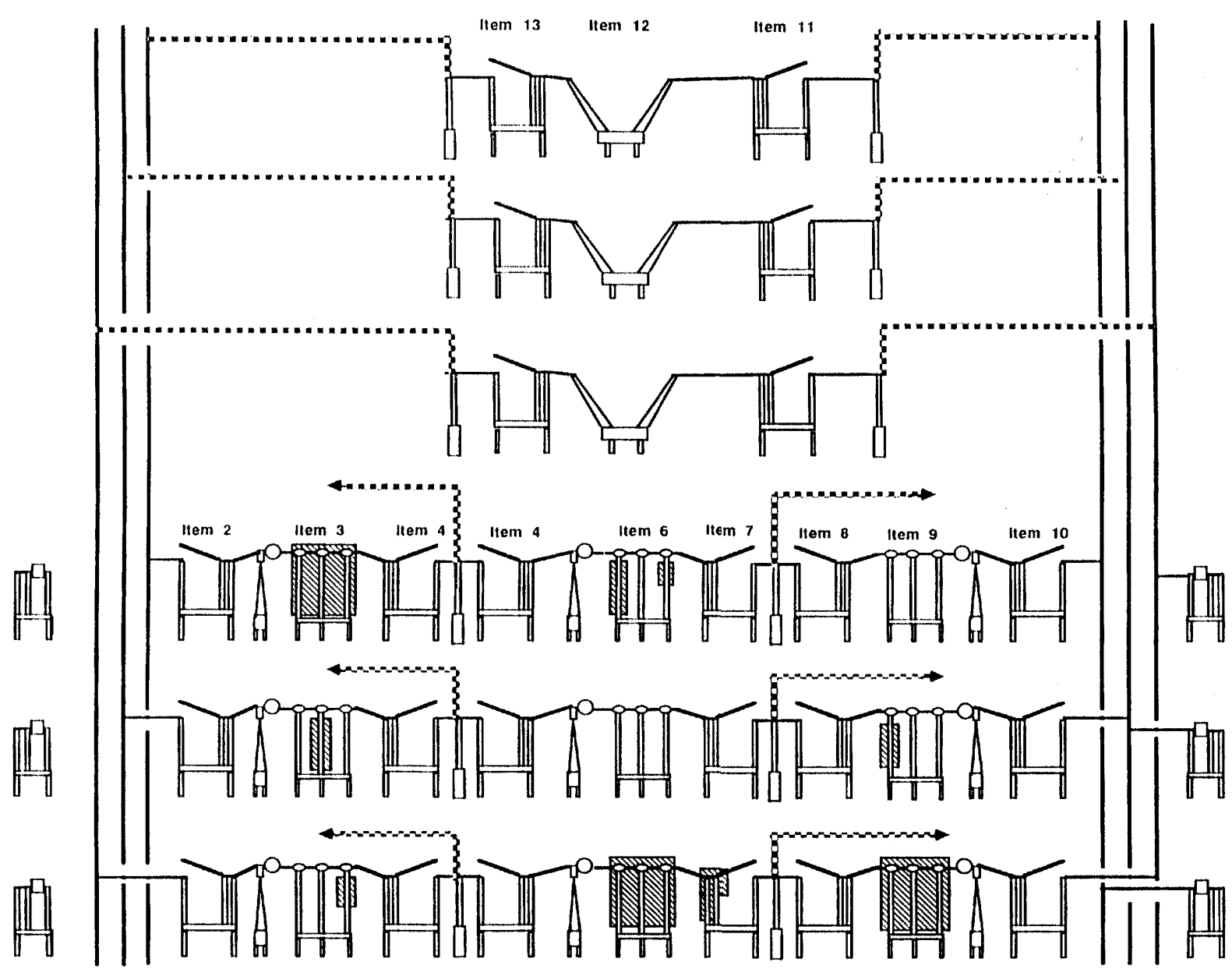

Figure 17.-Schematic diagram of 500-kV switchyard at the Metcalf Substation (fig. 1), showing locations of damaged and removed equipment and numbered items referred to in text. Equipment shown as undamaged may have required repair that was not obvious from cursory inspection. Same symbols as in figure 3. 
Fewer interrupter heads fell than at the Moss Landing Substation. Individual interrupter-head-support columns (columns adjacent to current transformers, the center column, and columns adjacent to disconnect switches) were damaged on some phases. None of the current transformers failed, although five developed oil leaks. The rigid-bus connections between the current transformers and the circuit breakers in place at the time of the 1984 Morgan Hill, Calif., earthquake had all been replaced with the flexible loops shown in figure 8 . The bussupport structures and buses were undamaged. Four line traps, five CCVT's, and 23 air disconnect switches were undamaged.

The HVB dead-tank circuit breaker was undamaged and showed no signs of distress. It had been installed on a pad remaining from a live-tank circuit breaker that was damaged in the 1987 Morgan Hill, Calif., earthquake. The three bolts used on each of the four legs are shown in figure 18; the equipment is nearly identical to that shown in figure 12 .

The $230-\mathrm{kV}$ switchyard was undamaged, but some disconnect switches became misaligned, so that they would not reclose once they were opened. The switchyard's two General Electric model ATB6 live-tank circuit breakers were undamaged (fig. 19). In past earthquakes, these circuit breakers were vulnerable to earthquake damage. All other circuit breakers of the oil type or dead-tank type were undamaged.

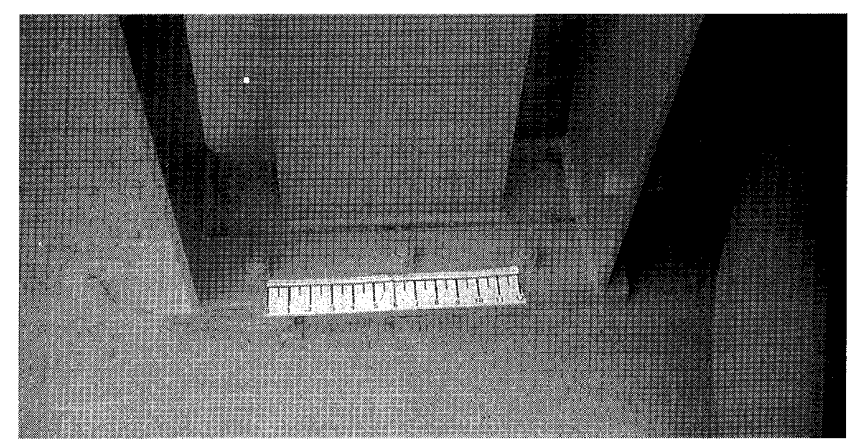

Figure 18.-Detail of bolted anchorage on 500-kV dead-tank circuit breaker at the Metcalf Substation (fig. 1).

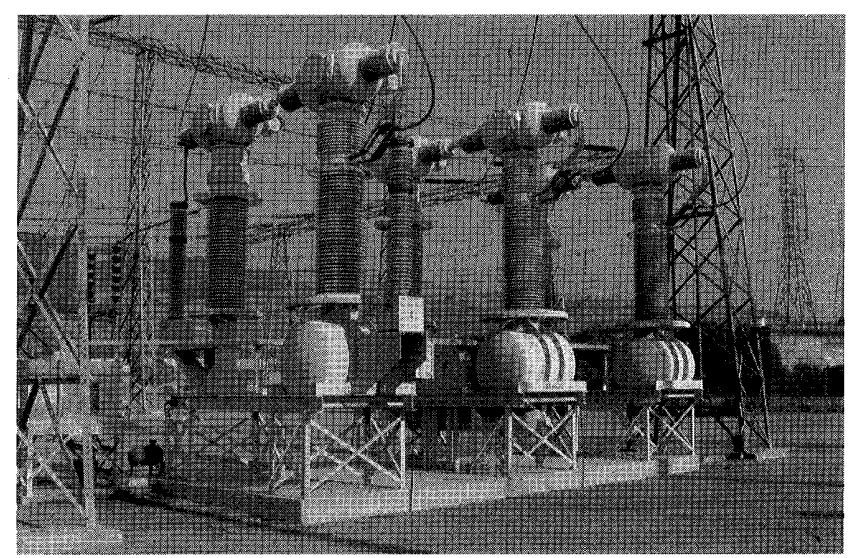

Figure 19.-Undamaged General Electric model ATB6 live-tank circuit breaker in 230-kV switchyard at the Metcalf Substation (fig. 1).

\section{SAN MATEO SUBSTATION}

The San Mateo Substation is located just north of the San Mateo Bridge, adjacent to San Francisco Bay and about $42 \mathrm{mi}$ from the earthquake epicenter (fig. 1). The nearest strong-motion-recording station, about 2 mi away in Foster City, recorded a peak horizontal ground acceleration of 0.16 $g$. The substation appears to be located on fill, but no evidence of liquefaction or lateral spreading was observed. However, circuit-breaker foundation pads, which were supported on piles, indicated that the ground surrounding the pads had settled 4 to $6 \mathrm{in}$. On the east boundary of the site, away from any equipment, some slumping occurred, and the ground was quite soft.

The San Mateo Substation has 60-, 115-, and 230-kV switchyards. The $230-\mathrm{kV}$ switchyard has a segmented double bus, as shown in figure 20. One circuit goes to the Martin Substation through an underground cable, four go to transformers that feed the $115-\mathrm{kV}$ bus, two go to the Newark Substation, and two go to power-generating stations.

Within the 230-kV switchyard at the San Mateo Substation, one General Electric model ATB4 and three General Electric model ATB7 live-tank circuit breakers were damaged. These circuit breakers have two interrupter heads, which are supported on porcelain columns formed of post insulators that are bolted together, as shown in figure 21. (The 500$\mathrm{kV}$ circuit breakers had three interrupter heads, which were held together by internal tendons.) The support structure (fig. 22) is a lattice structure anchored by eight cast-in-place bolts; the tank shown in the figure is the bottom part of a current transformer, which is incorporated into one of the unit's support columns. The circuit breakers exhibited three failure modes: failure of one of the porcelain support columns, commonly the column that contains the current transformer; failure of the ceramic members that make up the high-pressure-air plumbing; and blowing of the interrupter-head gaskets on the bushings that connect the two interrupter heads. A blown interrupter-head gasket is shown in figure 23. Similar equipment at the Edmonston Pumping Plant failed in the 1988 Tejon Ranch, Calif., earthquake; the failure modes were discussed in detail by Schiff (1989). Although the circuit-breaker-support structures at the San Mateo Substation were not as massive or stiff as their counterparts at the Edmonston Pumping Plant, this difference probably did not affect the response because the natural frequencies of the interrupter heads on their support columns are relatively low.

On the $230-\mathrm{kV}$ bus-support structure, several bus connections to disconnect switches were damaged. Two disconnect switches mounted on a bus-support structure failed. In two places, cables disconnected at hook-and-slot attachments to the buswork. Two CCVT's failed. Oil-type circuit breakers were undamaged.

A review of the disassembled circuit breakers in the "graveyard" at the San Mateo Substation indicated that the initial response of each circuit breaker caused the interrupter- 


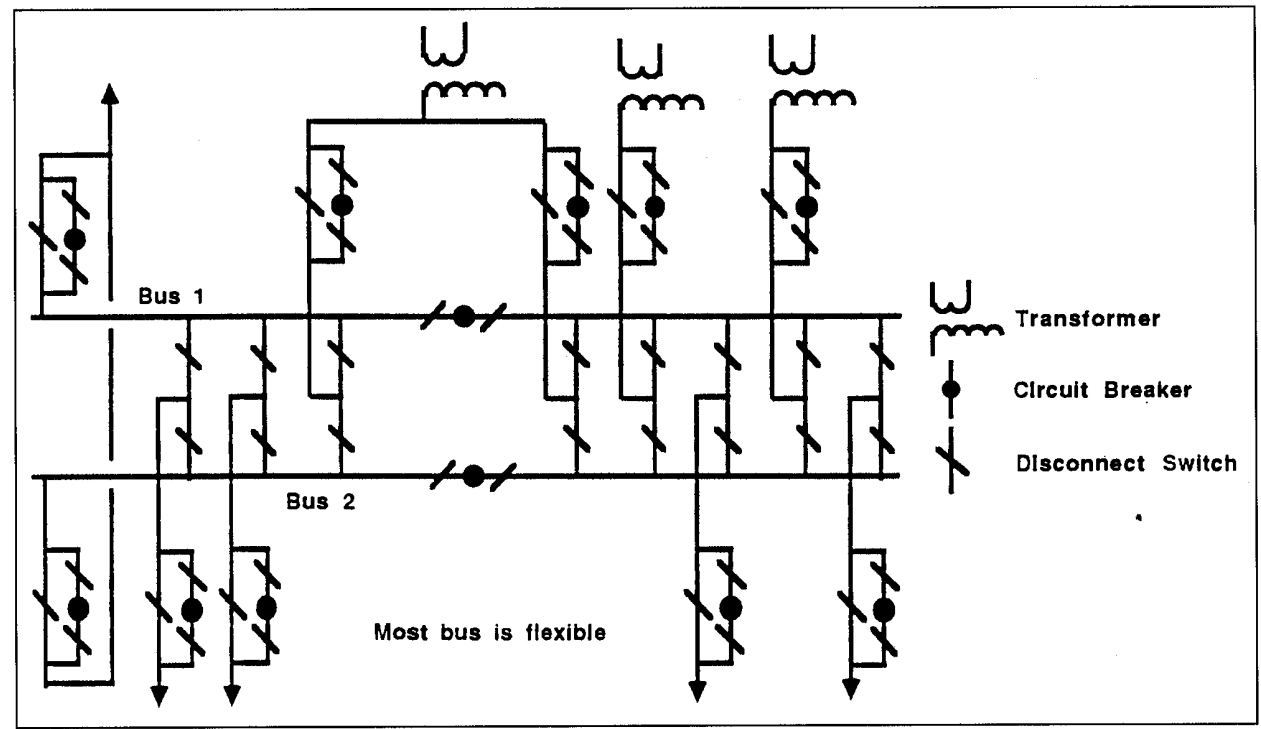

Figure 20.- One-line diagram of 230-kV switchyard at the San Mateo Substation (fig. 1). Most buses are flexible.

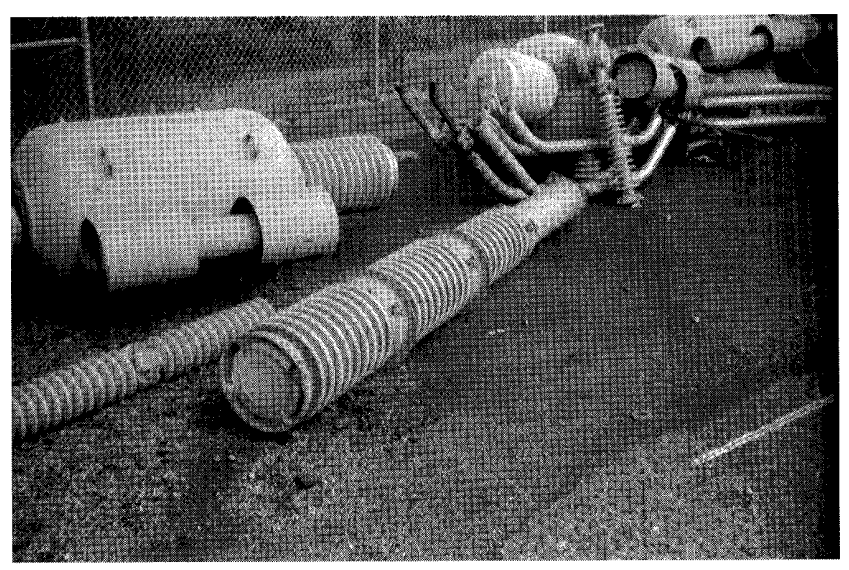

Figure 21.-Interrupter-head-support columns on 230-kV circuit breaker at the San Mateo Substation (fig. 1).

head gaskets to fail in one of two ways. (1) Inplane, inphase rocking of the two interrupter heads on their columns caused the interrupter-head gaskets to blow on the top and bottom of three sets of circuit breakers, as shown in figure 24; the gasket on one head was blown at the top, and on the adjacent head the gasket was blown on the bottom. (2) Out-of-plane, out-of-phase rocking on one set of interrupter heads caused the gaskets to blow on the side of the bushings. Data from the Edmonston Pumping Plant indicate that this type of failure occurs before the support columns shatter. The absence of surviving porcelain members associated with the high-pressure-air supply and current-transformer- and interrupter-headsupport columns suggests that these members shattered and were discarded with other porcelain shards.

The San Mateo Substation has three banks of 230/115$\mathrm{kV}$ transformers. One bank of transformers developed oil leaks

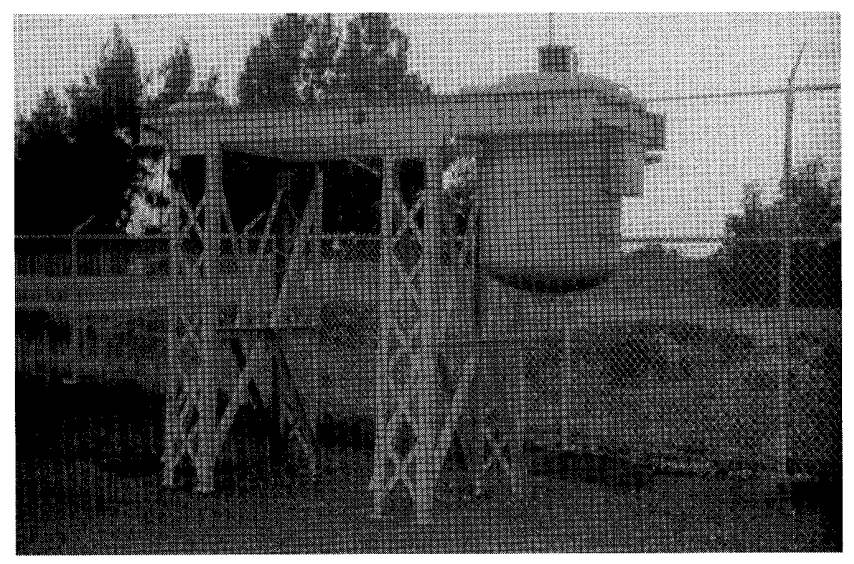

Figure 22.-Support structure of 230-kV live-tank circuit breaker at the San Mateo Substation (fig. 1).

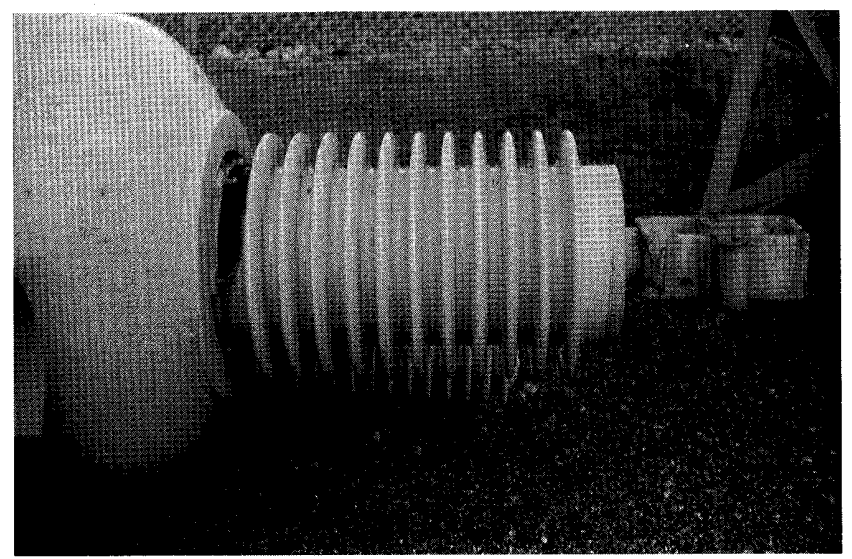

Figure 23.-Blown interrupter-head gasket on 230-kV circuit breaker at the San Mateo Substation (fig. 1). 


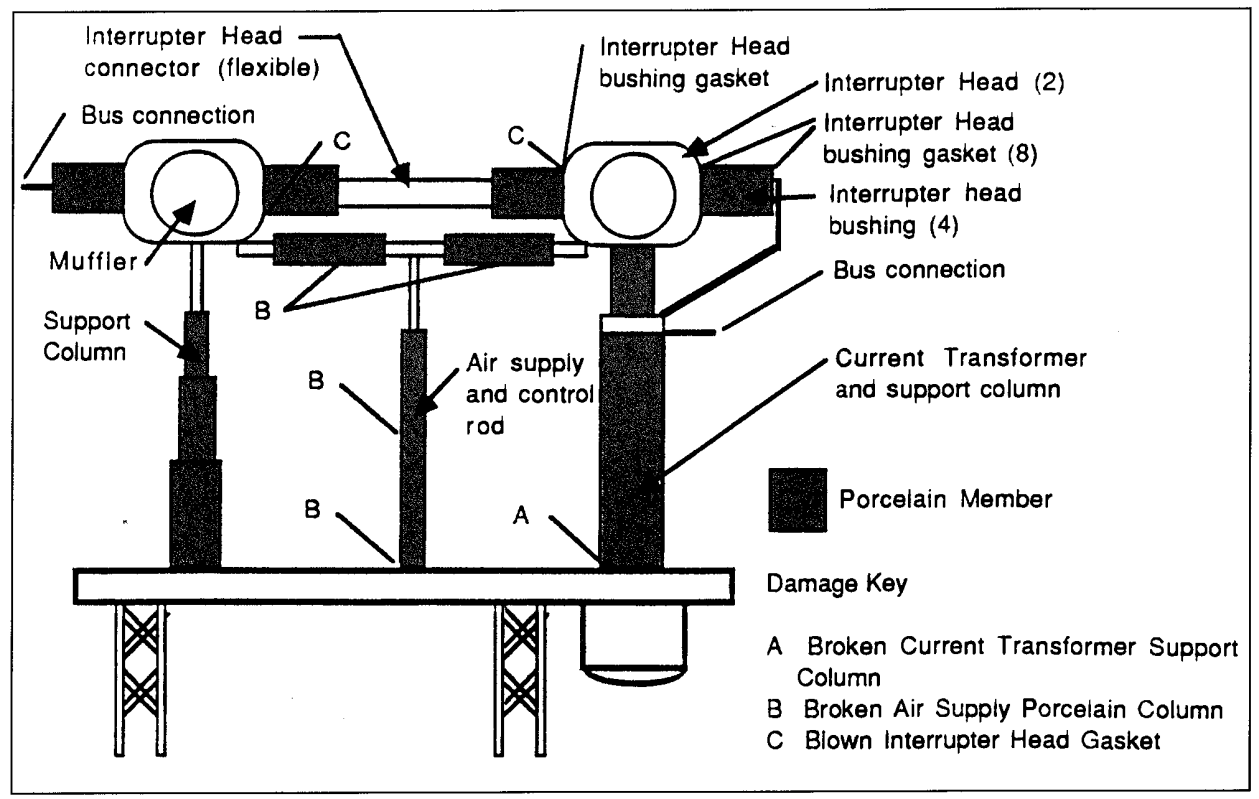

Figure 24.-Schematic diagram of General Electric model ATB7 circuit-breaker failures at the San Mateo Substation (fig. 1).

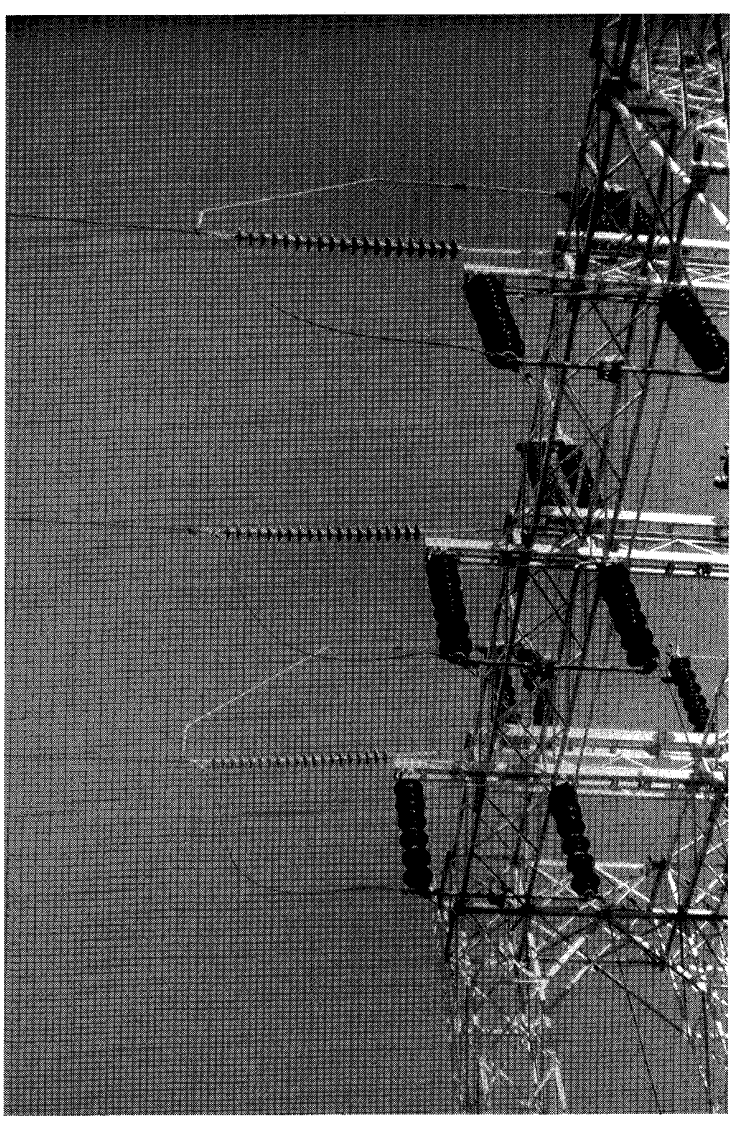

Figure 25.-230-kV bus-support structure at the San Mateo Substation (fig. 1).

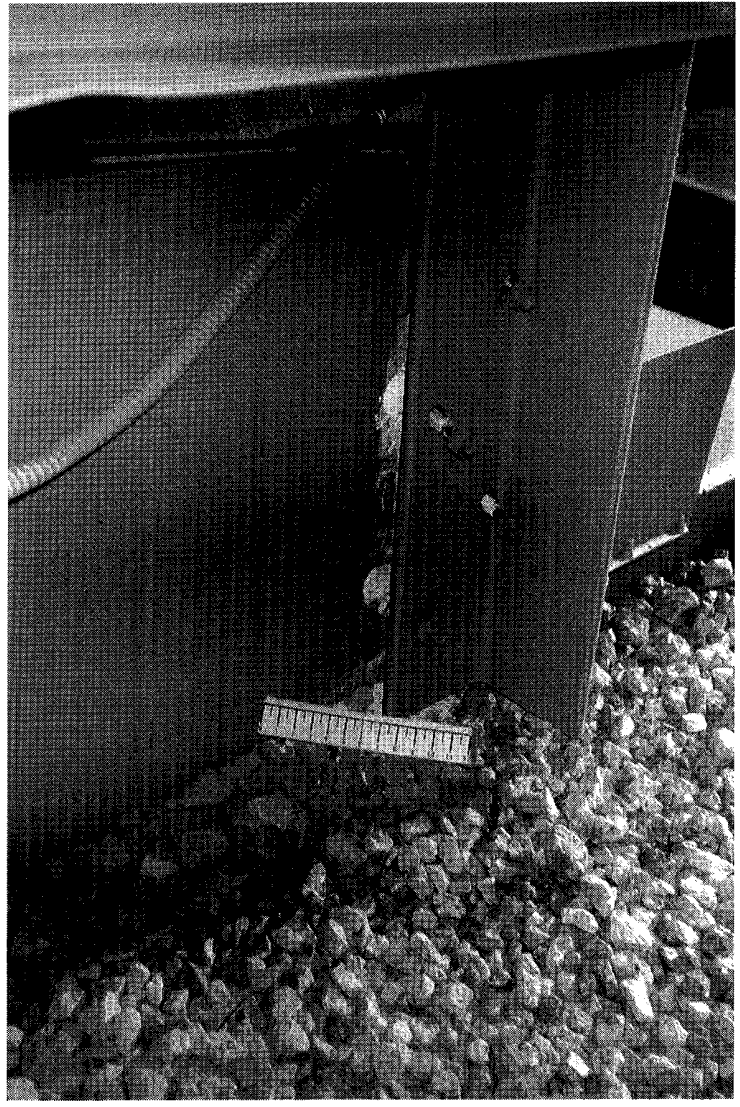

Figure 26.-Anchorage failure on $115 / 60-\mathrm{kV}$ transformer at the San Mateo Substation (fig. 1). 
at the pipe flanges of the upper pipes that support the transformer radiators. The seals had to be replaced to stop the leaking; the transformers were otherwise undamaged.

No damage was reported in the $115-\mathrm{kV}$ switchyard. In the $60-\mathrm{kV}$ switchyard, a bus connection to a disconnect switch mounted on the bus-support structure and anchorage to three $115 / 60-\mathrm{kV}$ transformers were damaged, but transformer operations were unaffected.

Three problems were noted with items mounted on the $230-\mathrm{kV}$ bus supports. The top of the $230-\mathrm{kV}$ bus-support structure is shown in figure 25 . The rigid bus connection on the center phase to the bypass switch on top of the bus failed and is not shown. The casting that connects the bus to the switch failed, and the bus rotated around the cable until it came in contact with the buswork. Porcelain members failed on two disconnect switches mounted high on the bus. In two places, where the insulators connect the flexible bus to the bus structure, the hook-and-slot attachment disengaged and dropped the bus.

In some disconnect switches, failures of metal connections caused slipping of the rotating action at the base of the switch, which normally causes the switch to open. Several oil-type circuit breakers and three large synchronous condensers were undamaged.

Within the $60-\mathrm{kV}$ switchyard, a rigid-bus connection between flexible bus and a disconnect switch on top of the bus-support structure failed similarly to the one described above. Anchorage of one of two banks of the skid-supported $115 / 60-\mathrm{kV}$ transformers failed, as shown in figure 26 . The old, grouted-in-place anchors failed, but transformer operation was unaffected.

\section{MONTE VISTA SUBSTATION}

The Monte Vista Substation has a $230-\mathrm{kV}$ switchyard adjacent to a $115-\mathrm{kV}$ switchyard and a $60-\mathrm{kV}$ switchyard located about half a mile away. All three switchyards are in the hills below Monte Bello Ridge just west of Cupertino, about $11 \mathrm{mi}$ from the earthquake epicenter (fig. 1). The nearest strong-motion-recording instrument, about $6 \mathrm{mi}$ away in Saratoga, recorded a peak ground acceleration of $0.34 \mathrm{~g}$.

The $230-\mathrm{kV}$ switchyard at the Monte Vista Substation has three $230-\mathrm{kV}$ circuits from the Metcalf Substation and two to the Jefferson Substation. Two transformer banks provide power to the $115-\mathrm{kV}$ bus and one bank provides power to the $60-\mathrm{kV}$ bus.

The porcelain member of a CCVT on a $230-\mathrm{kV}$ line at the Monte Vista Substation failed, as shown in figure 27. Post insulators that supported transfer buses on top of the bus-support structures above two transformer banks failed. One intact transfer bus and one transfer bus resting on top of the bus-support structure, with post-insulator supports missing, are shown in figure 28. On an adjacent bus-support structure, one phase was intact, and one phase was missing. Part of the post-insulator support can be seen at the top of figure 28 . Note that all loads that restrain torsion of the bus-support structure would be carried by the post insulators which support the transfer buses. In some places, the transfer bus fell across the phases of the circuit. In one place, this failure damaged a bell on an insulator string that supported the bus; the bell was replaced.

A $230-\mathrm{kV}$ lightning arrester supported on a $230 / 115-\mathrm{kV}$ transformer failed at its base. One single-phase $230 / 60-\mathrm{kV}$ transformer was damaged internally. An isolated bus-support pad was damaged when expansion anchorbolts shattered the top of the pad. All other bus supports had cast-in-place anchors and were undamaged. The bus connections to several disconnect switches were misaligned, apparently owing to shifting of individual bus members; whether this misalignment affected the switch operation is uncertain.

Two relatively new BBC three-phase dead-tank circuit breakers, 115 and $230 \mathrm{kV}$, were undamaged. No live-tank circuit breakers were located in the switchyard.

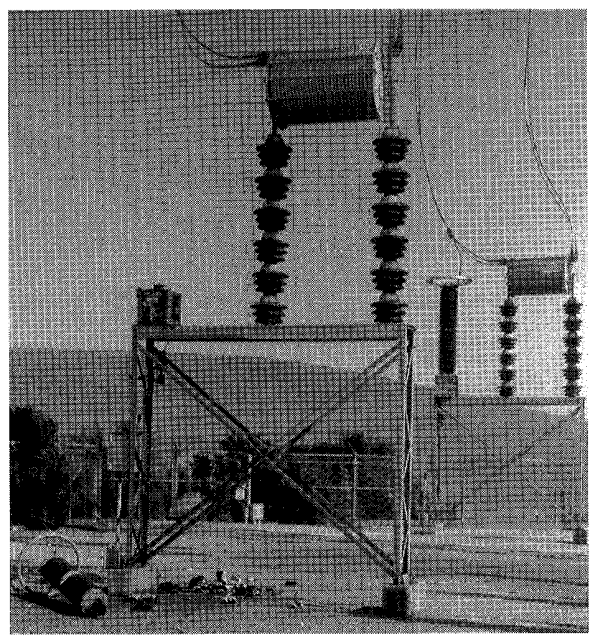

Figure 27.-Damaged capacitatively coupled voltage transformer at the Monte Vista Substation (fig. 1).

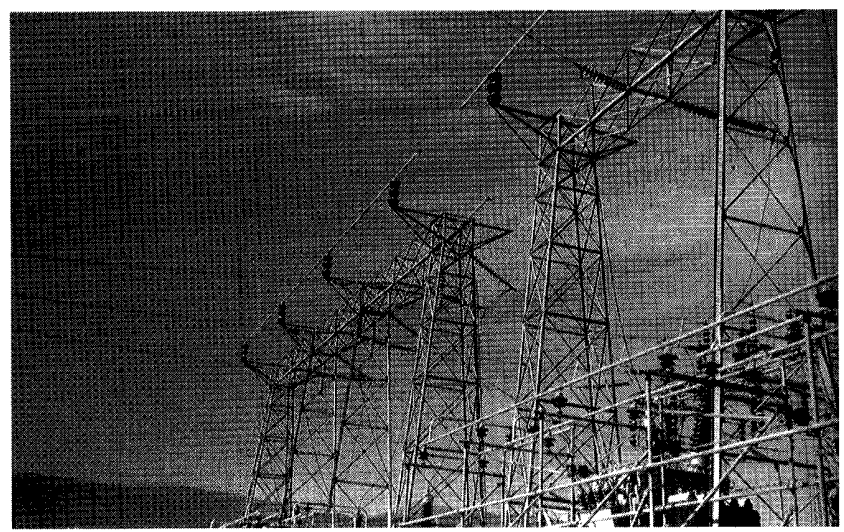

Figure 28.-Bus-support structure and transfer buses at the Monte Vista Substation (fig. 1). 


\section{NEWARK SUBSTATION}

The Newark Substation is located at the southeast end of the bay, about $33 \mathrm{mi}$ from the earthquake epicenter. Gaskets on live-tank circuit breakers leaked.

\section{LOS BAÑOS SUBSTATION}

The Los Baños Substation is $7 \mathrm{mi}$ west of Los Baños, about $47 \mathrm{mi}$ from the earthquake epicenter (fig. 1). Strong-motion records from Los Baños Game Preserve and San Luis Reservoir show about the same peak ground acceleration as those from the 1984 Morgan Hill, Calif., earthquake-about $0.05 \mathrm{~g}$. In the 1989 Loma Prieta earthquake, the substation was undamaged, whereas in the Morgan Hill earthquake, three phases of $500-\mathrm{kV}$ circuit breakers were severely damaged, and nine others were somewhat less damaged (Schiff, 1985). Rigid connections between current transformers and circuit breakers were replaced with flexible connections after the Morgan Hill, Calif., earthquake. Evidence was observed that these rigid connections contributed to the damage in that earthquake.

\section{EARTHQUAKE DAMAGE TO THE POWER-DISTRIBUTION SYSTEM}

Relatively little damage to the power-distribution system was reported. Throughout most of the earthquake-affected area, aerial distribution is used. Many lines were downed, and thousands of fuses in distribution feeders were blown. Some pole-mounted distribution transformers fell from their poles. Slots in the transformer-mounting brackets slide over the heads of bolts that extend through the poles and are secured by nuts. Seismic loads and, possibly, age deterioration allowed the damaged transformers to slip off the bolts and fall. Several 4-kV transformers were severely damaged when 12-kV lines strung above the 4-kV lines fell and came in contact with the 4-kV lines. From 50 to 75 transformers were damaged, and replacements had to be trucked in from storage. Crossarms broke on some poles. Several poles fell over because of rotten bases, and some sound poles broke. Many poles in the Santa Cruz Mountains were lost because of landslides.

Within downtown San Francisco and parts of the Marina District, underground power distribution is used. Transformers generally are mounted in vaults or on pads and restrained at corners by 4.5 -in. angle brackets, which are bolted to the pads. No problems were discovered with the transformers bolted to pads. In the Marina District, vaults for two 12$\mathrm{kV}$ vault transformers appeared to have floated to the surface, and conduits to vaults were broken. Many conduits were broken, but the conditions of cables are uncertain. Less damage was reported to conduits in the Marina District than originally expected.
At the Delphin Substation near Santa Cruz, the anchorage of three single-phase transformers failed, allowing motion that caused arcing. Service at the substation was still totally disrupted at the time of our site visit on October 20, 1989. Some soil liquefaction apparently occurred at the site.

In general, the overall damage to the power-distribution system in the San Francisco Bay region was characterized as being similar to that from a severe winter storm of a magnitude that may occur once a year.

\section{REFERENCES CITED}

Schiff, A.J., 1973, Earthquake effects on electric power systems: American Society of Civil Engineers Proceedings, Power Division Journal, v. 99, no. 2, p. 317-328.

1985, The Morgan Hill earthquake of April 24, 1984-investigation of lifelines: Earthquake Spectra, v. 1, no. 3, p. 615632.

1989 , Lifeline response to the Tejon Ranch earthquake: Earthquake Spectra, v. 5, no. 4, p. 791-812.

Stepp, J.C., ed., 1990, Industrial facilities, chap. 7 of Benuska, Lee, ed., Loma Prieta earthquake reconnaissance report: Earthquake Spectra, v. 6, supp. 90-01, p. 189-238.

\section{APPENDIX: EMERGENCY POWER- ENGINE GENERATORS}

The earthquake performance of emergency generators was generally poor, particularly when the importance of these systems is taken into account. In addition to some power facilities, emergency generators are typically found in critical facilities, such as hospitals and emergency operation centers. This appendix identifies the common failure modes for engine generators and gives installation criteria, as well as discussing maintenance problems.

\section{FAILURE MODES}

The following failure modes are commonly observed in engine generator systems.

Failure of vibration isolators. - Rotating equipment is commonly mounted on vibration isolators to isolate the engine vibrations from its support structure. When subjected to ground excitations, the supported equipment typically undergoes a large-amplitude response, causing it to damage the isolator. Some isolators made of brittle materials, such as cast iron, can fail possibly causing the unit to move excessively or tip over.

Failure of batteries.-Batteries are commonly required to start the emergency-power system. These batteries are commonly damaged because they and (or) their rack are inadequately secured, cells impact restraints or other cells and crack cases, slack is not provided in the electrical connec- 
tions to accommodate relative displacements, or the battery rack collapses.

Failure of utility connections.-Failure of one or more of the numerous "utility" connections (cooling-heating water, fuel line, powerline, oil line) can disrupt system operation and the flow of power.

Failure of day and storage tanks.-The day tank, which contains a small amount of fuel and is located near the engine generator, is commonly unanchored, allowing it to move or tip over. The fuel lines can break, stopping the engine and creating a fire hazard. The main fuel-storage tanks can move and break connections. Tanks on legs made of steel angles commonly fail, and horizontal tanks not anchored to their saddles can slide and break fuel-line connections.

Failure of cooling system.- Some engine-generators have a remote cooling system because of the location of an engine generator. The cooling tower or coils commonly are unanchored, and waterlines can break. Makeup water is needed if evaporative-cooling towers are used.

Failure offlexible coupling.-The flexible coupling provided between the engine and the generator can fail as a result of excessive relative deflections between the units, because each unit has its own independent support structure.

\section{OPERATING AND MAINTENANCE ISSUES}

Engines may fail to start because air dampers have not been opened, cooling water is not turned on, batteries are old or run down, diesel fuel is old and fouled, or fuel filters or injectors are clogged. Engines have failed when units were not tested under full load or when relays that sense a power outage failed to operate. The load to be carried by the generator commonly increases between the time of its design and the time when it is needed, and so generator capacity may be inadequate.

\section{INSTALLATION GUIDELINES}

On the basis of observations from this and other earthquakes and the inspection of engine generators, the following guidelines are provided to help ensure engine-generator reliability.

The equipment should be rigidly mounted to its foundation.-Most of the failures noted above would have been eliminated if the equipment were rigidly mounted to its foundation. If vibration isolators are necessary, units with castiron components should be avoided. Seismic performance can be improved by providing the engine generator with snub- bers to prevent excessive motion. Anchorage adds little to the cost of installation and should be very conservative. Expansion anchors are not recommended for vibrating loads. Cast-in-place or grouted anchors designed for ductile failure should be specified.

Batteries should be firmly secured to their racks.-Securing batteries to their racks prevents them from falling off the rack or vibrating against each other. Stiff foam spacers should be placed between cells and cell restraints to prevent impacting. The rack must be anchored and braced, so that it can support the substantial battery weight.

Interconnecting utilities should be provided with adequate flexibility and slack.-Utilities for units mounted on vibration isolators should be provided with slack in the connections to accommodate the motion allowed by the isolators.

The day tank should be adequately secured.-At many installations, the day tank is added almost as an afterthought and is commonly supported by flimsy straps. Furthermore, the tank itself may be poorly constructed. The tank, its supports, and, in particular, the connections should be able to support a force in any direction equal to twice the tank's weight when full of fuel. Fuel-storage tanks should be anchored.

The unit's cooling system should be self-contained.Cooling systems consisting of a radiator mounted to the engine generator skid have performed well in earthquakes. If an external cooling system is required, its anchorage and the security of the water system should be evaluated. If evaporative cooling is used, an emergency supply of makeup water should be available because the normal water supply may be disrupted.

Engine and generator mounts should be integral.-To prevent misalignment of the engine and generator, their mounts should be secured to the same support structure.

Personnel should be provided with starting instructions.- Instructions for starting the engine should be posted so that if problems arise, available personnel can start the engine. Such critical items as opening dampers and coolingsystem valves should be noted. Maintenance should include checking batteries (acid level, specific gravity, charging, age), cleaning fuel filters, and replacing old fuel (fuel should not be older than five years). Units should be periodically tested under full load. The relay to sense a power outage should be checked carefully for corroded contacts.

Seismic specifications should be issued for new installations.-Installation specifications for new equipment should be called out on engineering drawings, and equipment should be inspected in the field to ensure that these specifications are followed. 


\section{COMMUNICATION SYSTEMS}

By Anshel J. Schiff, Precision Measurement Instruments and Stanford University;

Alex Tang, Nortel Canada, Inc.;

Lawrence F. Wong, Pacific Bell;

and

Luis Cusa, Los Angeles Department of Airports

\section{CONTENTS}

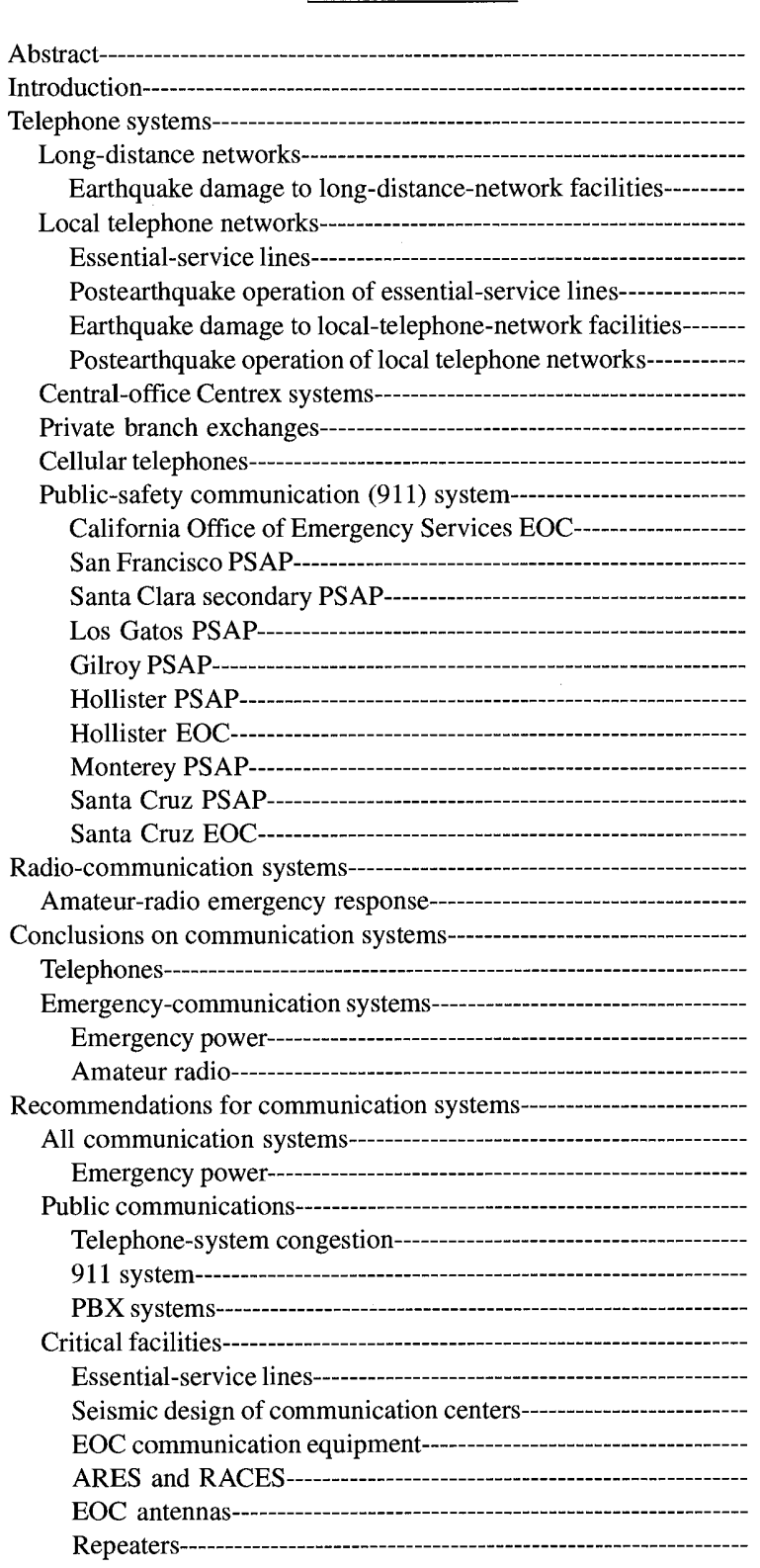

Page

A23

24

24

24

25

25

25

25

25

26

27

27

27

28

29

29

29

29

29

29

30

30

30

30

30

31

32

32

32

33

33

33

33

33

33

33

33

33

34

34

34

34

34

34

34

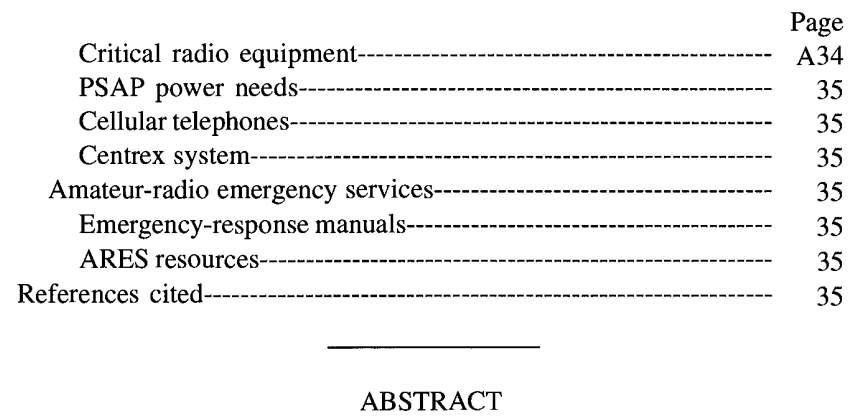

Immediately after the earthquake, the public switched network was difficult to use because of congestion caused by a huge increase in traffic volume. Dialtone delays were as long as 3 minutes. Congestion during business hours continued to be a problem for 4 days after the earthquake.

Relatively little damage to central-office telephone equipment was reported. Commercial power in the earthquake-affected area was generally lost. In three central offices, problems were reported with the engine generators used to recharge batteries. In all but one central office, replacement generators were obtained before the batteries discharged. At one central office, three of the five switches had to be shut down to conserve power until a replacement generator could be obtained. The trade literature reported acid spills, indicating that some batteries failed.

The most significant and costly damage was to a large building in Oakland that housed Pacific Bell and AT\&T facilities. The building was severely damaged structurally, and all but essential personnel were evacuated. A water tank that supplied makeup water for the air-conditioning cooling tower failed, and so air-conditioning capacity was limited. The building was extensively seismically upgraded after the earthquake. Except for a brief interruption in the operation of the enhanced public-safety communications (911) system, telephone equipment in the building continued to operate.

The performance of the cellular-telephone system was mixed. Some system damage was reported, but many cellu- 
lar-telephone sites have limited reserve power when commercial power is lost. Users in some areas indicated that service was good, while in other areas service outage was reported. Cellular-telephone sites can have congestion problems when demand exceeds capacity. Because of problems with the public switched network, both the number and use of cellular telephones increased, and performance degraded over time as the use increased.

The 911 system had many problems. Congestion of the telephone system made it difficult to get though to publicsafety answering points (PSAP's). Several PSAP's had their own problems. Some centers lost power, and their display panels could not indicate which lines were ringing or which were busy. Because of the long delay in getting a dialtone, even on essential-service lines, transfer of a call to the appropriate agency took much longer, and so fewer calls could be handled. In smaller offices, the operator also dispatches emergency-response services, such as fire, rescue, and police. Dispatching is done by radio, but because repeaters were not functioning, some vehicles to be dispatched could not be reached. In severely damaged areas, the resources available to the dispatcher were quickly depleted, and so immediate response to calls could not be made.

Generally, radio-communication systems worked well, except when repeaters were needed. Repeater sites are located on many hilltops in the earthquake-affected area. Many repeaters had only limited emergency power, and so a few hours after commercial power was lost, the repeaters shut down. The emergency power at several repeater sites failed. The equipment at some repeater sites was damaged because of severe ground motion at the sites and poor seismic design and installation practices. Amateur-radio support personnel played an important role in providing the only means of communication or in supplementing telephone-system communications at local emergency-operation centers.

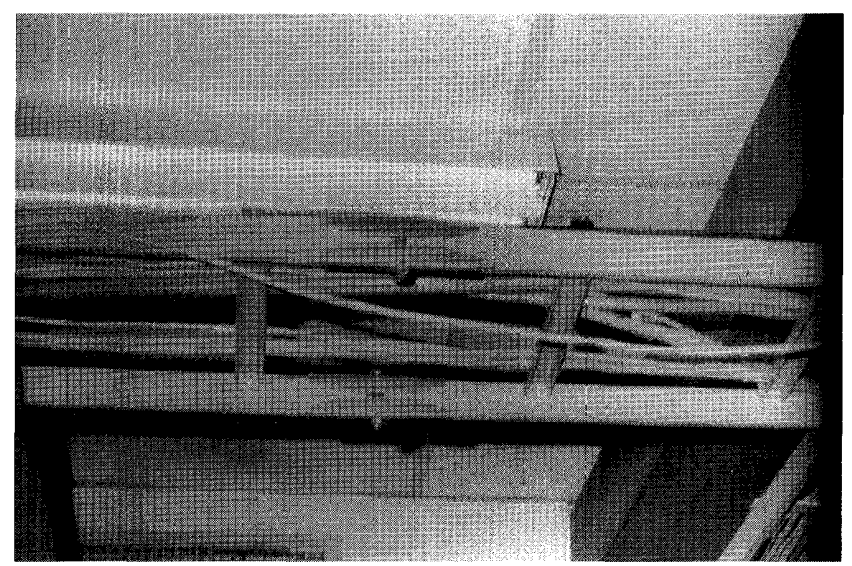

Figure 1.-Cable-tray hardware used in communication equipment.

\section{INTRODUCTION}

The communication systems considered here are telephone systems, cellular telephone systems, private radio systems, and amateur-radio operators ("hams"). Radio and television broadcast media and newspapers are discussed by Rapaport (this chapter). Because of the many communities affected and the range of communication systems involved, we could not canvas each medium in the entire earthquakeaffected area.

\section{TELEPHONE SYSTEMS}

\section{LONG-DISTANCE NETWORKS}

Long-distance telephone service in the earthquake-affected area is provided primarily by AT\&T; MCI and U.S. Sprint also provide service. Long-distance carriers can block or limit access of long-distance calls to and from specific areas codes through network-load balancing, which frees up circuits for use within an area code.

Telephone traffic worldwide increased significantly as a result of the earthquake. For example, between 5:00 and 9:00 p.m. P.s.t. October 17, the AT\&T network attempted 40 million worldwide calls, in contrast to the usual 18 million, although only a fraction of these calls were completed. On the next day, 27.8 million calls were attempted to the 408 and 415 area codes that serve the earthquake-affected area. Only 9.5 million calls were completed, still representing almost a threefold increase over the normal daily volume of 3.5 million.

Calls to the 408 and 415 area codes were blocked by long-distance carriers and Pacific Bell on October 18 and 19 to improve service within the earthquake-affected area. On October 18, 70 percent of outbound calls and 30 percent of inbound calls were completed on AT\&T systems. Telephone representatives cited recent large-scale introduction of technical innovations, such as the use of digital switches and optical fiber, as reasons for being able to carry the high volume of calls. Long-distance telephone networks apparently were unaffected by seismic damage to equipment or technical problems.

The press reported that residents in the 408 area code could not call a nearby hospital, which was located in the 415 area code, because of long-distance blocking. However, it was not long-distance blocking that caused this problem, because calls between different area codes that are close to each other do not use long-distance carriers and thus are not subject to long-distance blocking. The problem is that callers served by a different central office than the hospital's would have difficulty getting through. The solution to this problem is for the hospital to be served directly by some lines from the nearby central office, a technique known as "dual homing." This so- 
lution, however, has additional costs for connecting a line to another central office, and more than one central office may be required.

\section{EARTHQUAKE DAMAGE TO LONG-DISTANCE-NETWORK FACILITIES}

In one Oakland facility, support clips failed on several heavily loaded cable trays, which were part of the AT\&T system, so that the trays sagged about $1 \mathrm{ft}$. Also, friction clips used to connect cable-tray sections slipped, allowing cabletray sections to separate and in some places to sag. The function of the cables in the tray, however, was unaffected. Cable-tray hardware is unique to communication equipment (fig. 1). Pacific Bell has improved hardware details by adding pins that provide a positive connection to the friction clips; however, the less reliable clips are used in communication equipment by telephone and industrial companies in California and other parts of the country. Overloaded cable trays aggravate these problems. No damage to switches or other communication equipment used by long-distance carriers was reported.

\section{LOCAL TELEPHONE NETWORKS}

Local telephone service in the earthquake-affected area is dominated by Pacific Bell. Gilroy is served by Continental Telephone, and Los Gatos by General Telephone (GTE).

\section{ESSENTIAL-SERVICE LINES}

The switch in the central office that routes calls can handle only a fraction of the lines that are connected to it at any one time. The central office takes advantage of the fact that only a few lines are normally active at any time. After a major earthquake, telephone usage increases dramatically, and the switch cannot immediately handle all of the requests for service. As a result, a user may have to wait for a dialtone before making a call. Under extremely heavy loads, this delay can be as long as several minutes. However, most users are unaware that if the telephone system is undamaged, those who wait for a dialtone can eventually make a call. Telephone companies have developed procedures and equipment that give a high priority to lines for essential services, such as police departments, hospitals, and government and selected emergency-operations centers (EOC's). Users who satisfy certain criteria can get essential-service lines. For example, all of Pacific Bell's pay telephones are essential-service lines. The operation of essential-service lines is unclear; telephone personnel described two methods used. In the first method, calls using essential-service lines go to the head of the queue for calls requesting service. In the second method, when de- mand for service exceeds a preestablished load threshold, lineload control is automatically invoked by the switch, so that essential-service lines do not have to wait for a dialtone. According to this method, the excess capacity in the switch is used to handle non-essential-service lines on a rotating basis.

\section{POSTEARTHQUAKE OPERATION OF ESSENTIAL-SERVICE LINES}

For reasons that are not entirely clear, the operation of essential-service lines did not operate as expected in the earthquake because line-load control was generally not activated. As a result, essential-service lines commonly had dialtone delays of 10 to $15 \mathrm{~s}$, significantly affecting public-safety-communication (911)-system operations when operators had to transfer calls to other agencies. This delay may have led some 911 operators to believe that they could not make outgoing calls. The inability to make outgoing calls was reported at two emergency-communication centers, even though all telephone equipment reportedly was functioning normally. In Sacramento, where no earthquake damage occurred, a 1minute dialtone delay on an essential-service line was reported, at which time the caller abandoned the call and used a radio to get through, suggesting that line-load control should have been, but was not, activated.

At an office in Oakland, the computer that provides the enhanced 911 system with automatic address-location information for northern California shut down for about 15 minutes, without affecting the basic operation of the 911 system.

\section{EARTHQUAKE DAMAGE TO LOCAL-TELEPHONE-NETWORK FACILITIES}

Although damage to Pacific Bell's communication equipment was minor and did not significantly affect service, the loss of commercial power did cause some problems in three central offices. All but one of Pacific Bell's 160 central offices worked throughout the disaster without impairment. Central offices contain batteries to operate the telephone system for several hours in case commercial power is lost. In addition, the central offices have engine generators to recharge the batteries, so that telephone service can be maintained for 2 to 21 days without commercial power and without refueling. However, some problems with engine generators were reported. In one central office in San Francisco, asbestos was being removed from the room that contained the engine generator, putting the generator out of service. A rented generator, located outside the building, served as a replacement during the remodeling. This generator failed to start, and workers found and replaced a clogged fuel filter. The generator then started, but it would not carry load and eventually caught fire. A replacement generator was obtained before any disruption of service occurred at the central office. In anoth- 
er central office, which has diesel- and turbine-powered generators, the turbine-powered generator had a faulty governor that caused fluctuations in speed, and so it had to be taken out of service. A cooling-system water pump for the diesel engine was shut off, and the diesel engine shut down automatically when it overheated. Partial service was maintained by shutting down parts of three of the five switches at the central office until additional backup power could be obtained. At the central office in Hollister, an engine generator could not be started. A replacement generator was obtained before it was discovered that a damper, used to shut off the air intake, was closed.

In San Jose, two circuit packs (circuit boards used in telephone equipment) came out of their motherboard sockets in the earthquake, similar to occurrences in Long Beach, Calif., during the 1987 Whittier Narrows, Calif., earthquake, also in an area of relatively low amplitude shaking. In the 1985 Mexico City earthquake, numerous circuit packs fell from equipment.

In Oakland, a major facility that contained Pacific Bell and AT\&T equipment was severely damaged structurally, but no significant damage to communication equipment was reported. On the roof, a water tank that supplied makeup water for a cooling tower used in the air-conditioning system was damaged, but cool weather made the tank water unnecessary. In light of the short duration and small bedrock motion in this area from the earthquake, it can be speculated that more severe ground motions could have caused the loss of the building. Had this loss occurred, communications in northern California would have been severely disrupted for a long time.

At a Pacific Bell building in Watsonville, peak ground accelerations of $0.39 \mathrm{~g}$ and roof accelerations of $1.24 \mathrm{~g}$ were recorded by instruments maintained by the California Strong Motion Instrumentation Program of the California Division of Mines and Geology. The structure and the equipment that it housed were undamaged. No damage to trunklines or user looplines was reported. Even in the Marina District of San Francisco, where liquefaction occurred, buried telephone vaults did not crack or float to the surface.

In Gilroy, which is served by Continental Telephone, no damage to telephone equipment was reported. The electronic switch (AT\&T 5 ESS), which was anchored to the floor and braced to a wall, pulled its wall anchorbolts from the wall. Commercial power was briefly interrupted, but a diesel generator operated. The long disruption of commercial power in the Hecker Pass and Summit Road areas, in the hills west of Gilroy, required portable generators to be brought in because these sites had only limited battery backup power. A few service drops to homes were damaged, but service needs were not out of the ordinary.

In the January 2, 1990, issue of Communications Week, an industry news magazine, an article based on an internal Pacific Bell memorandum described some of the problems caused by the earthquake. This article confirmed the problems associated with emergency power discussed above, not- ing that the central telephone office in Hollister was down for 6 hours, that "some pretty severe acid spills in some of the offices" were reported, and that "they lost international trunks, as well as many other services," owing to failure of emergency power at a central office. A Pacific Bell spokesperson interviewed for the article disputed some of the interpretations made by the memorandum's author, but not the factual accounts.

\section{POSTEARTHQUAKE OPERATION OF LOCAL TELEPHONE NETWORKS}

On the day after the earthquake, Pacific Bell had a record volume of 80 million calls in the nine-county San Francisco Bay region (the daily average volume is 55 million calls). As a result of the heavy volume, delays in getting a dialtone and problems in completing calls were reported. In general, although calls could be made within most local areas, calls between areas served by different central offices or with different area codes were more difficult to make. Although many telephones were reported to be not working, most of them were actually working, but users thought that they were not because of the delay in getting a dialtone or problems with private branch exchanges (PBX's). In many areas, telephone service degraded during peak-load times in the morning and afternoon for several days after the earthquake. Service announcements on the radio immediately after the earthquake requested that only emergency calls be made; these announcements were, at best, only minimally effective.

The operations of the emergency-response community were impaired by communication problems, but generally the emergency response worked well. The overall good performance of the emergency response is partly attributable to the moderate intensity of shaking in most high-populationdensity areas. The emergency-response community was not significantly overextended, and many of the problems confronting regional EOC's were associated with an abundance of aid and supplies, rather than shortages.

In Gilroy, the electronic switch was saturated for a few minutes after the earthquake; however, it remained operational. At the request of Pacific Bell, line-load control was imposed by Continental Telephone to limit calls being transferred to the 408 area code to every other call. Although the Gilroy switch was physically capable of implementing essential-service lines, Continental Telephone does not use that feature.

GTE provides service to Los Gatos, Morgan Hill, and nearby mountain areas. Six central offices and several smaller facilities in the mountains serve the area. Commercial power was lost, but emergency power operated, except in Los Gatos, where a diesel generator stopped when the day tank ran out of fuel. The pump that supplies the day tank from the main tank did not work, and repair took about $3 \frac{1}{2}$ hours. Essential-service lines were jumped to a trunk at another central office for service; however, the 911 system still had problems. 
It should be noted that GTE operates its essential-service lines differently from those described above: Essential-service lines are given only assurance of service, not special dialtone priority; thus, essential-service lines must compete for dialtone with all other lines. Some of the mountain areas have stations with batteries that last 8 hours; emergency generators were provided to these areas. Some parts of the telephone system were without power for 4 days. No equipment problems were reported. It took about 3 days before fast dialtone response returned.

\section{CENTRAL-OFFICE CENTREX SYSTEMS}

Several organizations use the Centrex system for communications. Centrex is a trademark for a group of features, and similar packages are offered under different names. With this communication system, telephoning within an organization involves dialing only four or five digits, but the switching is typically done at a telephone company's central office, rather than by a PBX located at the organization site. When the switch in the central office is overloaded, a long wait for a dialtone may be noticed, even for a call within the organization. In situations where facilities of the organization are separated and served by different central offices, a second delay may occur when transferring a call to the second central office. Dialtone delays for a Centrex system are due to the load on the switch in the central office and not necessarily to activity in the organization using the system. Getting a dialtone quickly is of vital importance for telephone systems in critical facilities, such as hospitals, where good internal communications are needed for efficient operation. If a PBX is used instead of Centrex, it must be selected so that it can handle extreme loads within the facility.

\section{PRIVATE BRANCH EXCHANGES}

A more common cause of disruption of the telephone system within organizations was the lack of emergency power for PBX's, which are the privately owned telephone systems used by companies and large organizations for telephone service within a facility or an organization. PBX's also connect to outside lines provided by the local telephone company. When commercial power is lost, many of these systems have limited or no emergency-power capabilities, and so all or most of the telephones in a given office or an entire building will not operate. Commonly, users are unaware that the problem is with the PBX and assume that the commercial carrier's system is not working. It is important for people to know that emergency calls can generally be made from pay telephones or adjacent offices which are not run by the same PBX.

Some damage to smaller PBX systems was reported. These systems have many manufacturers, not all of whom have developed equipment that is as seismically rugged as traditional telephone equipment. Also, many PBX's may not be installed with the same attention to seismic hazards that telephone-company equipment receives.

\section{CELLULAR TELEPHONES}

Cellular-telephone systems consist of an array of transceivers (radio transmitters and receivers) called cells; these cells communicate to subscribers' mobile telephones (cellular telephones) and are connected through leased lines, private lines, and microwave links to a switch operated by the cellular-telephone company. Larger companies may have several switches, which are typically connected to each other by communication lines of the cellular-telephone company and to the central office of the local telephone company. The link that connects the cellular switch to the public telephone system is similar to a central office, and so it generally has better access than does an individual subscriber. In each area, cellular-telephone service is typically provided by two cellulartelephone companies: users can subscribe to both companies to enhance the reliability of their cellular telephone. Typically, each cell transceiver has battery backup power and may have engine generators; however, due to space limitations, backup power may be limited. Each cell is monitored, and losses of commercial power, low batteries, and generator failures are logged at a service office to facilitate maintenance.

The cellular-telephone-company switch completes calls between cellular-telephone subscribers connected to the switch, without entering the regular telephone system. The response time for intracellular telephones depends on the traffic load that is placed on the cell and the switch that serves it. The number of calls that a single cell can handle simultaneously depends on the cellular equipment but typically ranges from 15 to 60 . Most of the switches used by cellular-telephone companies can assign a high priority of service to some of their subscribers. With most of these systems, high-priority users go to the head of the queue in the cellular-telephone company's switch. However, these features were not implemented on cellular-telephone systems in the San Francisco Bay region. The National Communications System has petitioned the Federal Communications Commission to authorize a nationwide Cellular Priority Access System (CPAS) for emergency responders.

For cellular calls to telephones outside the switch's service area, private lines may be used to connect to another telephone-company switch, or the public-telephone system must be entered. Processing of the call would then be the same as for any telephone user. It should be noted that the service areas of adjacent cells overlap, and so the loss of a cell may not prevent calls from within that area from being completed.

Some conflicting reports about the operation of cellular telephones were received shortly after the earthquake. Some reports claimed that their cellular telephones worked much better than wireline telephones, whereas others said that us- 
ers were unable to complete cellular-telephone calls. Calls completed within a cellular switch will depend on the load on the switch and the capacity of the switch relative to its customer base. The load on each of the switches that must handle the call always influences the response time. One problem with adding telephones just after an earthquake to supplement communication capabilities at an organization (such as an EOC) is that the cell serving that area may become saturated, thereby degrading the service provided to all cellular-telephone users in the area.

One company with four cellular switches lost power to a cell located on Loma Prieta peak. The generator failed to start, but a new engine-circuit-control card, installed the next morning by a crew flown in by helicopter, corrected the problem. Another cell, located in a building that was condemned because of structural damage, continued to function.

In Los Gatos, cellular-telephone service from one company was unavailable for about half an hour, and then service became intermittent. Reports indicated that microwavecommunication antennas were misaligned. An equipment rack for one of the cellular-telephone companies on the fourth floor of a major communications building in Oakland pulled expansion anchors from a wall, tipped over, and caused a short circuit, which blew a fuse. A recording head on one of two computer disks mounted in an equipment rack crashed, damaging a sector of a disk; the disk was reformatted and continued to operate.

\section{PUBLIC-SAFETY COMMUNICATION (911) SYSTEM}

The public-safety communication system, commonly referred to as the 911 system, is the primary means for individuals to obtain emergency services, such as police, fire, and medical assistance. The system consists of public-safety answering points (PSAP's), which have operator positions (consoles), radio-communication capability, a tape system to record all calls, and emergency backup power. Some PSAP's also have a computer-aided dispatch system that logs dispatches and indicates the disposition of units on the basis of data provided by the PSAP. Typically, each county has a PSAP that receives emergency calls from unincorporated areas within the county and from communities that do not have their own PSAP. Some county emergency-communication centers have as many as 60 operator positions, and police, medical, and fire dispatchers may be located in the same facility. In other areas, sheriff's departments operate the system, and many cities have their own PSAP's. Most PSAP's have enhanced 911 systems, with automatic address-location and telephone-number information: The PSAP operator has a display that shows the address and telephone number of the calling party, and the system logs the calls. Within California, 92 percent of the State is served by enhanced 911 service.
In larger county 911 systems, which may have as many as 30 operator positions, an operator will receive a call, identify the appropriate response agency (fire, police, or medical), and transfer the call to a dispatcher for that agency. In smaller emergency-communication centers, such as those for a city, which may have as few as two operator positions, the operator also serves as a dispatcher. In a location where the sheriff's department operates the 911 system, police calls will be dispatched, and fire and medical calls transferred.

PSAP's typically do not use amateur-radio emergencycommunication resources, but EOC's have integrated them into their system and commonly make extensive use of their resources.

Interviews were conducted with 15 emergency-communication centers, EOC's, and emergency-response organizations, primarily by telephone. These interviews were conducted 5 to 10 weeks after the earthquake, and some of the individuals interviewed had not been at the center during the emergency-response period. Some individuals dealt primarily with public relations and could not provide the technical details requested, and others had been so busy at the time of the earthquake that they could not recall many details. Some organizations were called twice: First, a dispatcher was interviewed, and then a followup call was made to the head of the agency. Commonly, agency heads reported fewer problems than did the dispatchers.

The most serious and most common problems were related to the inability of many emergency-communication centers to make long-distance calls, for example, to area codes 408 and 415, which were blocked by network-load control, and to area codes 916 (Sacramento, Calif.) and 202 (Washington, D.C.). Another serious problem was the difficulty in calling numbers within the same area code that are served by different central offices. At some centers, delays in getting a dialtone were reported, even on essential-service lines. For this reason, the centers could not transfer calls to the appropriate agencies, and they had to use radio or ring-down lines; because this procedure is much slower, fewer incoming calls could be handled.

Various problems associated with emergency power were reported. At some sites, the emergency power is derived from an engine generator, and a pause of 10 to $30 \mathrm{~s}$ occurs after commercial power is lost before emergency power is available. With the loss of power, display panels go black, and so it is impossible to know which line is ringing, even though the telephones are working. Several emergency-communication centers did not have uninterruptable power supplies for their computer-aided dispatch systems, and so they had to revert to backup paper messages.

In smaller centers, where the operator normally also does the dispatching, another individual did the dispatching to allow the operator to answer more calls. In severely damaged areas dispatchers worked from 12 to 14 hours per day, and food and drinks were needed to sustain them; however, wa- 
ter supplies were disrupted, and food at local grocery stores was almost gone before the initial bedlam had subsided enough to allow time for the dispatchers to shop. At several centers, repeaters used for radio communication were inoperative or worked only intermittently. This failure generally did not cause any serious problems because remaining repeaters gave adequate coverage; when they did not, dispatches were made directly to emergency responders, without the use of repeaters. below.

The responses of several PSAP's and EOC's are given

\section{CALIFORNIA OFFICE OF EMERGENCY SERVICES EOC}

The California Office of Emergency Services (OES) lost power for about 2 hours, but emergency power worked without problems. Telephones became saturated during peak hours for about a week after the earthquake. One to five hams were available around the clock for 4 days; they were primarily used when the telephone system became saturated at peak hours during the day.

\section{SAN FRANCISCO PSAP}

Commercial power was out for about 3 days at the San Francisco PSAP. After a short delay, the center's emergency power came on, but there was concern throughout the period that it might fail. The computer-aided dispatch system was down because of a power outage, and the 15 operator positions were saturated with calls. Problems with transferring calls to other agencies, whose lines were often busy, were reported. The ring-down lines worked (ring-down lines go through the telephone company's central office but not through the switch), but information had to be relayed over the telephone because ring-down calls cannot be transferred; therefore, the dispatch process was unusually slow. The ratio of dispatches to calls received was especially low.

\section{SANTA CLARA SECONDARY PSAP}

The Santa Clara secondary PSAP, which is operated by the California Division of Forestry, receives fire calls transferred to it from the Santa Clara County PSAP. Commercial power was out for 2 hours at this PSAP, but emergency power worked well. Essential-service lines worked well, but there was a 2- to 3-minute delay in getting a dialtone on non-essential-service lines. This situation improved around midnight, but by 7:00 the next morning telephone lines were again saturated. Four hams were on site for 48 hours: two to operate radios and two to serve as information officers. Three or four amateur-radio operators were also used as "shadows" with mobile units to reduce the load on regular radio chan- nels. (A "shadow" is a ham who travels with a fire chief or other official and provides independent radio communications to that individual.) The PSAP received about 40 to 50 calls in the first four hours. Most calls concerned actual or suspected gas leaks; several calls were related to downed powerlines and medical needs. Four fires were reported: two were grass fires started by downed powerlines, and two were structural fires of unknown origin. There were adequate firefighting resources; however, the three regular units were supplemented by three volunteer units.

\section{LOS GATOS PSAP}

Outgoing telephone calls GTE could not be made from the Los Gatos PSAP for 4 hours after the earthquake. During this time, operators used radio communications to contact agencies. At the EOC, hams were on duty 24 hours a day until November 1, 1989, to coordinate with the American Red Cross and shelters. Hand-held radios were in short supply for the additional police who were mobilized.

\section{GILROY PSAP}

Calls could not be placed from the Gilroy PSAP until midnight October 18, after which only intermittent calls were able to get out. The hams were very helpful; PSAP operators could not have gotten through to the appropriate agencies without them. A delay in dialtone on essential-service lines was reported. Although resources were not depleted, volunteer police and fire fighters came in to supplement regular crews. Most calls were related to gas leaks at water heaters and meters; however, no fires were reported.

\section{HOLLISTER PSAP}

Commercial power was off for 3 days at the Hollister PSAP. Although the emergency generator worked, it stopped periodically for short periods, apparently owing to overload. On the second day, the Pacific Gas and Electric Co. (PG\&E) brought in a portable generator to supplement the main unit thereby solving the problem. Long-distance calls could not be made from either the PSAP or the EOC, except on one line from San Juan Bautista, which was in constant use by EOC personnel. The PSAP could not communicate with the ambulance unit, even though the unit was nearby. Owing to the heavy police load, PSAP operators could not dispatch the public-works crews. The radio repeater used by the dispatcher did not have emergency power, and so it was out of service until commercial power was restored 3 days after the earthquake; this failure may have contributed to communication problems. The PSAP had only two operator positions, which were unable to keep up with answering calls and dis- 
patching. The PSAP obtained permission for mutual aid, and trained dispatchers from Monterey were brought in to answer the telephones while the local operators dispatched. The fire department took over their own dispatch from their site. One of the most serious communication problems was that large gas leaks could not be reported to PG\&E. Fortunately, no fires broke out. The PSAP was unaware that hams could have communicated with some of the key locations it wanted to contact, and it could have installed stations at the PG\&E service center.

A resident in the area, who was familiar with the operation of the telephone system, indicated that on a home line one would get a dialtone and calls appeared to be ringing but there would be no answer, even though the caller knew that someone was at the number dialed. This difficulty occurred on October 18 and 20 and intermittently on October 19, suggesting that operation of the switch may have been problematic.

\section{HOLLISTER EOC}

The Hollister EOC used the same emergency power as the PSAP. After the earthquake, the telephones did not work until midnight. After midnight, the telephones worked only intermittently, and delays were reported in getting a dialtone on essential-service lines. Hams played an important role, providing a van with radio gear. Two hams worked inside the EOC, and two in the van. There were not enough telephone lines at the EOC, and so, on the second day, Pacific Bell added six lines. The OES is making changes by putting a 20-line console into the PSAP, adding an emergency generator to the repeater, and adding generators to other facilities in the county. Permanent radio equipment is being added for ham use.

\section{MONTEREY PSAP}

Monterey County has an integrated 911 system that serves most of the county from nine positions in Salinas and six positions in Monterey. Commercial power was out about $1 \frac{1}{2}$ days, but the emergency power worked. Computer-aided dispatch was down because of a power outage. The county has an independent communication system, which worked well because it does not use the switched networks. Commercial telephones were saturated, and the essential-service lines had a dialtone delay. Radio-communication channels were busy but usable. Repeaters worked, although some secondary units that did not have backup power went down.

\section{SANTA CRUZ PSAP}

Commercial power was lost for about 2 hours at the Santa Cruz PSAP and was sporadic for some time after that. Emergency power worked but ran out of fuel during one of the subsequent power outages. No dialtone delay was reported, but calls could not be made to the southern part of the county because of line or circuit busy signals. Overloading of the 911 system prevented callers from reaching the PSAP. During one 25-minute interval shortly after the earthquake, radio communications to the ambulances in the southern part of the county were inoperative. During another 25-minute period, about 2 hours after the earthquake, all power and telephones were dead for an unknown reason. Even after telephone communications improved, some areas in Watsonville could not be telephoned. As a result of a training program, equipment in the PSAP had been secured, and so the tape unit and other items did not fall over. Between 5:00 p.m. and midnight, more than over 300 callers reported gas leaks. The PSAP had an unlisted telephone number for contacting the local PG\&E office. Several structural fires and grass fires were reported, and some mobile homes had fires related to gas leaks. Ambulance resources were exhausted in 5 minutes, but no serious injuries were reported, and so individuals were able to provide for their own transportation to the hospital.

\section{SANTA CRUZ EOC}

The Santa Cruz EOC shares power with the PSAP. After the earthquake, calls could not be made to the southern part of the county, and so the hospital could not be contacted. At about 8:00 p.m., a call was received from the hospital, and its status was then determined. The hospital worked with the city EOC. The radio in the hospital, which was part of the medical network, went down because a circuit board had vibrated loose. The radio remained down for 3 days; however, a hand-held unit was used, although it had limited power. The fax machine in the EOC worked well and was especially useful. In addition to the disruption of lifelines to the hospital, a support for the tank that holds the oxygen supply for the hospital failed, causing the tank to tilt and break its connections. The hospital used portable oxygen for 3 days while the tank was being repaired.

\section{RADIO-COMMUNICATION SYSTEMS}

There are several types of voice radio-communication systems. Many have a base station, which is commonly a fixed facility with a high-powered transmitter and a fixed antenna. Mobile units can communicate with the base station and with each other. Ultra-high-frequency (UHF) systems are used by emergency-response agencies, such as police and fire departments and PSAP's, as well as by other organizations, including hams and cab companies. Repeater stations, commonly located on hilltops and ridges, improve the coverage and range of UHF radios by receiving and retransmitting signals. Other organizations, such as banks, telephone 
companies, and cellular-telephone companies, use microwave networks and commonly locate their antennas on hilltops to maximize transmission range. Most peaks in the San Francisco Bay region host several such antennas.

Although these hilltops provide good radio coverage, they generally are remote, difficult to reach, and subject to severe ground motions in earthquakes. Many of these sites sustained severe ground motions, and soil failures made access more difficult. An individual on Mount Umunhum reported that he saw the top of the 45 -ft-tall power pole, which supported the transformer providing power to the transmitters at the site, swing back and forth about $15 \mathrm{ft}$. The transformer, which was bolted to the pole, fell to the ground after tearing loose the steel mounting tabs. At this site, an abandoned, blast-hardened, reinforced-concrete U.S. Air Force radar tower was severely damaged. Two 500-gal propane tanks that rested in cradles but were otherwise unanchored moved, broke their piping connections, and disrupted the fuel supply to the engine generator at the site. At this site, emergency power was restored within half an hour; commercial power was restored in about 3 days.

Many radio-communication sites lost commercial power. At one site, the emergency generator tipped over and was inoperable; at a second site, the batteries that start the generator were dead; and at a third site, the batteries tipped over, broke, and spilled acid on equipment. Many sites were without power until commercial service was restored. Many sites have only battery backup power, and so, if commercial power is off for an hour or two, the transmitter goes off the air. Highelevation repeaters used by hams appeared to be particularly vulnerable because they lost about 30 of their 35 systems in the earthquake-affected area; however, not all of these repeaters are used for emergency communications. On Mount Diablo, a repeater used by hams operating out of OES region 2 was down for about 2 hours because of the failure (not earthquake related) of a control board. Pacific Bell's facilities, which typically have their own enclosures and emergency power, performed well, even where ground motion was very severe.

Much of the equipment located at hilltop stations was damaged. Because some of these facilities are critical, they are discussed below together rather than in association with a specific facility with a given site. Sites typically have a few small structures that contain electronic equipment. At one site that served about 30 different antennas, each with its own electrical cabinet, all 30 systems were inoperable as a result of the earthquake. Only two of the cabinets were anchored, and most were thrown across the room, breaking antenna and power connections. Backup batteries fell, broke connections, and spilled acid over other equipment that had fallen to the floor. One cabinet, though anchored at its base and top, leaned over at about $45^{\circ}$, breaking its antenna connection. Although some systems could be restored, many needed major repair and were out of service for an extended period. Only a few damaged antennas or failures of antenna feeds between the antenna and equipment enclosures were reported.

Some important radio-communication facilities were disrupted. For example, U.S. Coast Guard Channel 16, the emergency channel for ship-to-shore radios, and a radio transmitter for the station at Monterey were down until 10:00 a.m. October 18. One repeater used for emergency service was lost; it was replaced with a private unit. Two additional units were used for emergency service to expand capabilities. One or two repeaters were temporarily disrupted by hams who objected to their conversion to emergency use, and one repeater was jammed.

\section{AMATEUR-RADIO EMERGENCY RESPONSE}

Hams are licensed by the Federal Communication Commission to operate within a wide band of radio frequencies under five grades of license; higher grades allow access to a broader frequency band. Although all frequencies in the amateur band are open, some are reserved, by agreement, for emergency use. The American Radio Emergency Service (ARES), a ham organization, is organized to provide emergency-communication assistance. Three sections of ARES are located within the earthquake-affected area: the San Francisco, East Bay, and Santa Clara sections. Another organization, with many of the same members as ARES, is the Radio Amateur Civil Emergency Service (RACES).

Several amateur-radio networks are in operation. The radio equivalent of a telephone modem for use with computers is referred to as a packet system. After the earthquake, the utilization of this network varied. Some stations had little or no use, while one handled 4,000 messages an hour.

As an example of how ARES works, the Palo Alto district has 45 members who live within the district and 10 to 15 members who live outside the district but work in the area. Several sites are set up to accommodate hams: Locations that have provided space and a hookup to a permanently installed antenna include Palo Alto City Hall (EOC), five schools, and four hospitals (Stanford University Hospital, Childrens Hospital at Stanford University, the Palo Alto Clinic, and the Veterans' Administration Hospital). In city hall, a room has been provided next to the EOC, which has a permanently installed radio with backup emergency power. The Palo Alto section's emergency-response manual includes information on parking, antenna drops, and other important details for each location. Hams have their own hand-held radios that, with the facility's antennas, can have a direct range of about $3 \mathrm{mi}$; however, a local repeater extends the range to $20 \mathrm{mi}$. Mountaintop repeaters have longer ranges, but they typically are not used for local operations. Individuals are assigned to each site. At the onset of an emergency situation, members monitor emergency channels to see what is going on and then make decisions on whether to operate the sites. The organization can also provide "shadows." 
Within minutes after the earthquake, the amateur-radio station at the Palo Alto City Hall EOC was staffed. A total of 14 operators were on duty in the district. Others hams checked in but were not needed; some went to Los Gatos, Hollister, and Santa Cruz. The local repeater was particularly busy and became saturated at times, but without causing undue disruptions. Because telephone communications remained operational in the area, the ham emergency network was not called upon to provide the critical link that it did in other areas, although it did provide information on assessing the extent of earthquake damage, as well as providing communications to relocation centers.

The ARES network played a much more important role in the harder hit areas, where telephone communications were not disrupted. In Hollister, the telephones in the EOC could not be used to communicate out of the local area, and the emergency power was a problematic. ARES had developed and made available to the EOC a communications van, as well as operators to run it.

At the OES region 2 EOC, one to five ARES operators worked around the clock for 4 days. Radios were used primarily during peak hours when telephones would get saturated, a situation that lasted for about a week after the earthquake.

Members of the Emergency Response Institute, a local hams group, met on January 13 and 14, 1990, to assess the earthquake performance of RACES and ARES; they made the following observations. There is a need for prearranged networks to operate on preassigned frequencies. The effects of the earthquake covered a larger area than had previous emergencies, and so there was a need for better coordination on a regional basis; communications at this level were difficult. The antenna drops at agencies that were to be supported could not be found. At some important sites, such as regional EOC's, the concentration of public-safety radios and ham radios caused problems because fixed antennas were too close together. Although all sites were provided with operators, some areas became overworked. Agencies were unaware of the services that RACES and ARES could provide. Operators should come prepared, and their gear should have emergency power. EOC's should have permanent packet computer facilities with similar equipment and software with auto-printing, so that printing can run by itself, to make training manageable. More emergency repeaters are needed, which should be distributed at more sites for reliability; and portable units should be available to be put into service as need arises. Note that three repeaters were converted to emergency use: one to replace a failed unit, and two to increase capabilities. Two or three repeaters may have been purposely jammed.

As a result of the earthquake, several organizations have become aware of the services that amateur-radio organizations can provide, and discussions are under way for establishing networks for utilities, departments of public works, and blood banks. For example, discussions are under way with PG\&E to set up antenna drops at service centers to enable those locations to be contacted directly to report gas leaks and downed powerlines. Another example is Santa Clara County, which is installing packet systems at EOC's in 15 cities within the county.

Another problem that OES communications staff noted is a tendency to use very high frequency (VHF) equipment, rather than high-frequency (HF) equipment. Although $\mathrm{HF}$ equipment is less mobile and requires a higher grade FCC license, it does have a much longer range and is independent of repeaters, which commonly are unreliable or become saturated in an emergency. The U.S. National Communications System has established the Shared Resources (SHARES) HF radio program for use by Federal agencies across the Nation. In 1993, nearly 1,000 SHARES HF radio stations were in operation.

\section{CONCLUSIONS ON COMMUNICATION SYSTEMS}

\section{TELEPHONES}

Telephone equipment performed well during the intense shaking in the epicentral area and the moderate shaking in most other areas. Most equipment problems were with emergency-power generators, although they had little effect on system performance. The congestion of the telephone system was especially severe until midnight on the day of the earthquake. The emergency-response community had difficulties using telephones during working hours for several days after the earthquake. In general, people had difficulty in getting a line to call 911 for emergency service. Fortunately, relatively few injuries and fires were reported.

\section{EMERGENCY-COMMUNICATION SYSTEMS}

Overall, emergency-communication systems performed well. This good performance is partly attributable to the moderate intensities of ground shaking in most high-population-density areas. The emergency-response community was not significantly overextended. In addition, many of the problems confronting regional EOC's were associated with an abundance of aid and supplies, rather than shortages. The major problem at emergency-communication centers and EOC's was congestion of the telephone system. Essentialservice lines generally had moderate to long delays in getting a dialtone, an unexpected situation that slowed 911 service. Radio communications for dispatch worked well in most places, but power outages to repeaters degraded radiodispatch performance. Some PSAP's had difficulty in contacting utilities and public-works crews. 


\section{EMERGENCY POWER}

Emergency power failed after the earthquake. Important equipment in several facilities was not provided with emergency power. At many critical facilities, emergency power was unreliable.

\section{AMATEUR RADIO}

Amateur-radio emergency-communication groups played an important role during the earthquake. These groups were particularly helpful to EOC's when telephone lines became saturated; they also fulfilled their usual role of support for the American Red Cross and various shelters. However, several organizations that could have used amateur-radio services were unaware that they were available.

\section{RECOMMENDATIONS FOR COMMUNICATION SYSTEMS}

The following recommendations are provided as a basis for discussion, because many of the issues are quite complex and implementation must be well thought out.

\section{ALL COMMUNICATION SYSTEMS}

\section{EMERGENCY POWER}

Improvements are needed in the reliability of emergency power. Those who install engine-generator sets, the batteries needed to start them, and their fuel supplies must consider earthquake loads in their designs (see Schiff, this chapter). Individuals who may be called upon to start the units, if they do not start automatically, and to keep them running should be given appropriate training. Improvements in the reliability of commercial power would reduce the need for emergency power. To improve power-system restoration, the Telecommunication Electric Service Priority (TESP) program is available from the U.S. Department of Energy and the National Communications System to rapidly restore power to critical telephone-company facilities.

\section{PUBLIC COMMUNICATIONS}

\section{TELEPHONE-SYSTEM CONGESTION}

New approaches are needed for mitigating telephonesystem congestion. Significant congestion of telephone systems was reported after the 1987 Whittier Narrows, Calif., and the 1989 Loma Prieta, Calif., earthquakes, even though telephone systems were not significantly damaged and emergency-response needs were not fully taxed. In an earthquake that severely affects high-population-density areas, telephone-system congestion presents a significant safety problem. In the 1989 earthquake, public-service announcements requesting that telephones be used only for emergencies were frequently aired on the radio and television, but they did not prevent congestion. The personal need for individuals to know whether family or friends were safe typically was more compelling than admonitions to limit telephone use to emergency calls. Alternative strategies should be considered for controlling nonemergency calls. Initially, requests that usage be limited to emergency calls are appropriate; but after the initial crisis, perhaps people should be asked to make personal calls at off hours and keep them brief.

A second approach is to establish a procedure for the appropriate agency, probably the OES in California, in which the appropriate authority (the governor) would declare a communications emergency. This declaration would apply to selected area codes in the affected area but would carry no penalties; it would simply involve airing public-service messages announcing that a communications emergency has been declared and that calls to and within the selected area codes are to be limited to emergency use only. Clearly, an extensive public-education program would be required before this system could be used, to avoid causing undue alarm when it is used. If such a program had been established, the 1989 earthquake probably would not have warranted its use.

A third approach is for State and local officials to utilize the Government Emergency Telecommunication Service (GETS), a Federally sponsored service available through the National Communications System, that gives priority on the public switched network to official emergency responders.

\section{SYSTEM}

The public needs more information on the use of the 911 system in an earthquake. Public-service messages throughout the year should indicate that in a major disaster there may be a 2- or 3-minute delay in getting a dialtone but that, with patience, calls can be made. If 911 is busy, callers can use the seven-digit numbers listed in the telephone book for the desired agency. Finally, pay telephones should provide quicker access to a dialtone than other telephones. Recommendations for the redesign and improvement of the performance of the 911 system were presented by the Federal Communication Commission (1993).

\section{PBX SYSTEMS}

Organizations that use a PBX and need their telephones after an earthquake should consider earthquake performance 
more carefully. PBX units should be anchored and protected from falling objects. Emergency power should also be provided.

\section{CRITICAL FACILITIES}

\section{ESSENTIAL-SERVICE LINES}

The performance of essential-service lines, which was poor in this earthquake, needs evaluation and improvement. Dialtone delays longer than 1 minute were reported for essential-service lines, delaying the transfer of calls at PSAP's and greatly increasing their response time.

Essential-service lines should be available to all communities, and the service implied by having such a line should be well defined. Essential-service lines are not now available in all communities; for example, they are not offered in Gilroy or Morgan Hill, whereas in Los Gatos they are available, but calls on essential-service lines have to compete for access to trunks like any other call once the central office is contacted. If calls must be transferred at a PSAP, dialtone delay effectively makes the line unusable. At a minimum, emergency responders must know what to expect from their essential-service lines.

\section{SEISMIC DESIGN OF COMMUNICATION CENTERS}

The seismic-design criteria for important communication centers should be reevaluated. New technologies, such as optical fiber and digital-switching equipment, make the concentration of communication resources inevitable. The increasing importance of these facilities mandates such a reevaluation.

\section{EOC COMMUNICATION EQUIPMENT}

EOC communication equipment should be upgraded to take advantage of computers. Personal-computer systems have hardware and software that allow packet technology to be used over radio networks. Such packets systems should be integrated into the EOC's communication system. Computers would be able to transfer messages faster, provide hardcopy at both ends, and log all communications. They would also help provide discipline in message format, to ensure that the date, sender name and title, and recipient name and title are included. Such features as electronic bulletin boards could also be incorporated. As an example, the National Communication System has piloted a World-Wide Web (WWW) server called ERLink in which users can post information from their desktop or laptop computer to the WWW server, allowing the emergency-management community to share information quickly.

\section{ARES AND RACES}

The utility of ARES and RACES to EOC's should be enhanced. The value of ARES and RACES to EOC operations was amply demonstrated in the earthquake, which was only moderately damaging. More damaging earthquakes will increase the need for reliable long-distance communications, particularly between county and regional EOC's. One method for establishing communications between these EOC's would be the creation of an HF radio network, which could be done at low cost if antennas were installed at EOC's. Many ARES members have the licenses and equipment to establish radio-frequency (RF) networks, and they could do so if the antennas, which are not portable, were available. Within California, no central authority exists which can mandate that antennas be installed. Designated funding by an appropriate agency, such as the Federal Emergency Management Agency, may provide the incentive to add this resource to EOC's. In addition, cooperation with the Federal HF radio SHARES program should be encouraged.

\section{EOC ANTENNAS}

Antennas associated with EOC's should be evaluated. The many radios that were assembled at one EOC caused problems because the antennas were too closely spaced. Antennas should be evaluated for this deficiency and corrected.

\section{REPEATERS}

Repeaters used for emergency services, such as ARES, should have generator-based backup power to ensure their operation for extended periods. Although many repeater sites have this capability, it has a significant cost. Because these emergency repeaters provide a critical service to the emergency-response community, a means should be established for members of the emergency-response community, such as the OES, to bear the cost of emergency power.

\section{CRITICAL RADIO EQUIPMENT}

Installation standards are needed for critical radio equipment. This equipment should be installed using highly conservative criteria, particularly when it will be located on peaks or ridges. Ground motions can be greatly amplified on peaks, and so accelerations may be unusually high. Because of the inaccessibility of these sites and frequent damage to access roads, equipment reliability is of special concern. Finally, if any item of critical equipment is located in a room, all the equipment should be installed with the same high standard because nonessential equipment may fall over and damage essential equipment. Repeaters used by hams for emergency 
operations should be installed using these same high standards. Implementation of such standards would be difficult because no governmental or trade organization of antennasite operators exist. Two steps to initiate improved practices would be (1) to establish seismic-resistance guidelines for the installation of communication equipment and (2) to establish model lease agreements that site operators could use and that government agencies could require. Most good, seismically resistant installations already require that equipment be anchored, a relatively inexpensive task.

\section{PSAP POWER NEEDS}

The power needs of PSAP's should be evaluated. The use of small, uninterruptable power supplies should be considered for operator-position consoles, lights, and computeraided dispatch. With these power supplies, short interruptions of power from engine generators would not disrupt PSAP operations.

\section{CELLULAR TELEPHONES}

Cellular telephones provide an alternative communication method. They can avoid the congestion associated with common-carrier switched networks. However, overuse of the cellular-telephone network can also lead to congestion. Adoption and implementation of the National Communications System-initiated CPAS program should be encouraged.

\section{CENTREX SYSTEM}

Critical facilities that need internal telephone communications during an emergency-response period should evaluate the appropriateness of using the Centrex system. This system has one drawback: If a central-office switch becomes saturated, telephone communications within the critical facility may be significantly degraded.

\section{AMATEUR-RADIO EMERGENCY SERVICES}

\section{EMERGENCY-RESPONSE MANUALS}

Hams should have emergency-response manuals that list the sites that hams support, identify the locations of antenna drops, provide the names of contacts at these sites, and identify various amateur-radio networks and their frequencies.

\section{ARES RESOURCES}

ARES should evaluate whether it is overextending its resources. ARES is currently planning to expand into other areas where its services are needed, such as utilities, public works, and blood-bank networks. In the earthquake, however, there was a shortage of operators to fill needed slots at some locations. Future earthquakes of similar magnitude or larger that occur closer to large urban areas will greatly expand the number of sites that must be serviced, and so the emergency can be expected to last longer. One problem in the 1989 Loma Prieta earthquake may have been that ARES was underutilized to the point that some operators lost interest.

\section{REFERENCE CITED}

Federal Communication Commission, 1993, Network reliability: a report to the nations: Chicago, National Engineering Consortium. 
THE LOMA PRIETA, CALIFORNIA, EARTHQUAKE OF OCTOBER 17, 1989:

PERFORMANCE OF THE BUILT ENVIRONMENT

\author{
LIFELINES
}

\title{
MODELING THE IMPACT OF THE EARTHQUAKE ON TELECOMMUNICATION SERVICES
}

By Michael L. Cohen, MITRE Corp.

\section{CONTENTS}

Page

Abstract-

Introduction-

Background

Model-validation methodology-

Observed earthquake effects--

Earthquake-model methodology-

Model-validation results-

Conclusions and recommendations

Conclusions-

Recommendations

Acknowledgments

References cited-

A37

37

37

38

38

40

40

41

41

41

42

42

\section{ABSTRACT}

This paper presents the methodology and results of validating a personal-computer-based model designed to simulate the effects of the 1989 Loma Prieta earthquake on local, public-switched-network telecommunication services (that is, the local telephone system). The model attempts to account for both direct effects due to switching-office building damage, and indirect effects due to commercial electricaland emergency-generator-power outages. Three statistical measures were used to validate the model against the observed data: paired-sample-hypothesis test, Fisher's exact test, and Pearson's correlation coefficient.

Overall, the model was found to be invalid for the 1989 Loma Prieta earthquake. However, the building-damage submodel, at the 10-percent-damage-threshold level, was found to be valid for predicting site-by-site building damage. Also, the telecommunications-impact submodel, at the 15-percent-damage-threshold level, was found to be valid for predicting patterns of telecommunication-service disruption. In conclusion, I recommend that a better model be developed which is valid for estimating both building damage and telecommunication-service disruption.

\section{INTRODUCTION}

Communication lifelines, such as those provided by the Nation's public switched network (PSN), are essential to effective and speedy recovery from damaging earthquakes. A capability to model the effects of major earthquakes on communications lifelines will yield three important types of benefits: (1) an identification of the network nodes and links where failures are most likely to occur and, therefore, where earthquake-mitigation measures are needed; (2) an ability to quantify the earthquake-mitigating telecommunication-service enhancements provided by various protective measures; and (3) an ability to estimate building damage and telecommunication-service disruption after an earthquake, so as to identify where recovery resources are most needed.

In support of its mission (under Presidential executive order 12472) to ensure that the Federal Government has adequate communications under all circumstances, including crisis or emergency, the Office of the Manager, U.S. National Communications System (OMNCS), undertook the modeling project reported on and summarized in this paper. Details were presented by MITRE Corp. (1991).

\section{BACKGROUND}

Communications required by the Federal Government during national-security and domestic emergencies are referred to as national-security/emergency-preparedness (NS/ EP) telecommunications. Government officials who require or use such telecommunication services are referred to as NS/ EP telecommunications users. Much of the Government's NS/ EP telecommunications are provided through the PSN. Therefore, an ability to model the impact of earthquakes on those parts of the PSN serving NS/EP telecommunications users would support two major OMNCS objectives: (1) provide a modeling tool to quantify the telecommunication-service enhancements provided by the OMNCS' National Level Program during disaster or attack; (2) project the initial damage and NS/EP telecommunication-service disruptions in real time, so as to facilitate emergency response, service restoration, and disaster recovery. 
From April 1989 through February 1990, OMNCS sponsored a task performed by MITRE Corp. to develop and apply a prototype model for accomplishing these objectives. Initially, the model was to be developed and applied to a set of postulated scenarios for the New Madrid, Mo., seismic zone, which affects seven of the Central United States. Before this prototyping effort was completed, the 1989 Loma Prieta earthquake occurred in California. Subsequently, MITRE Corp. was requested to validate the prototype model against the actual building damage and NS/EP telecommunication-service disruptions that occurred. This model-validation effort was carried out from August 1990 through June 1991; the results, conclusions, and recommendations are reported in this paper.

\section{MODEL-VALIDATION METHODOLOGY}

In general terms, the model-validation methodology consisted of the following steps: (1) use the 1989 Loma Prieta earthquake as a test case for validating the model; (2) compare the model's projected building damage and NS/EP telecommunication-service disruption with the observed effects of the earthquake; (3) on the basis of a comparison using statistical tests, validate the model; and (4) report the conclusions to OMNCS.

To implement this approach, a definition of model validity was needed, followed by a specification of the statistical tests required to measure it. Because validating a model is similar to testing a scientific theory, a definition of model validity can be adapted from the philosophy-of-science literature: "To accept that a model is valid is to be convinced that what a model predicts about what is observable is true" (paraphrased from van Fraassen, 1980). More specifically, a model is valid if its predictions consistently agree with observation, and a model is invalid if its predictions disagree with observation. Note, however, that a single experiment, such as the natural experiment provided by the 1989 Loma Prieta earthquake, cannot totally validate a model although it can support its validity.

To make the transition from this general definition of validity to specific statistical tests, we must first introduce some more specific model-validation concepts. For the purposes of this work, three such concepts are: (1) site-by-site validity - the model makes a high percentage (say, 70 percent or greater) of correct predictions of damage or disruption on a site-by-site basis; (2) proportion validity-the model correctly predicts the overall proportion or pattern of damage or disruption as measured by several statistical tests; and (3) absolute sample validity - the model is found to possess both site-by-site validity and proportion validity. This third concept is the one desired to hold as a result of any model-validation process. We can never conclude, however, that a model is unqualifiably "absolutely" or "completely" valid, no matter how many tests we carry out, although strong support for its validity would be provided by a testing process that showed it to have an absolute sample validity for every sample tested in every earthquake.

Now, we are ready to specify the statistical measures to be used in applying these model-validation concepts. Siteby-site validity is implemented through three percentage measures: (1) a high percentage (say, 70 percent or greater) of the model's predicted damage or disruption must agree with the observed damage or disruption, (2) a high percentage of the model's predictions of no damage or no disruption must agree with the observations of no damage or no disruption, and (3) a high percentage of the model's overall predicted results of damage or disruption must agree with the overall results of observed damage or disruption.

Similarly, proportion validity is implemented by several statistical measures. (1) Same proportion is the statistical test of comparing the proportions in paired binomial samples; here, the samples consist of the predicted and observed proportions of damage/no damage or disruption/no disruption. A successful result is the inability to reject the null hypothesis of no difference between the sample proportions at the 95percent-confidence level. (2) Probability of proportions is the nonparametric analog (known as Fisher's exact test) of the same-proportion test. This statistical measure yields the probability of obtaining the proportions found in each sample under the null hypothesis of no difference in the proportions of the underlying populations (equivalent to the assumption that the model perfectly replicates reality). (3) Significant positive correlation is Pearson's correlation coefficient applied to the correlation between predicted and observed results. A positive correlation that is significantly different from 0 at the 95percent-confidence level represents a successful test on this statistical measure.

To satisfy both site-by-site validity and proportion validity, the model's predictions must pass all three tests under each statistical measure.

\section{OBSERVED EARTHQUAKE EFFECTS}

Data were collected on the impact of the 1989 Loma Prieta earthquake on three types of facilities: NS/EP telecommunications-user office buildings, telecommunications central offices, and high-voltage $(230 / 500 \mathrm{kV})$ power-transmission substations. The types of data collected were building damage, power outages, and PSN disruption; the data sources are listed in table 1.

NS/EP telecommunications users were interviewed by telephone, using a standardized survey questionnaire. Out of a total of 313 Government NS/EP telecommunications users located in a 100-mi radius of the earthquake epicenter, 43 were randomly selected to be interviewed. The only criterion applied in the selection process (other than the ability to make telephone contact and complete the questionnaire) was that there be a good geographic distribution throughout the areas 
Table 1.-Data sources for observed earthquake effects.

[NS/EP, national security/emergency preparedness; PSN, public switched network]

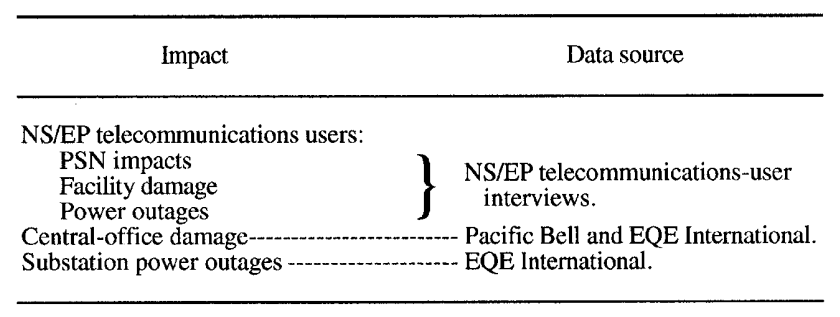

Table 2.-Statistics for survey of national-security/emergency-preparedness telecommunications users.

[Sample size: 43. NS/EP, national security/emergency preparedness; PSN, public switched network]

\begin{tabular}{|c|c|}
\hline Impact & $\begin{array}{l}\text { No. of NS/EP } \\
\text { telecommunications } \\
\text { users (percent) }\end{array}$ \\
\hline 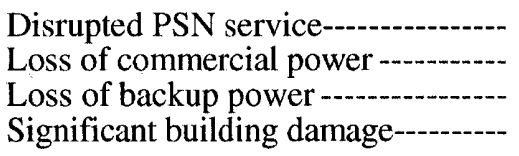 & $\begin{array}{rr}9 & (21) \\
18 & (42) \\
6 & (14) \\
2 & (5)\end{array}$ \\
\hline
\end{tabular}

Table 3.-Earthquake effects reported at public-switched-network central offices.

[EPG, emergency-power generator]

\begin{tabular}{|c|c|c|c|c|}
\hline Central office & CLL1 code & Damage & Power impact & Service impact \\
\hline $\begin{array}{l}\text { Oakland } \\
\text { (1587 Franklin St.). }\end{array}$ & $\begin{array}{l}\text { OKLDCA0327C, } \\
\text { OKLDCA0389E }\end{array}$ & $\begin{array}{l}\text { Yes; } 30 \text { percent } \\
\text { structural overall. }\end{array}$ & No - - & $\begin{array}{l}\text { No (except for } \\
\text { enhanced } 911 \text { system } \\
\text { interruption). }\end{array}$ \\
\hline $\begin{array}{l}\text { San Francisco } \\
\text { (Bush/Pine Sts.). }\end{array}$ & SNFCCAO1 CGO-3 & 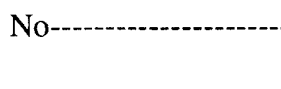 & $\begin{array}{l}\text { Yes; 2-hour } \\
\text { EPG loss. }\end{array}$ & Yes; about 2 hours. \\
\hline $\begin{array}{l}\text { Santa Cruz } \\
\text { (3640 Capitola Rd.). }\end{array}$ & SNCZCA1147H & $\begin{array}{l}\text { Yes; } 10 \text { percent: } \\
\text { internal power- } \\
\text { supply disconnect, } \\
\text { minor interior } \\
\text { cracking. }\end{array}$ & No --..-.-...-. & Yes; about 1 hour. \\
\hline
\end{tabular}

of highest modified Mercalli intensity within the 100-mi radius, as mapped by MITRE Corp. (1991).

The results of this survey are summarized in table 2 . Those results concerning the number (and identity) of users who reported PSN disruption and those who reported significant building damage provide the particular observed effects that were used in the model-validation process.

Of a total of 30 PSN central offices (end offices, local tandems, access tandems) that provided local telecommunication service to and from these 43 NS/EP telecommunications-user locations (listed by MITRE Corp., 1991), only 3 central offices reported significant earthquake effects (table 3).

Supporting these central offices, in turn, were about 20 high-voltage power substations, of which only 6 reported significant effects (table 4).

The purpose for collecting data on substation power outages was to determine whether taking these outages into account, insofar as they affected central offices in the homing chain to NS/EP telecommunications users, had any bearing on the model's ability to predict telecommunication-service disruption.
Table 4.-Earthquake effects reported at high-voltage substations supporting public-switched-network central offices.

[Do., ditto]

\begin{tabular}{cc}
\hline Substation & \multicolumn{1}{c}{ Power impact } \\
\hline $\begin{array}{c}\text { Moss Landing } \\
(230 / 500 \mathrm{kV}) .\end{array}$ & $\begin{array}{c}\text { Contributed to Santa Cruz/Monterey/San Jose- } \\
\text { area outages. }\end{array}$ \\
$\begin{array}{c}\text { Monte Vista } \\
(230 \mathrm{kV}) .\end{array}$ & Transformers tripped. \\
$\begin{array}{c}\text { Metcalf } \\
(230 / 500 \mathrm{kV}) .\end{array}$ & $\begin{array}{c}\text { Contributed to Santa Cruz/Monterey/San Jose- } \\
\text { area outages. }\end{array}$ \\
$\begin{array}{c}\text { San Mateo } \\
(230 \mathrm{kV}) .\end{array}$ & $\begin{array}{c}\text { Substation damage; isolated San Francisco area } \\
\text { from 230/500-kV grids. }\end{array}$ \\
$\begin{array}{c}\text { Martin } \\
(230 \mathrm{kV}) .\end{array}$ & Shed load due to San Mateo substation damage. \\
Embarcadero \\
$(230 \mathrm{kV})$.
\end{tabular}




\section{EARTHQUAKE-MODEL METHODOLOGY}

Anecdotal evidence from past earthquakes suggests little correlation between building damage and telecommunication-service disruption; however, other anecdotal evidence suggests some correlation between power outages and telecommunication-service disruption. The proposed methodology establishes a statistical framework in which both of these hypotheses can be tested by using observed data on building damage, power outages, and telecommunication-service disruption.

This section describes the methodology used to predict building damage and NS/EP telecommunication-service disruption. The predicted disruption was tested in two ways: with and without taking into account the effects of substation power outages.

Before providing an overview of the modeling methodology, the OMNCS-established constraints on model selection must be mentioned. The first constraint was that for this prototype modeling effort, the models must be selected from the open literature. Thus, candidate models were identified through literature review, not through a Government solicitation or request-for-proposal process. Second, the models must not require too much building- or equipment-specific detail; that is, only such building- or equipment-specific detail as could be obtained through existing OMNCS data bases or through the brief NS/EP telecommunications-user interviews and resource-constrained data-collection effort would be permitted. This second constraint eliminated from consideration most structural-engineering building-damage models.

After a review of the literature, one of the few models that satisfied these constraints was the model of Thiel and Zsutty (1987a, b), researchers at the Earthquake Engineering Research Institute. Their model is a nonproprietary model with all of the variables and parameter values disclosed, but not so detailed as to make data collection infeasible. The model predicts the structural damage to a building as a function of four variables: (1) the building's seismic vulnerability (a range of about 60 discrete values), (2) the building-site resonancefrequency coupling, (3) the soil conditions at the building site, and (4) the randomly oriented peak ground acceleration. The product of these four variables, together with some curvefitting coefficients and exponents, constitutes the probability-of-damage parameter $P$, which, in turn, generates the probabilities for each of the five discrete damage states required to predict the damage to a given building (Thiel and Zsutty, 1987a). This model was applied to both NS/EP telecommunications-user office buildings and central offices. The combined sample of 73 buildings ( 43 office buildings and 30 central offices) was used as the basis for validating the building-damage submodel.

The model of Thiel and Zsutty (1987a, b), however, could not be applied as straightforwardly as described above. Instead, their model had to be calibrated because of its discovered systematically low predictions in initial runs (pretesting).
The calibration involved establishing a damage threshold at or above which a building (for example, a central office) would be considered nonfunctional and below which it would be considered functional. Because the correct damage threshold is unknown, several thresholds were tested: 10,15 , and 25 percent. Application of these damage thresholds to the output of the building-damage submodel transformed that output from a value within the range $0-100$ percent to a binary output of 0 or 1 , representing no functional loss or functional loss, respectively. In short, the model was validated separately and completely at each of the calibrated damage thresholds.

To determine the impact on NS/EP telecommunications users, the following analytic principle was used: If one or more of the central offices in the homing chain serving an NS/EP telecommunications user (that is, an end office, local tandem, or access tandem) were projected by the buildingdamage submodel to be nonfunctional, then the NS/EP telecommunications user was projected to have lost local PSN service. A projection of this type was made for each of the 43 NS/EP telecommunications users interviewed.

The above projection of telecommunication-service disruption does not take into account the possible impact of power outages on NS/EP telecommunications users. A simplistic concept was applied to attempt to take such power outages into account: identify all of the major high voltage (230/500 $\mathrm{kV}$ ) power substations closest to each central office; if all of those substations (generally, two or three) reported earthquakeinduced power outages, then the central office was assumed to have lost its utility-supplied power. It was further assumed, under this simplistic approach, that if all the substations reported power outages, the total power-outage duration would be sufficiently long that the central office would have exhausted its battery-plus-emergency-generator backup power and go out of service. The key question was whether or not this simplistic approach to account for the impact of power outages would improve the validity of the model for projecting telecommunication-service disruptions.

\section{MODEL-VALIDATION RESULTS}

Model-validation tests were run with each of the three damage thresholds for the statistical measures of site-by-site validity and proportion validity. The test using power-outage effects was run only at the 15-percent-damage threshold because this level was determined to be the best for predicting telecommunication-service disruption. The results are summarized in tables 5 through 7.

From the data listed in table 5, the 10-percent-damagethreshold model possesses site-by-site validity (assuming that a 70-percent-correct prediction is adequate) for NS/EP telecommunications-user office buildings and central offices. No threshold model was found to possess proportion or absolute sample validity.

From the data listed in table 6, the 15-percent-damagethreshold model possesses proportional validity for local tele- 
Table 5.-Model-validation results for public-switched-network central offices.

[Sample size: 73. n/a, not applicable]

\begin{tabular}{|c|c|c|c|c|}
\hline \multirow{2}{*}{$\begin{array}{l}\text { Model-validation } \\
\text { concept }\end{array}$} & \multirow{2}{*}{ Statistical test } & \multicolumn{3}{|c|}{ Damage threshold (percent) } \\
\hline & & 10 & 15 & 25 \\
\hline \multicolumn{5}{|l|}{ Site-by-site validity: } \\
\hline & Correct damaged ${ }^{1}$ & -100 & 0 & 0 \\
\hline & Correct undamaged ${ }^{2}$ & -70 & 87 & 99. \\
\hline & Correct overall ${ }^{3}$ & 73 & 81 & 92 \\
\hline 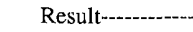 & - & - Yes & No & No \\
\hline \multicolumn{5}{|l|}{ Proportion validity: } \\
\hline & $\begin{array}{l}\text { Same proportion }{ }^{4} \text { at the } \\
95 \text {-percent-confidence } \\
\text { level. }\end{array}$ & No & Yes & $\mathrm{n} / \mathrm{a}$ \\
\hline & $\begin{array}{l}\text { Probability of proportions } \\
\text { under the null hypothesis. }\end{array}$ & $\begin{array}{l}\text { Low } \\
(\sim 0)\end{array}$ & $\begin{array}{l}\text { Moderate } \\
(0.28)\end{array}$ & $\begin{array}{l}\text { Low } \\
(0.1)\end{array}$ \\
\hline & $\begin{array}{l}\text { Significant positive correlation } \\
\text { at the } 95 \text {-percent-confidence } \\
\text { level. }\end{array}$ & Yes & No & No \\
\hline Result--..--........ & 16ver. & No & No & No \\
\hline
\end{tabular}

1 Predicted percentage of correct damaged.

2Predicted percentage of correct undamaged.

3Predicted percentages of total correct (damaged plus undamaged)

4Predict binomial samples: proportion of success for the null-hypothesis test (rejected at the 95-percent-confidence level).

sFisher's exact test (nonparametric): probability of getting sample proportions under the nuil hypothesis.

6Pearson's correlation coefficient

Table 6.-Model-validation results for local telecommunication services.

[Sample size: 43 ]

\begin{tabular}{|c|c|c|c|c|}
\hline \multirow{2}{*}{$\begin{array}{l}\text { Model-validation } \\
\text { concept }\end{array}$} & \multirow{2}{*}{ Statistical test } & \multicolumn{3}{|c|}{ Damage threshold (percent) } \\
\hline & & 10 & 15 & 25 \\
\hline \multicolumn{5}{|l|}{ Site-by-site validity: } \\
\hline & Correct service disrupted ${ }^{1}$ & 89 & 33 & 0 \\
\hline & Correct service not disrupted ${ }^{2}$ & 32 & 94 & 100 \\
\hline & Correct overall ${ }^{3}$ & 44 & 81 & 79 \\
\hline Result--_-_- & - & No & No & No \\
\hline \multirow[t]{4}{*}{ Proportion validity: } & Same proportion ${ }^{4}$ at the & No & Yes & No \\
\hline & $\begin{array}{l}\text { 95-percent-confidence } \\
\text { level. }\end{array}$ & IN & Ies & 100 \\
\hline & $\begin{array}{l}\text { Probability of proportions } \\
\text { under the null hypothesis. }\end{array}$ & $\begin{array}{l}\text { Low } \\
(\sim 0)\end{array}$ & $\begin{array}{l}\text { Moderate } \\
(0.19)\end{array}$ & $\begin{array}{l}\text { Low } \\
(\sim 0)\end{array}$ \\
\hline & $\begin{array}{l}\text { Significant positive correlation } \\
\text { at the } 95 \text {-percent-confidence } \\
\text { level. }\end{array}$ & No & Yes & No \\
\hline Result--------.-. & - & No & Yes & No \\
\hline
\end{tabular}

1Predicted percentage of correct service disrupted.

2Predicted percentage of correct service not disrupted.

3Predicted percentages of total correct (damaged plus undamaged).

${ }^{4}$ Paired binomial samples: proportion of success for the null-hypothesis test (rejected at the 95-percent-confidence level).

${ }^{5}$ Fisher's exact test (nonparametric): probability of getting sample proportions under the null hypothesis.

6Pearson's correlation coefficient.

communication services without accounting for power-outage effects. No threshold model was found to possess siteby-site or absolute sample validity.

From the data listed in table 7, slightly improved numerical results were obtained by including power-outage effects; however, the pattern of results does not differ qualitatively from that in table 6.
Table 7.-Model-validation results at the 15-percent-damage threshold for local telecommunication services that reported power outages.

[Sample size: 43 ]

\begin{tabular}{|c|c|c|}
\hline $\begin{array}{l}\text { Model-validation } \\
\text { concept }\end{array}$ & Statistical test & Result \\
\hline \multicolumn{3}{|l|}{ Site-by-site validity: } \\
\hline & Correct service disrupted & 44 \\
\hline & Correct service not disrupted ${ }^{2}----$ & 94 \\
\hline & Correct overall ${ }^{3}$ & 84 \\
\hline \multicolumn{3}{|l|}{ Overall result } \\
\hline \multirow[t]{4}{*}{ Proportion validity: } & & \\
\hline & $\begin{array}{l}\text { Same proportion }{ }^{4} \text { at the } \\
\text { 95-percent-confidence } \\
\text { level. }\end{array}$ & Yes \\
\hline & $\begin{array}{l}\text { Probability of proportions } \\
\text { under the null hypothesis. }\end{array}$ & $\begin{array}{l}\text { Moderate } \\
\quad(\sim 0)\end{array}$ \\
\hline & $\begin{array}{l}\text { Significant positive correlation } \\
\text { at the } 95 \text {-percent-confidence } \\
\text { level. }\end{array}$ & Yes \\
\hline Overall result --- & - & Yes \\
\hline
\end{tabular}

'Predicted percentage of correct service disrupted.

${ }^{2}$ Predicted percentage of correct service not disrupted.

3Predicted percentages of total correct (damaged plus undamaged).

4Paired binomial samples: proportion of success for the null-hypothesis test (rejected at the 95-percent-confidence level).

5Fisher's exact test (nonparametric): probability of getting sample proportions under the null hypothesis.

6Pearson's correlation coefficient.

\section{CONCLUSIONS AND RECOMMENDATIONS}

\section{CONCLUSIONS}

- Neither the building-damage submodel nor the telecommunications-impact submodel was found to be (absolute sample) valid for the 1989 Loma Prieta earthquake.

- The building-damage submodel, without imposing thresholds, underpredicts the observed damage levels.

- The building-damage submodel, at the 10-percent-damage threshold, might be used on an interim basis for the Loma Prieta region to predict site-by-site damage (for example, for the OMNCS' National Level Program supporting analysis).

- The telecommunications-impact submodel, at the 15-percent-damage threshold, with or without power-outage effects, might be used with caution, on an interim basis, for the Loma Prieta region to predict the proportion of telecommunication-service disruption (for example, for realtime emergency response).

\section{RECOMMENDATIONS}

- A single model for the Loma Prieta region and other California earthquake-prone areas needs to be developed that 
is valid for predicting both building damage and telecommunication-service disruptions.

- Models need to be developed and validated for other earthquake-prone areas of the United States.

- The U.S. National Science Foundation and the National Communications System should continue to sponsor further research on telecommunications impacts, as well as power-outage effects.

- OMNCS should phase in validated models on a region-byregion basis for the purposes of supporting analysis for the U.S. National Communications System's National Level Program and for real-time emergency response.

\section{ACKNOWLEDGMENTS}

This research was supported by the Office of the Manager, U.S. National Communications System under contract F19628-89-C-0001, program element 3127K, task order
3110. Public release of the research was authorized in March 1992 by Dennis I. Parsons, Assistant Manager, U.S. National Communications System. The work was carried out at MITRE Corp.'s Washington C3 Center in McLean, Va.

\section{REFERENCES CITED}

MITRE Corp., 1991, Earthquake model validation; final results: McLean, Va., briefing prepared for Office of the Manager, U.S. National Communications System.

Thiel, C.C., Jr., and Zsutty, T.C., 1987a, Earthquake characteristics and damage statistics: Earthquake Spectra, v. 3, no. 4, p. 747792.

1987b, Earthquake parameters and damage statistics: San Francisco, technical report prepared for Forell/Elsesser Engineers.

van Fraassen, Bas, 1980, The scientific image: Oxford, U.K., Oxford University Press. 


\title{
THE MEDIA: RADIO, TELEVISION, AND NEWSPAPERS
}

\author{
By Richard J. Rapaport, Freelance Writer
}

\section{CONTENTS}

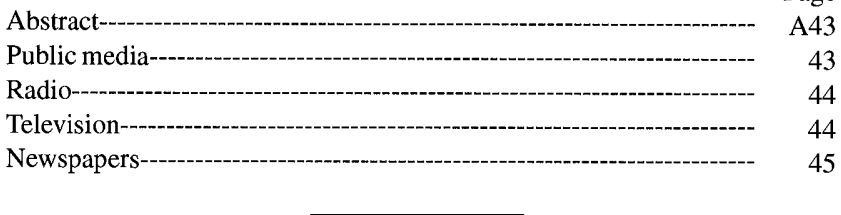

ABSTRACT

The media organizations in the San Francisco Bay region that had planned for a major disaster (that is, had emergency-preparedness plans and emergency-power generators) performed well in the earthquake. Many media organizations, however, were poorly prepared, and senior management commonly was unaware of the inadequacy of their emergency planning, particularly with regard to the absence of emergency-power generators.

The key problem for all media was the loss of commercial power and the inadequacy or absence of emergency-power-generating capacity. Partial loss of telephone communications, loss of broadcast towers, and difficulty in accessing the more severely earthquake-affected areas by ground transportation also impaired coverage. The response of the electronic media was probably enhanced by the presence in San Francisco of additional staff and equipment to cover the 1989 World Series, which was scheduled to begin minutes after the earthquake occurred.

Individual television- and radio-station performance varied; five radio stations were able to broadcast during the first few hours after the earthquake. The designated Emergency Broadcasting System (EBS) station (KNBR-AM) was one of the first radio stations back on the air, but because its staff was isolated at the ballpark, it failed to provide useful information beyond the standard EBS alert.

Loss of commercial power, which was also a key problem for the three major newspapers in the area and had the greatest impact during the first 36 hours after the earthquake. The San Jose Mercury-News, the newspaper closest to the epicenter, was able to restore full power to all its facilities within an hour from its emergency-power generators; and it produced its normal morning edition, including 100,000 extra copies and an earthquake supplement. The San Francisco dailies, the Chronicle and Examiner, neither of which had emergency-power generators, relied on emergently procured small generators and Macintosh computers to compose abbreviated editions but were unable to print until commercial power was restored to the printing plant the morning after the earthquake. They also relied on a special temporary feed from the Pacific Gas and Electric Co. (PG\&E) to provided full power to their main office on the night after the earthquake. The distribution of newspapers was not significantly impaired by damage to the transportation system, although delivery to homes and news racks was spotty.

\section{PUBLIC MEDIA}

The 1989 Loma Prieta earthquake tested northern California's media in an unprecedented way. The last temblor of comparable consequence, in 1906, happened long before the advent of television, at a time when radio was barely out of Marconi's laboratories. Indeed, the only San Francisco Bay region medium that covered the 1906 earthquake was the newspapers, and in 1989 the events of more than 80 years ago were so remote that little or no collective memory remained on how to deal with a disaster of such magnitude.

Radio, television, and newspapers were forced to rely on emergency plans, when any plans existed at all. After the 1989 Loma Prieta earthquake, the key problems for all the media generally involved the loss of commercial power and a lack of emergency-power-generating capacity. To a lesser extent, they also had a transportation problem, which made coverage difficult when electrical power was restored. This problem contributed to the limited coverage in the epicentral area, causing most of the world to believe that San Francisco was the hardest hit area, rather than Santa Cruz and its surroundings.

There was a critical disparity in reports of the number of dead from the earthquake, largely because of the changing statements of the Alameda County Sheriff, who later admitted to "shooting from the hip" about the number of deaths on the Cypress Avenue viaduct. The highest death toll reported was 270.

One factor that skewed coverage of the earthquake also made it as pervasive and comprehensive as it was: The San Francisco Bay region media, and large components of the 
national media, were in place and geared up for northern California's most important media event in years, the 1989 World Series.

From a media point of view, the earthquake's timing was uncanny. Moments before the third game of a World Series matchup between the two San Francisco Bay region teams, the earthquake rumbled through. With much of the country already tuned in, the earthquake gave radio, television, and, to a lesser extent, newspapers a great opportunity to display their news gathering and disseminating abilities under fire. Coverage ran the gamut from the extraordinary to the abysmal.

\section{RADIO}

One of the first stations to get back on the air after the earthquake was KNBR-AM, the designated Emergency Broadcasting Station (EBS) for the San Francisco Bay region. As planned, KNBR's EBS alert cut in, but when the alert ended, the station returned to local coverage of the 1989 World Series from Candlestick Park.

No extensive damage at Candlestick Park was reported, and officials, fans, and sports media were not even sure whether the game would be canceled. The KNBR announcer told listeners that there would be a slight earthquake delay before getting to the starting lineups. On another station providing World Series coverage, the announcer got out the San Francisco telephone book and began reading the earthquakeemergency section in the front.

KGO's AM studio, built on landfill near Embarcadero One in downtown San Francisco, was hard hit. Wire copy, books, and nearly all other objects fell to the floor, and two of their three broadcast towers were knocked down. KGO was off the air for about 40 minutes. Because it has a large news staff and was able to utilize the resources of KGO-TV and the ABC network, KGO-AM provided some of the best radio coverage in the days after the earthquake. It covered the story about the devastation around Santa Cruz, Los Gatos, and Watsonville, which was largely missed by less news oriented radio stations and by television, a medium dependent on highly technical equipment and satellite and microwave relays.

Ultimately, many radio listeners turned to KCBS-AM, probably because it is the only all-news station in the San Francisco Bay region. When the earthquake hit, KCBS was 30 seconds away from the end of the national news feed and $2 \frac{1}{2}$ minutes away from switching to live network coverage of the World Series. The station had dozens of reporters all around the San Francisco Bay region, an anchor booth at Candlestick Park, and another portable studio outside the park. The earthquake knocked out both the electrical power and most of the telephones at KCBS' offices in downtown San Francisco, but a rooftop emergency-power generator kicked in almost immediately, and the station came back on the air after only a few seconds. With the telephones to Candlestick Park out, the KCBS announcer could broadcast but did not know whether anyone was picking him up; and like many people at Candlestick Park, he did not know how severe the earthquake really was.

With official information slow to arrive, KCBS staff began to take calls from listeners, hoping to pinpoint the epicenter and assess the damage. Reporters, both on duty and off, also began to check in. Piece by piece, an accurate picture of the earthquake began to emerge.

About 6:15 p.m., the KCBS emergency-power generator failed, but engineers were able to tap into another generator, which gave the station a few lights in the broadcast studio and the ability to stay on the air. For the rest of the night, however, gallons of kerosene had to be hauled up 30 flights of stairs-the elevators were out-to keep the generator going.

Five radio stations in the region used flashlights, emergency-power generators, and a degree of telephone service to keep the San Francisco Bay region informed, reassured, and connected during the first dark hours after the earthquake. Telephone calls from listeners and from professional reporters provided a dramatic and informative picture of a region in an emergency.

The largely improvised coverage, particularly at KCBS and KGO, went as smoothly as if it had been planned for years. Both stations abandoned their normal commercial formats for the rest of the first week after the earthquake, acting as information clearinghouses as the extent of the transportation, communication, and property damage became apparent. Large parts of the Nation were able to share in the dramatic radio coverage, which was so compelling that affiliated stations in New York, Chicago, Los Angeles, and elsewhere tapped into the satellite uplinks carrying KGO and KCBS and carried them live until the following morning.

Several days later, the New York Daily News quoted the manager of New York's WCBS-AM as saying, "[KCBS] had a large number of reporters on the scene immediately and were way ahead of reporters from UPI and other news services."

\section{TELEVISION}

Because television is quite pervasive and yet has a limited focus, its coverage ultimately may have done as much harm nationally and internationally as it did good regionally. The sight of network news anchors standing in front of the same burned and broken Marina District block or at the collapsed freeway in Oakland left an impression of absolute destruction in a measure equal to that of the 1906 earthquake and fire.

KGO was out in front from the start. Network sports commentator Al Michaels was able to provide several minutes of live audio color commentary before ABC's power went down entirely. $\mathrm{ABC}$ exploited its use of the Goodyear 
blimp, which was circling Candlestick Park and veered off to take the first shots of the downed span in the San Francisco-Oakland Bay Bridge.

Surprisingly good coverage also came from the San Francisco independent station KOFY, which provided half a dozen of its employees with minicams. These amateurs managed to bring back some of the rawest, yet most powerful, visual images of the earthquake.

One of the most striking video shots, which was aired repeatedly, was taken by tourists who happened to be caught near the collapsed span of the San Francisco-Oakland Bay Bridge with their own camera. The video showed a car plunging over the edge of the open span and striking the inclined collapsed span. The tourists sold their videotape to all three of San Francisco's major commercial stations within hours.

KRON, the local NBC station, which had been making huge strides in providing the San Francisco Bay region with serious and measured news coverage, was caught with its power down and its anchor out of town. Because KRON did not own an emergency-power generator, it went off the air as soon as the earthquake hit. Either because of the power outage or, as was later claimed, because of the failure of an NBC network employee to set a switch, KRON was unable to feed its earthquake footage to the network. NBC viewers across the nation thus remained unaware of the damage for hours.

\section{NEWSPAPERS}

The morning San Francisco Chronicle did not appear on Wednesday, October 18, until early afternoon. At that time, the paper put out an eight-page "Earthquake Extra" that had been put together by flashlight on Macintosh computers.

That same afternoon, the San Francisco Examiner managed to outdo its partner newspaper by a mere eight pages. Neither paper was able to include ads or classified sections.

In contrast, the San Jose Mercury-News was able to put out its normal edition the next morning, as well as a 12-page color wraparound about the earthquake. They printed more than 100,000 extra copies of the newspaper, thousands of which were distributed in news-hungry San Francisco.

The Mercury-News was no less damaged in the earthquake than the Chronicle/Examiner; San Jose was actually closer to the epicenter than San Francisco. Nor did the Mercury-News avoid the power outage that dogged the San Francisco papers. What distinguished the Mercury-News' response was simply that it had planned for a major crisis, whereas the Chronicle/Examiner had not.

When the earthquake hit, power at the Mercury-News went down for an hour because a switch to the massive emergency-power generators malfunctioned; but when the switch was repaired, full power was restored to the newsroom and the presses. By 6:00 p.m., the Mercury-News was functioning fully. Photographs and text of a 12-page color World Series supplement were quickly changed and the Mercury-News was ready to print a color earthquake supplement for the next morning.

At the Chronicle, however, the story was entirely different. Top Chronicle management sent a worker to the roof to start their emergency-power generator; they were surprised to find that there was no emergency-power generator. What senior management of the Chronicle and Examiner had imagined was a generator was actually a series of batteries designed to accommodate the orderly shutdown of computers in case of an emergency.

Even though the Chronicle had an agreement with the Mercury-News that would allow each to use the other's newsroom and print facilities in case of a strike or emergency, the Chronicle did not use the San Jose paper's facilities. Instead, they managed to procure several small gasoline generators, and the staff began the task of producing a skeleton version of the newspaper with several Macintosh computers, a laser printer, a Xerox machine, and an old Royal manual typewriter.

Throughout the night of Tuesday, October 17, reporters and editors were led up the darkened stairs of the Chronicle's Fifth and Mission Streets headquarters to the third-floor conference room. There, the entire editorial staff huddled around a huge table, editors reading and correcting copy while lowerranking employees stood behind them with flashlights. By early morning, the "Earthquake Extra" had been composed.

The Examiner staff, using their own Macintosh computers, several cellular telephones, and a small generator, produced a 16-page edition. When electrical power was restored to the San Francisco Newspaper Agency's Army Street printing plant by early the next morning, both the Chronicle and Examiner were finally able to get out their newspapers.

The lateness of delivery and the hunger for news about the earthquake had created an almost-insatiable demand for newspapers. One enterprising Examiner driver managed to sell 7,500 papers from the back of his truck, but this meant that many news racks remained empty. Home delivery of both the Chronicle and Examiner was spotty. Both the Mercury-News and the Sacramento Bee capitalized on the shortcomings of the San Francisco dailies, selling or giving away tens of thousands of papers that they had trucked in.

The next night, things were easier for the San Francisco dailies. Electrical power was still out at the Fifth and Mission Streets headquarters, but PG\&E managed to rig an electrical conduit (which required that electrical power be cut off to the San Francisco Hall of Justice and Jail for several hours) that allowed printing of expanded, if not preearthquake-length, newspapers.

Although the San Francisco Chronicle and Examiner were unable to agree on an emergency-power-generator-sharing arrangement, in general, an unprecedented degree of cooperation prevailed between the less affected suburban newspapers and the crippled inner-city newspapers. In addition to the Mercury-News, both the Marin Independent Journal and the Oakland Tribune offered assistance, and the 
Examiner actually availed itself of the Independent Journal's photographic laboratories.

In general, the suburban newspapers seemed to have fared better than the city newspapers. On the day after the earthquake, while the San Francisco dailies were struggling just to get an edition out, several suburban dailies, including the San Jose Mercury-News, the Marin Independent Journal, the Contra Costa Times, and the Daily Review were able to put out special color sections with a vast array of information about the earthquake. 
THE LOMA PRIETA, CALIFORNIA, EARTHQUAKE OF OCTOBER 17, 1989: PERFORMANCE OF THE BUILT ENVIRONMENT

LIFELINES

\title{
WATER AND WASTEWATER SYSTEMS
}

\author{
By LeVal Lund, Civil Engineer; \\ Gordon Laverty, Laverty Associates; \\ Holly Cornell, $\mathrm{CH}_{2} \mathrm{M}$ Hill; \\ Alvin R. Guerrero, Southern California Edison; \\ Michael Cassaro, University of Louisville; \\ Andries Godschak, Seismic Construction Consultants; \\ John McLaughlin, Archon Associates; \\ Curt Edwards, Pountney \& Associates; \\ George Brodt, Los Angeles Department of Water and Power; \\ Donald Ballantyne and Ronald Eguchi, EQE International; \\ Mark Pickett, Omar Abu-Yasein, and Chenwun Lay, University of Toledo; \\ Anshel J. Schiff, Precision Measurement Instruments; \\ James R. Blacklock, University of Arkansas, Little Rock; \\ and \\ Steven French, California Polytechnic State University
}

\section{CONTENTS}

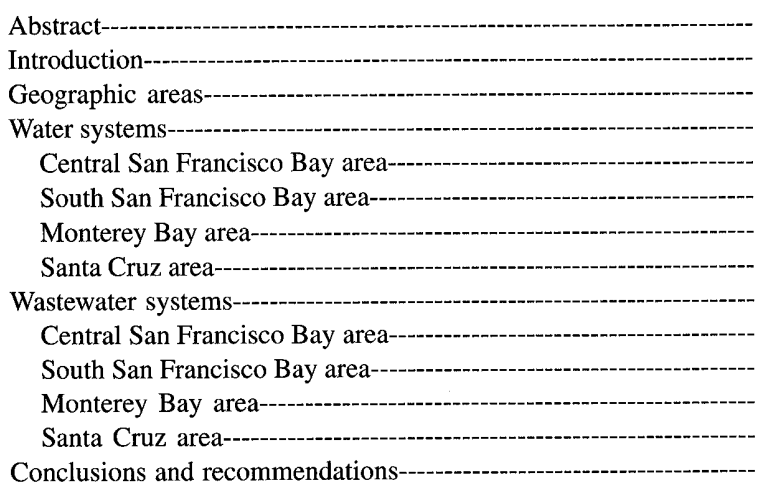

Page

A47

47

48

49

49

51

54

55

56

57

57

59

59

60

\section{ABSTRACT}

The earthquake significantly affected water and wastewater (sewage) lifelines. The damage was concentrated in the San Francisco and Oakland areas adjacent to San Francisco Bay that underwent liquefaction, and in the Santa Cruz area along the San Lorenzo River. Damage was reported in other areas to facilities without proper seismic design and construction, mostly to water and sewer mains of older construction and in liquefaction areas. The loss of commercial power affected the operation of water-pumping stations and sewerlifting facilities, most of which did not have emergency power. Damaged steel tanks were of older designs without seismic construction, and one posttensioned-prestressed-concrete tank was damaged. In both water- and wastewater-treatment plants, mechanical equipment in large basins was damaged from seis- mic vibration and sloshing of the water. Most of these plants had emergency backup power. Water supply to the earthquakeaffected region from aqueducts from the Sierra Nevada were unaffected by the earthquake.

\section{INTRODUCTION}

After the earthquake, the Earthquake Investigation Committee of the American Society of Civil Engineers' Technical Council on Lifeline Earthquake Engineering (TCLEE) conducted a preliminary reconnaissance survey of water and wastewater (sewage) lifelines. The reconnaissance group consisted of 15 members, who were divided into teams of 2 or 3 to interview the operators, managers, or engineers of the individual water and sewage agencies. The teams waited until several weeks after the earthquake before conducting their survey, by which time these agencies had completed most of their emergency-recovery operations and were available to talk, as well as being better prepared to assess the impact of the earthquake on their operations.

The water and wastewater agencies surveyed consisted of municipally owned water and (or) sewer departments, county water districts, special districts, community services districts, mutual water companies (fig. 1), and private water companies. Some of these agencies provide retail water only, wholesale treated water only, or both. The sewage agencies collect wastewater, treat wastewater, or both.

Water resources for the earthquake-affected region are supplied by long aqueducts from the Sierra Nevada or the delta (confluence of the Sacramento and San Joaquin Rivers) by way of either the South Bay Aqueduct or the California 
Aqueduct of the State Water Project, pumped from local ground-water basins and collected as local surface water from streams and springs. The wastewater-treatment facilities discharge treated water into San Francisco Bay, the Pacific Ocean, Monterey Bay, and sewage lagoons.

\section{GEOGRAPHIC AREAS}

The agencies investigated and their locations are shown in figure 1 . The earthquake-affected area is subdivided into four geographic areas: (1) central San Francisco Bay: San Francisco, Alameda, and Contra Costa Counties, including the cities of San Francisco, Oakland, Alameda, Berkeley, and other cities; (2) south San Francisco Bay: Santa Clara and San Mateo Counties, including the cities of Palo Alto, San Jose, and Los Gatos and surrounding area; (3) Monterey Bay: Monterey and San Benito Counties, including the cities of Hollister and Watsonville; and (4) Santa Cruz: Santa Cruz County, including the cities of Soquel, Santa Cruz, Aptos, and Scotts Valley, the San Lorenzo Valley, and the Santa Cruz Mountains and surrounding area.

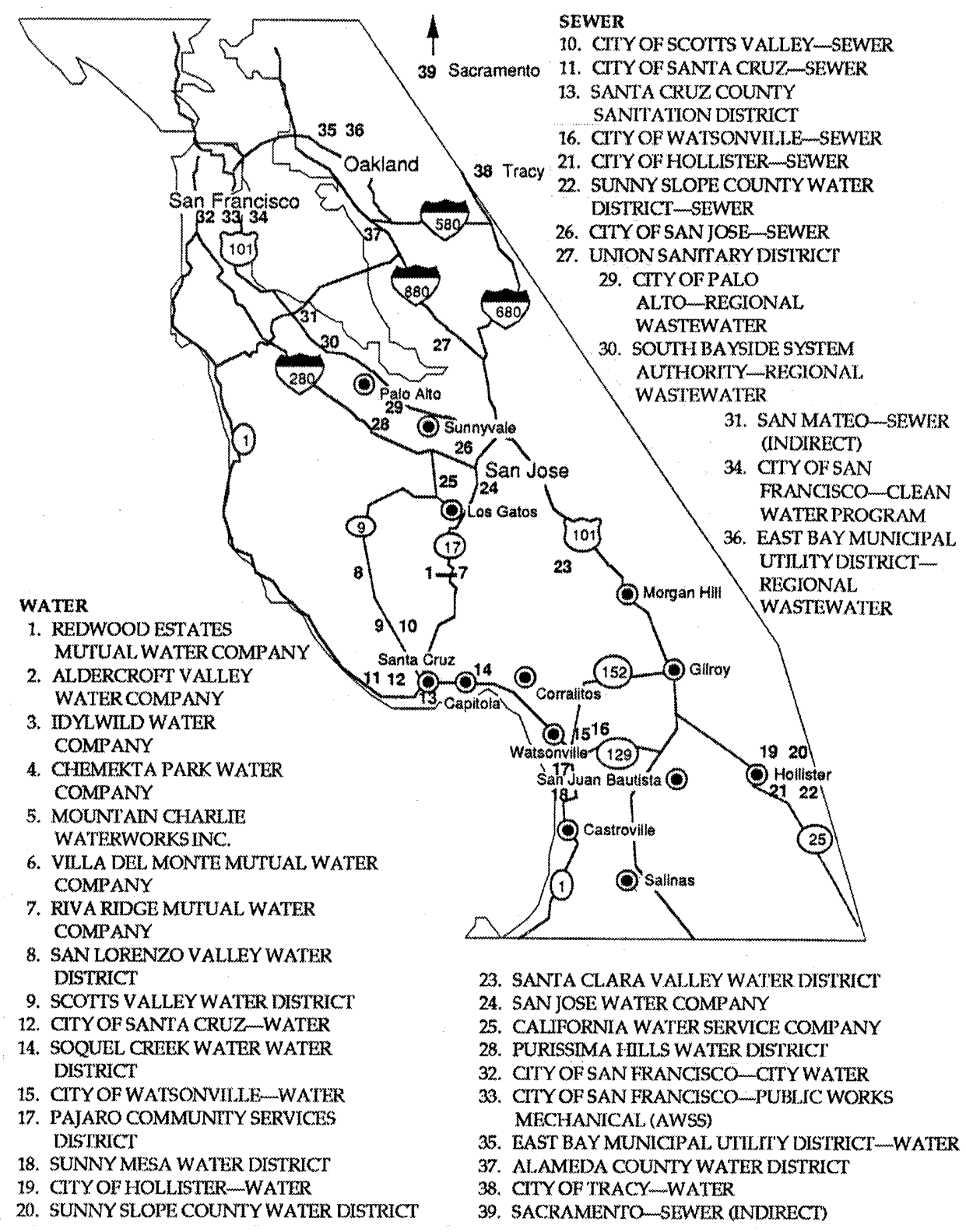

Figure 1.-San Francisco Bay region, showing locations of water and sewage agencies surveyed. 


\section{WATER SYSTEMS}

\section{CENTRAL SAN FRANCISCO BAY AREA}

In the central San Francisco Bay area, no damage to the Mokelumne, Hetch Hetchy, South Bay, or California Aqueducts or to any of the aqueduct storage reservoirs was reported. The Hetch Hetchy Aqueduct supplies wholesale water to 32 water purveyors on the San Francisco peninsula and in the south San Francisco Bay area (80-85 percent of aqueduct total). The reported damage to retail water purveyors in the peninsula and south San Francisco Bay area served by the Hetch Hetchy Aqueduct was minimal.

\section{EARTHQUAKE DAMAGE AND RESTORATION}

Approximately 350 water-main repairs were reported in the central San Francisco Bay area, primarily in the older, unstable areas the along the bayshore in Oakland, Berkeley, and Alameda (fig. 2), and in San Francisco in the infirm (unstable) areas of the Marina District and South of Market area and along the bayfront. The longitudinal and circumferential breaks occurred mainly in 4-, 6-, and 8-in.-diameter cast-iron pipe (sand cast) with fixed (cement or lead caulked) bell-andspigot joints. The breaks were due to tension, compression, or bending associated with differential settlement, especially in areas of liquefaction. Corrosion of the pipe and fittings also played a part in some of these breaks. The mains in the Marina District, which were installed in the 1930's and earlier, were unlined (fig. 3). More than 100 repairs were reported in the Marina District out of a total of about 150 in the entire city. San Francisco is replacing the damaged pipe in the Marina District with 9,000 ft of ductile-iron pipe with rubber-gasket joints. Leaks in 20- and 30-in. water mains were fixed with repair couplings. Most of the water-main breaks in Alameda occurred in 6- and 8-in.-diameter welded-steel pipe because of joint corrosion.

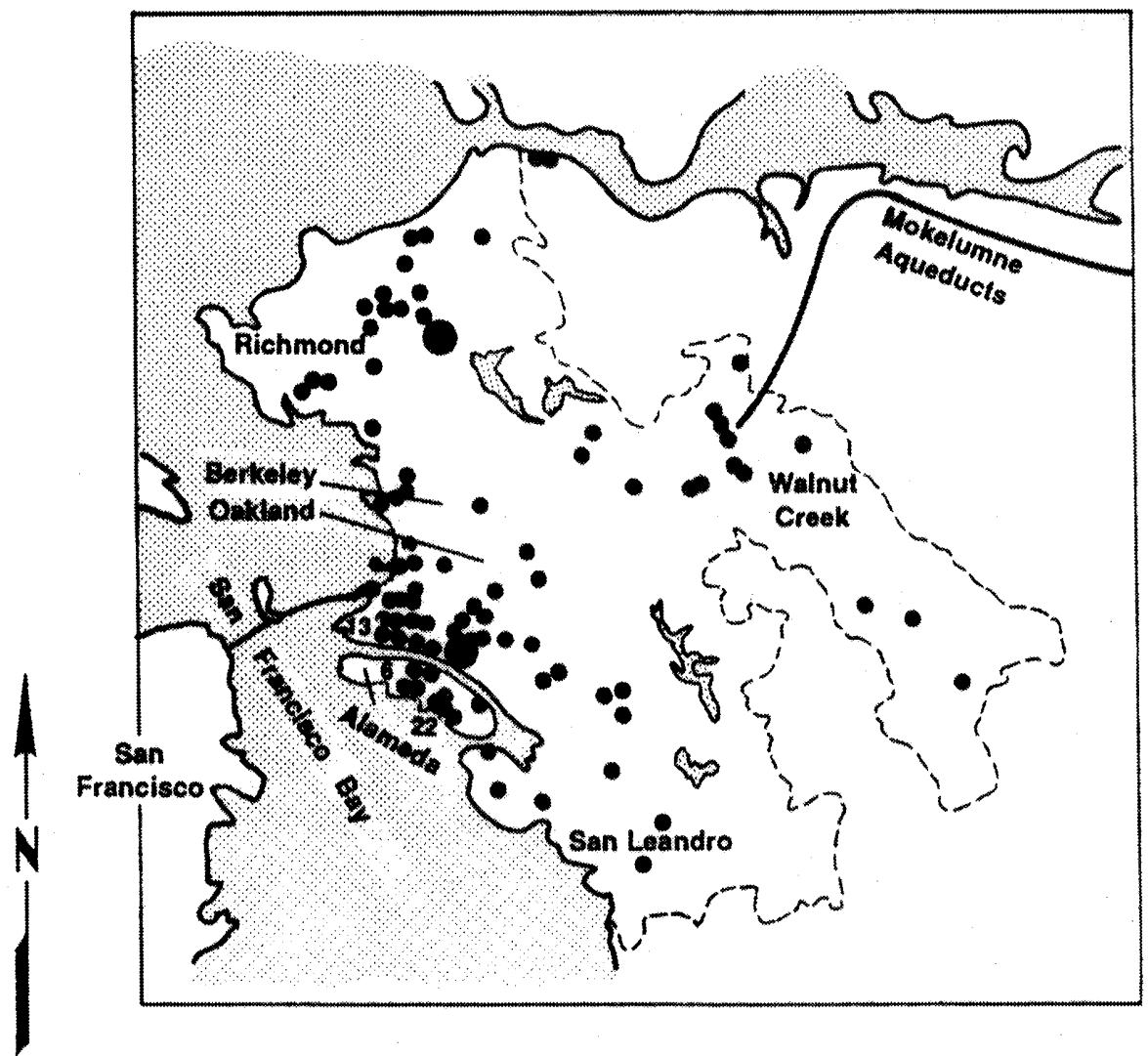

\section{LEGEND}

-..- Service Area

- Pipe Break Location

Main Pipe Breaks

22 Number of Breaks
Figure 2.-East bay, showing locations of water-main breaks reported by East Bay Municipal Utility District. 


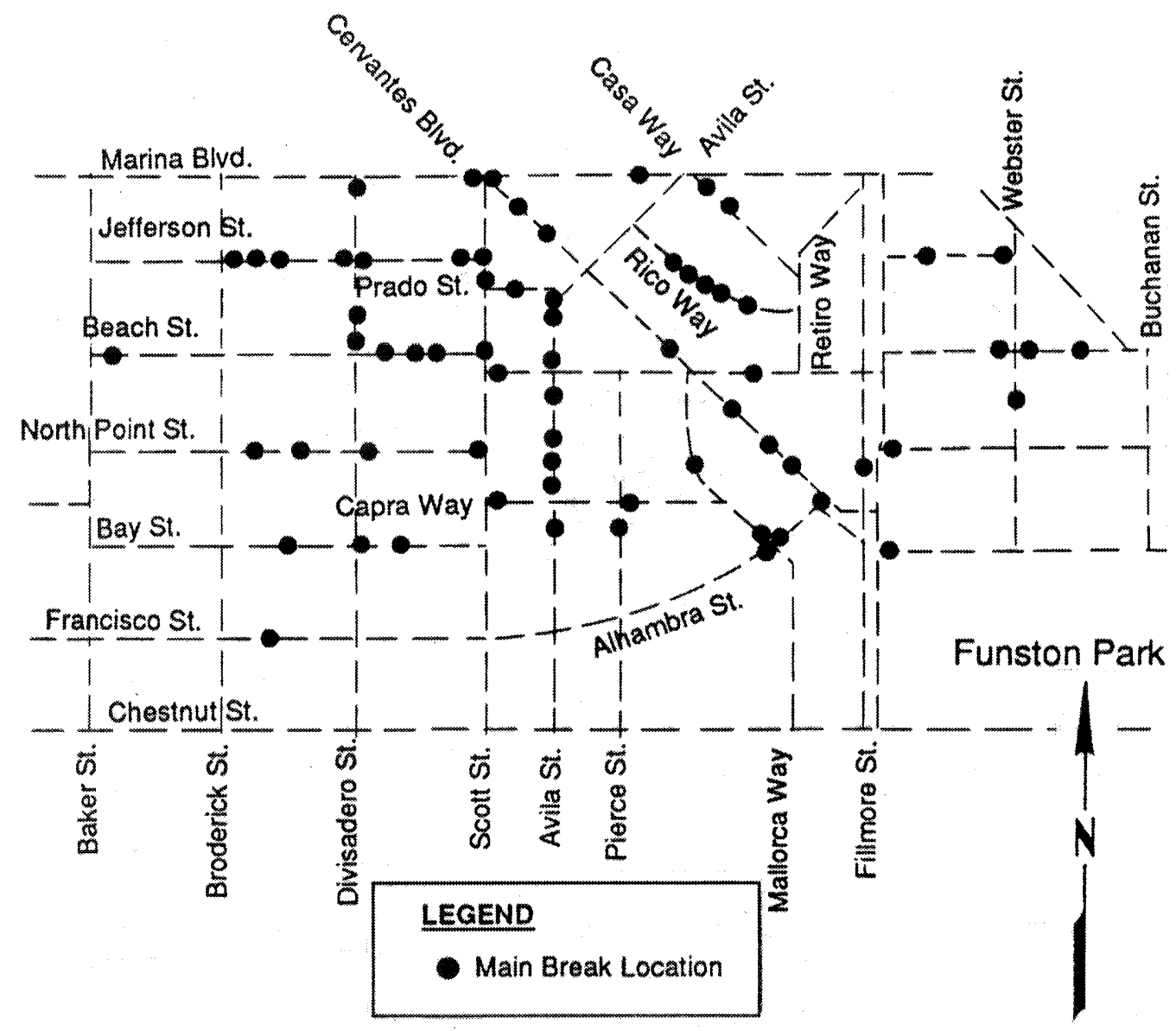

Figure 3.-Marina District of San Francisco (fig. 1), showing locations of water-main breaks reported by San Francisco Water Department.

Approximately 100 service-connection breaks were reported in the central San Francisco Bay area in connections made of galvanized iron, copper, and polyvinyl chloride (PVC).

In San Francisco and the east bay, no physical damage to water-storage facilities or water-pumping plants was reported. The most significant impact of the earthquake on water and wastewater systems was a power outage to facilities lasting several hours to several days. San Francisco has 400 million gal of water stored at high elevation within the city. The San Francisco Fire Department has an independent water storage and distribution system for fire suppression. A break in a 12-in.-diameter line and damage to hydrants drained a 750,000-gal tank that supplies water to the lower zone of the system in about 20 minutes; this system and its response are described in more detail in another chapter of this report.

Eight hydropneumatic water-pumping plants in San Francisco, which provide pressure to higher elevations, lost power for 4 to 10 hours. The area served by these plants had enough water under lower pressure for public fire protection. The city is budgeting funds to purchase portable gen- erators for this area. A dual-drive (diesel/electric) pump, in the central part of the city, had a 4-hour fuel supply in a day tank, which was to be replenished by fuel pumped from an auxiliary fuel tank. After the earthquake, the electric fuel pump lost its commercial power, and the dual-drive pump stopped when the fuel in the day tank was depleted. The San Francisco Fire Department uses the fire-engine pumpers connected between fire hydrants to pump water to higher elevations when necessary.

Treasure Island, a U.S. Navy facility in the middle of San Francisco Bay (fig. 1), is served by a water-pumping plant in San Francisco and a pipeline on the San Francisco-Oakland Bay Bridge. During the 3-day power outage after the earthquake, water service was discontinued. The U.S. Navy connected an emergency-power generator to activate the water-pumping plant. Some broken water mains and sewers were reported on the island.

No damage to water-treatment plants was reported in the central San Francisco Bay area. A break occurred in a 60-in.-diameter modified prestressed-concrete-cylinder rawwater-inlet line to the Sobrante Water Filtration Plant (fig. 1 ); a separation occurred in the weld of the spiral-welded 
cylinder. An 8-ft section of similar pipe was welded into place, and service was restored within 4 days (fig. 4). A compression failure of bell and spigot joints occurred in a 20 -in.-diameter cast-iron pipe installed in 1916 under a 20-ft-thick fill. The pipeline was isolated by valves and abandoned, and because of redundancy, no customer was out of water because of this failure. A building housing a booster water-pumping station (5,500 gal per minute [gpm]) in Berkeley (fig. 1) was severely stressed, but it continued to operate because the electrical and mechanical equipment was undamaged.

\section{IMPACT ON USERS AND HINDRANCE TO RESTORATION}

A loss of water supply occurred in those areas with damaged water mains and areas affected by a power outage to pumping plants. Repair crews in San Francisco were slowed down while working adjacent to buildings on the verge of collapse; they needed rotating lights on their equipment to indicate the emergency nature of the work. The volume of paperwork required by the Federal Emergency Management Agency (FEMA) to be eligible for reimbursement was time consuming. The city had adequate repair materials and was able to resupply its stock from manufacturers on short notice.

\section{EMERGENCY RESPONSE AND FUTURE IMPROVEMENTS}

Shortly after the earthquake, San Francisco Water Department personnel returned to the city yard and were supplemented by an apprentice class in progress in the yard at the time of the earthquake. Personnel worked on repairs around the clock. San Francisco Water Department workers staffed the city's emergency-operations center (EOC). An emergencypower generator provided electrical power to the yard offices and the normal 24-hour water-trouble office. Telephone lines were saturated; however, mobile radios worked well. The yard's emergency-power generator, which is tested weekly under load, operated as expected. The fuel pumps were not on emergency power, and the refueling of emergency repair vehicles and equipment was delayed until a portable generator was connected to the fuel pumps.

In Oakland (fig. 1), the water-operations-control center lost electrical power for several hours until an emergencypower generator was connected, but it still remained in service. An alternative EOC is needed in case the main center is out of service; EOC's need emergency-power generators in case of a longer power outage. Additional emergency supplies, portable lights, portable pumps, portable generators, and pipe need to be distributed throughout the service area in the event that the central warehouse is out of service.

\section{SOUTH SAN FRANCISCO BAY AREA}

Water is imported to the south San Francisco Bay area from the delta by way of the South Bay Aqueduct of the State Water Project; from the San Luis Reservoir by way of the Santa Clara Conduit of the San Felipe Project, a division of the U.S. Bureau of Reclamation's Central Valley Project; and from the Sierra Nevada by way of the Hetch Hetchy Aqueduct. The local water supply consists of wells pumping from the ground-water basin and water collected from a few streams and springs. No damage was reported to the aqueducts or aqueduct reservoirs.
Figure 4.-Damaged 60-in.-diameter raw-water line to the Sobrante Water Filtration Plant.

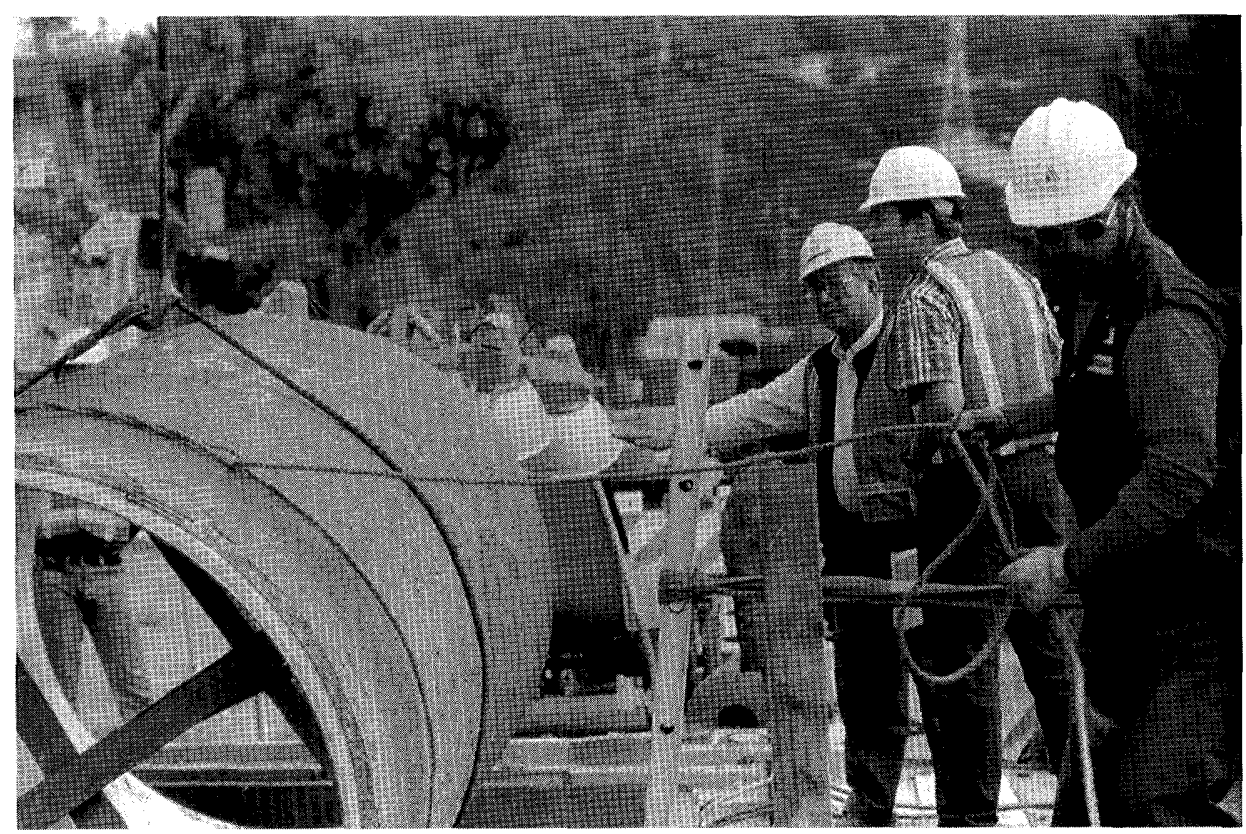




\section{EARTHQUAKE DAMAGE AND RESTORATION}

A minor leak ( $400 \mathrm{gpm})$ occurred in one of the two legs of the Santa Clara Conduit where it crosses the Calaveras fault east of Gilroy. The 96-in.-diameter conduit separates into two 66-in.-diameter legs for the 2,000-ft crossing of the fault zone. The rubber-gasket joint on the 66-in.-diameter prestressed-concrete-cylinder pipe pulled slightly apart. The leg was gated off on the day after the earthquake, and the full water requirement was supplied by the other leg as designed. Several air valves failed because of inverted-pendulum action on a few of the feeder lines from the conduit. The water supply from the State Water Project system was undisrupted.

Approximately 120 water-main repairs were reported in the area of San Jose, Cupertino, Campbell, Los Gatos, and Los Altos. These leaks occurred in water mains ranging in diameter from less than 4 to $37 \mathrm{in}$. of steel, cast iron, asbestos cement, and ductile iron, three-fourths of which were in 25to 30-year-old steel pipe with limited corrosion protection. More than half of the leaks were holes in the pipe caused by corrosion; others were caused by pulled joints and circular breaks. Most of the leaks occurred in the Los Gatos area. Approximately 10 service-connection repairs were reported.

Several water tanks were damaged in the Los Gatos-San Jose area. An unanchored 100,000-gal bolted-steel tank built in 1966 had an "elephant's foot" buckle. Panels were unbolted and replaced with new panels of the same size, and the tank was back in service within 3 days. The inlet/outlet underneath a 700,000-gal welded-steel tank built in the 1950's separated from the floor plate. The floor plate and inlet/outlet were reconstructed, and the tank was back in service in $1 \frac{1 / 2}{2}$ days. A 10,000-gal redwood tank collapsed and was replaced with a 10,000-gal welded-steel tank.

In Los Altos Hills, a 1.1-million-gal posttensioned-precastconcrete tank failed (fig. 5). This tank, constructed in 1962, used precast vertical wall panels wrapped with posttensioned wire and coated with gunite. A 4-in.-wide rupture along a vertical joint released the water from the tank, which was nearly full.

No damage or disruption was reported to booster waterpumping plants or wells except for the a power outage for as long as 4 days.

Four major water-treatment plants supplying treated water are located in the south San Francisco Bay area. Three of the four upflow clarifiers at the Rinconada Water Treatment Plant, constructed in 1968 with a capacity of 80 million gal per day (mgd), sustained wave-action and differentialmovement damage to the interior metal structure. A laboratory worker reported that the wave almost reached the top of a 30-in.-high railing around the basin. Inside each clarifier is floculator-center-feed clarifier equipment supported on a 39in.-diameter steel column. This column, anchored at the base (a pendulum), rotated and cracked the casting of the rotatingfloculator gear-drive housing. About half of the radial launderers (wiers) pounded against and tore away from the clarifier walls. Some of the launderers fell down on and jammed the rotating sludge scraper (fig. 6). A fourth clarifier, which was empty at the time of the earthquake, was undamaged and was placed into service within 24 hours. One of the damaged clarifiers was put back into operation as a static chemical mixer for direct filtration, without removing the damaged equipment. The plant operated at 50-percent capacity, adequate for the winter demand, while a contractor repaired the other clarifiers. The water-quality laboratory performed well, even though some unanchored equipment moved. Restraining devices kept bottles containing chemicals on their open shelves (fig. 7).

At the Montevina Water Treatment Plant, constructed in 1970 with a capacity of $20 \mathrm{mgd}$, baffling in the coagulation basins was destroyed by wave action. The baffling was replaced by agency crews. A broken 30-in.-diameter raw-water line to the plant from the Austrian Dam was repaired in 1 day. No damage to the Penitencia (constructed in 1974 with a capacity of 40 mgd) or Santa Teresa (constructed in 1989 with a capacity of 100 mgd) Water Treatment Plants was reported. At a watertreatment plant (with a capacity of $10 \mathrm{mgd}$ ) near Tracy, $45 \mathrm{mi}$ northeast of the epicenter, sloshing of water moved the center

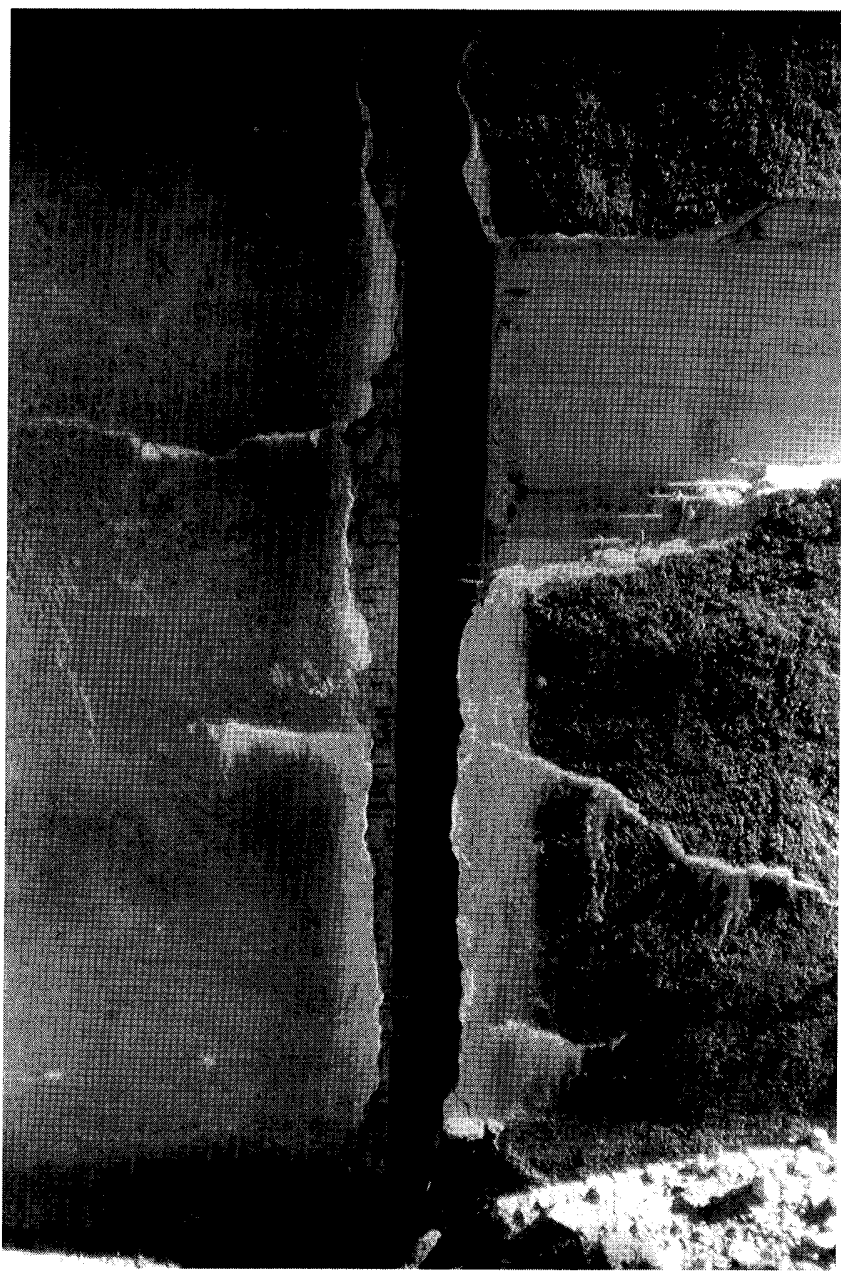

Figure 5.-Failure in 1.1-million-gal posttensioned-precast-concrete water tank in Los Altos Hills. 
column, causing the sludge scraper to bind against the clarifier structure. The plant was shut down, and the system was supplied from wells.

\section{DAMS AND RESERVOIRS}

The principal dams and water-distribution reservoirs in the central San Francisco Bay area were aerially inspected on the day after the earthquake by the California Division of Safety of Dams or the U.S. Army Corps of Engineers and were inspected on the ground within hours after the earthquake by their owners or consultants. Most reservoirs were at a low level because of third-year drought conditions in California.
The Austrian Dam, constructed in 1950 with a capacity of 6,200 acre-ft, had cracks in the embankment and spillway. The embankment cracks were excavated and recompacted, and the spillway cracks were filled with epoxy. The Lexington Dam, constructed in 1952 with a capacity of 21,200 acre$\mathrm{ft}$, had transverse cracking at the abutments, which was repaired by recompaction.

\section{IMPACT ON USERS AND HINDRANCE TO RESTORATION}

Officials issued an advisory to boil water in Los Gatos for 1 day because the Montevino Water Treatment Plant was
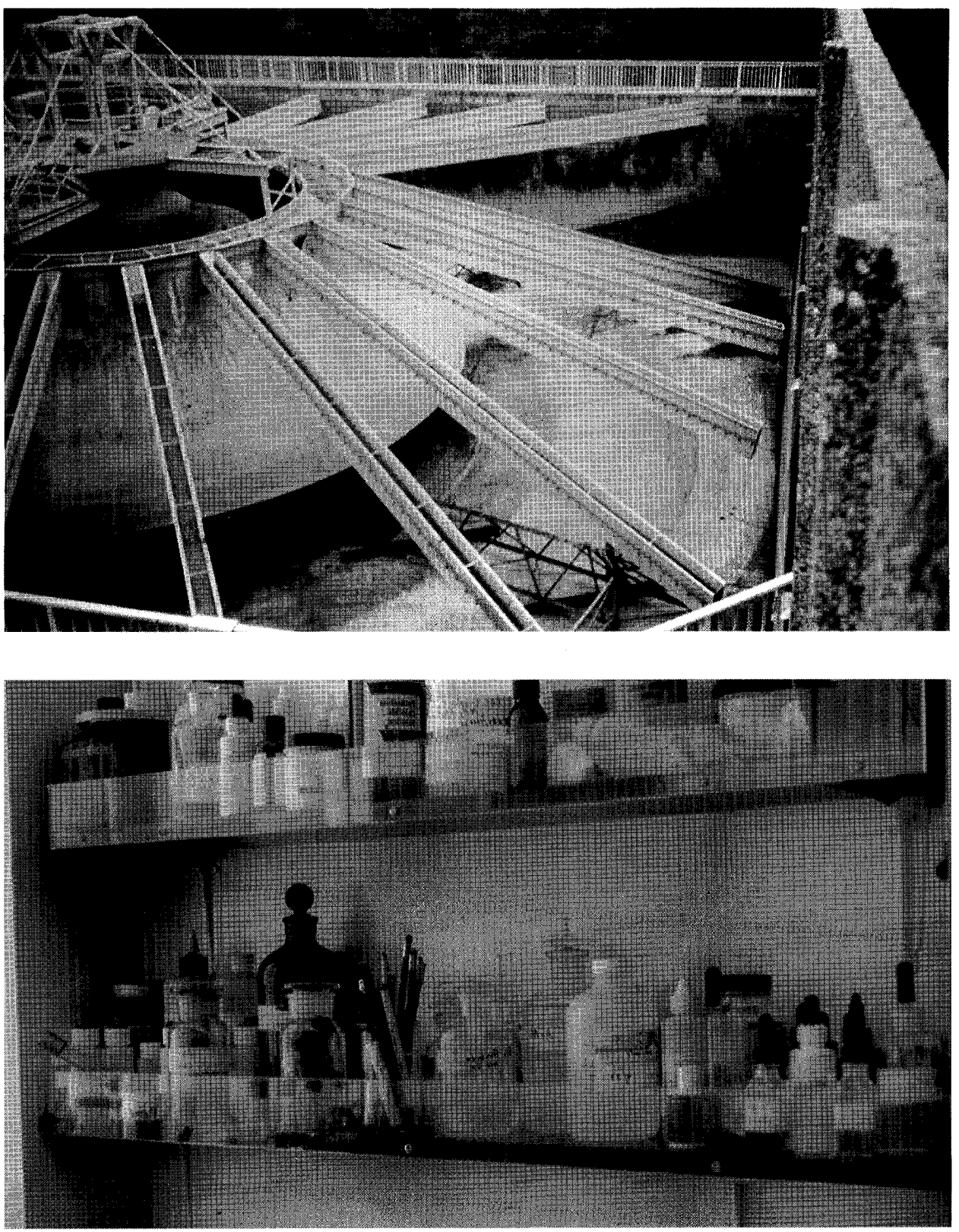

Figure 6.-Damaged water purifier at the Rinconada Water Treatment Plant.

Figure 7.-Chemical shelves in water-quality laboratory at the Rinconada Water Treatment Plant, showing restraining devices. 
out of service and many water-main leaks were reported. This measure was precautionary, and no water contamination was detected. The Rinconada Water Treatment Plant, with 15 million gal of stored treated water, supplied Cupertino initially while the plant was being brought back into operation. When this limited operation began, the water supply was restored to Los Gatos. The loss of power was a hindrance to restoration of the water supply, indicating a need for emergency-powergeneration facilities and a complete set of system reference drawings to be located at the EOC. Private contractors were valuable in the restoration process; however, it was reported that they were not as efficient as the agency forces.

\section{EMERGENCY RESPONSE AND FUTURE IMPROVEMENTS}

Offduty employees at water and wastewater agencies returned to their normal work locations shortly after the earthquake. The larger agencies operated by using their mobile radios because most telephones were blocked as result of the high volume of calls. A more reliable, direct communication link needs to be established between regional water retailers and wholesalers, because of postearthquake problems with the public telephone system.

\section{MONTEREY BAY AREA}

The Monterey Bay area relies for its water supply on stream and spring flows, and pumping from ground-water basins.

\section{EARTHQUAKE DAMAGE AND RESTORATION}

In the area of Hollister, Watsonville, Pajaro, and Sunny Mesa, approximately 60 water-main repairs in 4-, 6-, and 8-in.diameter pipe were reported, as well as an unknown number of leaks in the Moss Landing area, where severe liquefaction occurred. Failure modes included push-on-joint failures and bell, circumferential, and longitudinal cracking. Some of the leaks occurred in areas of liquefaction and at bridge abutments. In the Watsonville area, most leaks occurred in cast-iron and asbestos-cement pipe; ductile-iron pipe with rubber-gasket joints was reported to have performed well in the earthquake.

In Hollister, most water-main breaks occurred in 4- and 6-in.-diameter cast-iron pipe with lead-caulked joints within the Calaveras fault zone. Asbestos-cement pipe was reported to have performed well in the earthquake. Approximately 70 service-connection leaks were reported in the Hollister area.

In Hollister, a 2-million-gal welded-steel tank, constructed in the 1960's, performed well in the earthquake; however, a pulled coupling in a private-building 6-in.-diameter fire-service line, caused by collapse of an adjacent unreinforcedmasonry building, almost drained the tank.
No damage or disruption was reported to 14 wells or pumping plants in Hollister, except for a cracked well-discharge pipe, a broken air valve (inverted-pendulum action), and the loss of power.

In Watsonville, a 1-million-gal welded-steel tank, constructed in 1971, buckled on one side at the shell-roof connection because of failure or yielding of the rafter bracket. The electronic water-level-transmitting device at this tank was damaged by wave action and required repair. Also at this tank, the pilot line on the altitude valve broke, causing a minor leak. In spite of this damage, the tank did not leak and continued to operate. Watsonville's nine other reservoirs performed well in the earthquake.

In Pajaro, an unanchored 600,000-gal welded-steel tank, on a wick (vertical gravel) drains foundation, constructed in 1986 by using an American Water Works Association (AWWA) Standards design, performed excellently in the earthquake, even though located in a river bottom, a potentially liquefiable area. At Sunny Mesa, a 200,000-gal. welded-steel tank, constructed in 1968, was tilted with its base lifted off its foundation on one side and settled as much as $2 \mathrm{in}$. on the other side; however, it did not leak. An 8-in.-diameter tee on the inlet/outlet broke and released all but $4 \mathrm{ft}$ of water in the tank before the tank outlet valve was closed. No damage was reported to an elevated tank at Moss Landing.

In Watsonville, a slow-sand-filter water-treatment plant, constructed in 1930 with a capacity of $2.5 \mathrm{mgd}$, treats the stream- and spring-water supply. The concrete basins leaked, apparently at the construction joints, and the plant was put out of service. A $150-\mathrm{lb}$ chlorine cylinder at a booster waterpumping facility toppled when its anchorage failed, causing release of chlorine gas.

The Newell Creek Dam in the Monterey Bay area (see below), constructed in 1960 with a capacity of 8,700 acre-ft, had a longitudinal crack on the upstream face, which was excavated and recompacted. All reservoirs were considered capable of handling the winter runoff; however, they were closely monitored during reservoir filling for any possible damage that may have gone undetected.

\section{IMPACT ON USERS AND HINDRANCE TO RESTORATION}

In downtown Watsonville, water-main breaks and power outages made it impossible to keep the area pressurized and created the potential for contamination. A notice to boil water was issued within 24 hours after the earthquake and maintained for 3 days, until water-quality tests were completed. No contamination was found. In Hollister, the loss of commercial power and the absence of emergency-power generators allowed the water in the sewage system to rise to the level of the manhole covers, creating, in conjunction with water-system damage, possible contamination of the water system. Notice was issued to boil water or to use water available from U. S. National Guard trailer tanks until the safety 
of the water system could be ensured. No contamination was reported. Generators for operating the sewage pumps were obtained about 14 hours after the earthquake. A loss of water service occurred to areas of broken water mains and to about 20 percent of the other areas for as long as 2 days because of a power outage; a few customers were without a public water supply for 2 weeks.

An auxiliary emergency-power generator and four auxiliary engine-driven pumps in the Watsonville area continued to operate, but one of the pumps temporarily lost a cooling-water line. Supply of fuel to emergency engine generators became a problem because the supply tanks at the sites were not big enough to last for more than a few hours. Supply trucks were not readily available because of the extreme demands for them and because of traffic delays caused by police barricades, detours, damage to roads and bridges, and collapsed buildings. Water emergencyrepair crews and equipment had access difficulties, which had not been considered in developing emergency-response plans. More isolation valves and regular valve maintenance were needed to facilitate the isolation of smaller areas for repair. In Watsonville and Pajaro, the headquarters' office radios had no emergency-power generator, and because of the power outage, the offices were unable to directly communicate with the field however, communications were available between service-vehicle radios. Maintenance personnel put in long hours of work. After the first day, some people were ordered to go home and sleep; however, others continued to work. In the future, work shifts should be scheduled to reduce fatigue during recovery operations.

The power outage in the Monterey Bay area lasted from 1 to 3 days. Auxiliary emergency-power generators were placed in operation; however, too few of these generators were available to serve the area's needs, and they lacked the fuelstorage capacity for long power outages. The high volume of calls caused disruptions in telephone service. A reliable system is needed to monitor repairs and system operations so as to quickly establish a priority for repairs.

\section{EMERGENCY RESPONSE AND FUTURE IMPROVEMENTS}

The Watsonville city and regional emergency-response plans worked well; however, water and wastewater operations need to be included in local and regional plans. In Hollister, the road to the main water tank was jammed with vehicles because other government offices are located on the same road, and workers had trouble getting through to check the tank. Enough maintenance people, materials, and equipment were available to repair the water system; however, only two people in Watsonville knew how the system operates. The need to quickly return the system to operation required them to work long hours without relief, emphasizing the need for cross-training of personnel in system operation. The notice to boil water in Watsonville pointed to a need to establish State-wide guidelines for water-qualitytesting procedures and public notification.

\section{SANTA CRUZ AREA}

In the Santa Cruz area, the water supply is from wells pumping from the ground-water basin, and from surface streams and springs.

\section{EARTHQUAKE DAMAGE AND RESTORATION}

Approximately 240 water-main repairs were reported in the Santa Cruz area. Most of the leaks occurred in cast-iron pipe with leaded joints and small-diameter galvanized pipe at the threads. Asbestos-cement and ductile-iron pipes with rubber-gasket joints were mostly undamaged. The breaks occurred in $3 / 4$ - to 12 -in.-diameter pipe in unstable ground (alluvium and beach areas) and to threaded steel pipe acquired from the original private or mutual water system. More than 250 service-connection problems were reported.

Of the wells and booster water pumps in the Santa Cruz area, only three wells in the San Lorenzo Valley were damaged. The wells filled with sand and were redrilled. At one booster water-pumping plant, a transformer fell off the wall mounting, but it was undamaged and was remounted. In the Soquel area, the only reported damage was minor altitudevalve malfunctions in some of 18 water-storage reservoirs (6 million gal). One tank and the adjacent hydropneumatic water-pumping plant were taken out of service as a precautionary measure because of the appearance of ground-surface cracks on the steeply sloping site.

In Scotts Valley, the unanchored 400,000- and 750,000gal welded-steel tanks (on concrete ringwalls) were damaged at the wood-roof connection to the tank shell. The two tanks drained because their inflow and outflow pipes broke. All of these tanks were repaired and returned to service. No damage was reported to an unanchored 1.25-million-gal weldedsteel tank, constructed in 1983 and situated on a concrete ring located on bedrock, using AWWA Standards design.

The San Lorenzo Valley lost five redwood tanks ranging in size from 10,000 to 150,000 gal. These tanks were replaced within the year.

In the Santa Cruz Mountains, several small private and mutual water companies were completely devastated by the earthquake. The area, which was originally developed as a summer-cabin retreat, had grown into a year-round commuter residential area. Most of the water systems grew from an individual well, spring, or stream pump without any planning, design, or financing. The facilities consisted of redwood and bolted-steel tanks, PVC and galvanized-iron piping, small pumps, and small water-treatment equipment without any seismic design. The tanks and inflow and outflow piping were severely damaged. Some tanks collapsed, piping broke above and below the ground, equipment was damaged, and power was lost for several days. In several places, the motion of the tank damaged piping that had inadequate flexibility (fig. 8). Because of third-year drought conditions in California, many 
of the residents maintained their own water-storage tanks. These tanks continued to be filled by tanker trucks because in some areas a public water system was not available until March 1990. Limits in engineering and maintenance staffing, system maps, financing, and mutual aid made it extremely difficult to restore these systems. The Coachella Valley Water District, Santa Clara Valley Water District, Los Angeles Department of Water and Power, and other agencies provided personnel and equipment for field repair and engineering assistance.

\section{IMPACT ON USERS AND HINDRANCE TO RESTORATION}

In Aptos, Capitola, and Soquel, water service was interrupted for only a few hours, if at all, except for the area served by the above-mentioned booster water-pumping plant with the transformer problem, which was out of service for as long as 3 days. The city of Santa Cruz issued an advisory alert to boil water for 7 days. No positive bacteriologic samples were found. About 40 percent of the water-supply system was without water initially, 90 percent of water service was restored within 24 hours, and complete restoration was effected within 4 days.

In Scotts Valley, the impact of the earthquake was limited; only one break was reported in the asbestos-cement pipe that is used in 90 percent of the water-supply system. Generators were used on a rotating basis to operate wells and pumps. The San Lorenzo Valley lost power for as long as 4 days; however, 80 percent of residents received water by using portable generators to operate the wells and pumps. An advisory notice was in effect for 7 days to boil or chlorinate the water, but no bad water-quality samples were found.

Closed bridges and landslides restricted the movement of repair teams because these obstacles required detours and slowed the effort to reach critical locations. Crews were concerned about personal safety because of potential hazards from damaged buildings, landslides, and fallen trees, as well as from working in unshored trenches during aftershocks. A notice was issued to boil water until water-supply management was satisfied there was no longer a need. A more uniform water-boiling policy is needed.

\section{EMERGENCY RESPONSE AND FUTURE IMPROVEMENTS}

In the area of Aptos, Capitola, and Soquel, the EOC, a part of the emergency-operations plan, was fully staffed within 5 minutes after the earthquake. Inspection teams of two people were established to survey the facilities; their first priority was to inspect and secure the water tanks. The telephone system was saturated, and so teams relied on the use of mobile radios and the headquarters radio, which had emergency power. Three contractors with experience in waterworks volunteered and supplemented the agency's crews in the restoration. People need to be cross-trained to handle emergency calls.

In Santa Cruz, crews were dispatched within an hour to inspect the reservoirs and the Newell Creek Dam, and they began to repair leaks within 2 hours. Crews worked in 12hour shifts with the assistance of three private contractors. Emergency-power supplies need to added for two major pumping plants.

\section{WASTEWATER SYSTEMS}

Few sewer-main breaks have been identified since the earthquake because most sewage flows with gravity and so

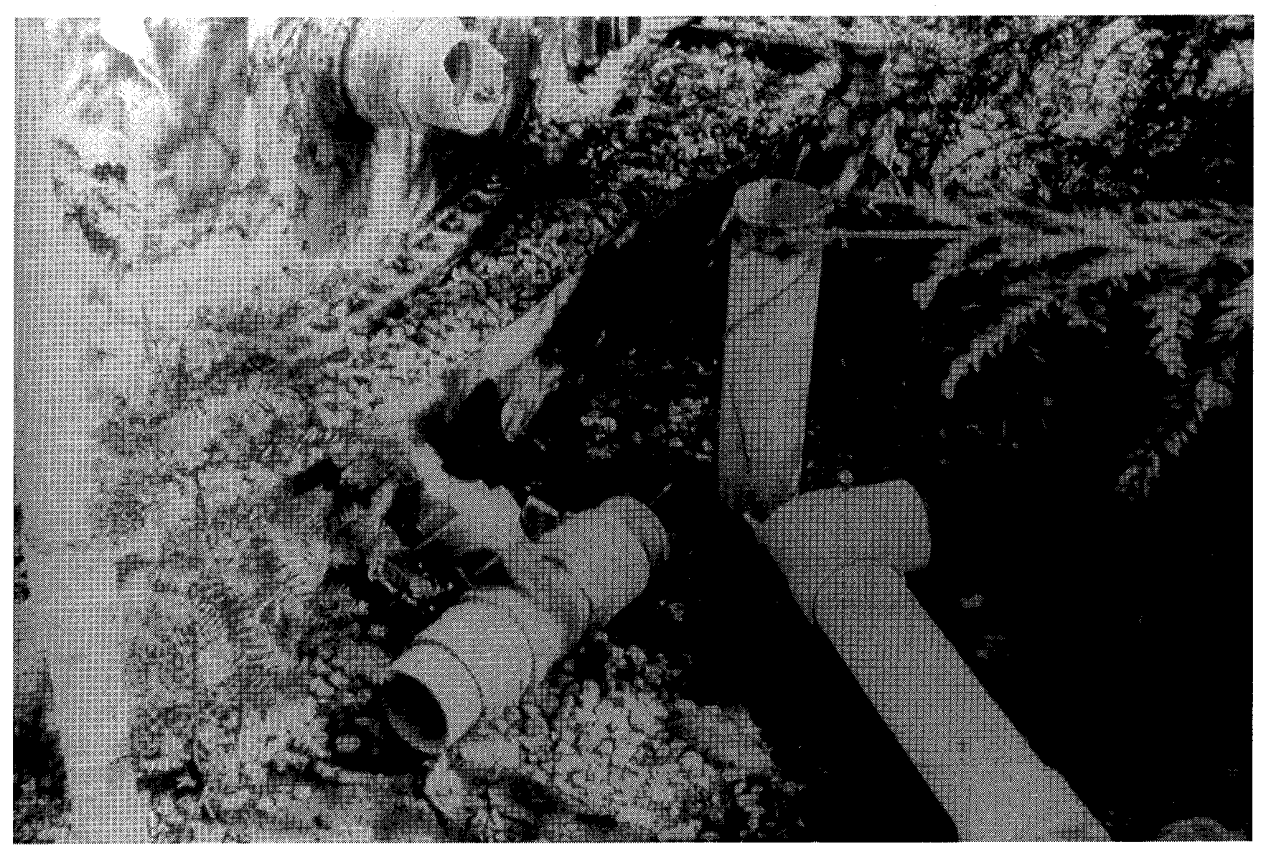

Figure 8.-Tank inlet-outlet piping in the Santa Cruz Mountains damaged because of inadequate flexibility. 
wastewater does not normally appear at the surface of the ground. However, at least as many sewer-main breaks as water-main breaks may be assumed to have occurred, especially in the same areas of unstable ground. Contacts with wastewater agencies indicated that they were performing videocamera surveys of the sewer mains to determine the extent of the damage. Investigators identified breaks in sewer pressure lines (force mains) when power was restored to sewage-pumping stations.

\section{CENTRAL SAN FRANCISCO BAY AREA}

\section{EARTHQUAKE DAMAGE AND RESTORATION}

A six-block area of Alameda constructed on 1960's dredged fill underwent severe liquefaction, causing damage to the sewer mains. The proposed method of repair was to thread a polyethylene-plastic sleeve inside the damaged 4and 6-in.-diameter vitrified-clay pipe.

No major structural damage was reported at the regional wastewater-treatment plants in San Francisco and Oakland; however, the power outage caused some short-time releases of sewage into the Pacific Ocean and San Francisco Bay. The Oakland regional plant lost commercial power from two feeds for 7 hours. At an industry upstream from the plant, a 20,000gal caustic-chemical tank drained into the sewer system. This drainage raised the $\mathrm{pH}$ to 11 in the sewer system, causing the biomass already affected by oxygen starvation to die and severely disrupting the plant's secondary activated-sludge process. No power was available to run the secondary-treatment

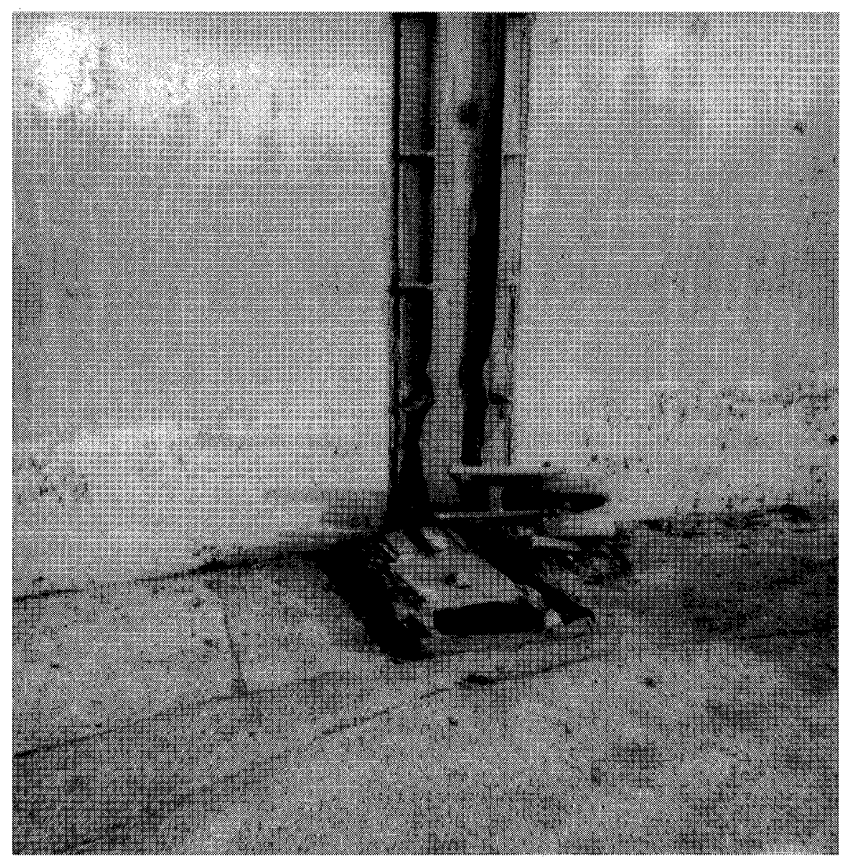

Figure 9.-Failed roller-guide assembly on digester cover at regional wastewater-treatment plant in Oakland (fig. 1). system because the sludge gas-engine generators were not designed for emergency startup. A floating digester cover rotated, damaging the 12 -in. cast-iron roller guides. Several failures were reported: The roller-guide-assembly anchorage failed on most guides, on some anchorages the guide assembly failed, and on one anchorage the wheel axles failed (fig. 9). A similar sloshing problem was reported on four of the eight digester covers at a wastewater-treatment plant near Sacramento, $100 \mathrm{mi}$ northeast of the epicenter.

In San Francisco, most of the observed damage to the combined (wastewater and storm water) sanitary sewer system involved frames around catchbasins and manholes. Because it is a combined system, a large-capacity conveyance facility around the city holds storm water during storms (before treatment), reducing spillage into the bay while the wastewater-treatment plants were out of service because of the power outage. Observed damage included circumferential cracks in 84- and 96-in.-diameter outfall lines and a leak in a pressurized 66-in.-diameter reinforced-concrete pipe with rubber-gasket joints.

\section{IMPACT ON USERS AND HINDRANCE TO RESTORATION}

Almost no wastewater-system users in the central San Francisco Bay area were affected by the earthquake, except in localized areas where minor blockage or loss of a force main may have occurred because of loss of power for pumping. An emergency-power supply is needed for sewage-pumping plants. The sewer system probably was unavailable in unstable areas where significant breaks occurred in the water-system piping; however, because water was unavailable, the sewers were not much needed at the time.

\section{EMERGENCY RESPONSE AND FUTURE IMPROVEMENTS}

The San Francisco and Oakland EOC's operated as planned (see section above entitled "Water Systems"). In Oakland, the sludge gas-engine generators were modified to operate automatically under emergency conditions. In both cities, sewage discharges into the ocean and the bay could have been avoided with an adequate emergency-power supply and the automatic startup of emergency-power generators.

\section{SOUTH SAN FRANCISCO BAY AREA}

\section{EARTHQUAKE DAMAGE AND RESTORATION}

Several regional wastewater-treatment plants are located in the south San Francisco Bay area. Structurally, they all performed well in the earthquake.

The Palo Alto Wastewater Treatment Plant, constructed in 1938 and expanded in 1972 and 1986, with a capacity of 
40 mgd, serves Mountain View, Los Altos, Los Altos Hills, Stanford University, Palo Alto, and East Palo Alto. Fiberglass scum troughs were damaged by wave action in four rectangular clarifiers. The troughs were attached to the concrete wall with a fabricated fiberglass bracket, which broke at the angle point (fig. 10). Some of the troughs fell onto the sludgesweeping scraper in the bottom of the clarifier, causing the scraper to jam. In one of two circular clarifiers, the pendulum-action vertical center support rotated from the earthquake motion, causing the radial scum trough to bind. The other circular clarifier was dry at the time of the earthquake.

A small leak occurred at the concrete junction box between the tertiary dual-media filter and the two 96-in.-diameter reinforced-concrete effluent lines. On the roof of the primary sedimentation basins, several of the 2 - by 3 - $\mathrm{ft}$ aluminum access covers fell into the basin when dislodged by sloshing sewage. Workers removed the scum troughs and access covers from the bottom of the basins and freed the radial scum trough in 2 days. The plant was put back in operation within 2 hours by activating the empty circular clarifier and by storing effluent in the effluent-holding tanks, discharging only tertiary water into the bay. The sludge-burning incinerator was secured for a time until it could be inspected. No damage was reported to the sewage-collection system feeding this plant. The plant lost commercial power but operated by using emergency-power generators.

The cities of Fremont, Newark, and Union City are served by the Alvarado Wastewater Treatment Plant, constructed in 1980 and expanded in 1987 with a capacity of $35 \mathrm{mgd}$. The plant, located on a 20 -ft-thick engineered compacted fill, sustained no structural damage from the earthquake. The chlorine building, which is constructed on piles, also was undamaged. No power outage occurred to the plant; however, it has 100-percent backup emergency-power generators. Wave action tore loose the center-well fiberglass baffles in two primary and two secondary clarifiers. The plant has six primary and six secondary clarifiers; however, only four of each are operated under normal conditions. The plant operation was switched to the other clarifiers. Plant workers repaired the damaged baffles in 2 days. A crack was reported in a 12 -in.-diameter cast-iron pipe that fed an outof-service digester which stored reclaimed water. The pipe was repaired after the digester was drained and cleaned. Two of three booster sewage-pumping stations lost power; however, the emergency-power generators operated automatically. The generators had been tested weekly under load. No leaks were detected in the sewage-collection system. A consulting civil engineer inspected the plant after the earthquake, and the only damage noticed was superficial cracking, which was repaired by pressure grouting.

Menlo Park, Redwood City, San Carlos, and Belmont are served by the South Bayside Wastewater Treatment Plant, with a capacity of $24 \mathrm{mgd}$, where no structural damage was reported. The damage to the fiberglass baffles in the clarifiers, caused by sloshing water, was almost identical to the damage sustained at the Alvarado Wastewater Treatment Plant. Baffles were replaced with a modified design that includes straps to keep them from falling into the clarifier.

In the City of San Mateo Wastewater Treatment Plant, the multiple-hearth sludge incinerator was damaged. The incinerator's center shaft probably moved back and forth at least $2 \mathrm{ft}$ in each direction, damaging the center shaft and furnace refractory bricks. Other damage included waterline and gasoline breaks and damage to fiberglass chlorine contact-basin baffles, caused by sloshing water.

No damage was reported to the San Jose wastewatertreatment facilities.

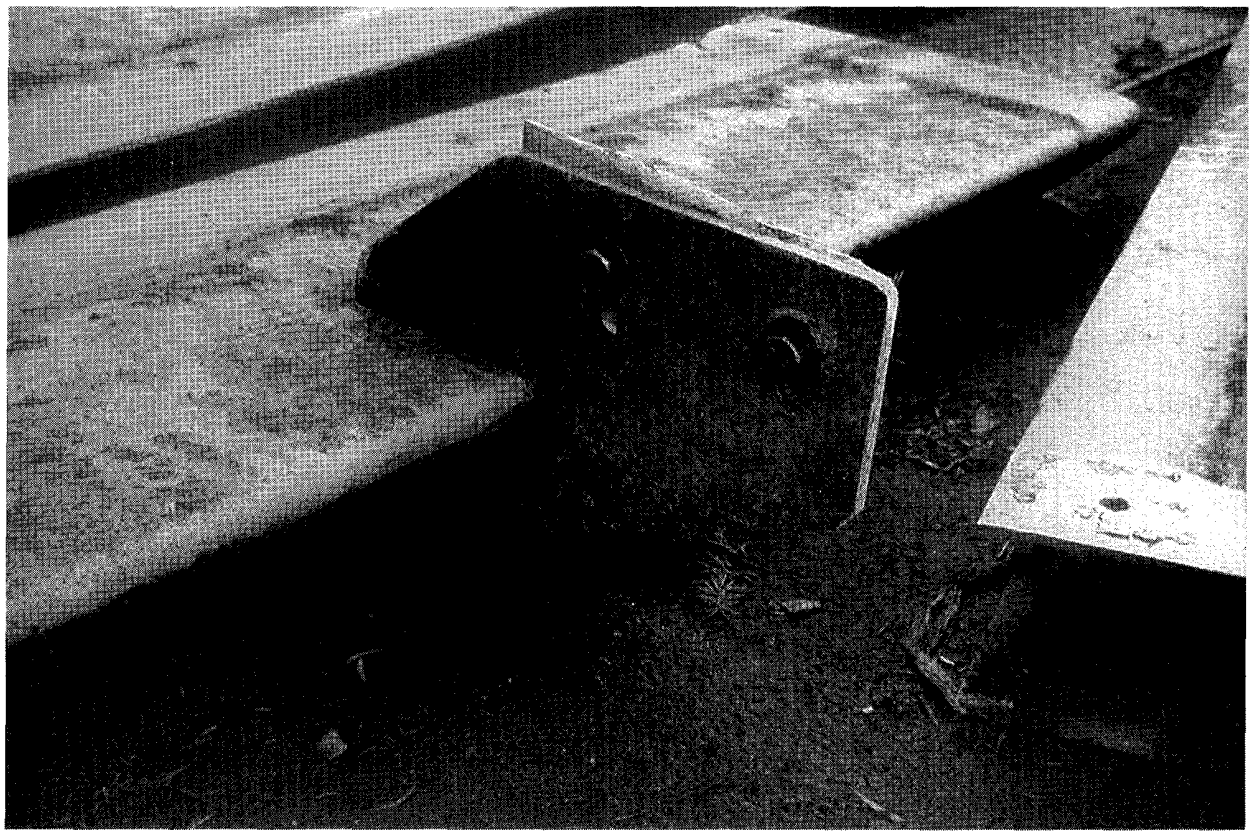

Figure 10.-Damaged bracket on scum trough of clarifier at the Palo Alto Wastewater Treatment Plant (fig. 1). 


\section{IMPACT ON USERS AND HINDRANCE TO RESTORATION}

No wastewater-system users in the south San Francisco Bay area were affected by the earthquake because of the availability of an emergency-power supply and redundant components. At the Palo Alto Wastewater Treatment Plant, the fallen scum troughs and access covers in the clarifier basin, which was full of cloudy sewage, were difficult to see and thus difficult to remove.

\section{EMERGENCY RESPONSE AND FUTURE IMPROVEMENTS}

The Palo Alto Wastewater Treatment Plant, which operates continuously, exercised its emergency-response plan. The plan's first priority was to see that the emergency-power generators were started to maintain the biologic-treatment system, which controls the quality of the water discharged into the bay. The plant's four emergency-power generators (250$500 \mathrm{~kW}$ ), two fixed and two portable, which are tested monthly under load, operated satisfactorily after the earthquake. The plant purchased an additional portable $500-\mathrm{kW}$ unit. Telephone-line saturation was a problem; however, activities were directed by using the city's radio, radio-equipped vehicles, and four portable radios.

At the Alvarado Wastewater Treatment plant, which also operates continuously, the emergency-response plan was not exercised. All personnel reported to the plant after the earthquake. A consultant had performed an earthquake-vulnerability assessment on the plant before the earthquake. The high-volume telephone problem was resolved by interconnecting the plant's mobile-radio system with a county public-works radio system.

\section{MONTEREY BAY AREA}

\section{EARTHQUAKE DAMAGE AND RESTORATION}

In Watsonville, the earthquake did not cause blockage of the sewerlines, but preliminary inspection of many of the sewers indicated broken pipes, misalignment, and grade changes. The pipes were concrete with rubber-gasket joints; older pipes may be cement-mortar caulked. A preliminary inspection indicated that the damage could be widespread, and further inspection by video camera is required. The liquefaction at Front Street caused a sewer grade to reverse and broke other parts of the sewer. The vitrified-clay pipe pulled apart at the joints. The onland portion of the 36-in.-diameter welded-steel, cementmortar-lined outfall developed two leaks (joint separation) where it crossed a low-lying unstable-soil area. Draining the area of water was not feasible, but divers made repairs by applying mastic. The advanced primary wastewater-treatment plant, which was upgraded in 1985, was virtually undamaged; it had been designed to withstand seismic forces.
At the Hollister Wastewater Treatment Plant, primary effluent water is put into lagoons for evaporation. A dike on one of four lagoons slumped slightly; however, the lagoons continued to operate. The extent of sewer-main damage was determined by further inspection.

\section{IMPACT ON USERS AND HINDRANCE TO RESTORATION}

Almost no wastewater-system users in the Monterey Bay area were affected by the earthquake, except in localized areas with small blockages or power outages, which inactivated the force mains. In areas of water-main damage, sewer mains probably also were damaged; however, without water, the sewer system was not much needed.

The difficulties with traffic, telephone, radio, and personnel training were the same as those in the water system (see section above entitled "Water Systems")

\section{EMERGENCY RESPONSE AND FUTURE IMPROVEMENTS}

The problems and needs of the wastewater systems in the Monterey Bay area are the same as those of the water systems (see section above entitled "Water Systems").

\section{SANTA CRUZ AREA}

In the Santa Cruz area, a county sanitation district collects sewage from the built-up areas of the county, except the incorporated cities of Scotts Valley and Santa Cruz. This system is for collection only; treatment is provided by the city of Santa Cruz. Although it is basically a gravity system, it has several sewage-pumping stations, all of which have emergency-power generators.

\section{EARTHQUAKE DAMAGE AND RESTORATION}

The most serious damage in the Santa Cruz area was several leaks in the county's 36-in.-diameter steel, plasticlined, cement-mortar-coated force main in a ravine near the San Lorenzo River. The main, which carries 5 to $8 \mathrm{mgd}$, separated at a joint. The joint was gated off, and the sewage was bypassed by a temporary pipeline into Monterey Bay. The site had to be drained of water with well points, and in 9 days a steel butt strap was welded into place to close the 8-in. gap. Two more leaks that occurred in the vicinity were also repaired with difficulty, because water was present at the site and utilities were nearby. Several leaks or alignment problems were reported, but unless the difficulty was serious enough to block the flow or cause contamination problems, immediate repairs were not undertaken because of other problems facing the county. 
The city of Santa Cruz operates the regional wastewater-treatment plant, constructed in 1965 and expanded in 1976 and 1989 , with a capacity of $17 \mathrm{mgd}$, which collects sewage from the city and processes the county flow from a 36-in.diameter force main. No structural damage to the plant, which is constructed on piles, was reported, and it continued to operate after the earthquake. In three or four places, 6-in.-diameter ductile-iron-pipe below-grade structure-wall penetrations were sheared off when the ground settled away from the pilesupported structures. The pipelines were relocated to penetrate the structure wall above grade. A construction joint on the sedimentation basin's effluent channel cracked, causing leakage and slight undermining of the structure. The joint was repaired within 24 hours of the earthquake. No damage was reported, even though liquefaction occurred along the alignment of the four lines approaching the plant (the city's 30- and 54-in.-diameter, the county's 36-in.-diameter, and Scotts Valley's 12-in.-diameter treated-wastewater force mains). The Scotts Valley line bypasses the plant and joins the joint outfall line. About 800,000 gal of raw sewage was released in Santa Cruz as a result of the 30- to 35-hour loss of power to the sewage-pumping stations. Miscellaneous breaks in the 6- to 54-in.-diameter collection system were reported. The plant lost power for almost 24 hours, but it operated with an emergency-power generator. Only three portable generators were available for the 17 sewage-pumping stations.

No serious problems were reported at the Scotts Valley wastewater-treatment plant, constructed in 1985, with a capacity of $0.95 \mathrm{mgd}$, other than a few isolated masonry cracks. The plant continued to operate for 63 hours on emergency backup power. Because of a power outage at remote sewage-pumping stations, crews had to shuttle a trailer-mounted generator from station to station to avoid overflows, until they were able to purchase and hook up generators at each station. Miscellaneous damage to the 8- to 12-in.-diameter PVC-pipe system was reported. The Scotts Valley 12-in.-diameter force main to the ocean outfall, on the levee along the San Lorenzo River, separated at a bell-and-spigot joint. Contractor crews repaired it within 24 hours of the earthquake, without taking the pipe out of service.

As with other wastewater systems, the Santa Cruz and Scotts Valley underground gravity facilities were thoroughly surveyed by video cameras. Most of the sewage-disposal systems in the Santa Cruz Mountains are of the private cesspool or septic-tank type.

\section{IMPACT ON USERS AND HINDRANCE TO RESTORATION}

Almost no wastewater-system users in the Santa Cruz area were affected by the earthquake, except in localized areas with small blockages or power outages to the sewagepumping plants supplying the force mains. The sanitation district's repair of the 36-in.-diameter main was impeded by high ground water, and a system of well points had to be installed to drain the construction area. Telephone service was saturated, and telephones remained unusable for 15 hours. The sanitation district's electrical power was out for 2 hours, but emergency-power generators were available and functioned properly. The district was short of trained personnel because county forces were busy with more critical functions.

\section{EMERGENCY RESPONSE AND FUTURE IMPROVEMENTS}

Santa Cruz County's emergency-response plan worked well; however, the sanitation district considered that the priorities set by the plan left the district on its own and even reduced its ability to respond rapidly. The city of Santa Cruz has a well-documented emergency-response plan, which includes fire and police radios in all vehicles. Better radio-communication procedures and specific assignments for personnel in emergency-response operations are needed. Santa Cruz is requesting the purchase of five emergency-power generators. Scotts Valley has an excellent emergency-response plan and is purchasing three additional generator units. In Scotts Valley, all public-works vehicles are equipped with two-way radios, and they have six hand-held radios.

\section{CONCLUSIONS AND RECOMMENDATIONS}

The biggest impact of the earthquake on water and wastewater systems was the loss of commercial power, especially because it lasted so long. Because of the chance that the electrical-power system will fail in an emergency such as an earthquake, the U.S. Environmental Protection Agency (EPA) requires either a dual power supply or an emergency-power supply at their newly funded treatment plants.

The TCLEE reconnaissance group had insufficient time to contact all the water and wastewater systems in the earthquake-affected area; therefore, a complete survey is left to future researchers. Also, the group could not include all the available information in this report, and so these details are left to future researchers for study.

On the basis of this preliminary reconnaissance survey, the 1989 Loma Prieta earthquake has reinforced the lessons learned in previous earthquakes that water and wastewater systems should do the following.

Provide emergency power for critical operating, treatment, and support facilities.-Water- and wastewater-treatment facilities and emergency operations were significantly disrupted by the earthquake because of the loss of commercial power. Emergency power should be available on site at these facilities because generators are difficult to obtain and deliver after an earthquake. The emergency power should be installed, maintained, and tested as described by Schiff (this chapter).

Maintain portable light plants, generators, chlorinators, and pumps-Portable light plants are necessary for night-time 
repair work. Portable generators can be used to operate portable pumps to drain construction sites or to operate portable chlorinators to disinfect repaired water mains.

Develop a separate radio-communication system, independent of the telephone system.-After the earthquake, as is typical after similar earthquakes, the telephone system was blocked by a high volume of calls. Regional or city emergency radio-communication systems give priority to fire, police, and medical emergencies. A separate radio-frequency system should be available for dispatching repair crews and equipment to water and wastewater systems. A base station, an alternative base station, an emergency-power supply, and mobile units should be a part of this system (see Schiff, Tang, and others, this chapter).

Maintain an inventory of repair materials, parts, and fuel.-No shortage of repair materials, parts, or fuel was reported for the medium-size to larger water and wastewater agencies; however, some agencies reported that their supplies of specific items were almost depleted. Some small agencies had essentially no inventory and had to order, and sometimes wait for, needed repair materials.

Improve the State-wide mutual-aid program.-A utilities division of the California Office of Emergency Services (OES) coordinates the water, gas, and electrical mutual-aid program. Each activity is administered by a representative designated from a major utility as the State operating engineer to coordinate the program. Although volunteer mutual aid was available after the earthquake, both the organization and testing of the communication system for the OES need to be reviewed.

Establish guidelines for State-wide emergency water-quality sampling and public notification.-Small and medium-size water and wastewater agencies who rely on outside water-quality laboratories and have no public-relations staff need some uniform guidelines as to what minimum testing is required to ensure that the water supply is potable in an emergency. Also, radio stations should be provided with sample news releases that they can use to tell the public when they should boil water in the case of a potentially polluted water supply.

Conduct an earthquake-vulnerability assessment of system facilities.-Each water and wastewater agency should conduct an earthquake-vulnerability assessment of its system, either by outside consultants or inhouse engineering or technical personnel. These people need to be trained as to what to look for in evaluating the facilities. They should identify (a) simple and low-cost mitigation measures, such as anchorage of equipment, chemical or compressed-gas tanks, supply cabinets, and warehouse storage facilities; (b) mediumcost mitigation, such as emergency-power supplies, roof-towall connections, or wall-to-footing connections for buildings that house pumps or treatment equipment; and (c) facilities that require more detailed engineering analysis, such as large tanks, large buildings, and treatment plants. The detailed analysis could require demolition and complete reconstruction of the facility, resulting in a high-cost mitigation measure.
Develop an emergency-response plan.-Each water and wastewater agency should have a simple emergency-response plan, even though many of these agencies normally operate on a continuous emergency-response basis. This plan should include, but not be limited to, emergency-reporting procedures, reporting locations, alternative assigned duties, training, provision for providing meals to field locations, a plan for inspecting critical facilities, a plan for an alternative operating center, and a method for exercising and updating the plan.

Incorporate into local or regional emergency-response plans a more active participation by water and wastewater agencies.-In some places, an agency or its contractors had difficulty in entering secured areas because the agency had not been recognized in advance as an emergency-response organization. This difficulty could be alleviated by incorporating the agency into the local or regional emergency-response plan.

Provide a method, possibly computer based, for logging problems and system operations to establish priority for repair activities.-During an emergency, many contacts to water and wastewater agencies are made by telephone, by radio, and through the EOC. A system needs to be developed to sort out the problems in order to establish a priority for restoration.

Conduct a crosstraining program to include all personnel in emergency response.-Smaller agencies with limited personnel should crosstrain their office personnel in staffing the EOC, telephone switchboard, and radio; in understanding system operations; in logging operational data (pump, treatment, and valve operations); and in understanding the types of restoration activities (locations, crews, equipment, materials and time to complete the repair). The agency should collect data if it is eligible for disaster funds.

Train personnel in appropriate communication procedures.-Personnel need to be trained in the operation of telephone and radio equipment, so that they can obtain the appropriate information in a minimum of time and dispatch this information to field crews.

Conduct regular periodic emergency-response exercises.-Each emergency plan needs to be tested by regular and different simulated emergency scenarios, both inhouse and on a local or regional basis. One of the most critical parts of this exercise is to test the communication system, so as to show whether the plan needs to be modified.

Provide flexible pipe joints.-Pipe with flexible joints, such as rubber-gasket, reinforced-concrete, vitrified-clay, ductile-iron, PVC, and asbestos-cement pipes, performed well in the earthquake; however, only a few of these pipes may have been installed in unstable areas. In areas of potential soil liquefaction, fully restrained flexible-joint pipes should be provided. Cast-iron, clay, and concrete pipe with rigid caulked joints; corroded steel pipe; and galvanized-iron screw pipe were the most heavenly damaged.

Provide flexible pipe connections to wells, tanks, pumps, and other rigid structures.-Tank and well connection pip- 
ing was damaged during the earthquake because of differential movement. Where connecting piping was fitted with mechanical double-flexible joints, the piping performed well.

Provide adequate anchorage for air valves and other heavy appurtenances that are installed in an inverted-pendulum position.-A few air valves installed on a small pipe in a vertical position broke at the threaded connection, owing to vibration.

Design mechanical appurtenances in treatment-plant basin facilities for wave action.-Wave action (sloshing) and vibration caused by earthquakes can damage treatment-plant mechanical appurtenances. In both wastewater- and municipal water-treatment plants, digester and clarifier basins, scum troughs, launderers, and baffles were damaged, requiring a shutdown of operations.

Provide for breakaway or fusible connections and (or) safety cables or chains to prevent malfunctioning mechanical equipment from interfering with other equipment in treatment-plant basins. - Differential movement between mechanical equipment and reinforced-concrete basins caused the mechanical equipment to undergo tension on one side and compression on the other side of the basins. The damaged equipment fell to the bottom of the digester or clarifier and caused a malfunction of the rotating or traveling sludge scraper at the bottom of the basin.

Provide for redundancy in water and wastewater systems. - Linear waterlines and sewerlines should have redundancy by the use of piping loops, piping grids, multiple storage and pumping facilities, interconnected pressure zones, and alternative power supplies.

Install isolation valves and establish a regular valvemaintenance program.-Isolation valves are important in isolating the waterlines and sewerlines in unstable ground, in poor soil, in areas of high landslide susceptibility, and at canyon and creek crossings. Reliable operating valves are necessary to minimize the size of areas that must be taken out of service for damage repair.

Anchor water-quality-testing equipment and supply cabinets.-No damage was reported in water- and wastewatertesting laboratories; however, in other laboratories, equipment fell, small chemical-storage containers fell off shelves, and supply cabinets tipped over. Small chemical containers on open storage shelves should be restrained by a wire, bar, or shelf lip. Laboratory equipment should be anchored to the bench, a shelf, or a structural wall. 


\title{
THE LOMA PRIETA, CALIFORNIA, EARTHQUAKE OF OCTOBER 17, 1989: PERFORMANCE OF THE BUILT ENVIRONMENT
}

\author{
LIFELINES
}

\section{WATER-DISTRIBUTION SYSTEM}

By John M. Eidinger, G\&E Engineering Systems, Inc.

\section{CONTENTS}

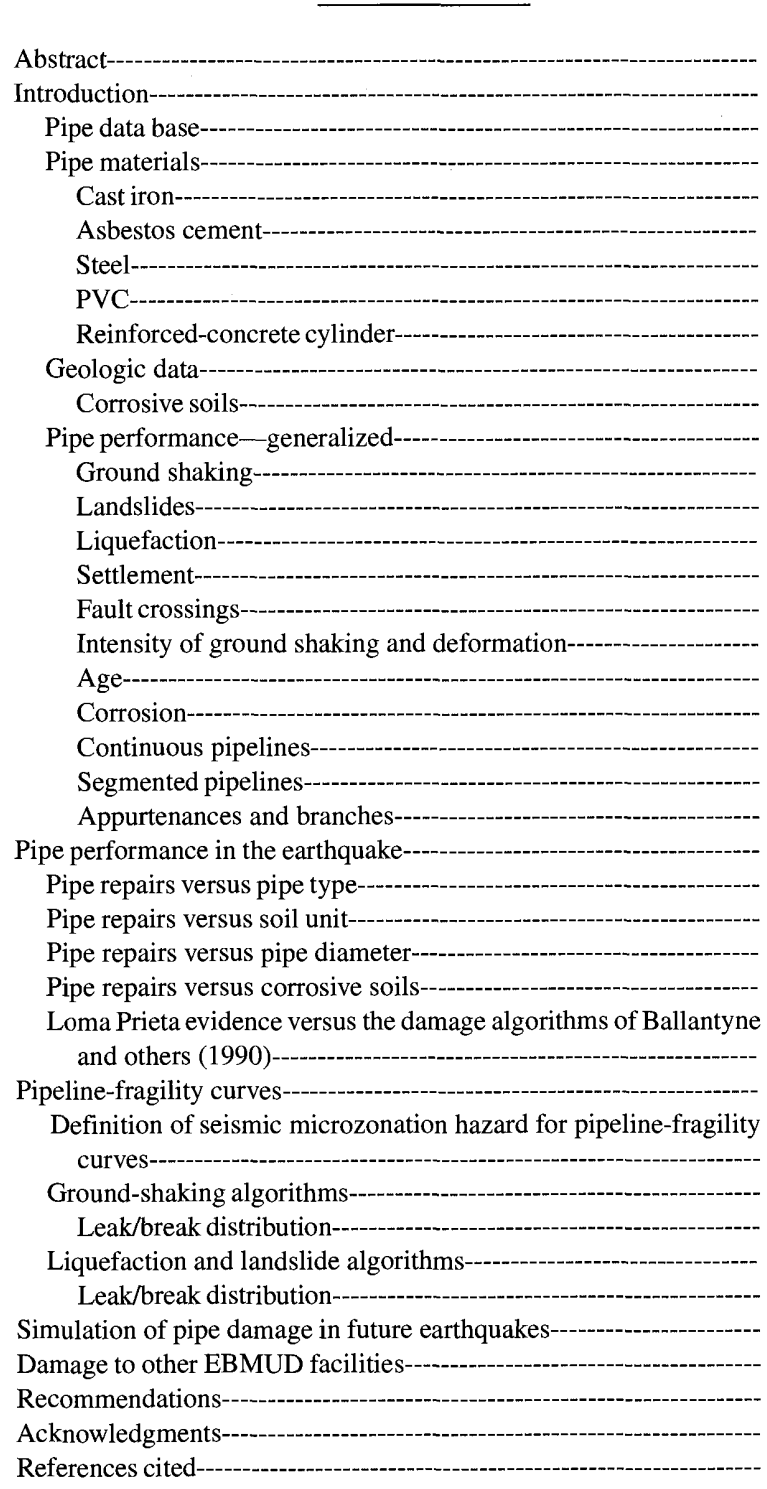

ABSTRACT

This paper documents the performance of the East Bay Municipal Utility District (EBMUD) water-distribution sys- tem in the 1989 Loma Prieta earthquake. A total of 135 buried pipes were reported damaged, ranging from 60 -in.-diameter aqueducts to small-diameter cast-iron, asbestos-cement, and steel pipelines. The pipeline damage was correlated with peak ground velocity, soil conditions, pipeline diameter, pipeline materials, and corrosive soil conditions. In combination with data from other earthquakes, this paper presents new pipeline fragility curves for both ground shaking and permanent ground deformation hazards. Using these curves, this paper presents forecasts pipeline damage due to future larger earthquakes that can affect the EBMUD water-distribution system.

\section{INTRODUCTION}

This paper provides detailed documentary evidence of the performance of the East Bay Municipal Utility District (EBMUD) water-distribution system in the 1989 Loma Prieta earthquake. EBMUD was organized in 1923 under the Municipal Utility District Act of 1921. In 1928, EBMUD acquired the properties of the East Bay Water Co., a corporation formed by consolidation of 15 smaller companies, the oldest of which was incorporated in 1865 (National Board of Fire Underwriters, 1933). Today, EBMUD's water-distribution system serves about 1.2 million people; its service area comprises 21 cities in the east bay, including Oakland, Berkeley, San Leandro, San Lorenzo, El Cerrito, Kensington, Albany, Richmond, Pinole, El Sobrante, Rodeo, Crockett, Hercules, Walnut Creek, San Ramon, Alamo, Pleasant Hill, Orinda, Moraga, Lafayette, and parts of Hayward. The water-distribution system is bisected by the Hayward and Calaveras faults, which are capable of generating $M=7.25$ and 6.75 earthquakes, respectively.

At the time of the earthquake, EBMUD's water-distribution system included 6 water-treatment plants, 175 treatedwater reservoirs (mostly tanks), 125 pumping plants, and 3,800 mi of buried pipe. EBMUD also operated more than 20 office, warehouse, and maintenance buildings.

\section{PIPE DATA BASE}

A data base was developed of the pipe inventory of the EBMUD water-distribution system. The System Earthquake 
Table 1.-Length of pipeline in the EBMUD water-distribution system, by year of construction.

\begin{tabular}{cccccc}
\hline & $\begin{array}{c}\text { Approximate } \\
\text { Period }\end{array}$ & \multicolumn{4}{c}{ Pipe material used (percent) } \\
\cline { 3 - 6 }$(\mathrm{mi})$ & Cast iron & Steel & $\begin{array}{c}\text { Asbestos } \\
\text { cement }\end{array}$ & PVC \\
& & & & & \\
$1850-99$ & 60 & 98 & 2 & -- & -- \\
$1900-9$ & 40 & 98 & 2 & -- & -- \\
$1910-19$ & 70 & 97 & 3 & -- & -- \\
$1920-29$ & 300 & 88 & 10 & 2 & -- \\
$1930-39$ & 480 & 85 & 13 & 2 & -- \\
$1940-49$ & 450 & 90 & 6 & 4 & -- \\
$1950-59$ & 810 & 25 & 23 & 52 & -- \\
$1960-69$ & 720 & 2 & 48 & 50 & -- \\
$1970-79$ & 350 & 1 & 41 & 58 & -- \\
$1980-89$ & 100 & 0 & 35 & 40 & 25 \\
$1990-92$ & 1 & 0 & 35 & 0 & 65 \\
Unknown & 30 & -- & -- & -- & -- \\
& & & & & \\
\hline
\end{tabular}

Risk Assessment (SERA) geographic-information-system software was used to map and analyze the buried pipelines. This data base uses a set of about 1,400 maps maintained by EBMUD that reflect the water-distribution system as of about 1986. Each map shows the location of a buried pipe at high resolution (1:12,000 scale), as well as the pipe's attributes (diameter, material of construction, lining, coating, date of installation). Owing to various issues involved with the data base, a percentage of actual pipes in the ground were omitted from the analysis. The "missing" pipes constitute about 10 percent of the total inventory, and so the results presented here should be viewed accordingly.

The following observations are summarized in table 1.

- Most of the water-distribution system's cast-iron pipe was installed from the 1800's through 1949.

- In the 1950's, asbestos cement pipe was used for about half of all new pipe installation, and steel and cast-iron pipe for most of the rest.

- In the 1960's and 1970's, steel and asbestos-cement pipe were used for almost all new pipe installation.

- In the 1980's, polyvinyl chloride (PVC) pipe was introduced as a common pipe material. Asbestos-cement pipe installations have been phased out since the mid-1980's.

Thus, most of EBMUD's pipes are of three types: cast iron ( 45 percent), asbestos cement ( 30 percent), and steel (23 percent); the remaining 2 percent are made of $\mathrm{PVC}$ and other materials. In general, the material types were installed during the following time periods: (1) cast-iron pipe from 1850 to 1950 , (2) asbestos-cement pipe from 1950 to 1985 , and (3) steel pipe from 1950 to the present. Of a total of $3,800 \mathrm{mi}$ of pipe, about $1,570 \mathrm{mi}$ is 6-in.-diameter or smaller cast-iron, steel, asbestos-cement, and other types of pipe. Most (88 percent) cast-iron pipes are 4-, 6-, or 8-in. diameter, some (8 percent) are 12-, 16-, or 20-in. diameter, and the rest are 24in. diameter or larger. Most (92 percent) asbestos-cement pipes are 6- or 8-in. diameter, some (5 percent) are 12-in. diameter, and the rest are 16-in. diameter or larger. Most (65 percent) steel pipes are 12- to 60-in. diameter, and the rest are 6- or 8- in. diameter. Some pretensioned-concrete (24-, 36-, 42-, and 54-in. diameter) and reinforced-concrete-cylinder (48- and 54-in. diameter) pipes have also been used. Only $350 \mathrm{mi}$ (less than 10 percent) of pipe is larger than 12-in. diameter; the rest is smaller.

\section{PIPE MATERIALS}

\section{CAST IRON}

Cast iron is considered to be a brittle material, with a tensile-strain capacity of generally less than 0.5 percent. The strength of cast-iron pipe depends on its manufacturing process; pit-cast (sand molding) pipe is typical before 1930, and centrifugal-cast pipe is common thereafter. The tensile strength of centrifugal-cast pipe (about $28,000 \mathrm{lb}$ per square inch [psi]) is about twice that of pit-cast pipe. Pit-cast pipe was manufactured mostly in 12-ft lengths, and centrifugalcast pipe typically in 18 -ft lengths.

Caulked bell-and-spigot joints are the most common. Both portland-cement- and lead-caulked joints were used. A substitute lead caulk (leadite, a sulfur-sand-salt sealing compound) was also used during World War II. Cement-caulked joints are fairly rigid and of low strength, making them vulnerable to breakage or leakage under seismic loadings, whereas lead-caulked joints are somewhat more flexible. Leadite-caulked joints can weaken the pipe because of the expansivity of leadite at lower temperatures; this weakness can crack the pipe bell, as well as promote corrosion.

\section{ASBESTOS CEMENT}

Asbestos cement is a brittle material composed of a mixture of portland cement and asbestos fibers, with a tensile strength of about 2,000 psi. Standard manufactured length is $13 \mathrm{ft}$. Pipe joints consist of short cylindrical asbestos-cement sleeves that fit over the ends of adjoining pipe segments; rubber rings are located in grooves to provide for a flexible watertight gasket. The joints can deflect freely as much as about $5^{\circ}$, but they do not provide a rigid connection in the axial (that is, longitudinal) direction.

\section{STEEL}

Steel is a strong ductile material, with a tensile-strain capacity of generally more than 2 percent. Steel pipe cylinders are fabricated from such standard steels as American Society for Testing and Materials (ASTM) A 283, grade C (yield stress [Fy], 30,000 psi); ASTM A 570, grades 30 (Fy, $30,000 \mathrm{psi}$ ), 33 (Fy, 33,000 psi), or 36 (Fy, 36,000 psi); ASTM A 36 (Fy, 36,000 psi); API 5LX, grade X-42 (Fy, 42,000 psi); and ASTM A7 (Fy, 34,000 psi). Typically, steel pipe 
has a portland-cement-mortar lining, a helical steel shell, and a reinforced-cement-mortar coating. More recently installed steel pipe (post-1960's) may have other coatings, such as coal tar, extruded plastic, or tape wrap. Very old steel pipes (pre-1930's) were commonly unlined and uncoated. Pipesegment lengths are typically about 20,30 , or $40 \mathrm{ft}$.

The joints in steel pipe are typically electric arc welded. Several different configurations were used:

- Bell-and-spigot girth joints (also called slip or lap joint) with either single (outside) or double (inside and outside) fillet welds. Single welds are the most common. This type of joint is most common for straight runs of pipe.

- Butt-strap girth joints with two outside fillet welds and a butt weld between adjoining pipes. This type of joint is sometimes used for larger diameter pipes at multiple joint bends, as well as in straight runs. The butt straps are generally larger in diameter than the main pipe.

- Butt-weld girth joints between adjoining pipe segments. This type of joint is typically used for multiple joint bends.

- Some very old steel pipe used riveted joint connections.

\section{PVC}

PVC pipe consists of extruded polyvinyl chloride plastic. PVC has a tensile strength of about 6,000 psi. Standard manufactured lengths are $20 \mathrm{ft}$. The joints in PVC pipe consist of a bell-and-spigot arrangement, with elastomeric gaskets integral in the bell. The joints can deflect freely for several degrees, but they do not provide a rigid connection in the axial (that is, longitudinal) direction.

\section{REINFORCED-CONCRETE CYLINDER}

About $15 \mathrm{mi}$ of larger-diameter reinforced-concrete pipe was used in the EBMUD water-distribution system, mainly for major aqueducts built before 1930. The pipe consists of a thin steel cylinder (14 gage) with a reinforced-concrete layer on its exterior. The reinforcing has both circumferential and longitudinal steel bars. The pipe is cement-mortar lined. The total thickness of the wall is about 6 in. Pipe-segment lengths are $12 \mathrm{ft}$ (54-in. diameter) and $16 \mathrm{ft}$ (48-in. diameter).

The joints in reinforced-concrete-cylinder pipe consist of a bell-and-spigot arrangement, using steel bell-and-spigot rings that are welded to the steel cylinder. A lead gasket is located between the rings; the connection area is covered with cement mortar. The joints do not provide a rigid connection between pipe segments.

\section{GEOLOGIC DATA}

Various geologic data were entered into the SERA software. The sources of these data include soil and landslide maps by Geomatrix Consultants, landslide maps by the U.S. Geological Survey, and corrosive-soil maps by EBMUD. The underlying accuracy of the Geomatrix and U.S. Geological Survey data is $\pm 100 \mathrm{ft}$, and of the EBMUD soil data $\pm 250 \mathrm{ft}$.

On the bases of these data, the EBMUD service area was divided into seven generalized geologic soil units, with the following predominant soil conditions:

- Bay mud or bay fill: unconsolidated, water-saturated, dark plastic carbonaceous clay and silty clay, underlain by a few layers of sand. These areas were further subdivided into zones of high, or moderate to high, liquefaction susceptibility.

- Young alluvial soils: coarse, medium, and fine alluvium; unconsolidated, moderately sorted, permeable gravel and sand, silt, and clayey silt and unconsolidated, plastic silt and clay. These areas were further subdivided into zones of low or very low liquefaction susceptibility.

- Merritt sand: Pleistocene beach and dune-sand deposits; loose, well-sorted, fine to medium sand. Not susceptible to liquefaction.

- Old alluvial soils: late Pleistocene alluvium; weakly consolidated, slightly weathered, poorly sorted, irregularly interbedded clay, silt, sand, and gravel. Not susceptible to liquefaction.

- Rock: Not susceptible to liquefaction, although landslides can occur.

Different soils respond differently when subjected to earthquake motions. Generally, peak ground velocities are somewhat amplified in young alluvial soils and greatly amplified in areas of bay mud or bay fill. A total of $128 \mathrm{mi}$ of pipe was located in the worst (bay mud or bay fill) soils (fig. 1); in addition, $99 \mathrm{mi}$ of pipe is located in mapped landslide areas.

\section{CORROSIVE SOILS}

A map was prepared by EBMUD showing relative soil corrosivity, on the basis of nonseismic pipe-repair experience and judgment. Metal pipes located in high-corrosivity soils have higher repair rates than those located in noncorrosive soils. Three corrosive-soil areas were defined: (1) those associated with a high incidence of corrosion to metal pipe (that is, high-corrosivity soils), (2) those associated with a medium incidence of corrosion to metal pipe (that is, mediumcorrosivity soils), and (3) those associated with a low incidence of corrosion to metal pipe (that is, noncorrosive soils).

\section{PIPE PERFORMANCE-GENERALIZED}

\section{GROUND SHAKING}

The term "ground shaking" refers to the transient soil deformations due to seismic-wave propagation. Ground shak- 
ing can cause a significant percentage of the overall pipe damage; it affects a wide area and can produce well-dispersed damage. Corrosion will accentuate damage, especially in segmented steel, threaded steel, and cast-iron pipes, although noncorroded cast-iron pipes have commonly failed as well. Welded-steel pipelines are damaged primarily at welds with poor root penetration and poor weld fusion.

\section{LANDSLIDES}

A landslide is a permanent displacement of soil mass, which can heavily damage buried pipe. Landslides cause localized severe pipe damage (that is, high pipe-damage rates over a small area). Landslides were mapped in many hundreds of locations in the east-bay-hill areas. More landslides will occur if an earthquake occurs during the rainy winter season than during the dry summer season. Some landslides are small and displace only a few inches, whereas other landslides may involve $100,000 \mathrm{yd}^{3}$ of soil or more, over many feet of distance, and damage entire areas of pipelines.

\section{LIQUEFACTION}

Liquefaction is a phenomenon that occurs in loose, saturated, granular soils when they are subjected to several cycles of strong ground shaking. Sands tend to compact and settle under such conditions. If these soils are saturated as they compact and settle, they displace pore water upward. This upward pressure on the pore water has two effects. First, it creates a quick condition in which the bearing pressure of the soils is temporarily reduced. Second, if the generated pressure becomes high enough, material can actually be ejected from the ground to form characteristic sand boils on the surface. This displaced material, in turn, results in further settlement of the site.

Lateral spreading is a phenomenon that can accompany liquefaction. At many sites, the layers of liquefiable materials are some distance below the ground surface. If the site has even a slight slope or is adjacent to an open cut, such as a depressed streambed or roadbed, gravity can cause the surficial soils to move downslope or toward the cut. Lateral spreading can be highly disruptive to buried structures and pipelines, as well as to structures supported on the site.

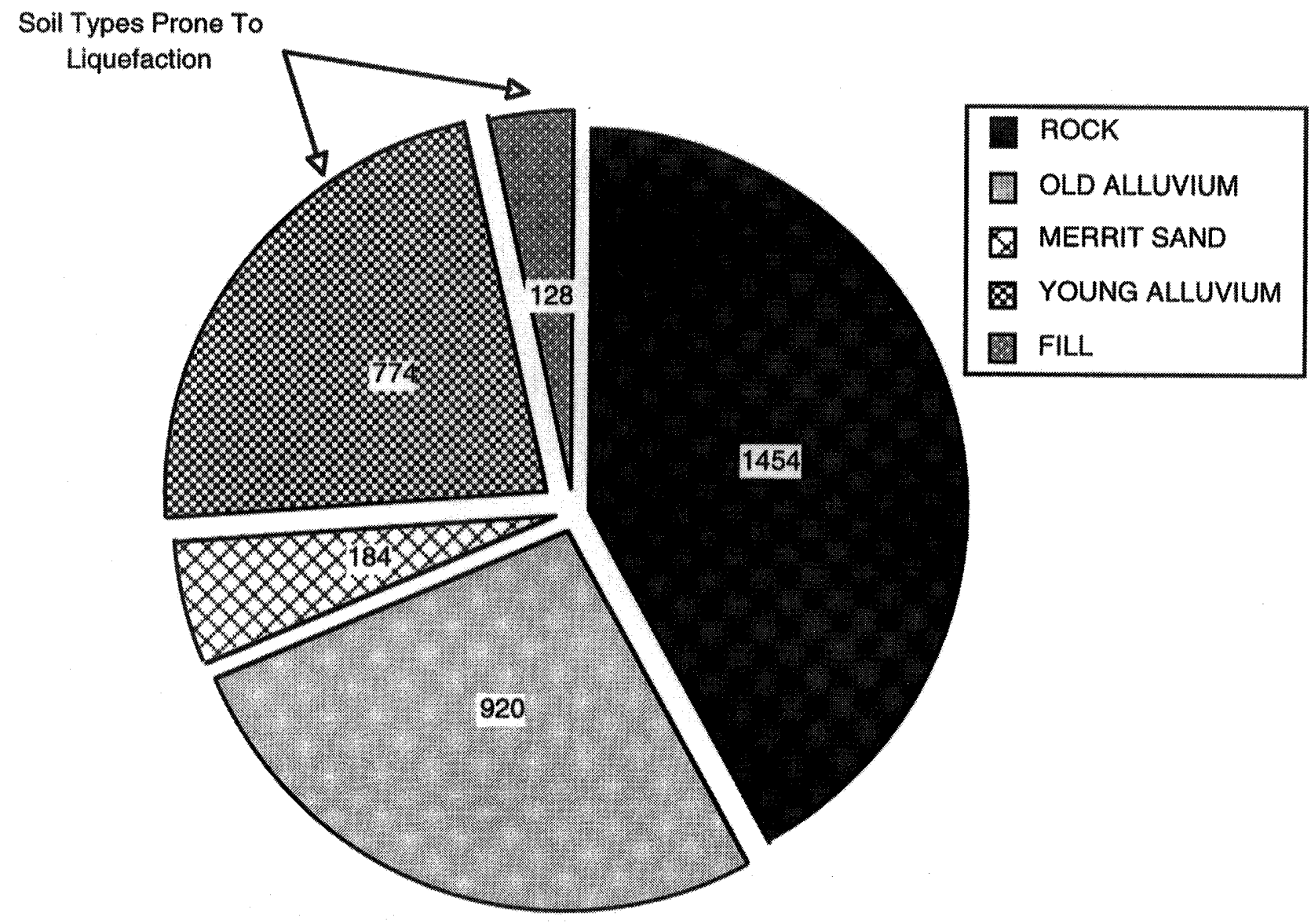

Figure 1.-Pie chart showing length of pipelines (in miles) versus soil type. 
Soil liquefaction can occur in certain soil units under certain conditions; for example, it is more likely to occur in the fill areas along the bay. Heavy concentrations of pipe breaks will occur in areas of liquefaction-induced lateral spreading. Similarly, liquefaction is more likely in long-duration earthquakes (more than $15 \mathrm{~s}$ ), but would be much more limited in shorter duration events (3-5s). The orientation of the pipe relative to the ground movement can affect the amount of damage. In general, ground movements that cause lateral (transverse) deformations of the pipe cause less damage than those parallel to the pipe run, because piping is relatively flexible in the transverse direction, as opposed to the axial direction, and can accommodate more transverse movement before damage occurs.

\section{SETTLEMENT}

Pipe breaks can occur because of relative vertical (differential) settlements at transition zones from fill to better soil, and in areas of young alluvial soils susceptible to localized liquefaction.

\section{FAULT CROSSINGS}

Localized offsets that occur in surface-fault-rupture areas can also damage buried pipe. Damage to segmented pipes (for example, cast-iron pipe with caulked bell-and-spigot joints) will be heavy where they cross surface-rupturing faults. Butt-welded continuous steel pipes may be able to accommodate fault-crossing displacements of as much as a few feet.

Butt-welded continuous steel pipelines are less prone to damage if they are oriented such that tensile strains result from the fault displacement, because tensile deformation takes advantage of the inherent ductility and strength of the steel, whereas compressive deformation results in pipe-wall wrinkling at relatively modest levels of pipe strain.

For continuous pipelines, it is advantageous to avoid bends, tie-ins, and local constraints close to the fault, so as to allow the pipeline that crosses the fault some additional length over which to distribute the imposed strains resulting from the fault offset.

Burial depth is also a factor at fault crossings. For shallow burial, less overburden is presented, and so less frictional resistance will be imposed by the soil on the pipe. The lower the frictional resistance, the easier the pipe will be able to deform, or buckle upward, in fault crossings without causing severe damage.

Two failure modes occur when a pipeline is deformed in compression: the pipeline may buckle as a beam, or it may deform by local warping and wrinkling of its wall. Beam buckling can occur across fault crossings, owing either to fault creep or to sudden fault offset if the burial depth is shallow.
Pipe-wrinkling failure occurs in thinner-walled water pipes at common burial depths.

\section{INTENSITY OF GROUND SHAKING AND DEFORMATION}

The stronger the intensity of ground shaking, the more damage an earthquake causes. Therefore, sites closer to the epicenter will generally sustain greater damage. Regarding ground failure due to liquefaction, landslides, or settlements, the amount of damage is related to the amount of soil deformation.

\section{AGE}

Older pipes appear to have a higher incidence of failure than newer pipes. Pipe damage in the Los Angeles area due to the 1987 Whittier Narrows, Calif., earthquake clearly showed a trend of increasing pipe breaks with age of pipe (Wang, 1990). Note that age effects are likely to be strongly correlated with corrosion effects, owing to the increasing levels of corrosion over time.

\section{CORROSION}

Corrosion weakens pipe because of the effective decrease in material thickness, as well as creating stress concentrations. Screwed or threaded steel pipes appear to fail at a higher rate than other types of steel pipes. Some cast-iron pipes also have higher incidences of corrosion failure (Isenberg, 1978, 1979; Isenberg and Taylor, 1984).

Damage to corroded pipelines can significant disrupt water service immediately after an earthquake and lead to increased maintenance for a long time after the event (many months in Seattle; years in the 1971 San Fernando, Calif., earthquake).

\section{CONTINUOUS PIPELINES}

Continuous pipelines are pipes with rigid joints, such as continuous-welded steel pipelines. Continuous pipelines built in accordance with modern codes of practice have generally performed better in past earthquakes than those constructed with other methods (Newby, 1954).

Experience has shown that some pipelines constructed before and during the early 1930's did not benefit from the same quality controls which prevail today. For example, the 1933 Long Beach, Calif. earthquake caused more than 50 breaks in high-pressure-gas pipelines in welded joints. Every break in large-diameter lines was discovered at welds that lacked proper penetration or bond with the body of the pipe. 
Experience has also shown that welded pipelines with bends, elbows, and local eccentricities will concentrate the deformation at these features, especially if permanent ground deformations induce compression strains in the pipe. Liquefaction-induced landslides during the 1971 San Fernando, Calif., earthquake caused severe damage to a 49-in.-diameter water pipeline at nine bend and welded joints ( $\mathrm{O}$ 'Rourke and Tawfik, 1983).

\section{SEGMENTED PIPELINES}

A jointed pipeline consists of pipe segments that are connected by relatively flexible (or weak) connections (for example, a bell-and-spigot cast-iron piping system). These pipe segments typically can fail in several ways: excessive bending deformations of the pipe barrel, excessive rotation at a joint, or pullout at a joint (Singhal, 1984). Segmented pipe with somewhat rigid caulking, such as portland cement or lead, cannot tolerate much relative movement before leakage occurs. Pipes with flexible rubber gaskets can generally tolerate more seismic deformations, but splitting at joints has been observed under moderate transverse landslide movements (Buel, 1998).

\section{APPURTENANCES AND BRANCHES}

Experience has shown that pipeline damage tends to concentrate at such discontinuities as pipe elbows, tees, inline valves, reaction blocks, and service connections. Such features create anchorpoints (rigid locations) that promote force/stress concentrations. Locally high stresses can also occur at pipeline connections to adjacent structures (for example, tanks, buildings, and bridges), especially if these connections are insufficiently flexible to accommodate relative displacements between pipe and structure. This condition was reported as the reason for most of the damage to service connections of water-distribution piping during the 1971 San Fernando, Calif., earthquake.

\section{PIPE PERFORMANCE IN THE EARTHQUAKE}

The 1989 Loma Prieta earthquake caused a modest level of damage to EBMUD's buried pipe. In this section, I review the damage data to discern trends in pipe performance, and then use this information to calibrate pipeline-fragility curves so as to better reflect actual pipe performance in earthquakes.

EBMUD's repair records for about 2 weeks after the earthquake were reviewed, and the locations and type of repairs were tabulated. At each repair location, the estimated level of ground shaking due to the earthquake was calculated, using attenuation and soil-amplification relations specific for the EBMUD service area in this earthquake. This procedure was required because low-level instrumental readings in
Table 2.-Repairs to EBMUD pipes due to the earthquake.

\begin{tabular}{ccc}
\hline Pipe material & $\begin{array}{c}\text { Number of } \\
\text { repairs }\end{array}$ & $\begin{array}{c}\text { Repair rate } \\
\text { (per 1,000 ft of pipe) }\end{array}$ \\
\hline Cast iron -------------- & 52 & 0.007 \\
Steel - & 46 & .012 \\
Asbestos cement--------- & 13 & .002 \\
PVC -002 \\
Service connections------- & 22 & --- \\
Total--------------- & 135 & --- \\
\hline
\end{tabular}

EBMUD service areas distant from the earthquake recorded ground motions somewhat larger (approx $0.075 \mathrm{~g}$ ) than would be predicted from the ordinary attenuation relations (approx $0.05 \mathrm{~g}$ ). Areas of liquefied soil and corrosive soil were compared to actual locations of damage to EBMUD's pipes. This information was then used to develop damage trends by using EBMUD's pipe data base, as described in detail in the following subsections.

\section{PIPE REPAIRS VERSUS PIPE TYPE}

The actual recorded earthquake repair information according to pipe type is summarized in table 2 . The locations of these repairs are shown in figure 2, and the level of ground shaking in the entire EBMUD service area due to the earthquake is mapped in figure 3.

The repair counts separately list the repairs made to service connections on the EBMUD side of the meter. A total of 113 repairs were associated with pipe, and 22 repairs with service connections. Note that additional service leaks occurred on the customer's side of the meter, but these leaks are omitted in table 2.

Cast-iron and steel pipe had the most repairs. The repair rates (number of repairs divided by length of pipe) indicate that asbestos-cement and plastic (PVC) pipe were the best performers and steel was the worst. This poor performance of steel pipe seems, at first reading, unusual because welded steel pipe is commonly assumed to perform better in earthquakes than castiron, asbestos-cement, or PVC pipe. As shown below, the relatively "worse" performance of steel pipe was found to reflect EBMUD's modern (post-1950) practice of installing only steel pipe in poor-soil areas; had EBMUD's practice been otherwise, a higher level of damage to the water-distribution system would likely have occurred.

The good performance of asbestos-cement and PVC pipe was also reported at other sites closer to the earthquake epicenter. This performance was attributed to their rubber-gasketed articulated joints, which provide flexibility to withstand seismic ground movements (Pickett and others, 1991). 
The distribution of actual earthquake repairs in EBMUD's service area is mapped in figure 2. Most repairs were west of the Oakland Hills, and notable concentrations are located in areas of deep fill and areas of liquefiable and corrosive bay mud or bay fill along the shores of Alameda Island and Oakland. Virtually all of the repairs shown on the south end of Alameda Island are for steel pipe. Steel pipe was used extensively here, and evidence was noted of modest soil movements, high-corrosivity soils, and, in some places, poor-quality construction that contributed to the high repair rate for steel pipe in this area. Still, repair rates would likely have been higher in this area if older cast-iron, asbestos-cement, or other weaker materials had been used.

\section{PIPE REPAIRS VERSUS SOIL UNIT}

The repair rates for cast-iron, asbestos-cement, and steel pipe according to soil unit are plotted in figure 4. (PVC pipe is not shown because of its small inventory.) For all pipe materials, a trend is evident for higher repair rates in bay mud or bay fill soils. The repair rates in bay mud or bay fill are about 10 times higher than in other soil units. Factors that promote higher repair rates in bay-mud or bay-fill soils include the following:

- Peak ground velocities (PGV's) in bay mud or bay fill were higher than in other soils because of site amplification. Ground-shaking damage to buried pipe is proportional to peak ground velocity.

- Bay mud or bay fill is most susceptible to permanent ground deformations (PGD's), which are particularly damaging to pipes. In a few areas with broken pipes, damage to road pavement was noticeable, possibly because of long-term settlements in these areas, not due to liquefaction. For about five pipes, clear evidence was observed of soil-liquefaction movements (more than a few inches), leading to pipe damage.

- Bay mud or bay fill is generally corrosive, thereby weakening metal pipe.

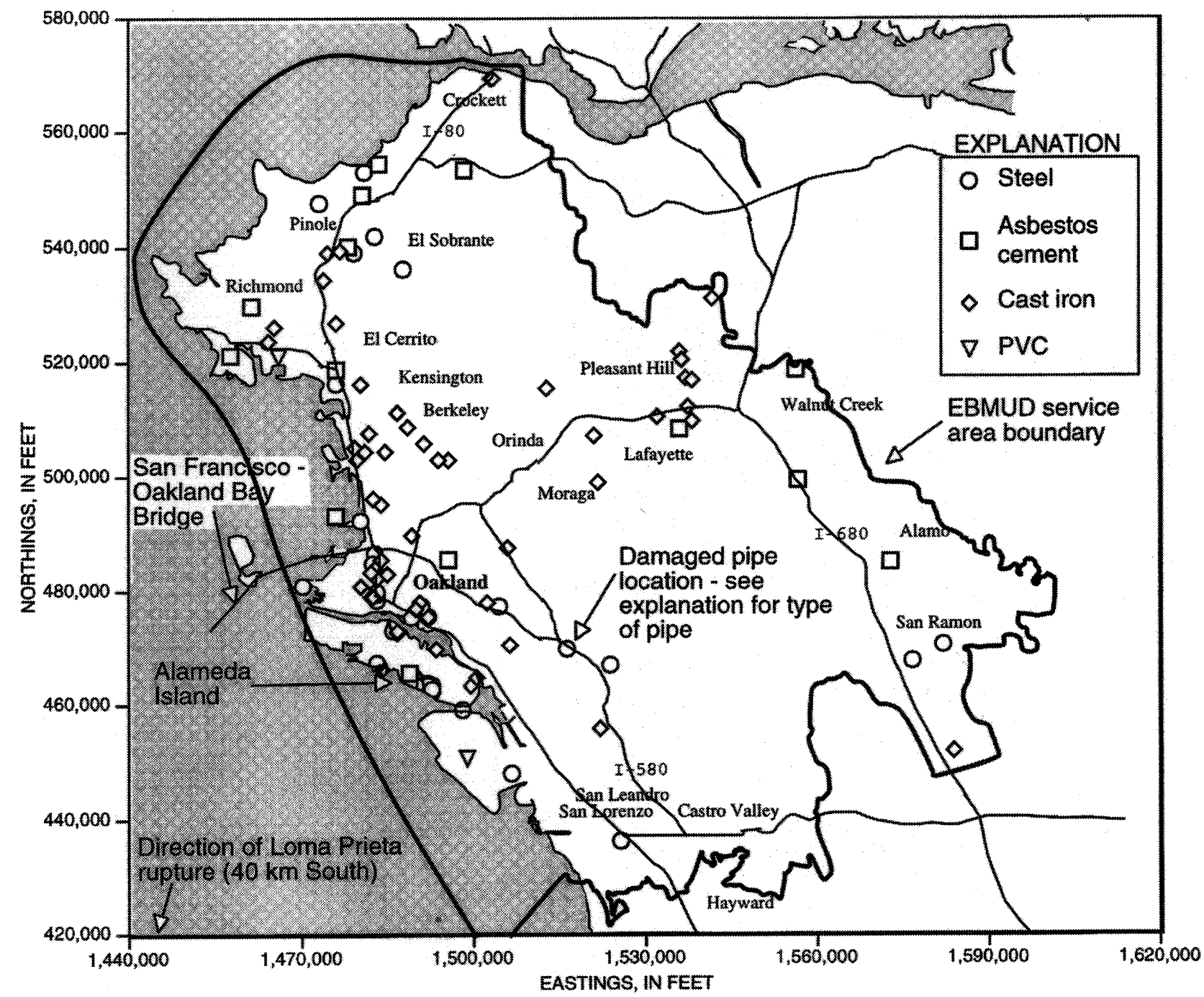

Figure 2.-East bay area, showing locations of pipe repairs due to earthquake. 


\section{PIPE REPAIRS VERSUS PIPE DIAMETER}

For cast-iron and asbestos-cement pipe, virtually all repairs were to pipes smaller than 12 -in. nominal diameter. Since most of the cast-iron and asbestos-cement pipes in the EBMUD water-distribution system are of small diameter, trend information on how pipe repairs were related to pipe diameter could not be reliably evaluated for these pipe types.

The repair rates for steel within two different diameter ranges are plotted in figure 5 . Note that smaller-diameter steel pipes had a higher repair rate, probably owing to two contributing factors. (1) Smaller diameter pipes tend to have a large number of bends, branches, and service laterals that produce virtual anchorpoints. These anchorpoints, in turn, contribute to damage under seismic motions. (2) Smaller-diameter pipes are thinner walled, making them more susceptible to corrosion.

Note that American Water Works Association-designed steel pipe using single-lap arc welds faired worse from ground shaking that would have been forecasted by using the damage algorithms of Ballantyne and others (1990). The actual damage to steel pipe appeared to be more a function of weld quality and corrosion than whether welds were by oxyacety- lene or electric arc. For example, poor-quality arc-welded pipes had higher repair rates than good-quality arc-welded pipes. Recent work by O'Rourke and Palmer (1996) corroborates this observation, suggesting that older oxyacetylenewelded pipes, with good-quality welds, may be more resistant to damage than has been suggested in some of the literature (for example, Ballantyne and others, 1990).

\section{PIPE REPAIRS VERSUS CORROSIVE SOILS}

The repair rates for cast-iron and steel pipe according to relative soil corrosivity are plotted in figure 6 . In areas where corrosion is not too important (noncorrosive and mediumcorrosivity soils), segmented cast-iron pipe fared worse than welded steel pipe, as expected, whereas in areas where corrosion is important (high-corrosivity soils), welded steel pipe fared worse than segmented cast-iron pipe. Note that both PGV's and PGD's in high-corrosivity soils vary considerably. Downtown Oakland, which has mostly cast-iron pipe and is in a high-corrosivity-soil area, had only about one-third the level of PGV relative to the dominantly steel pipe inventory

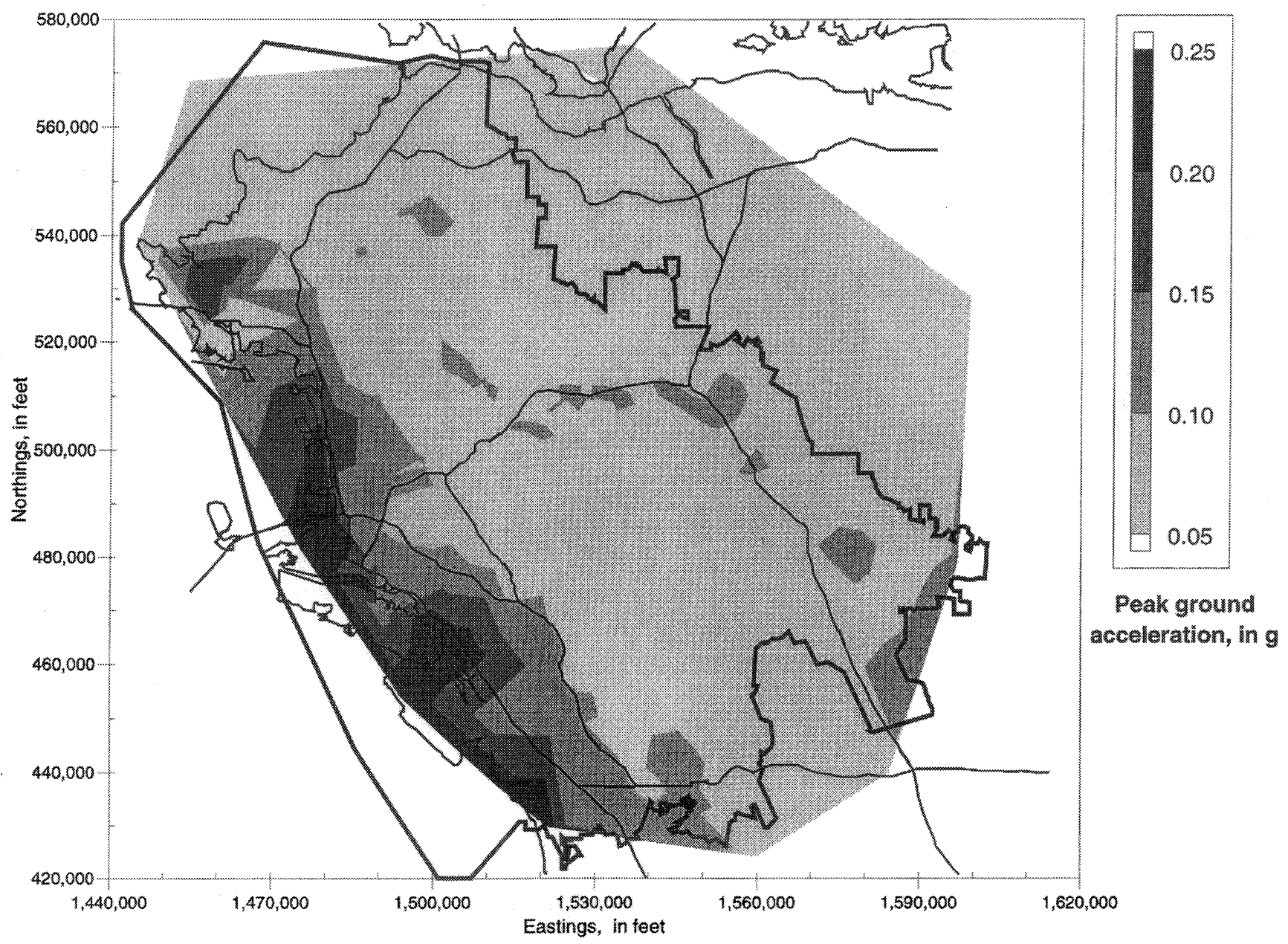

Figure 3.-East bay area, showing peak-ground-acceleration contours due to earthquake. 
located on Alameda Island in high-corrosivity soils. Although these factors tend to mask one another, the trend is that steel pipe is more susceptible than cast-iron pipe to corrosive-soil environments, all other factors being equal.

The repair rate for steel pipe versus diameter for the different corrosive soils is plotted in figure 7. Steel pipe shows the influence of diameter in high-corrosivity soils, with larger repair rates for smaller-diameter pipe than for large-diameter pipe. In figure 7, both PGV's and PGD's are relatively constant within each category, indicating that diameter dependency is important for steel pipe in high-corrosivity soils.

The data plotted in figures 6 and 7 indicate that corrosion effects are important for steel pipe and, to a lesser extent, for cast-iron pipe. (Note that most of the cast-iron and steel pipe inventory is in either medium- or low-corrosivity soils). Because corrosion is a continuing process, its effects should increase over the time since initial installation. The resulting repair rate according to the decade when the steel pipe was installed is plotted in figure 8 , showing that corrosion does have a time dependency and that older steel pipe has a higher repair rate.

The bulk of the damaged steel pipe in corrosive soils were installed in the late 1950's and early 1960's. These pipes are mortar lined and mortar coated, which was the most com-

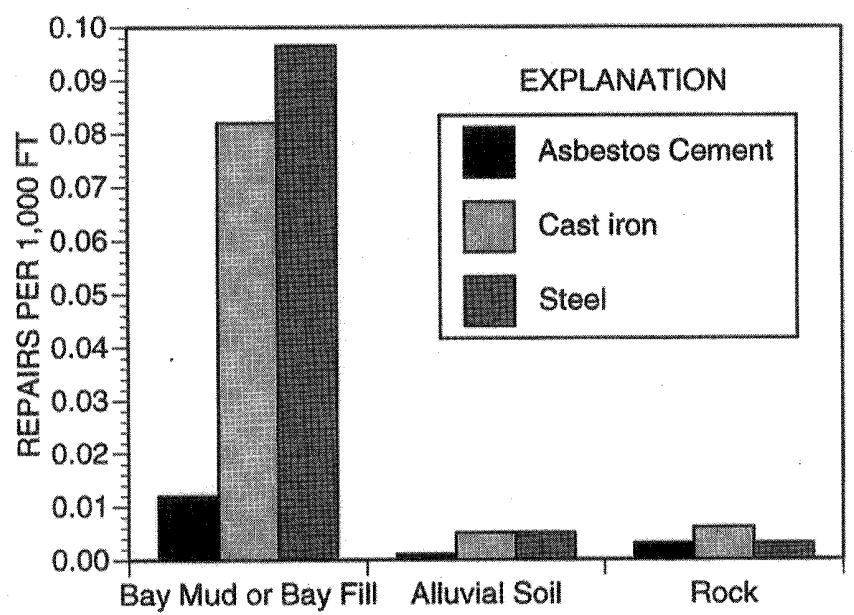

Figure 4.-Pipe-repair rate versus soil type.

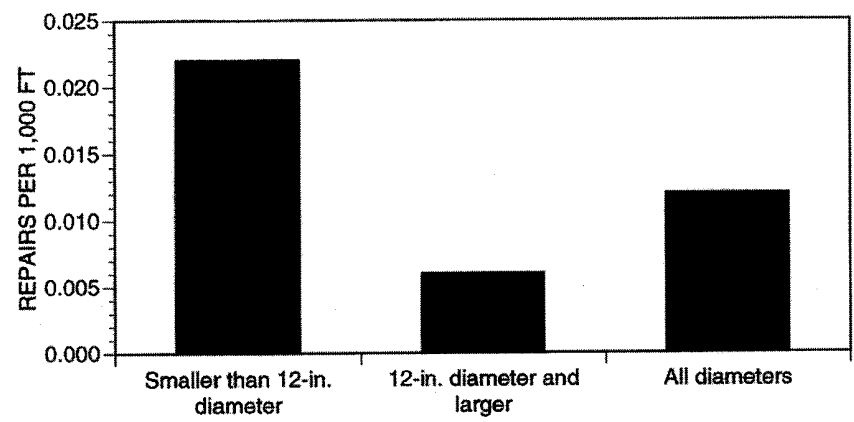

Figure 5.-Pipe-repair rate for steel pipe, by diameter.

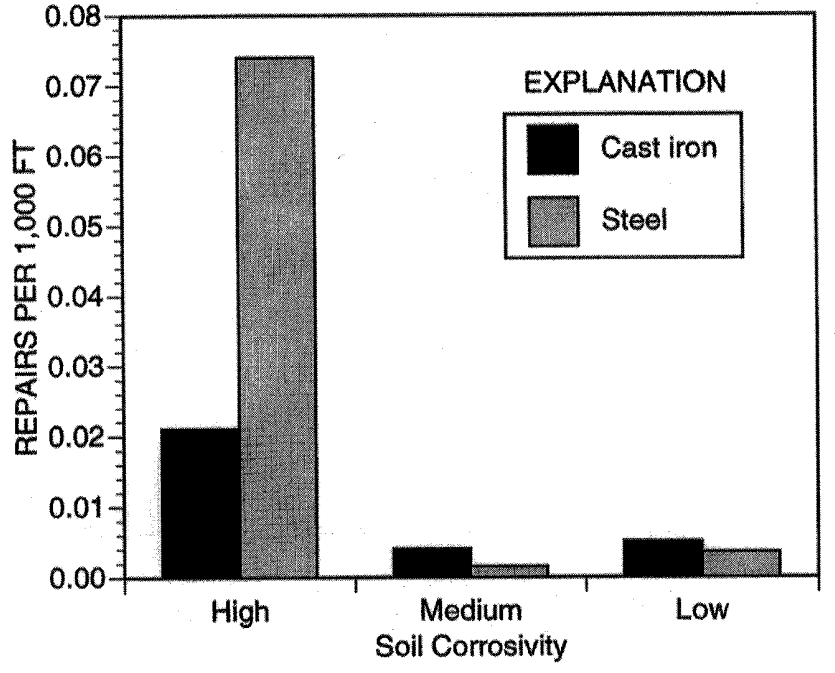

Figure 6.-Pipe-repair rate for cast-iron and steel pipe versus corrosive-soil type.

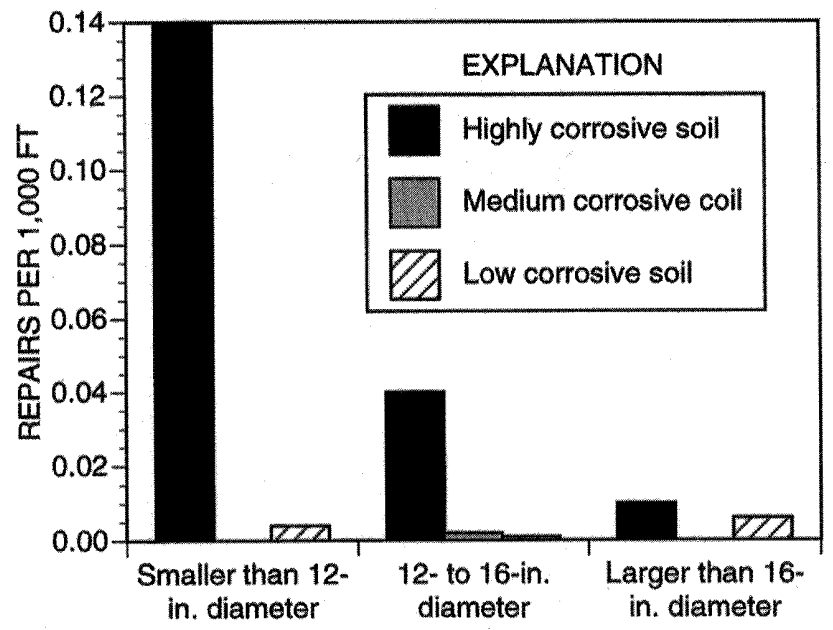

Figure 7.-Pipe-repair rate for steel pipe, by diameter and corrosive-soil type.

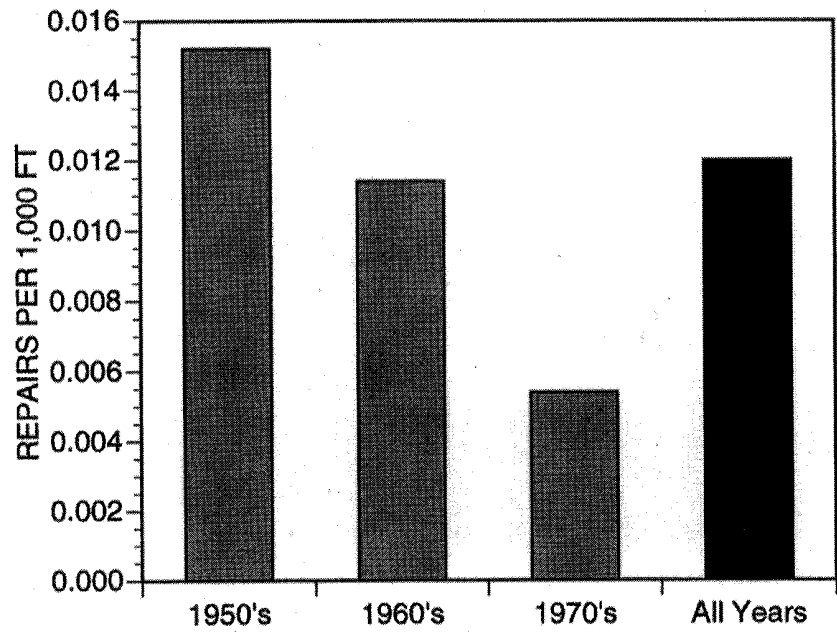

Figure 8.-Pipe-repair rate for steel pipe, by decade installed. 
mon installation of steel pipes in that era. More recently installed steel pipe (post-1970) use polyethylene, polypropylene, and tape-wrapped coatings. The different corrosion protection provided by these coatings, relative to mortar coating, was not studied.

\section{LOMA PRIETA EVIDENCE VERSUS THE DAMAGE ALGORITHMS OF BALLANTYNE AND OTHERS (1990)}

The pipe repair rates for the actual Loma Prieta earthquake data (digitized points) versus the pipeline-fragility curves of Ballantyne and others (1990) are plotted in figure 9. Note that the work by Ballantyne and others related piperepair rates to modified Mercalli intensity (MMI), whereas the current work relates pipe-repair rate to PGV. Accordingly, an MMI of VIII was equated to a PGV of $20 \mathrm{in} / \mathrm{s}$, which reasonably matches the empirical building damage versus instrumental readings. Similarly, an MMI of IX was equated to a PGV of $25 \mathrm{in} / \mathrm{s}$, and so on.

Although the Loma Prieta empirical repair rate at low PGV's (less than $10 \mathrm{in} / \mathrm{s}$ ) exceed those in Ballantyne and others (1990) by a large amount (factor of 10 or more), the low absolute values of these repair rates are not extremely important for overall system-analysis purposes. For example, by using the pipeline-fragility curves of Ballantyne and oth- ers and a PGV map similar to the peak-ground-acceleration map in figure 3 , we would predict a total of 155 repairs in the EBMUD water-distribution system, versus the actual 135 repairs (113 excluding service connections, 108 excluding service connections and PGD-attributed damage). This, on the whole, is a reasonable prediction; that is, given the wide range in empirical evidence as to pipe-damage rates, the fact that the prediction is within 20 to 40 percent is reasonable. However, the pipeline-fragility curves of Ballantyne and others are limited in that they (1) underpredict damage away from bay-mud or bay-fill shorelines and (2) overpredict damage in bay-mud or bay-fill shorelines. On the whole, these two effects tend to cancel each other, resulting in an overall reasonable prediction.

\section{PIPELINE-FRAGILITY CURVES}

The previous results summarize actual damage to EBMUD's pipes in the 1989 Loma Prieta earthquake and provide a known benchmark as to how EBMUD's buried pipe will perform in future earthquakes. From these and other data, we can develop empirical pipeline-fragility curves. Issues associated with pipeline-fragility curves include the following:

- Previous studies of past earthquakes have yielded repairrate data based on limited assessments. Many times large

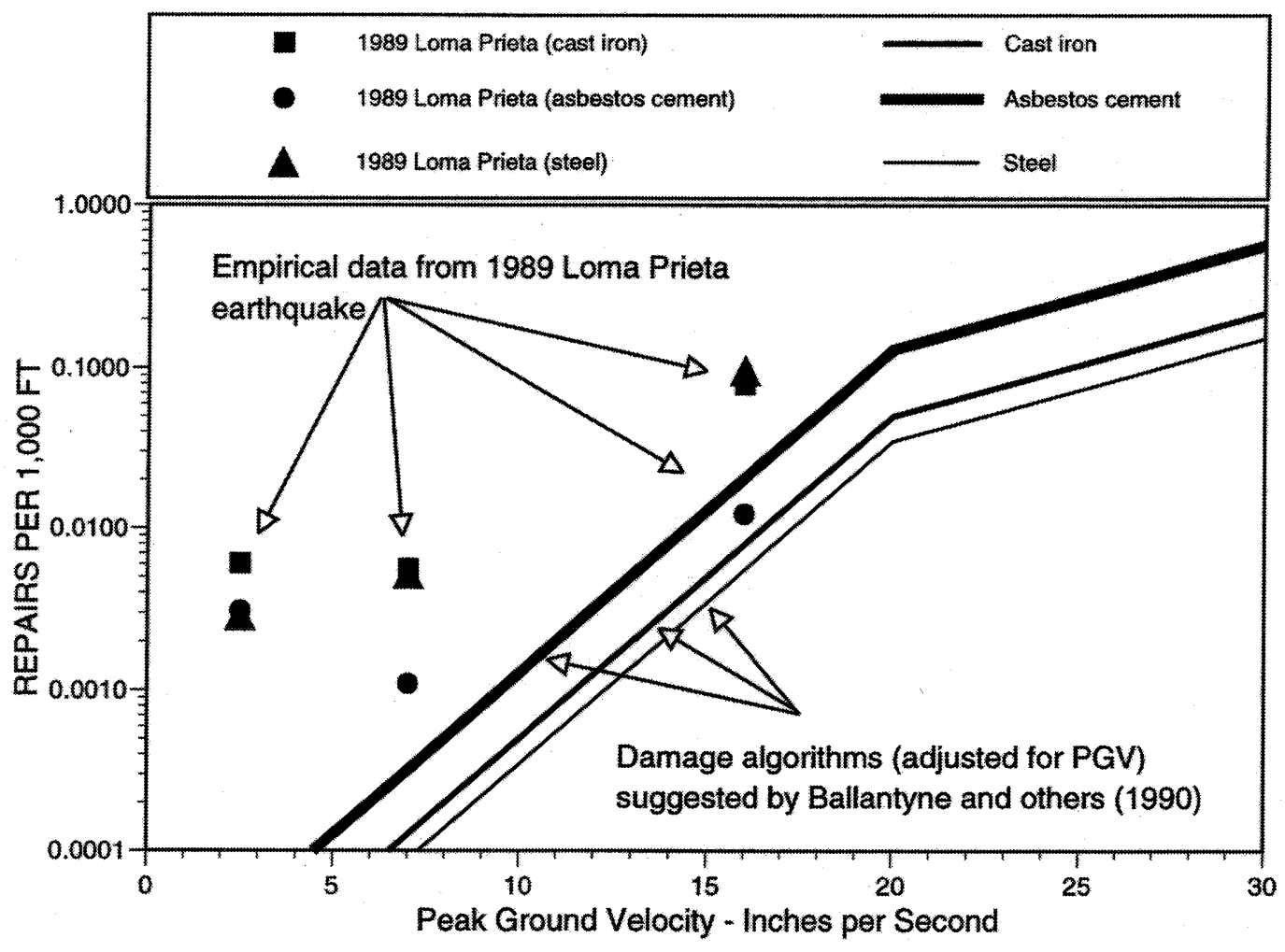

Figure 9.-Empirical pipe repair rate (symbols) compared to damage algorithms of Ballantyne and others (1990). 
areas were assigned a single MMI value, greatly ignoring microzonation issues. Many times, the actual mileage of pipe, pipe type, and level of shaking or induced PGD were estimated. Detailed attributes for every pipe (for example, age of installation, corrosive-soil conditions, type of joints) were commonly not tabulated. Data bases with detailed reviews of pipe damage are relatively limited.

- Most of the data collected to date are for earthquakes with relatively moderate levels of ground shaking. Most of these earthquakes generated ground-shaking levels in the range $0.10-0.30 \mathrm{~g}$ in those areas where the most pipe damage was reported. At these levels of ground shaking, most pipes actually are not damaged: a reported repair rate of 1 per 1,000 feet (a high repair rate) actually means that only 1 in 83 12-ft-long pipe segments actually fails. In other words, about 99 percent of the pipes are undamaged. Thus, the empirical evidence is mostly for repair rates in the "tails" of the pipe's fragility distribution.

- As correctly noted by Ballantyne and others (1990), earthquake-intensity data, such as MMI's for historical earthquakes, are mostly imperfect. For example, two different investigators can assign different intensities to the same data, as evidenced by assignments of MMI's of VIII or X to the city of Coalinga for the 1983 Coalinga, Calif., earthquake (Hopper and others, 1984, Thiel and others, 1987). The same is true for other measures of seismic intensity, such as peak ground acceleration, velocity, and vertical or lateral ground movements, particularly when these measures have been inferred on the basis of MMI data, not instrumental recordings. However, the city of Oakland was reasonably well instrumented in the 1989 Loma Prieta earthquake. The current study used 36 Oakland-area recordings (Geomatrix Consultants, 1992) in benchmarking pipeline-fragility curves to the earthquake: 24 horizontal and 12 vertical recordings (total).

- Ballantyne and others (1990) also noted that estimates of the pipeline exposed to the earthquake are generally approximate with respect to materials, joints, and total lengths of pipe. Few data are available that relate pipeline age or soil corrosivity to levels of damage. Repair data have often been reconstructed from the memory of workers or from incomplete or inaccurate data sets. One repair can be associated with several leaks in the same pipe barrel; conversely, one break can lead to several repairs. Although data on certain pipe materials can be complete at specific MMI's, they may not be complete for all pipe materials at all intensities. Given these weaknesses in past empirical pipeline-fragility data, the current study used rigorous geographic-analysis techniques to calculated the actual mileage of pipe in various soil types or ground-shaking levels, complete inventories of actual pipeline data by type, diameter, and so on, and a substantial number of instrumental recordings, supplemented by attenuation relations specific for this earthquake, and eliminated duplicated or nonearthquake damage records.
- Certain pipe materials and (or) joint units have only limited actual earthquake-performance data. Also, the quality of construction can vary among different countries or cities from which earthquake data were obtained.

- Repair data for some earthquakes represent data for limited lengths of pipe in high-intensity shaken areas; such data can lead to misleading damage trends, owing to smallsample-size effects.

- Repair data available in the literature commonly incorporate damage from ground shaking (wave propagation), as well as ground movements (for example, surface faulting, liquefaction, landslides). The quality of the process of disaggregating these data into components directly attributable to one type of earthquake hazard introduces additional uncertainty into the resulting data.

Such issues mean that judgment must be used in applying empirical data in the development of pipeline-fragility curves.

\section{DEFINITION OF SEISMIC MICROZONATION HAZARD FOR PIPELINE-FRAGILITY CURVES}

The pipeline-fragility curves incorporate refinements relative to the damage algorithms of Ballantyne and others (1990), or others proposed in the literature. As noted previously, most previous studies relate damage rates to MMI's. One major refinement is to develop a microzonation assessment for every pipe in a water distribution or transmission system. This microzonation assessment provides the following information:

- Peak ground accelerations are calculated at all pipe locations. These values adjust the rock-outcrop acceleration to account for soil-column-amplification/deamplification effects. For the EBMUD service area, soil amplifications have been based on actual recordings in the Oakland area (1989 Loma Prieta earthquake) in bay-mud, bay-fill, and alluvial-soil settings.

- PGV's are calculated at all pipe locations to account for local soil-amplification effects.

- The extent of liquefaction occurring in susceptible areas is considered at each pipeline-damage location. For a given earthquake, liquefaction will or will not occur. If it does occur, calculate the extent of PGD. Similarly, calculate whether soil movement occurs in landslide areas and, if it does, the extent of PGD.

The pipeline-fragility curves relate pipe performance to these three earthquake hazards as follows: (1) Groundshaking damage is related to PGV at the pipe location, (2) liquefaction damage is related to the amount and direction of lateral spreads and settlements (PGD), and (3) landslide damage is related to the amount of movement of the slide area (PGD).

Although pipe deformations are better described in terms of ground strain, the geotechnical community is not currently 
able to make such predictions on a regional basis. However, using PGD as the geotechnical "predictor" when properly corrected to empirical data is still useful for regional estimation purposes.

\section{GROUND-SHAKING ALGORITHMS}

New buried-pipeline-fragility curves were developed that correlate pipeline-repair rates to input ground shaking (PGV) or ground deformations (PGD). These fragility curves were further described by Eidinger and others (1995). The following paragraphs highlight the methodology.

The pipeline-fragility data plotted in figure 10 (groundshaking effect only) are based on the empirical evidence of the combined data set for all pipe materials from the 1965 Puget Sound, Wash., 1969 Santa Rosa, Calif., 1971 San Fernando, Calif., 1983 Coalinga, Calif., 1985 Mexico City, 1989 Tlahuac, Mexico, and 1989 Loma Prieta, Calif., earthquakes. Each data point represents the observed repair rate for a class of pipe exposed to similar motions. The data presented have not been adjusted to account for magnitude-duration effects, which could explain the higher damage rates reported in the Mexico City lakebed area (more than 1 minute of shaking, three data points).

The best-fit pipeline-fragility curve through the data in figure 10 is given by $n=0.00032$ (PGV) ${ }^{1.98}$, where $n$ is the number of repairs per $1,000 \mathrm{ft}$ and PGV is in inches per second. This curve should be multiplied by a dimensionless constant, $K_{1}$ (table 3), to account for various pipe materials (that is, total repair rate $=K_{1} n$ ). The "quality" column in the table describes the confidence in the current empirical data (quantity and completeness) to support the relative $K_{1}$ factors. In suggesting the "quality" of the data, " $\mathrm{B}$ " suggests that there is a reasonable amount of backup empirical data and study, "C" suggests that there are limited empirical data and study, and " $\mathrm{D}$ " is based largely on extrapolation and judgment, with only limited empirical data. The absence of " $\mathrm{A}$ " ratings suggests that there is still much room for future improvement in our current understanding of buried-pipeline earthquake fragility.

The seismic hazard is defined by the expected PGV at the pipe-segment location. The seismic hazard depends on the earthquake magnitude, distance to the fault rupture, attenuation characteristics, and local soil conditions.

\section{LEAK/BREAK DISTRIBUTION}

On the basis of experience from other earthquakes, pipe damage can be classified as two types: (1) breaks typically associated with longitudinal cracks, splits, ruptures, and complete circumferential failures; and (2) leaks typically associated with joint failure, partial circumferential failures, and corrosion-related failures (pinholes and small blowouts). For pipe smaller than 12 -in. diameter, $1 / \%$ of the damage is as-
Table 3.-Values of the ground-shaking constant $\mathrm{K}_{1}$ for pipelinefragility curves.

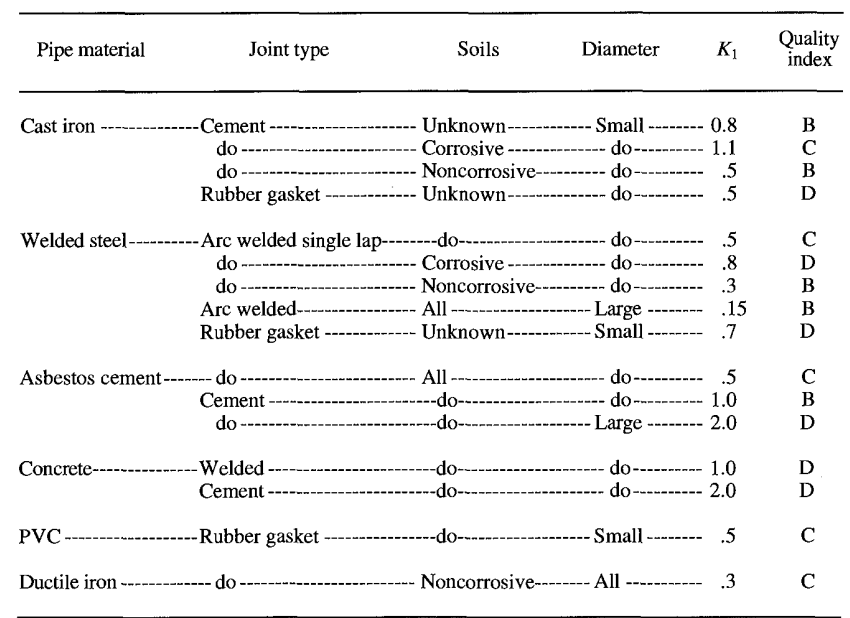

signed to breaks, and $5 / 6$ to leaks. This breakdown is based on empirical evidence from past earthquakes. The type of repair performed is generally the same for breaks as for leaks. Functionally, a break will disrupt water service, whereas some water service can be sustained if the pipe is only leaking.

For pipe of 12-in. diameter or larger, the repair rates are adjusted such that half of the damage is assigned to breaks and half to leaks, reflecting the damage to EBMUD's largediameter steel pipe in the 1989 Loma Prieta earthquake. This assignment considers that large-diameter pipes have fewer service connections, fewer hydrant laterals, and are generally less prone to corrosion than small-diameter pipes. All the damage to steel pipelines in the 1965 Seattle, Wash., earthquake was reported to be corrosion related; however, this was not found to be the case in the 1989 Loma Prieta earthquake.

When using these pipeline-fragility curves, it should be assumed that the leaks projected in earthquakes include broken service connections and miscellaneous appurtenances to main distribution pipes, up to the meter location to the customer. Service-connection breaks in pipe of about 1-in. diameter are functionally equivalent to leaks in the largerdiameter pipe main. These curves do not include damage to service lines on the customer side of the meter; the amount of such damage has been extensive in past earthquakes. For the first few hours to days after the earthquake, water lost through broken service lines will tend to depressurize the main water system, until such time when the service line is valved out at the meter.

\section{LIQUEFACTION AND LANDSLIDE ALGORITHMS}

The seismic hazard is defined by the amount of PGD caused by either soil liquefaction or landslide. The repair rate depends on the magnitude of PGD sustained by a par- 
ticular pipe segment. A regional geotechnical model that can be used to predict liquefaction and landslide PGD's was presented by Risk Management Solutions (1997).

For liquefaction in bay mud or bay fill, PGD's include both lateral spreading and vertical settlement. For liquefaction in young alluvial soils, PGD's are primarily from vertical settlement. The probability of liquefaction in these soils depends on peak ground acceleration at the site and on earthquake magnitude. For bay mud or bay fill, the amount of lateral PGD depends on the peak ground acceleration, the distance from the shoreline, and the duration of ground shaking. The PGD direction is assumed to be toward the shoreline. For vertical settlement, the amount of settlement depends on the duration of ground shaking. The total PGD is taken as the vector sum of the lateral and vertical components.

Landslides can occur in mapped landslide zones and the probability of occurrence is dependent on the season (winter/summer), the peak ground acceleration at the site, and the duration of ground shaking. The amount of lateral PGD is dependent on season, the peak ground acceleration, and the earthquake magnitude.

For pipe damage due to landslides, all damage is assigned to breaks. Landslides are generally associated with relatively large PGD's, resulting with many breaks.

The corresponding pipeline-fragility curve for estimating pipe repairs due to PGD's is given by $n=1.03$ (PGD) ${ }^{0.53}$, where $n$ is the repair rate per $1,000 \mathrm{ft}$ of pipe and PGD is in inches. The fragility data for cast-iron pipe are plotted in figure 11. As with ground shaking, this curve should be multiplied by a constant, $K_{2}$, to account for pipe materials and joinery (table 4). Most empirical damage data were for pipes located in poor-soil areas, and so a soil-corrosivity index is implied in the empirical data. Damage to pipelines due to liquefaction and landslides can be based on the same formulation; however, PGD's due to landslides are generally much larger than those due to liquefaction. A refinement for soil corrosivity could be made but is not covered in this paper. With the exception of cast-iron pipe (mostly smaller diameter), the empirical evidence is very limited, as denoted by the quality index. The recent 1995 Kobe, Japan, earthquake showed much higher break rates than expected for ductileiron pipe with mechanical or tyton joints $\left(K_{2} \sim 0.5\right)$, although pipes fitted with special slip joints capable of 2 to 3 in. of movement at every joint did quite well in moderate PGD's $\left(K_{2}<0.1\right)$; more study of ductile-iron and special-slip-joint performance is clearly mandated.

\section{LEAK/BREAK DISTRIBUTION}

For pipe damage due to liquefaction, half of the damage is assigned to breaks, and half to leaks.

\section{SIMULATION OF PIPE DAMAGE IN FUTURE EARTHQUAKES}

This section briefly describes the use of the pipelinefragility curves for earthquake analyses: benchmarks using the known Loma Prieta 1989 earthquake, and forecasts for future postulated scenario earthquakes.

For the 1989 Loma Prieta earthquake, the results of

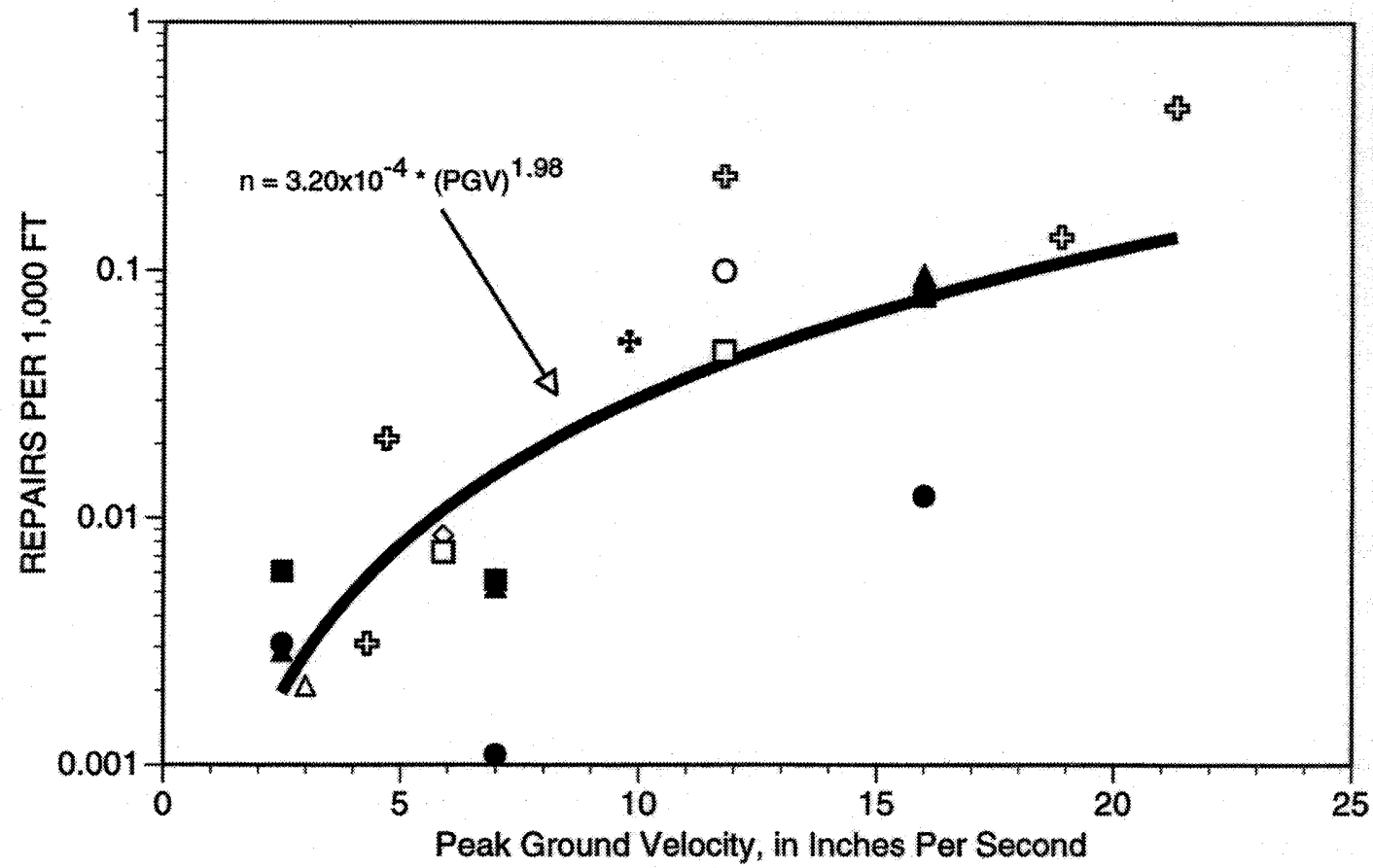

EXPLANATION

1989 Loma Prieta (cast iron)

1989 Loma Prieta (asbestos cement)

$\triangle 1965$ Puget Sound

$\diamond 1969$ Santa Rosa

1971 San

Fernando

1983 Coalinga

4. 1985 Mexico City

* 1989 Tlahuac 1989 Loma Prieta (steel)

Figure 10.-Pipe-repair-rate fragility curve versus ground shaking only. 
Table 4.-Values of the permanent-ground-deformation constant $\mathrm{K}_{2}$ for pipeline-fragility curves.

\begin{tabular}{|c|c|c|}
\hline Pipe material & $K_{2}$ & $\begin{array}{l}\text { Quality } \\
\text { index }\end{array}$ \\
\hline $\begin{array}{r}\text { Cast iron - }-1- \\
\text { Rubber gasket, mechanical --- }\end{array}$ & $\begin{array}{r}1.0 \\
.7\end{array}$ & $\begin{array}{l}\mathrm{B} \\
\mathrm{C}\end{array}$ \\
\hline 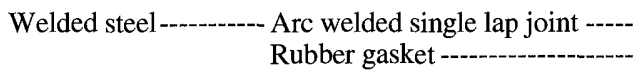 & $\begin{array}{l}.15 \\
.7\end{array}$ & $\begin{array}{l}\mathrm{C} \\
\mathrm{D}\end{array}$ \\
\hline Asbestos cement-- $\quad$ Cement-- do-- & $\begin{array}{r}.8 \\
1.0\end{array}$ & $\begin{array}{l}\mathrm{C} \\
\mathrm{C}\end{array}$ \\
\hline Concrete-1- & $\begin{array}{r}.8 \\
1.0\end{array}$ & $\begin{array}{l}\mathrm{D} \\
\mathrm{D}\end{array}$ \\
\hline PVC -- & .8 & $\mathrm{C}$ \\
\hline Ductile iron - - & .3 & $\mathrm{C}$ \\
\hline
\end{tabular}

Table 5.-Predicted number of pipeline repairs to the EBMUD water-distribution system due to a repeat of the 1989 Loma Prieta earthquake.

\begin{tabular}{|c|c|c|c|}
\hline & \multicolumn{3}{|c|}{ Number of repairs } \\
\hline & High & Low & Mean \\
\hline Total - & 161 & 108 & 138 \\
\hline Ground shaking -------- & 79 & 63 & 72 \\
\hline Liquefaction - & 86 & 41 & 66 \\
\hline Landslide--------_------- & 0 & 0 & 0 \\
\hline Fault crossing -- & 0 & 0 & 0 \\
\hline
\end{tabular}

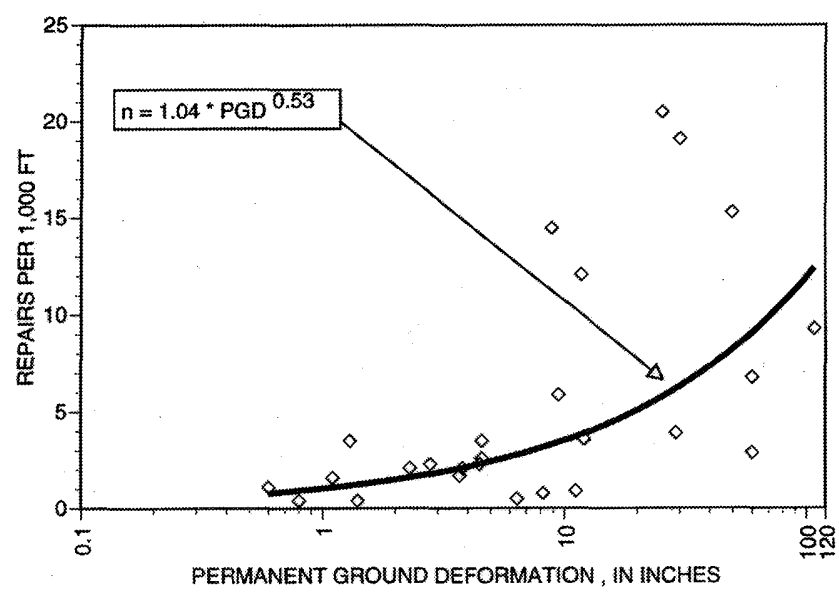

Figure 11.-Pipe-repair-rate fragility curve versus permanent ground deformation.
Table 6.-Predicted number of pipeline repairs to the EBMUD water-distribution system due to future large earthquakes, with or without lateral spreading in young alluvial soils.

\begin{tabular}{|c|c|c|c|c|}
\hline \multirow[t]{2}{*}{$\begin{array}{l}\text { Scenario } \\
\text { earthquake }\end{array}$} & \multicolumn{2}{|c|}{$\begin{array}{l}\text { Number of pipe repairs } \\
\text { with lateral spreading } \\
\text { in young alluvial soils }\end{array}$} & \multicolumn{2}{|c|}{$\begin{array}{l}\text { Number of pipe repairs } \\
\text { without lateral spreading } \\
\text { in young alluvial soils }\end{array}$} \\
\hline & Summer & Winter & Summer & Winter \\
\hline Hayward fault $(M=7)$-------. & 4,700 & 5,500 & 3,250 & 4,025 \\
\hline Hayward fault $(M=6)$ & 740 & 1,100 & 720 & 1,080 \\
\hline Calaveras fault $(M=6.75)$ & 860 & 990 & 600 & 725 \\
\hline Concord fault $(M=6.5)$ & 350 & 420 & 310 & 380 \\
\hline
\end{tabular}

systemwide analyses are listed in table 5 . These analyses predicts an average of 138 pipe repairs. This result compares well with the actual number of reported EBMUD repairs of 135.

Modifying the geotechnical model to adjust the potential for landslides in summer or winter conditions and the potential for lateral spreading in young alluvial soils moderately susceptible to liquefaction results in the predictions listed in table 6 . These results show that variances in the geotechnical model assumptions can lead to significant differences in the amount of predicted pipe damage.

A comparison of the results from analyses using the damage algorithms of Ballantyne and others (1990) with those using the updated pipeline-fragility curves indicates:

- The updated pipeline-fragility curves predict somewhat fewer repairs. The repair range predicted for the 1989 Loma Prieta earthquake is from 108 to 161 , whereas the repair range predicted using the damage algorithms of Ballantyne and others (1990) is from 135 to 179.

- The updated pipeline-fragility curves predict the distribution of repairs throughout the EBMUD service area better than the dispersion from using the damage algorithms of Ballantyne and others (1990), which predict too few ground-shaking-related repairs and a much tighter geographic distribution of pipe repairs relative to what was actually observed in the 1989 Loma Prieta earthquake.

\section{DAMAGE TO OTHER EBMUD FACILITIES}

Included in EBMUD's water-distribution system are 6 water-treatment plants, 175 treated-water reservoirs (mostly tanks), 125 pumping plants, and 23 office, warehouse, and maintenance buildings. As of 1988, there were 284 individual facilities (some sites include 2 or more facilities). For the most part, damage to these 284 facilities was either none or slight. This observation is attributed to the following factors:

- Ground-shaking levels at the 284 facilities were modest, generally ranging from 0.04 to $0.10 \mathrm{~g}$ (see fig. 3). Along the San Francisco Bay shoreline, where bay-mud deposits 
amplified motions to more than $0.20 \mathrm{~g}$, EBMUD has no above-ground water-system facilities.

- EBMUD has had longstanding practices to design its facilities for some level of earthquake motions. Only six facilities predate 1930, when the first seismic standards were used; however, each of these six facilities has since been seismically retrofitted to at least a minimum seismic capability.

- About half of the 284 facilities were built by using an equivalent base-shear value of either 10 or 13 percent of gravity (those built from 1935 to 1973).

- Beginning in 1973, EBMUD instituted self-imposed seismic standards that generally exceed the minimum seismic standards of the Uniform Building Code (UBC).

- Beginning in 1985, EBMUD adopted many provisions of the Applied Technology Council (ATC)'s specification ATC 3-06, as well as modern AWWA and API tank-design considerations. Pseudo-site-specific ground motions were used for all facilities within $6 \mathrm{mi}(10 \mathrm{~km})$ of active faults.

- Beginning in 1995, EBMUD updated its seismic standards to reflect current understanding of site specific ground motions, ductility considerations, and importance and redundancy issues. Before application of importance factors ( $\mathrm{I}=1,1.25$, or 1.5), site-specific PGA's can reach as high as $0.6 \mathrm{~g}$ for sites immediately adjacent to active faults.

Even so, some level of seismic damage did occur at a few facilities. Not all of this damage was immediately identified after the earthquake. The following paragraphs summarize the damage.

Office building.-Built to the 1988 UBC, this building is located in downtown Oakland on a firm-soil site. Probable ground motions at this site were in the range $0.05-0.10 \mathrm{~g}$. The building is a moment-resistant steel-frame structure, designed to $Z=0.4 \mathrm{~g}$ and $I=1.0$, following the UBC code. At the time of the earthquake, the structure was still under construction. The steel frame was essentially complete. Some external cladding (concrete panels) were dislodged in the earthquake.

Open-cut lined reservoir.-Built in 1956, this reservoir has storage capacity of 50 million gal. The reservoir is built into the ground. A precast concrete roof system covers the reservoir. Interior inspections in 1992 revealed that about 1 to 2 percent of the concrete panel to column connections had been dislodged. In a few locations, steel bars were exposed. From the outside, damage to the roof would not be apparent to the casual observer. Most likely, this site underwent ground motions in the range $0.10-0.15 \mathrm{~g}$. The original design basis for the roof was likely an equivalent static load of 0.10 times the weight of the roof. The damage was considered severe enough to preclude people from walking on the roof; however, the reservoir remains in service (through 1996). Currently, there are conceptual plans to retrofit the roof, but high cost and perceived modest benefit of such retrofit may preclude or postpone its implementation.

Steel tank.-The tank is built on grade. Most likely, this site underwent ground motions in the range $0.05-0.10 \mathrm{~g}$. The steel roof beams were severely twisted. The damage was ascribed to wave sloshing forces from the earthquake (but could have predated it?). From the age of this tank, it is unclear whether the roof system had been designed to withstand any hydrodynamic forces. (The main tank and its anchorage system were designed for earthquake forces.)

Pump station.-The building for one pump station in the Berkeley area (PGA, 0.05-0.10 g) was reported as being moderately damaged. The damage to the structure did not disrupt operation of the pumping plant, because the electrical and mechanical equipment were undamaged.

Power outages.-The earthquake caused widespread power outages in the EBMUD system. Generally speaking, the duration of these outages were under 24 hours. Due to the limited damage to buried pipes (except in shoreline areas), water-leak rates were modest, and no customers lost water supply attributable to loss of electric power.

Customer outages.-Less than 2 percent of EBMUD's 440,000 customers (one customer $=$ one billing account) lost water service as a result of the earthquake. Most of those customers that lost water service were located in areas with broken water pipes. Water service to these customers was restored as soon as pipe breaks were repaired (within 3 days).

Water losses.-One large pipe break (16-in.-diameter cast-iron pipe) was not located immediately after the earthquake. EBMUD's real-time data-acquisition system showed an unusual drawdown of water from a 150-million-gal reservoir. The earthquake occurred in the early evening, but the significance of the leak rate was not noted until well after dark. The pipeline break was found several hours after the earthquake, by tracing the pipelines leading from the reservoir, using flashlights. This pipeline break had probably not been identified earlier because the break location was in a field location with few, if any, people passing by. Another large raw-water-pipeline leak (60-in. diameter) occurred, forcing the closure of one of the water treatment plants. The area served by that treatment plant was also served by a second treatment plant, and so this pipeline break caused no customer outages. Postearthquake investigations of this 60 -in.diameter pipeline identified numerous poor welds (shop welds, not field welds) along the helical coil; the pipeline has since been entirely replaced.

\section{RECOMMENDATIONS}

The pipeline-fragility curves for buried pipelines, ca. 1996, still have room for improvement (see "quality index," tables 3,4). Rapid postearthquake field investigations are insufficient to add precision to these curves. The analysis of pipe vulnerability due to soil deformation (liquefaction and landslides) for the earthquake-affected area is essential if we are to learn from earthquakes what factors are most critical to causing buried-pipe failures. The use of geographic-analysis techniques should play a key role in this evaluation. This type 
of research is needed to develop more reliable designs for future pipeline installations for water utilities.

\section{ACKNOWLEDGMENTS}

This research was made possible by the collaboration of several engineers and scientists, including Bruce Maison, Robert Lau, and Joseph Young of the East Bay Municipal Utility District and Maury Power, John Egan, and Chuck Taylor of Geomatrix Consultants. Their efforts are greatly appreciated.

\section{REFERENCES CITED}

Ballantyne, D.B., Berg, E., Kennedy, J., Reneau, R., and Wu, D., 1990, Earthquake loss estimation modeling for the Seattle water system: report to U.S. Geological Survey under Grant 1408-0001-G1526.

Buel, B., 1998, Water supply emergency after action report: McKinleyville Community Services District.

Eidinger, J.M., Maison, B., Lee, D., and Lau, B., 1995, East Bay Municipal Utility District water distribution damage in 1989 Loma Prieta earthquake, in U.S. Conference on Lifeline Earthquake Engineering, 4th, San Francisco, 1995, Proceedings: American Society of Civil Engineers, Technical Council on Lifeline Earthquake Engineering Monograph 6.

Geomatrix Consultants, 1992, Strong motion recording stations, Loma Prieta earthquake, from assessment of earthquake-related geological/geotechnical hazards; Water System Seismic Evaluation Program, phase I: East Bay Municipal Utility District Report $1990 \mathrm{H}$.

Hopper, M.G., Thenhaus, P.C., Barnhard, L.M., and Algermissen, S.T., 1983, Damage survey in Coalinga, California, for the earthquake of May 2, 1983, in Bennett, J.H., and Sherburne, R.W., eds., The 1983 Coalinga, California earthquakes: California Division of Mines and Geology Special Publication 66, p. 5-8.
Isenberg, J., 1978, Seismic performance of underground water pipelines in the southeast San Fernando Valley in the 1971 San Fernando earthquake: New York, Weidlinger Associates, Grand Report 8.

1979, Role of corrosion in water pipeline performance in three U.S. earthquakes: U.S. National Conference on Earthquake Engineering, 2d, Stanford, Calif., Proceedings.

Isenberg, J., and Taylor, C.E., 1984, Performance of water and sewer lifelines in the May 2, 1983, Coalinga, California earthquake, in Lifeline earthquake engineering, performance, design and construction: New York, American Society of Civil Engineers.

National Board of Fire Underwriters, 1933, Report on the City of Oakland, California: Report 134.

Newby, A.B., 1954, Pipelines ride the shockwaves: San Francisco, Pacific Coast Gas Association Proceedings 45.

O'Rourke, T.D., and Tawfik, M.S., 1983, Effects of lateral spreading on buried pipelines during the 1971 San Fernando earthquake, in Earthquake behavior and safety of oil and gas storage facilities, buried pipelines and equipment (PVP volume 77): New York, American Society of Mechanical Engineers.

O'Rourke, T.D., and Palmer, M.C., 1996, Earthquake performance of gas transmission pipelines: Earthquake Spectra, v. 12, no. 3, p. 493-527.

Pickett, M.A., Laverty, G.L., Abu-Yasein, O.A., and Lay, C., 1991, Lessons learned from the Loma Prieta earthquake: American Water Works Association Journal.

Risk Management Solutions, 1997, Development of a standardized earthquake loss estimation methodology: report prepared for the National Institute of Building Sciences.

Singhal, A.C., 1984, Nonlinear behavior of ductile iron pipeline joints, Journal of Technical Topics in Civil Engineering, v. 110 , no. 1, p. 29-37.

Thiel, C.C., Jr., and Zsutty, T.C., 1987, Earthquake parameters and damage statistics: San Francisco, Forrell/Elsessor Engineers.

Wang, L., 1990, A new look into the performance of water pipeline systems from 1987 Whittier Narrows, California earthquake: Norfolk, Va., Old Dominion University, Department of Civil Engineering Report ODU LEE-05. 
THE LOMA PRIETA, CALIFORNIA, EARTHQUAKE OF OCTOBER 17, 1989: PERFORMANCE OF THE BUILT ENVIRONMENT

\author{
LIFELINES
}

\title{
WATER-AND WASTEWATER-TREATMENT PLANTS
}

By William F. Heubach, Summit Technology Consulting Engineers;

and

Donald B. Ballantyne, EQE International

\section{CONTENTS}

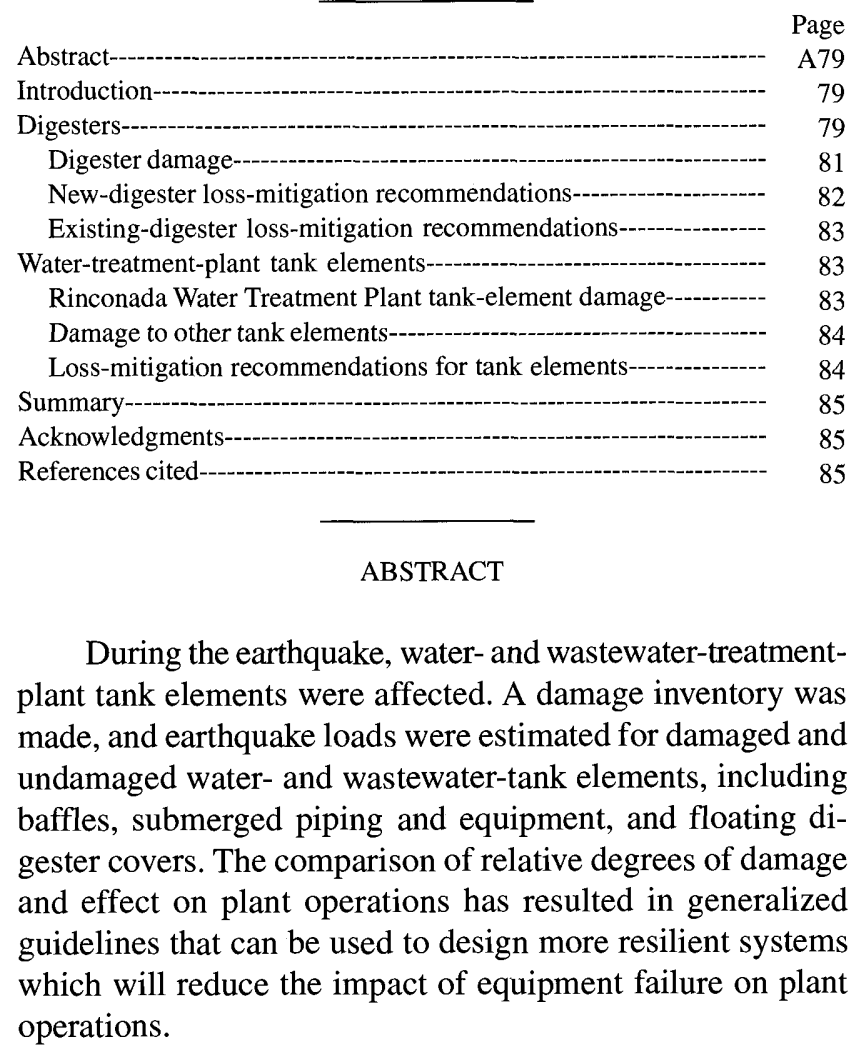

\section{INTRODUCTION}

The 1989 Loma Prieta earthquake was felt throughout central California and as far away as Los Angeles, Eureka, and western Nevada. Most metropolitan regions in the San Francisco Bay region were assigned a modified Mercalli intensity (MMI) of VI or VII; however, some areas, such as the Marina District of San Francisco and the area around the Cypress Street viaduct in Oakland, were assigned an MMI of IX. The epicentral area in the Santa Cruz Mountains was generally assigned an MMI of VII (Stover and others, 1990).

Although damage to water- and wastewater-treatmentplant tank elements was generally limited to the San Fran- cisco Bay region, significant damage to tank elements was reported as far away from the epicenter as the Sacramento Regional Wastewater Treatment Plant, approximately $100 \mathrm{mi}$ from the epicenter. The locations of some of the treatment plants addressed in this paper are shown in figure 1.

Most water- and wastewater-treatment-plant tanks are reinforced- and (or) prestressed-concrete structures. An inventory of the earthquake damage to water- and wastewatertreatment plants in the San Francisco Bay region revealed that basin and tank structures were not significantly damaged. Steel water-storage tanks built to American Water Works Association (AWWA) seismic specification D 100 also performed well. Generally, tanks that did sustain structural damage had not been constructed to AWWA seismic specification D 100.

Submerged and attached equipment in tanks, including floating tank roofs, were significantly damaged at some water- and wastewater-treatment plants. Repair costs ranged as high as $\$ 1.7$ million at one treatment plant.

In general, earthquake-load design standards do not exist for elements submerged and (or) attached to water- and wastewater-treatment-plant elements. Earthquake-induced loads are generally not considered when tank equipment is designed for treatment plants. Therefore, the level of earthquake damage to some San Francisco Bay region treatment plants is not surprising. In addition to summarizing the earthquake damage to various water- and wastewater-treatmentplant tank elements, this paper presents loss-mitigation recommendations.

\section{DIGESTERS}

Digesters are tanklike structures used in some wastewater-treatment processes. Raw sludge obtained from the settling of wastewater solids is pumped into digesters, where the volume of the solids is reduced by anaerobic bacterial digestion and gravity thickening. The digestion process can be accomplished by either a single digester tank or by a series of two tanks in which the raw sludge is decomposed by bacteria in the first tank and gravity-thickened in the second tank.

Many digester tanks use floating covers designed to move upward or downward when sludge is added or withdrawn. 


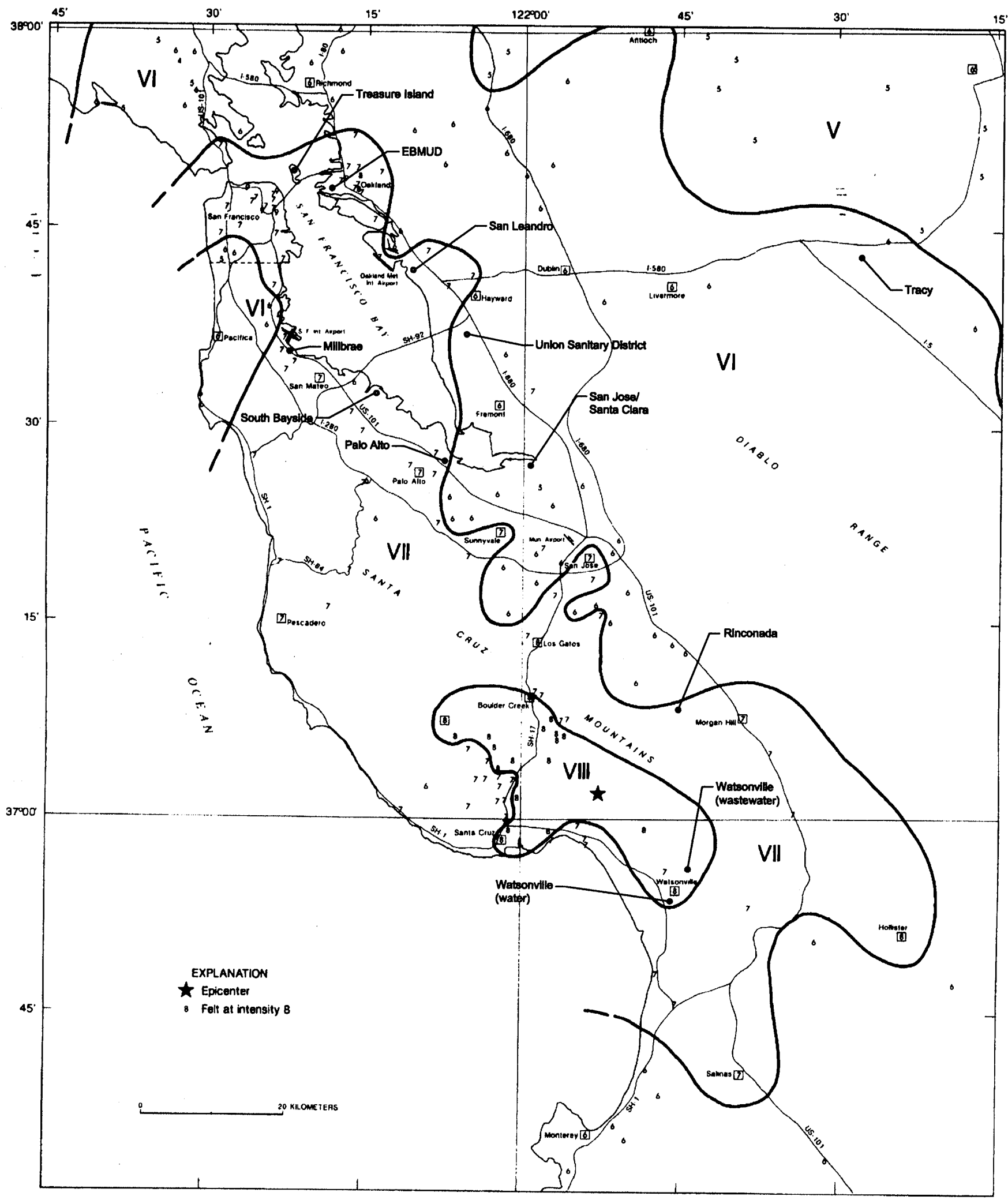

Figure 1.-San Francisco Bay region, showing locations of water- and wastewater-treatment plants studied and areas of modified Mercalli intensity (roman numerals). EBMUD, East Bay Municipal Utility District. From Stover and others (1990). 
Piping is used to transfer undigested sludge into the digester and to withdraw digested sludge, separated liquids (supernatant), and methane gas. Depending on the type of digester, heating equipment and mixing equipment, such as gas-injection tubing, may also be installed in the digester. A typical digester is shown in figure 2 .

\section{DIGESTER DAMAGE}

The basic digester-tank structural systems in wastewater-treatment plants affected by the earthquake performed very well. Generally, damage to nonstructural tank elements was due to sloshing digester liquid contents. The sloshing liquids caused floating digester roofs to rock up and down. Cover

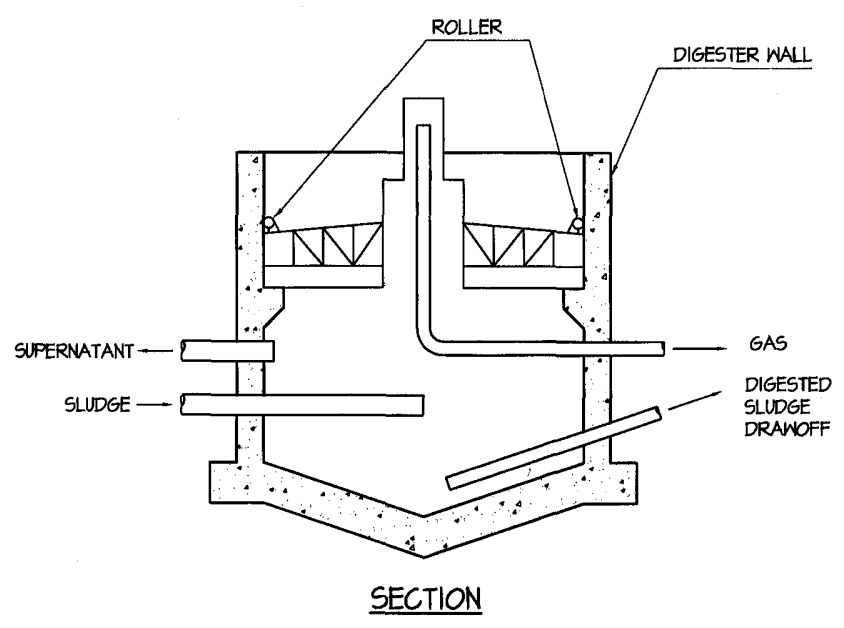

Figure 2.-Cross section of typical digester with floating cover.

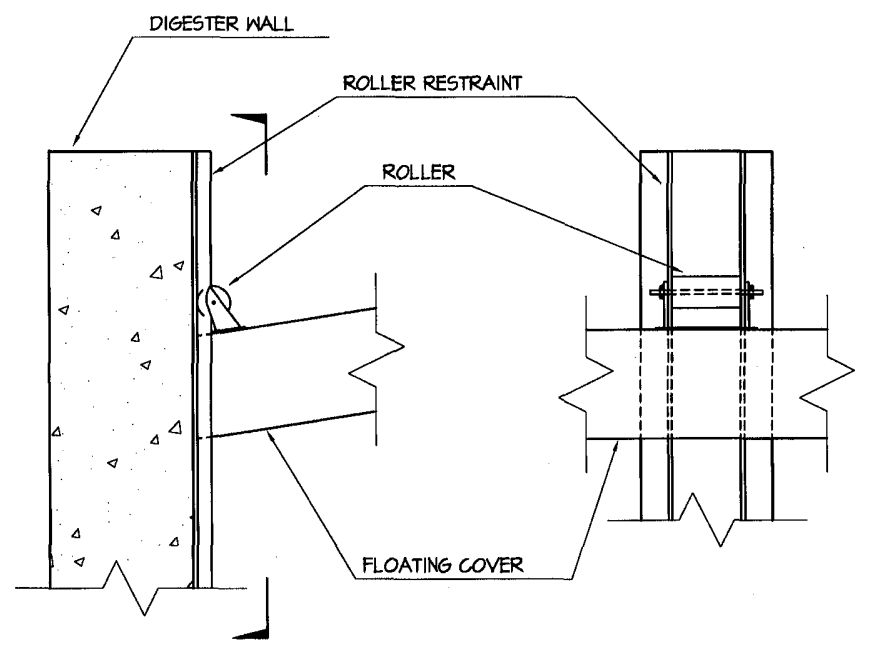

FLOATING COVER DETAIL

SECTION guides, designed to permit only uniform vertical movement of the digester roofs, were subjected to large horizontal forces as they resisted the horizontal component of the cover's displacement. Additionally, liquid turbulence, unsymmetric roof mass properties and (or) unsymmetric resistance of cover guides were the likely reasons why some covers rotated. Damage to digester elements, such as floating covers and cover guides, occurred at several treatment plants.

The area of the East Bay Municipal Utility District (EBMUD) wastewater-treatment plant in Oakland (near the Cypress Street viaduct) was assigned an MMI of VII. Most of the digesters at the plant use floating covers. Cover rotation is restricted by placing some of the rollers in slots (for example, fig. 3), using clips to travel in slots, or channels to guide clips attached to the digester covers.

Extensive damage occurred in the digester's cover-guide and antirotation assemblies. One digester cover rotated $4 \mathrm{ft}$. Typically, failure of the guide rollers occurred at the roller/ digester-cover interface. Roller/digester roof connections failed because of shearing of bolts and welds in the connection assemblies and (or) bending of the attachment brackets. Some of the tracks used to prevent rotation were bent by either rollers or guide clips.

No damage to digester flexible hoses or piping was reported. However, the fluids in one digester did slosh over the digester wall. Furthermore, corbels used to support access bridges between the digesters were damaged.

The MMI at the San Jose-Santa Clara Wastewater Treatment Plant, located near the southeast tip of San Francisco Bay, was likely V or VI. The floating digester covers at the plant are guided by cylindrical rollers attached to the top of the digester roofs by steel-clip assemblies. The rollers bear directly against the inside of the digesters' concrete walls. Rotational restraint is provided by cables that are connected between the roller attachments and metal clips bolted to the digester walls.

A total of 12 digesters rotated 6 to 8 in. counterclockwise. As was the case at the EBMUD wastewater-treatment plant in Oakland, roller-guide connections failed. On two digesters, rocking and rotation of the digester covers caused deflection of the gas-collection line that runs from the center of the digester covers and down the outside of the digesters. Eventually, the lateral pipe restraints connected to the digester walls failed. Differential movements between the rigid horizontal piping connected to the digester cover and the rigid vertical piping running down the digester wall caused the flexible rubber hosing between the two rigid sections to tear at the flange connection to the rigid vertical pipe. These two digesters had to be shut down until they could be repaired.

Three different types of digesters are used at the Sacramento Regional Wastewater Treatment Plant. The first type is about $90 \mathrm{ft}$ in diameter and uses a high dome-shaped floating cover. The guide and antirotation system is similar to that at the EBMUD wastewater-treatment plant in Oakland.

Figure 3.-Digester-roof roller-guide assembly. 
The second type of digester used at the Sacramento Regional Wastewater Treatment Plant is $100 \mathrm{ft}$ in diameter and has a flat, floating cover. Only one digester of this type is used at the plant, for sludge blending and storage. Guidance of the digester cover is accomplished with rollers and corkscrew-patterned curved tracks on the inner digester walls. The rollers and tracks are oriented so that as the digester cover rises and falls, the digester cover rotates. The corkscrew-patterned tracks force the digester roof to remain level as it rises and falls.

The third type of digester used at the Sacramento Regional Wastewater Treatment Plant has guide and antirotation systems that are similar to those at EBMUD's wastewatertreatment plant in Oakland. The digesters are $110 \mathrm{ft}$ in diameter. The covers are guided by rollers around the cover perimeter. Cover rotation is resisted by shaped plates that travel in vertical tracks bolted to the digester walls.

The Sacramento region was assigned an MMI of IV or V. Of the three different types of digesters used at the Sacramento Regional Wastewater Treatment Plant, only the third type of digester was damaged. As was the case at EBMUD's wastewater-treatment plant in Oakland, the roller/clip attachments to the digester covers failed when the bolts and roller brackets were sheared.

Unlike the digesters at EBMUD's wastewater-treatment plant in Oakland, digesters of the third type used at the Sacramento Regional Wastewater Treatment Plant mix their contents by gas injection. Piping, which is attached to the interior of the digester covers and fits into stationary draft tubes attached to the digester floors, was bent. The stationary draft tubes and draft-tube supports, along with the digester floor slab, did not appear to be damaged. Additionally, the corbels, which support the digester covers when the digesters are down for maintenance, were damaged. Corbel damage appeared to be restricted to spalling. Pounding of the corbels and covers also resulted in bending of the digester-cover skirt plates.

The earthquake damage to the digesters at other wastewater-treatment plants in the San Francisco Bay region was similar to that at the San Jose-Santa Clara, EBMUD, and Sacramento wastewater-treatment plants. Much of the digester damage could be easily repaired. For example, the damaged digesters at EBMUD's wastewater-treatment plant in Oakland continued to operate normally; however, more severe sloshing could have resulted in much more severe damage that would have resulted in loss of digester functionality or even release of methane gas. The earthquake damage to digesters at wastewater-treatment plants in the San Francisco Bay region is summarized in table 1.

\section{NEW-DIGESTER LOSS-MITIGATION RECOMMENDATIONS}

Table 1 and the previous discussion show that earthquake damage to digester systems in the San Francisco Bay
Table 1.-Earthquake damage to digesters at wastewater-treatment plants in the San Francisco Bay region.

[EBMUD, East Bay Municipal Utility District; MMI, modified Mercalli intensity]

\begin{tabular}{|c|c|c|}
\hline $\begin{array}{l}\text { Treatment plant } \\
\text { (fig. 1) }\end{array}$ & Digester damage & $\begin{array}{l}\text { Estimated } \\
\text { MMI }\end{array}$ \\
\hline San Leandro-.-.---. & - Sloshing broke glass veiwing ports. & VI-VII \\
\hline Sunnyvale -------- & $\begin{array}{l}\text { - Sludge sloshed over sides, and } \\
\text { alignment guides were damaged. }\end{array}$ & VI-VII \\
\hline Watsonville--.-- & $\begin{array}{l}\text { Existing concrete cracks in fixed } \\
\text { covers opened up farther. }\end{array}$ & VII-VIII \\
\hline Sacramento----- & $\begin{array}{l}\text { Alignment guides were damaged, } \\
\text { and corbels were damaged when } \\
\text { they pounded against one another. }\end{array}$ & $\mathrm{IV}-\mathrm{V}$ \\
\hline San Jose-Santa Clar & $\begin{array}{l}\text { Alignment guides failed. A gas- } \\
\text { collection line was severed by cover } \\
\text { rocking. }\end{array}$ & V-VI \\
\hline EBMUD ------- & $\begin{array}{l}\text { Alignment guides were extensively } \\
\text { damaged. Corbels were damaged by } \\
\text { pounding. }\end{array}$ & VII \\
\hline
\end{tabular}

region resulted from three basic mechanisms. Most digester damage resulted from the rocking (tilting) and (or) rotation of floating covers. The third cause of digester damage was caused by insufficient flexibility to accommodate differential movements between digester tanks and piping. Means of providing sufficient flexibility between digester tanks and appurtenances were documented by Hakala (1980).

The successful earthquake performance of digester fixed-position (nonfloating) covers at the Union Sanitary District, San Leandro, and Watsonville wastewater-treatment plants (fig. 1) suggests that one way to avoid cover rocking and rotation-induced damage is to use fixed covers in future digester designs. Sufficient freeboard to allow for sloshing of digester contents would have to be provided, or the cover would have to be strong enough to resist the sloshing forces.

Fixed covers would be subjected to large forces if sloshing fluids were allowed to impact digester covers. A design would have to be developed to reduce sloshing loading. One alternative design might be to install baffles around the tank interior walls so as to deflect sloshing liquids and reduce the sloshing forces on the roof. Alternatively, adequate freeboard could be provided by using the procedure outlined by Veletsos (American Society of Civil Engineers, 1984) to estimate the sloshing height. Because digester tanks are commonly situated on soft soils that tend to amplify longer-period motions, the calculations of special accelerations to be used in Veletsos' procedure should reflect the more dominant long-period ground motions. Otherwise, use of Veletsos' procedure may underestimate sloshing amplitudes.

One significant drawback of fixed-cover digesters is that digester operations are adversely affected by using fixed instead of floating covers. When floating-cover digesters are required, details can be designed that either reduce damage susceptibility or facilitate repair in the event that damage does occur.

The digesters with high-domed floating covers used at the Sacramento Regional Wastewater Treatment Plant performed better than other digesters at the plant with similar 
cover-guide and antirotation systems. The most probable explanation for this better earthquake performance is that less area of the high-domed floating digester cover was impacted by sloshing fluid. Furthermore, those areas that were impacted were subjected to much smaller sloshing-induced forces than corresponding areas of the flat floating digester covers. Therefore, the high-domed digester-cover guides and antirotation-system components were not subjected to the high levels of force that were applied to the flat-cover digester guides and antirotation-system components.

In addition to preventing damage to components of the cover guides and antirotation system, the high-domed floating digester covers limited rocking and rotation of the covers, and so pounding between the corbels and cover skirt did not occur.

The flat, floating digester cover with curved guide tracks at the Sacramento Regional Wastewater Treatment Plant also performed well. Because the tracks were curved, rocking of the cover was prevented. Still, the cover and guide systems were subjected to sloshing-induced forces. If the sloshing loads rotated the cover in the same direction permitted by the guide tracks, the cover and guide systems would be subjected to smaller forces than if rotations were not permitted. Larger forces would occur if the sloshing loads rotated the cover against its natural rotating direction. Therefore, although a rotating flat cover would not rock, the cover and guide systems could still be subjected to potentially large sloshing-induced forces.

\section{EXISTING-DIGESTER LOSS-MITIGATION RECOMMENDATIONS}

Although the damage to digesters at wastewater-treatment plants in the San Francisco Bay region was widespread, the only known digesters that had to be immediately shut down were the two with broken gas-collection lines at the San Jose-Santa Clara Wastewater Treatment Plant. Because this plant had sufficient excess capacity, plant operations were not significantly affected. Other digester damage affected digester performance to varying degrees.

For floating-cover digesters without attachments that could be damaged by rocking and rotational movements, it is probably not economical to retrofit the digesters by attempting to strengthen cover guides, antirotation systems, and floating covers. Repair costs in the event of an earthquake would most likely be less than the cost of retrofitting. If cover rocking and rotation could damage the attached piping and equipment, the potential economic and operationalcapability losses from an earthquake should be weighed against the cost of providing sufficient flexibility to attached piping and equipment, or of retrofitting digester covers.

Should a cost-benefit analysis indicate that retrofitting is feasible, one potential measure would be to use cover guides similar to the corkscrew-patterned tracks used on di- gesters at the Sacramento Regional Wastewater Treatment Plant. Depending on the digester, a curved-track guide system could be installed either above or below the digester cover. The digester cover may need to be strengthened if a curved-track system is chosen.

On some digesters, such as those with gas-injection tubing at the Sacramento Regional Wastewater Treatment Plant, cover rotation cannot be permitted. If the cover rotation must be zero, fixing the position of the digester covers may be a feasible means of mitigating earthquake damage.

\section{WATER-TREATMENT-PLANT TANK ELEMENTS}

Tanks for water-treatment clarification are typically used for mixing of chemical coagulants with the influent, flocculation, and sedimentation of particulate matter. Filtration is used after sedimentation to remove nonsettlable floc.

Coagulation and sedimentation can be done in compartmental tanks or in a single compartmented tank. In both types of tank, earthquake motions can cause sloshing of basin or tank contents. This sloshing stresses tank elements, including submerged equipment and baffles.

\section{RINCONADA WATER TREATMENT PLANT TANK-ELEMENT DAMAGE}

The Rinconada Water Treatment Plant, located about $17 \mathrm{mi}$ from the earthquake epicenter and only $5 \mathrm{mi}$ from the San Andreas fault (fig. 1), sustained the most damage of all water- and wastewater-treatment plants in the San Francisco Bay region. Three clarifiers were badly damaged by sloshing and wave action. A fourth clarifier, which was empty at the time of the earthquake, was undamaged. Repair costs to the three clarifiers were estimated at $\$ 1.7$ million.

Section and plan views of the affected clarifiers are shown in figure 4. Each clarifier has 177-ft-square sides and 22-ft-high concrete walls. Major equipment items include an EIMCO center-feed flocculator, a cone-shaped reaction well, a rotating flocculator, radial launders, and a rotating sludge scraper. The equipment-support designs did not consider resistance to earthquake-induced lateral forces.

Vertical structural support of the clarifier is provided by a 39-in.-diameter center steel column, fabricated from rolled steel plate, that is cantilevered from the center of the clarifier floor. The steel column either directly or indirectly supports the various rotating and fixed mechanisms.

Wave heights as high as $6 \mathrm{ft}$ above the water surface were observed. Once the water within the clarifier began to slosh, raw- and settled-water pipe connections between the steel column and reaction well separated. At this point, the reaction well was supported vertically only by four horizontal steel beams that cross at the top of the steel column. As 
the reaction well rocked with the sloshing fluids, the reaction-well-support system rotated and damaged other attached equipment. About half of the radial launders were torn away from and pounded the clarifier walls. Some of the damaged launders fell to the bottom of the clarifier and jammed the rotating sludge scrapers.

After the earthquake, the three damaged clarifiers were unable to perform their design functions. Water demands were met by bringing the empty, undamaged clarifier on line and using one of the damaged clarifiers as a static chemical mixer for direct filtration.

At the time of the earthquake, EIMCO, the gear manufacturer, was casting gears similar to those used at the Rinconada Water Treatment Plant for another project. EIMCO was able to supply replacement parts in 3 weeks instead of the normal 9 -month time period by adjusting its shipping schedules. However, repair still required $6 \frac{1}{2}$ to 7 months.

\section{DAMAGE TO OTHER TANK ELEMENTS}

Clarifiers at other water- and wastewater-treatment plants sustained various amounts of equipment and baffle damage. The most severe damage occurred at the Rinconada Water Treatment Plant (fig. 1). At the Alvarado, Palo Alto, and South Bayside wastewater-treatment plants, damaged baffles fell to
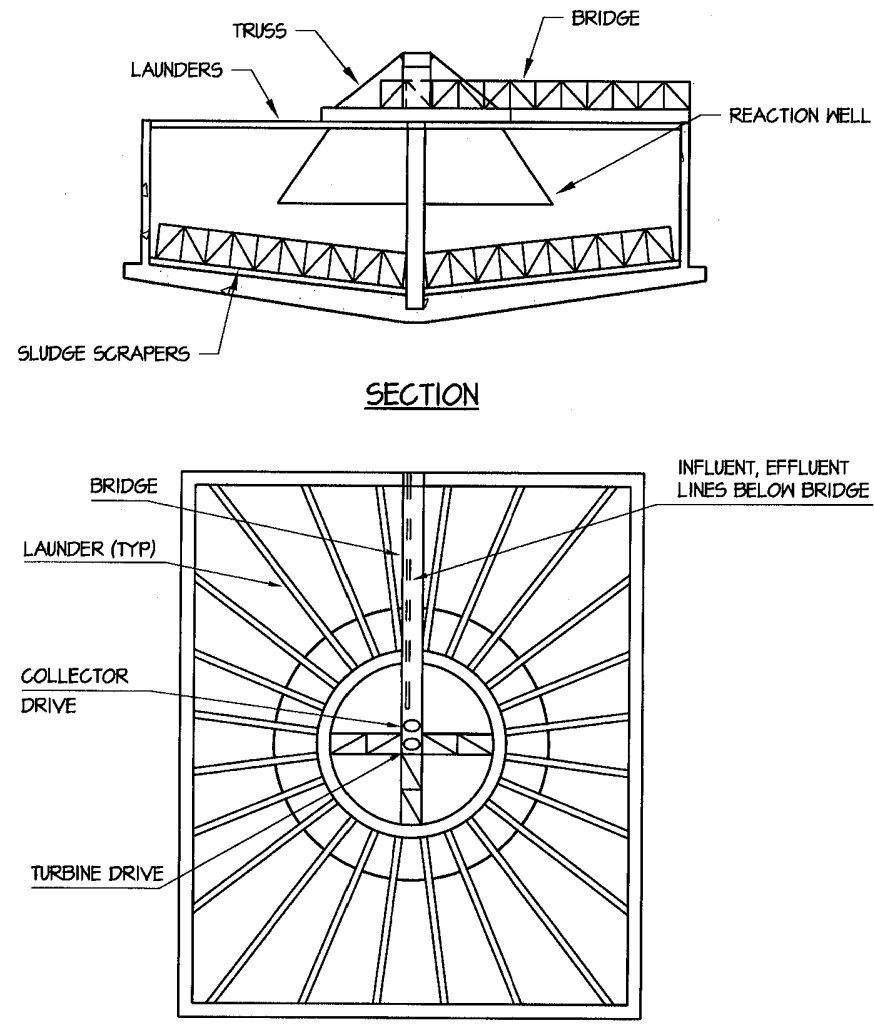

PLAN

Figure 4.-Clarifier design at the Rinconada Water Treatment Plant. the bottom of the clarifiers and caused the sludge scrapers to jam. At the Tracy water-treatment plant, a central column was deflected and jammed the scraper against the clarifier walls. Although the Tracy plant was shut down, water demands were satisfied by wells typically used only during the peak summer months. The earthquake damage to clarifiers at waterand wastewater-treatment plants in the San Francisco Bay region is summarized in table 2 .

The treatment-plant tank structures typically were not heavily damaged. The concrete basins leaked at the construction joints at a low-sand-filter treatment plant in Watsonville. When a construction joint between the primary sedimentation tanks and effluent channel cracked at the Santa Cruz Wastewater Treatment Plant, the leakage undermined the tank structure. Settlement of clarifier tanks occurred at both the Millbrae and Treasure Island sewage-treatment facilities.

\section{LOSS-MITIGATION RECOMMENDATIONS FOR TANK ELEMENTS}

Clearly, clarifier-equipment and baffle design should consider earthquake-induced sloshing loads. When dynamic forces are calculated for submerged equipment, the effects of the surrounding water must be considered. The effective mass, $m_{\text {eff }}$ can be approximated as (for example, Chopra and Liaw, 1976; Haroun and Bashardoust, 1986)

$$
m_{\text {eff }}=m_{0}+m_{1}+m_{2}
$$

where $m_{0}$ is the mass of the submerged object, $m_{1}$ is the mass of the fluid surrounded by the submerged object, and $m_{2}$ is the added mass due to interaction with the surrounding fluid. For a solid cylinder, the maximum effective mass equals the mass of the cylinder plus the mass of a volume of fluid that equals the volume of the cylinder (Haroun and Bashardoust, 1986).

The total force on the structural system must also include the viscous-drag force, $q_{\mathrm{D}}$ :

$$
q_{\mathrm{D}}=C_{\mathrm{D}} \rho_{\mathrm{1}} A|\dot{u}-\dot{v}|(\dot{u}-\dot{v}) / 2,
$$

where $C_{\mathrm{D}}$ is the drag coefficient, $\rho_{1}$ is the fluid density, $A$ is the project area, $\dot{u}$ is the fluid velocity, and $\dot{v}$ is the object's velocity.

The equation of motion can then be written as

$$
\begin{aligned}
& m_{\mathrm{eff}} \ddot{v}+c \dot{v}+k v= \\
& \quad C_{\mathrm{D}} \rho_{1} A|\dot{u}-\dot{v}|(\dot{u}-\dot{v}) / 2-\left[m_{\mathrm{eff}}-2(\ddot{u} / \ddot{G}) m_{1}\right] \ddot{G},
\end{aligned}
$$

where $c$ is the damping, $k$ is the stiffness, $\ddot{G}$ is the ground acceleration, and $m_{1}$ is the fluid mass displaced by the submerged object's enclosed volume.

Design-spectrum techniques can be used to estimate the sloshing forces from the equation of motion. These sloshing forces may be so large for some submerged structures that it 
Table 2.-Earthquake damage to clarifiers at water-and wastewater-treatment plants in the San Francisco Bay region.

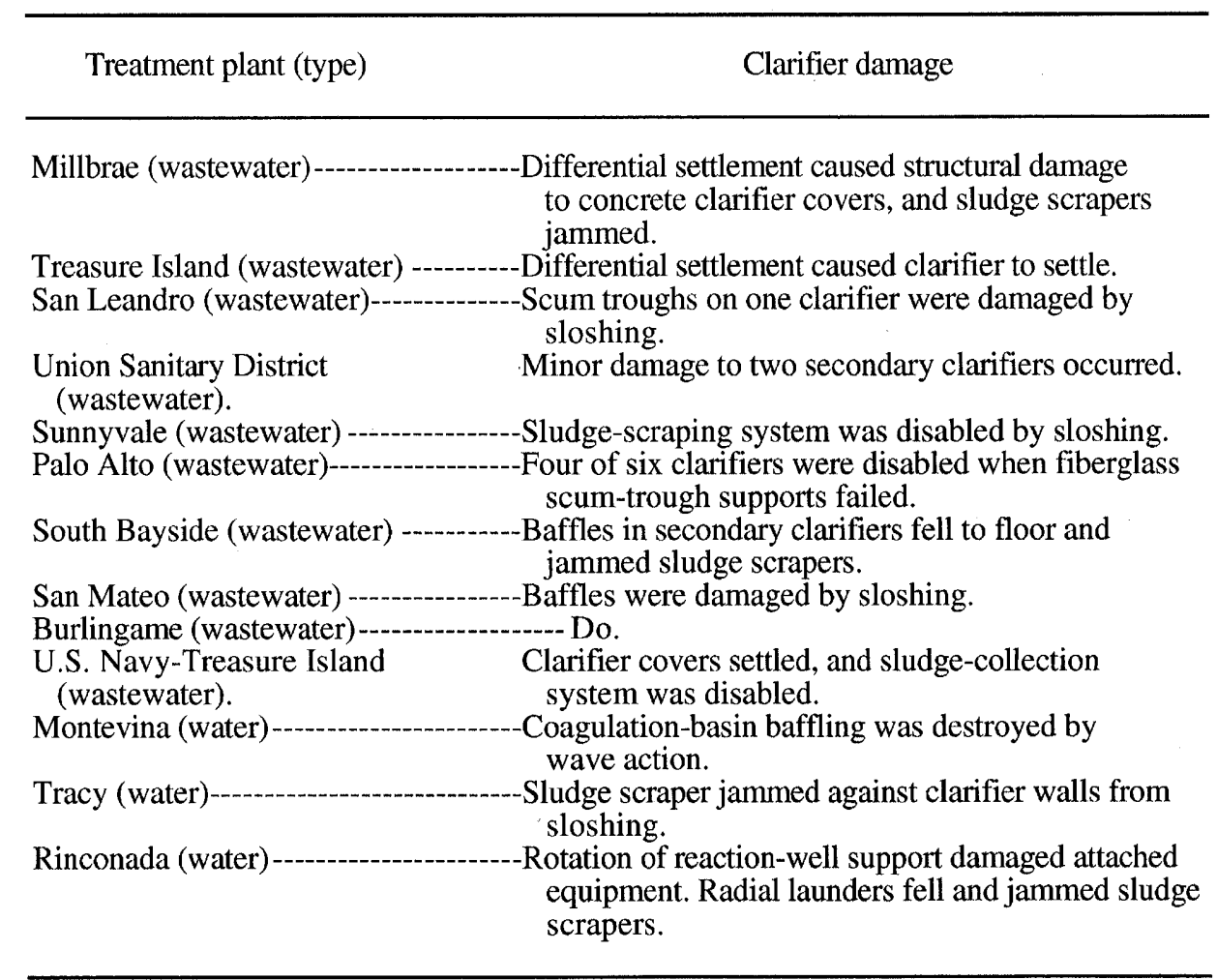

is impractical to design adequate resistance. For example, the forces that a rigid structural support for the reaction well at the Rinconada Water Treatment Plant would need to resist were estimated at 5,000 kips (Earl and Wright Consulting Engineers, 1989). Although smaller submerged nonstructural elements will most likely not have to withstand such large forces, typically, it will not be practical or economical to design structural systems to resist sloshing forces.

If it is impractical to provide adequate structural support to resist sloshing-induced forces in new-treatment-facility design or at existing treatment facilities, fail-safe or breakaway connections can be installed. If the connections between the tank walls and baffles are too strong, the forces from sloshing would likely destroy the baffles. Any equipment on the tank bottom could be damaged by the debris. However, if breakaway connections were installed with chain supports, the baffles could rotate once the breakaway connections failed and would no longer collect large forces from the sloshing liquids. The chains would prevent the baffles from falling to the tank floor and damaging other equipment, in addition to decreasing the loading on the baffles. As long as the secondary support system is flexible enough to decrease sloshing-induced forces, but rigid enough to prevent the supported component from impacting other pieces of equipment, repair of the baffling system would be relatively easy and inexpensive.

\section{SUMMARY}

The 1989 Loma Prieta earthquake resulted in a considerable amount of damage to nonstructural submerged equipment and tank attachments from sloshing liquids at waterand wastewater-treatment plants. The sloshing effects on equipment and attachments should be considered, and appropriate standards developed. It will generally not be feasible to design structural systems to resist the tremendous forces that can be generated by fluid sloshing because of operational requirements or economic practicalities. Still, fail-safe measures can be implemented so that even if attachments fail, repairs can easily be made.

\section{ACKNOWLEDGMENT}

This research was supported by National Science Foundation grant BCS-9002459.

\section{REFERENCES CITED}

American Society of Civil Engineers, 1984, Guidelines for the design of oil and gas pipeline systems.

Chopra, A.K., and Liaw, C.Y., 1976, Earthquake resistance design of intake-outlet towers: Proceedings of U.S.-Japan Seminar on 
Earthquake Engineering Research with Emphasis on Lifeline Systems.

Earl and Wright Consulting Engineers, 1989, Rinconada water treatment plant flocculation tank equipment response to seismic loadings.

Hakala, W., ed., 1980, Earthquake design criteria for water supply and wastewater systems: EQSI report prepared for U.S. National Science Foundation.
Haroun, M.A., and Bashardoust, F., 1986, Vibrations of submerged solids in a vibrating container: American Society of Civil Engineers Conference on Dynamic Response of Structures, 3d, Proceedings.

Stover, C.W., Reagor, B.G., Baldwin, F.W., and Brewer, L.R., 1990, Preliminary isoseismal map for the Santa Cruz (Loma Prieta), California, earthquake of October 18, 1989 UTC: U.S. Geological Survey Open-File Report 90-18, 24 p. 
LIFELINES

\section{LESSONS LEARNED BY WATER AND WASTEWATER UTILITIES}

By Mark Pickett, University of Toledo;

and

Gordon L. Laverty, Laverty Associates

\section{CONTENTS}

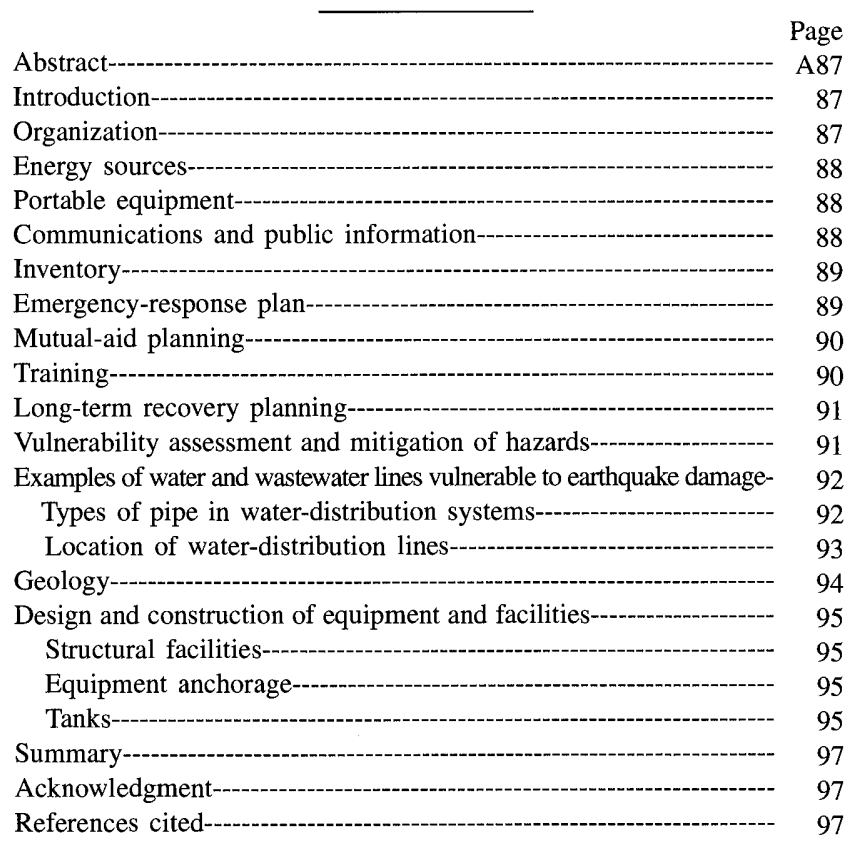

\section{ABSTRACT}

This paper states some of the lessons that water and wastewater utilities learned during the earthquake, those learned during the response period immediately after the earthquake, and those determined by analyses many months later. These lessons learned are grouped into two major categories: (1) utility operations, including preparedness and response; and (2) engineering design and facility performance. Although the implementation of these lessons will be costly, the utilities that implement them will have made a significant investment in earthquake-disaster mitigation.

\section{INTRODUCTION}

In the aftermath of the 1989 Loma Prieta earthquake, the Technical Council on Lifeline Earthquake Engineering of the American Society of Civil Engineers organized several damage-reconnaissance teams to inspect water- and wastewater-treatment plants and to interview their personnel in the Oakland-San Francisco-Santa Cruz-Hollister area. We were members of one of these teams. This paper reflects the lessons learned during the earthquake, those learned during the response period immediately after the earthquake, and those determined by analyses many months later. The lessons that can be learned from the earthquake are grouped into two major categories: (1) utility operations, including preparedness and response; and (2) engineering design and facility performance. The first category includes utility organization, energy sources, portable equipment, communications, inventory, emergency plans, mutual aid, training, recovery planning, and vulnerability assessment; the second category includes vulnerability assessment and the design and construction of equipment and facilities to resist earthquake-induced ground motion.

The field observations and the resulting lessons learned were assembled both from our damage reconnaissance and from numerous discussions with utility personnel in the months after the earthquake. Additional information on water and wastewater utilities was presented by Benuska (1990). The utilities investigated included five for water and three for wastewater, specifically the water and the wastewater utilities of the East Bay Municipal Utility District, the water and the wastewater utilities of Hollister, the water utility of Sunny Slope, the water utility of Santa Cruz, the wastewater utility of Sacramento, and the San Jose Water Co. of Los Gatos.

\section{ORGANIZATION}

The organization and management style practiced at water utilities significantly affects preparedness, immediate response, and focus of attention of field personnel. All the utility personnel interviewed indicated that although they believed that their organizations did fairly well during and after the earthquake, they made important improvements in subsequent months. Included in the improvements that were frequently identified were better definition of leadership roles, clearer statement of unit duties, improved emergency plan- 
ning to reflect the detailed events that must be dealt with in real disasters, and better preparation through "what if" thinking and plan exercising.

\section{ENERGY SOURCES}

When electrical power was lost, managers searched for immediate remedies, and in the months after the earthquake, they identified several salient points that can help provide better preparedness for the "next earthquake":

- Water and wastewater utilities should maintain close relationships with the local electrical-power company to ensure that the priorities of the utilities and the effect on these priorities of potential shutdowns (as requested by State or local authorities) are understood in advance of a disaster. Such shutdowns could affect the utilities' headquarters, treatment plants, pumps, and other facilities. Deliberate shutdowns are commonly avoidable.

- Portable electrical-power generators should be provided with the proper fittings and connections as required for each intended use. These generators should be periodically tested under load at each location where they may be used, such as at operations centers and pumping plants.

- Permanent engine-driven electrical-power-generator sets should be provided at critical support facilities, such as administrative headquarters, maintenance buildings, treatment plants, major control centers, laboratories, and petroleum-fuel stations.

- Regularly scheduled periodic tests of emergency-power or engine-driven systems should be conducted under load; power units may perform well without load but may fail when operated under emergency-power demands.

\section{PORTABLE EQUIPMENT}

All the utility personnel interviewed noted that more portable equipment was needed than was on hand in their own organization. These shortfalls were commonly due to budgetary constraints. However, within 24 hours of the earthquake, those responsible for these constraints became painfully aware of the consequences of false economy in regard to portable equipment. Additionally, it was observed that portable utility equipment needs the following attention:

- Perform preventive maintenance on a scheduled basis and test at least quarterly.

- Shelter portable lights, chlorinators, pumps, and other equipment in earthquake-, flood-, and fire-safe buildings so that they will be available when needed most.

- Store portable equipment in dispersed locations if the operations area of the utility requires access by way of tunnels and bridges or slide-prone routes. Preplan alternative access routes.

- Ensure that personnel know how to operate portable equipment and know the equipment's limitations.

\section{COMMUNICATIONS AND PUBLIC INFORMATION}

The following factors were determined to be required to ensure that utility response was adequate in the areas of communications and public information:

- In the calm atmosphere of predisaster operations, create fill-in-the-blank media-release forms with advice from the local media. It is also helpful to acquaint media personnel with the format of your utility's emergency-information statements.

- During the disaster, use these preplanned forms to let customers know, through the media, that their utility is staying on top of problems. Provide early damage reports and frequent updates.

- Develop a centralized source for the distribution of these forms and the dissemination of other information to the public, to ensure that accurate, consistent, and timely information is provided to the public by way of the mass media.

- Preplan employee communications for early notice of (1) how the utility is doing, (2) what they should do, (3) what transportation options exist, and (4) other employee and family instructions and information. Taped messages are useful and should be updated.

- Reserve a separate radio frequency dedicated to emergency utility operations. Sharing a frequency with other community disaster organizations (such as fire, police, or emergency medical services) may be a source of difficulty for small utilities. A base station, alternative base station, and emergency-power supply, as well as compatible mobile and personal radios, should be part of this system.

- Before the disaster, request that the utility's telephone lines be put on an essential-service status list, to provide the utility with improved access to dialtone when the telephone system is congested.

- Develop a radio-communication system that is not part of the public-switched-network lines, and acquire cellular telephones as a backup to the public-switched-network lines.

- Keep a supply of radio transceivers on hand. Most utilities discovered that they had too few portable radio transceivers, and quickly purchased more. Station-to-station two-way radios were preferred over base-operated systems because if the base was out, all radio communications were lost.

- Maintain stocks of batteries for battery-operated communication equipment.

- Provide a means for radio communication with police, fire, and emergency medical services in communities served by the utility. Frequency-scanner receivers can provide such emergency contact at an economical price. Test exercises of these systems are vital to ensure smooth communications during a disaster.

- Make previous arrangements with the local office of Radio Amateur Civil Emergency Services (RACES), so that amateur radio operators will report to the utility during an emergency.

- Prepare for handling postdisaster investigations. Utilities 
that are significantly damaged during an earthquake should expect visiting inspection teams who may arrive from all over the world. For this reason, organizational outlines, maps, system data sheets, and other informational handouts should be available for these visitors. These teams are composed of technical personnel who can be valuable sources of information to the utility.

\section{INVENTORY}

The earthquake emphasized the following important lessons related to the adequacy of supplies and their ease of access:

- Maintain an adequate inventory of repair materials to meet the needs of reasonable disaster-damage scenarios. Some smaller utilities had essentially no inventory of repair clamps and fittings for the full range of pipe sizes damaged (figs. 1, 2 ). These utilities had to order the needed material from suppliers and hope that mutual aid from another utility would provide the needed material in the meantime.

- Maintain a full range of petroleum fuels in onsite storage or in drums (within local fire-department limits). In case of a power outage, a method (and necessary equipment) should be provided so that fuel can be loaded, transported, transferred, and delivered to equipment. It may be more than a week before tank-truck supplies will reach your area. The

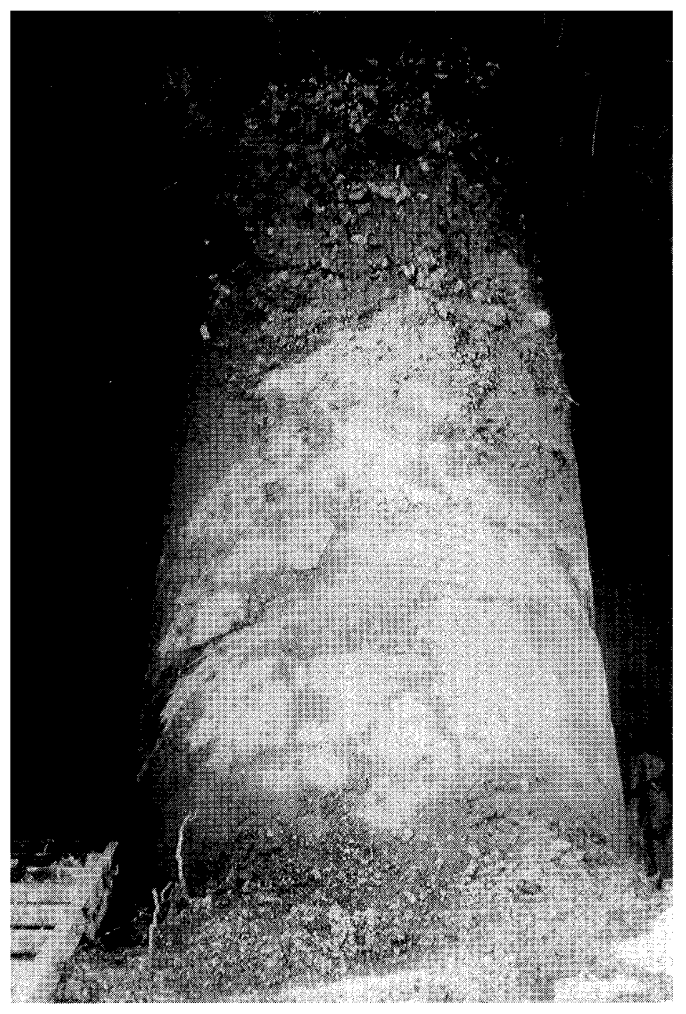

Figure 1.-Split on 14-gage-steel spiral-welded water barrier in 60-in.-diameter raw-water line. delivery of fuel may be delayed because of blockage of access routes or the fuel needs of higher-priority organizations.

- Before the disaster, discuss with current suppliers the probable availability of materials during a major emergency. Identify potential additional suppliers. Informal bid and payment procedures need to be in place before a disaster occurs.

- Prepackage and prelocate repair materials in locations that are difficult to reach so as to significantly speedup repair and recovery activities, including the proper number and sizes of such vital materials as pipes, valves, and repair clamps.

\section{EMERGENCY-RESPONSE PLAN}

In general, utility emergency-response plans (ERP's) were not well documented or preexercised before the earthquake. For this reason, utilities are encouraged to take the following steps:

- Develop or update a utility ERP. Most utilities contacted in the earthquake-affected area admitted serious shortcomings in this category. In most places where reasonable earthquake performance was reported, successes were attributable to the isolated existence of specific procedures or to intelligent employee response in the absence of a plan or procedure. (A "plan" describes the coordination of the response of all units of an organization; a "procedure" describes functional details and generally applies to a specific unit of the organization.)

- Coordinate the utility ERP with the plans of other agencies with whom the utility will function during a disaster. For example, including the police in the ERP and in exercises of the ERP would assure that the utility has emergency access priority to damaged facilities.

- Create an "incident-logging procedure" to record reports of and responses to events, including descriptions, times, reporter names, and actions taken. This procedure will provide a good working mechanism to handle first reports and to set priorities.

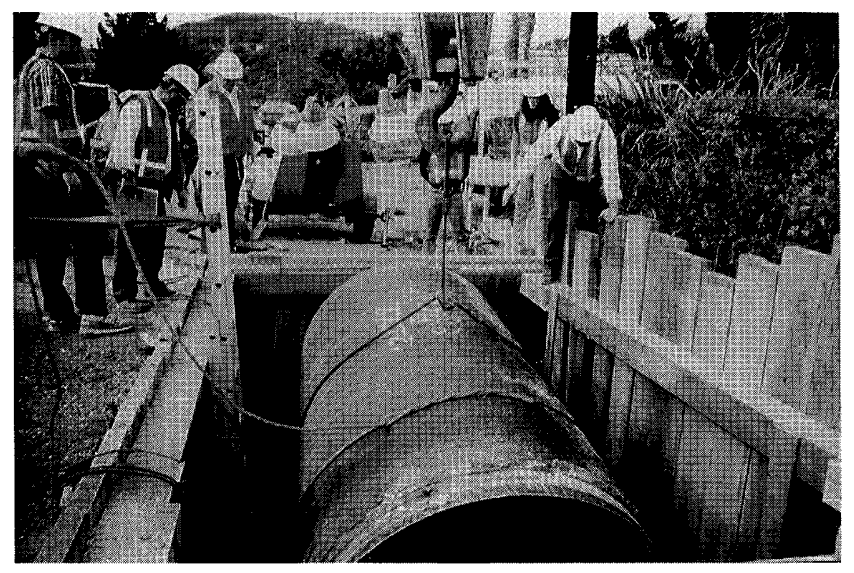

Figure 2.-Repair crew replacing section of split 60-in.-diameter raw-water line shown in figure 1. 
- Provide guidelines for water-quality sampling, alternative laboratory testing, notification of the public, reports to the health agencies, and related actions.

- Remember that microbiologic sampling is not a substitute for disinfection in the operation of water-distribution systems. The ERP should ensure that a sufficient inventory of disinfectant supplies will be available, even if vehicular access is limited. The ERP should include the training of personnel in the application of the disinfectant.

- Train personnel in emergency procedures. Health departments may be available for counsel, but utility operators must evaluate information and decide on a course of action to ensure maintenance of water quality. Therefore, the plan of action for potential problems should be determined before a disaster, and the plan should be periodically exercised.

- Orient employees in the content and use of the ERP by conducting periodic test exercises with conditions as close to real disaster conditions as possible. During these exercises, it is vitally important to practice communications with agencies that may assist in a mutual-aid relationship.

- Have State utilities submit their ERP to the California Office of Emergency Services and arrange for formal recognition of the participation of the utility under the State's Master Mutual Aid Agreement. Utilities in other States should submit their ERP to the appropriate State agency and arrange mutual-aid agreements with other utilities.

- Have State utilities participate in the activities of the Utilities Division of the California Office of Emergency Services. If such a division does not exist in other States, be instrumental in its creation.

- Ensure that the ERP includes a procedure for the operation of water-treatment facilities when various parts of the facility are inoperable because of earthquake damage. This procedure should include details of how a plant might be bypassed. Discuss this procedure with public-health officials.

- Create adequate identification cards for utility personnel and provide copies of valid cards to local police agencies, to improve checkpoint passage during an emergency.

\section{MUTUAL-AID PLANNING}

A mutual-aid plan is a formal written agreement signed between two or more organizations before a disaster; it identifies the actions and material that will be provided cooperatively during a disaster. The following activities were observed to be vital to successful mutual-aid preparedness:

- Ensure that formal written mutual-aid agreements exist with other agencies.

- Inform utility personnel about mutual-aid plans, procedures, and the utility's expectations.

- Participate in regional interagency meetings and test exercises to identify problems and improve performance.

- Be prepared to answer requests for aid from adjacent military facilities or other Federal or State organizations. Dur- ing the 1989 Loma Prieta earthquake, these organizations were unprepared to quickly handle the number of pipe breaks that occurred.

- Obtain previous authorization from fire-department officials for the utilization of fire engines as booster pumping equipment (fig. 3). This authorization will require cooperation between the water utility and the fire department for the provision of between-zone hydrants and portable hydrant assemblages (fig. 4), and may require that both organizations share in the cost of procuring these portable assemblies, which are made up of pipe crosses, regulators, valves, and large-diameter firehoses (max 5-in. diam for larger cities). Water utilities should obtain the necessary adapters for the various firehose diameters and thread types.

- Maintain close personal relationships with the personnel of nearby utilities to ensure cooperation under highly stressed conditions. Predisaster discussions regarding potential emergency situations and how the agencies will resolve them can prevent serious misunderstanding during an emergency.

\section{TRAINING}

Training translates good plans into good performance during a disaster. Critical training elements include the following:

- Acquaint all employees with the ERP to ensure that everyone understands the plan's goals and will work harmoniously to carry them out.

- Conduct training in all of the planned emergency actions and crosstrain employees to permit the coverage of essential jobs in an emergency. Training should include regular retraining of current employees, new-employee training, ERP exercises, and problem-solving sessions.

- Train employees in emergency communication procedures, including not only maintaining radio and telephone communications within the utility but also prohibiting individual

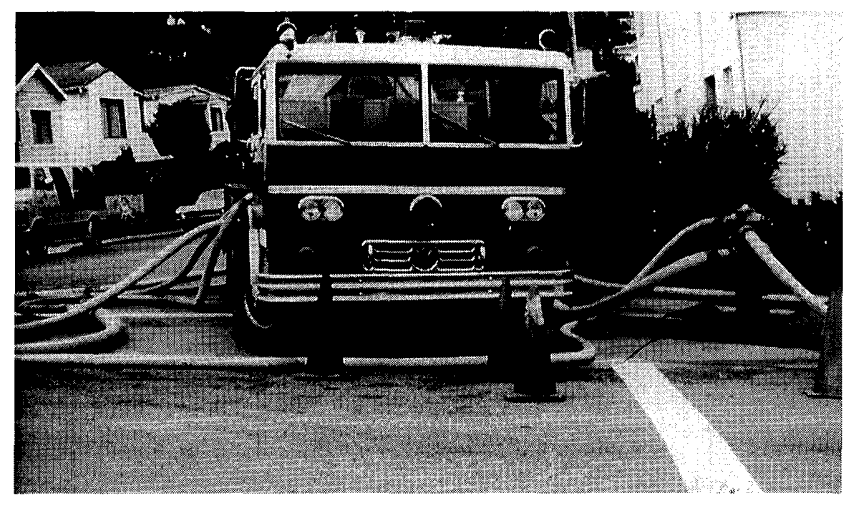

Figure 3.-San Francisco Water Department pumper providing booster-pump services to supply areas that were out of water because of numerous earthquake-related water-main breaks. 
employees from communicating with the mass media. Instead, employees should be trained to refer all requests for information to a centralized source for the dissemination of information to the public, to ensure that accurate, consistent, and timely information is provided to the public by way of the mass media.

- Thoroughly inspect facilities immediately after an earthquake. In Santa Cruz, 1,100 gal of zinc orthophosphate solution used for $\mathrm{pH}$ control was missing. The material was discovered in a plant's treated-water channel and removed; close inspection avoided a problem. A check valve with a failed exterior spring was the cause of the spill.

- "Boil order" planning is important, so that when called upon, the utility is prepared for action. Issue a "boil order" if any of the following events occur:

o Reduced pressure in water mains, which will create a vacuum.

o Water-main breaks too numerous to repair quickly.

o Sewers overflowing to the level of the manhole covers.

o Indications of broken sewers.

- "Boil order" instructions to customers should include:

o Bring water to a rolling boil and then turn off the heat.

o Water is drinkable when it cools.

o If heat is unavailable, filter water through a gauze/clean cloth, then mix in one teaspoon of bleach per gallon of water.

o Let bleach-water mixture stand for 15 minutes.

o Water is drinkable after 15 minutes.

- Review the section entitled "Coliform Rapid Detection Bacteriological Methods" in the manual by the American Public Health Association (1989, sec. 9211); 7-hour tests may be applicable.

- Train personnel to respond only to utility leaders and not to other public-employee supervisors who may tell them what their priorities should be. Conduct predisaster discussions with police and fire leaders to encourage chainof-command communications, so as to avoid conflicts in

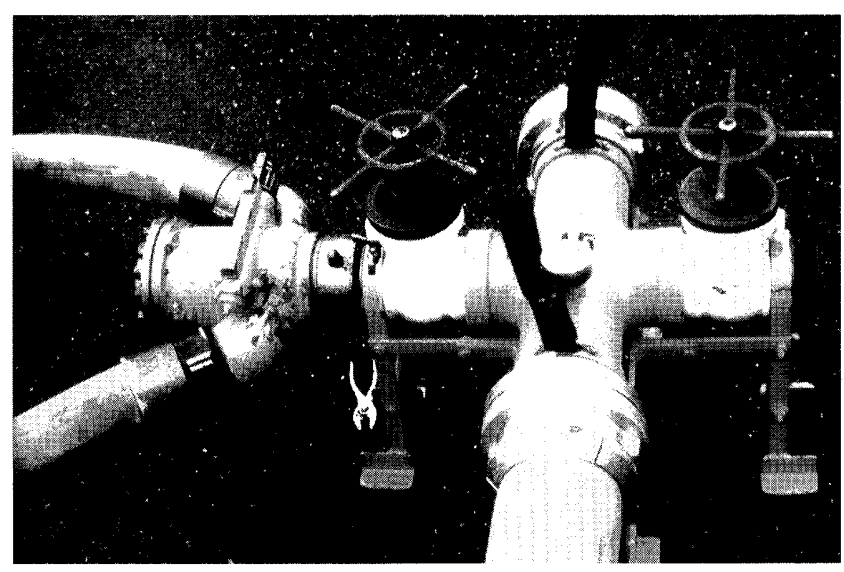

Figure 4.--Portable hydrant assembly used by the San Francisco Water Department consisting of valves, a regulator, and fire hosefitting connectors. the field during an emergency. As a corollary, field forces need to keep their own supervisors well informed, especially with respect to valve closures, so as to ensure that Emergency Operations Center (EOC) information will be accurate and that supervisory decisions will be correct.

\section{LONG-TERM RECOVERY PLANNING}

Planning only for the immediate response to an earthquake and other disasters is insufficient; long-term recovery actions must also be considered. Recovery planning must take into account broader issues, such as:

- Options to repair, such as abandonment or replacement at another location.

- Redundancy of pipelines and other facilities.

- Relocation away from newly observed fault areas.

- Rate-structure change reflecting the cost of loss-mitigation programs.

- Personnel training and procedures for recovery.

- Review and update of communication systems.

- Review and update of standard designs no longer appropriate for the area.

- Shared use with other agencies (for example, emergency equipment, laboratory facilities).

In addition, a procedure for the collection of utility revenues during the recovery period should be identified, including turnoff and turn-on procedures for emergency periods, especially with respect to nonpayment. Recordkeeping during emergencies is crucial to the recovery of insurance-covered costs or State/Federal emergency funds. These records should include:

- A first survey and quick estimate of the damage, to assist the State governor in determining whether a state of emergency should be declared.

- In accounting for the cost of disaster recovery, a mechanism of differentiating between costs for "repair to what it was" system repair and costs for system improvement/loss mitigation.

- A detailed description of the limits of work and the materials ordered (including pickup tags, trucking records, and so on), with the realization that State and Federal audits may not be performed for 3 or more years. For larger utilities, recovery of costs under $\$ 3,000$ per damage site is probably not economical.

\section{VULNERABILITY ASSESSMENT AND MITIGATION OF HAZARDS}

Each utility should develop a program to assess and minimize its vulnerability to earthquake damage. This program should consist of the following steps:

- Conduct a vulnerability assessment of the utility's treatment plant, reservoirs, and water-distribution facilities and 
equipment, consisting of a field assessment to identify the potential earthquake hazards to the utility's entire system. These hazards could be grouped in one of three categories; structural, operational, or geotechnical. For example, facilities and piping systems located in areas of alluvial soil or uncompacted fill are highly susceptible to damage in an earthquake. These areas would include old shorelines (Marina District of San Francisco), old riverbeds, and filled-in ponds.

- After the field assessment, itemize the utility's vulnerable elements, including items in the water-distribution system (such as valves, pumps, or lengths of piping), items in water- and wastewater-treatment plants (such as pumps, cylinders, electrical equipment, or computers), and such major items as tanks, reservoirs, and entire buildings.

- List the vulnerable elements in the order of their importance to the utility's operation. For some elements, a conscious decision may be made to accept the existing risk without mitigation; these elements should be specifically identified in writing.

- On the basis of this prioritized list, develop a plan for the mitigation or elimination of the hazard to these elements. Place this hazard-mitigation plan into action.

\section{EXAMPLES OF WATER AND WASTEWATER LINES VULNERABLE TO EARTHQUAKE DAMAGE}

\section{TYPES OF PIPE IN WATER-DISTRIBUTION SYSTEMS}

The 1989 Loma Prieta earthquake demonstrated the superior performance of asbestos-cement and polyvinyl chloride (PVC) pipe relative to cast-iron pipe. Although installation of asbestos-cement pipe has ceased in the United States because of the potential health risks associated with its use, we present the following observations to alleviate concerns about the seismic performance of existing water-distribution systems composed of this material.

For example, in the rural town of Hollister, the water utility was significantly damaged. (The San Andreas fault is about $10 \mathrm{mi}$ west of the town, and the Calaveras fault traverses the town.) The water mains near the branches of the Calaveras fault were mostly pre-1950 vintage, consisting of 4- and 6in.-diameter cast-iron mains, with lead-caulked bell-and-spigot connections. At the fault crossings, no special precautions had been taken, such as the use of flexible couplings. In this area, other lifelines and residences and designed structures were significantly damaged, and 11 water-main breaks occurred to cast-iron pipes. In a different area of Hollister, but still in the vicinity of the Calaveras fault branches, the water mains were 6- and 8-in.-diameter asbestos-cement pipe in $13 \mathrm{ft}$ sections, with rubber-ring-collar connections; the average ground cover was $3 \mathrm{ft}$ thick. The asbestos-cement pipes had cast-iron gate valves, and the service connections were either 0.75 -in.-diameter PVC pipe or 1-in.-diameter copper tubing. Only one of the asbestos-cement pipes was damaged; however, many breaks occurred on the customer side of the connection to the public system, as a result of differential ground settlement in the alluvial soil of the faulted area. Only two of the main breaks occurred in pipes 2 in. or smaller in diameter.

In the area of cast-iron water mains, some of the private breaks in the water-distribution system were due to shearing of the connection of the service tubing to the house; other breaks were due to shearing of the connection of the service tubing to the water main. As evidenced by the significant motion in many private residences, this shearing was caused by relative motion between the houses and the distribution mains. For example, within a four-block residential area (approx 700 by $1,700 \mathrm{ft}$ ), at least 10 houses were knocked off their foundations because of ground-motion-induced shear failure of the cripplewall (figs. 5, 6), and evidence of pavement and curb separation and differential motion and sidewalk seam opening of 1 to 4 in. (figs. 7, 8) was observed. These curb, pavement, and house motions indicate the significant ground motion and the settlement of alluvial soil that

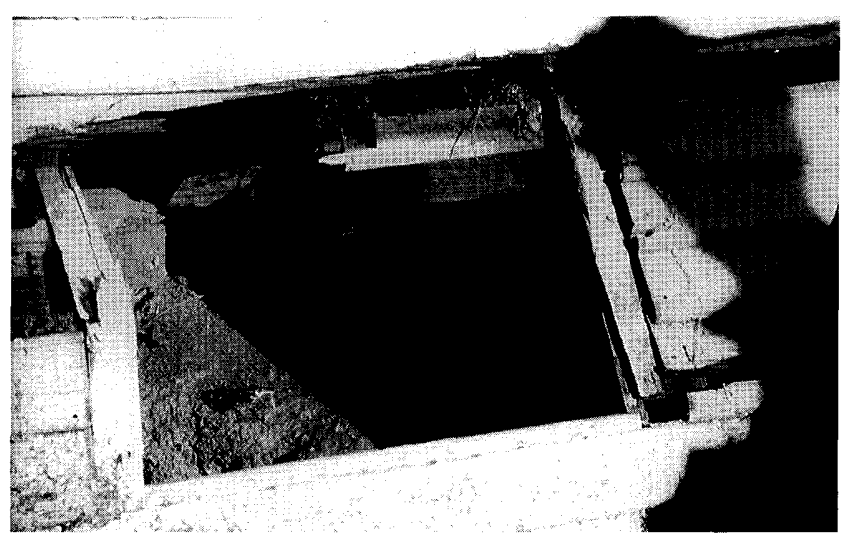

Figure 5.-Typical shear failure of cripple wall in a house in Hollister due to lateral ground motion and insufficient shear connectors.

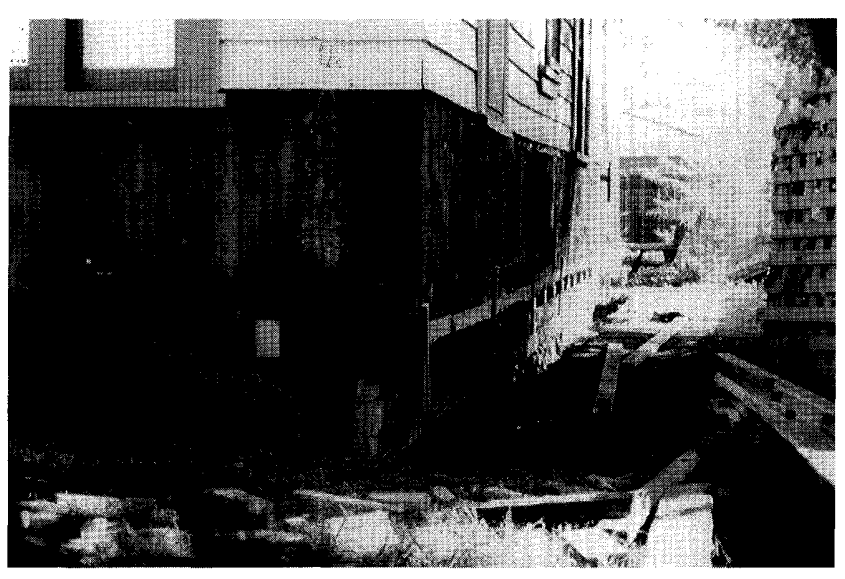

Figure 6.--Repair of cripplewall in a private residence in Hollister. 
occurred during the earthquake. This motion and settlement caused the numerous water-service connection breaks.

In the area where the water-distribution system consisted of rubber-gasketed asbestos-cement and PVC pipe, only one pipe break was reported, in a 0.75 -in.-diameter plastic connection to a house: a pullout break caused by relative motion between the house and the distribution main.

The scarcity of breaks in asbestos-cement and PVC pipe is attributable to several factors. The joints of both types of systems are more flexible than the lead-caulked joints in castiron pipe segments. (In asbestos-cement pipe, joints typically contain rubber gaskets, whereas in PVC pipe, the articulated joint allows for some pipe motion without breakage. The old lead joints of cast-iron pipes are inflexible, and any displacement will cause a leak.) Additionally, the wall thickness of old cast-iron pipe is likely to have been thinned by corrosion, making it vulnerable to fracture or rupture during an earthquake, whereas asbestos-cement and PVC pipe do not corrode and thus should maintain their design strengths. Also, in both asbestos-cement and PVC pipe, the typical segment length of $13 \mathrm{ft}$ provides more flexibility than that provided by the typically shorter segment lengths of cast-iron pipe.

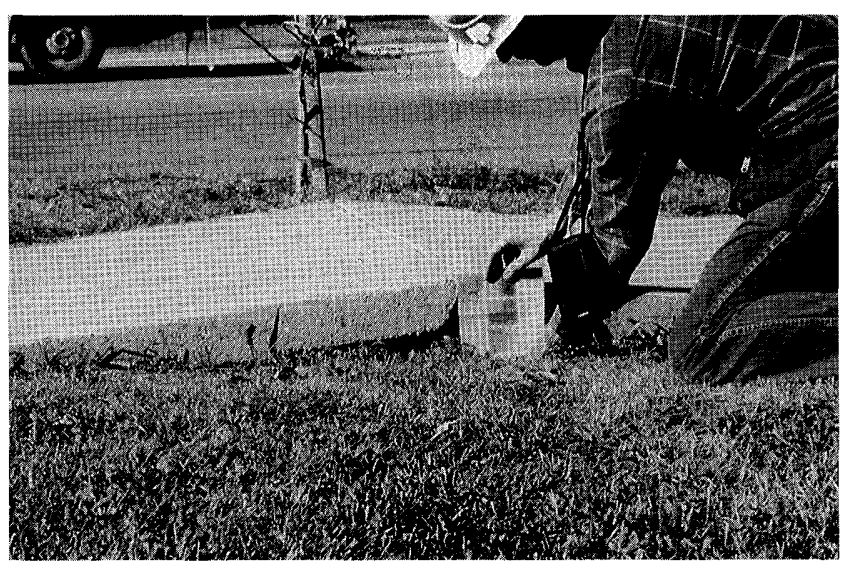

Figure 7.-Buckling of sidewalk in Hollister due to ground settlement.

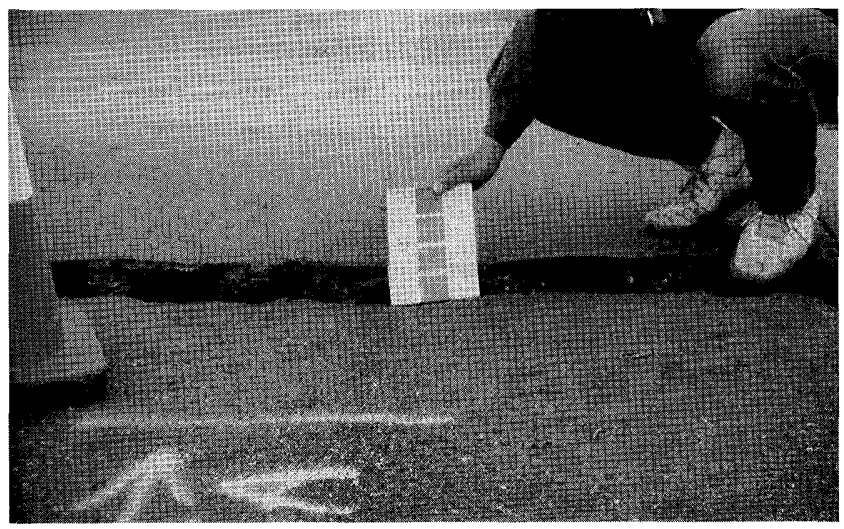

Figure 8.-Cracking of pavement in Hollister due to differential ground settlement.
The superior earthquake performance of asbestos-cement pipe was also demonstrated in areas farther away from the epicentral region. In the East Bay Municipal Utility District (EBMUD) in Oakland, the total number of repairs in the water-distribution system exceeded 120 . Only 13 of these repairs occurred in asbestos-cement pipe, and the rest in steel, PVC, and cast-iron pipe. Many of the breaks in cast-iron pipe were caused by compression, as indicated by jammed bells. Numerous shear and bending failures were also reported. One break in a 20 -in.-diameter line in Oakland caused a rapid loss of water level in EBMUD's central reservoir; this break was caused by a thrust failure in the bell-and-spigot connections of an 18-ft segment of cast-iron pipe that had been laid in 1916 in an area underlain by bay mud (fig. 9). In EBMUD's water-distribution system, the superior earthquake performance ( 2 to 3 times lower repair rate) of asbestos-cement relative to cast-iron pipe was again due to the factors mentioned above for Hollister (see Eidinger, this chapter).

\section{LOCATION OF WATER-DISTRIBUTION LINES}

Utilities should identify the locations in water-distribution systems where pipes are vulnerable to damage. The 1989 Loma Prieta earthquake caused much damage to buried pipe in areas of uncompacted fill soil and in naturally occurring sand and alluvial soil; however, very little damage to pipe was reported in areas of firmer or compacted fill. The damage occurred because long runs of pipe were subjected to differential ground settlement or differential lateral ground motion.

Additionally, pipes are commonly conveyed across bodies of water by vehicular bridges. Because bridges constructed in areas of uncompacted fill or alluvial soil are supported on piles, differential settlement and differential lateral motion between the bridge and the roadway may be caused by an earthquake. During the 1989 Loma Prieta earthquake, such motion broke pipes conveyed by the San Francisco-Oakland Bay Bridge and by several bridges in Santa Cruz (fig. 10).

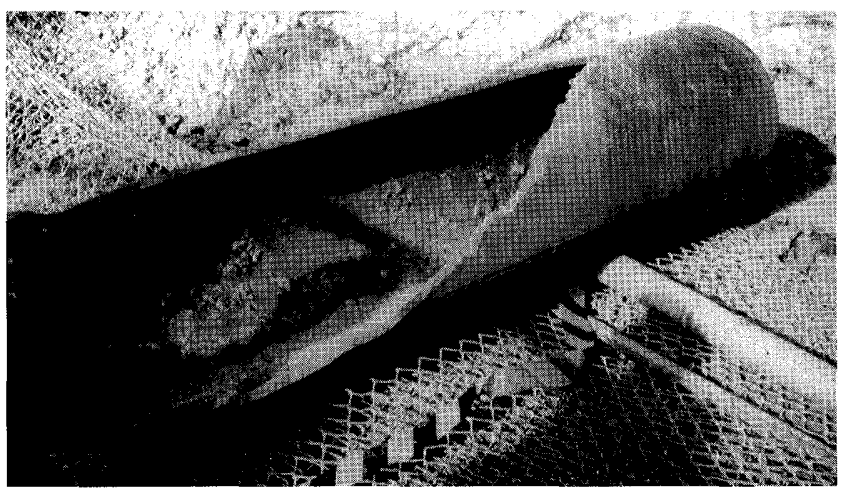

Figure 9.-Failure at bell-and-spigot connection of 20-in.-diameter cast-iron pipe in Oakland due to axial thrust in waterline. 
Utilities also need to be aware that long-term creep of the ground may significantly affect buildings, equipment, and pipes. For example, in the Hayward fault area of Oakland, the ground creeps continually at a rate of about $1 / 8$ to $1 / 4$ in. per

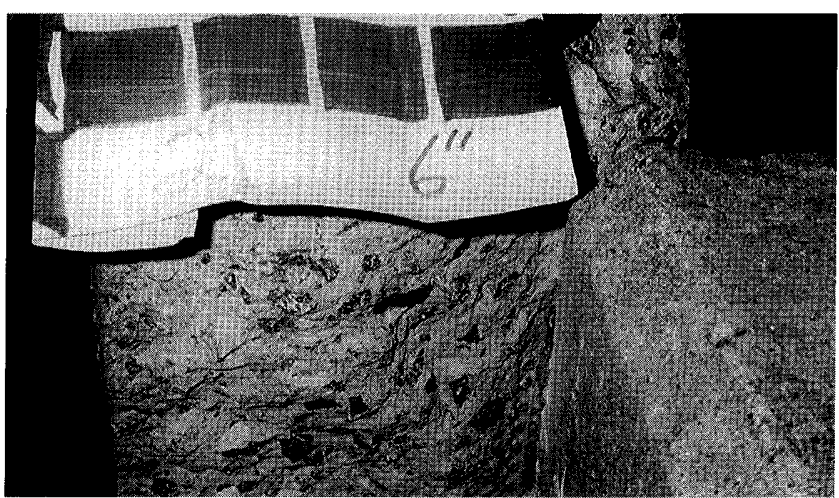

Figure 10.-Differential lateral motion between curb on a pile-supported bridge and the curb on approach road would break any waterlines conveyed by this bridge in Santa Cruz.

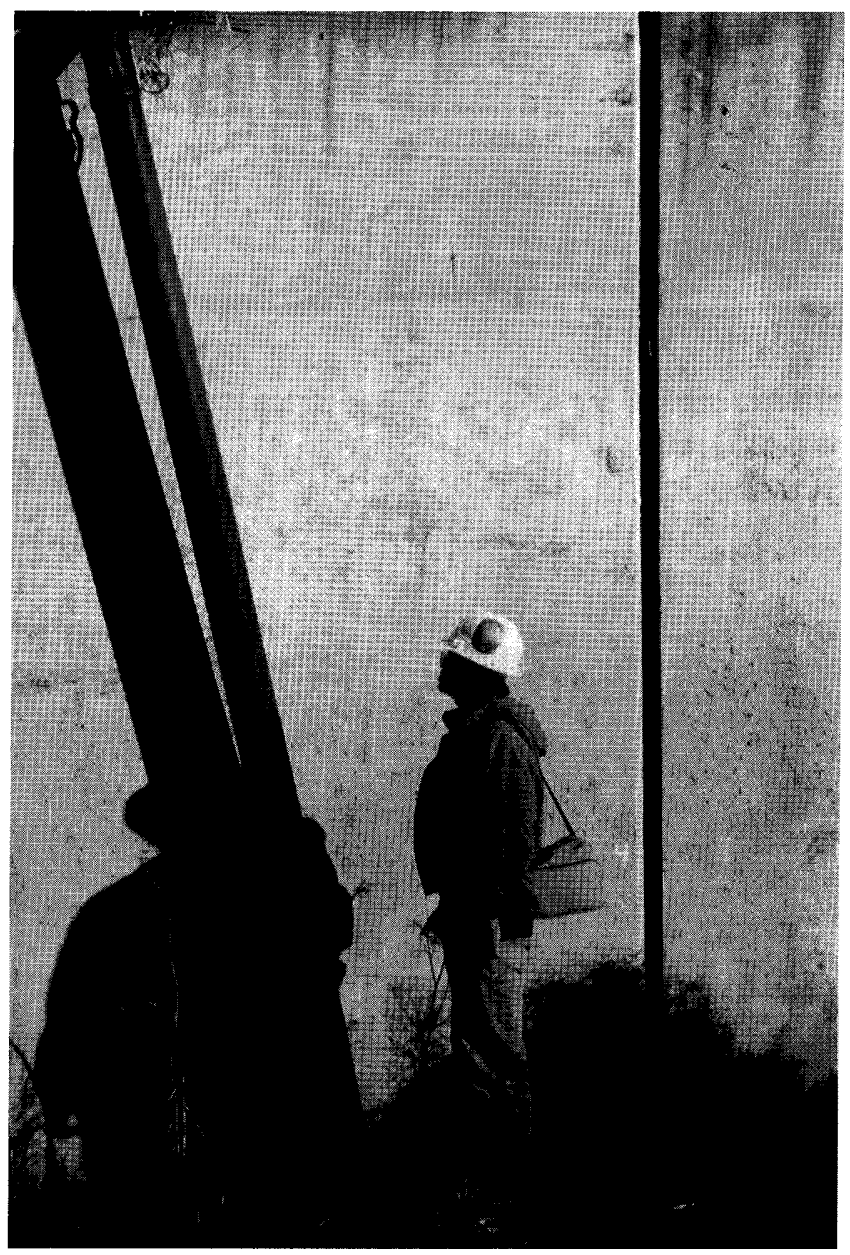

Figure 11.-Differential lateral motion between top and bottom of pipe in area of the Hayward fault in Oakland due to ground creep of about $1 / 8$ to $1 / 4$ in/yr. year, causing the pipe shown in figure 11 to become inclined from its originally vertical position. In a pumphouse located about one block from this pipe, creep has caused gradual movement of the supports for the suction and discharge piping of several pumps (figs. 12, 13).

\section{GEOLOGY}

The 1989 Loma Prieta earthquake emphasized the fact that regional and local geology must be considered and understood during the planning and design of utility facilities and water-distribution systems. Many utilities adversely affected by the earthquake did not consider soil conditions adequately. Some facilities as far away as $100 \mathrm{mi}$ from the epicenter were significantly damaged.

One excellent source of information is the U.S. Geological Survey's "Soils Reports," which identify soil types, faults, and levels of anticipated ground motion in different areas. When this information is combined with information

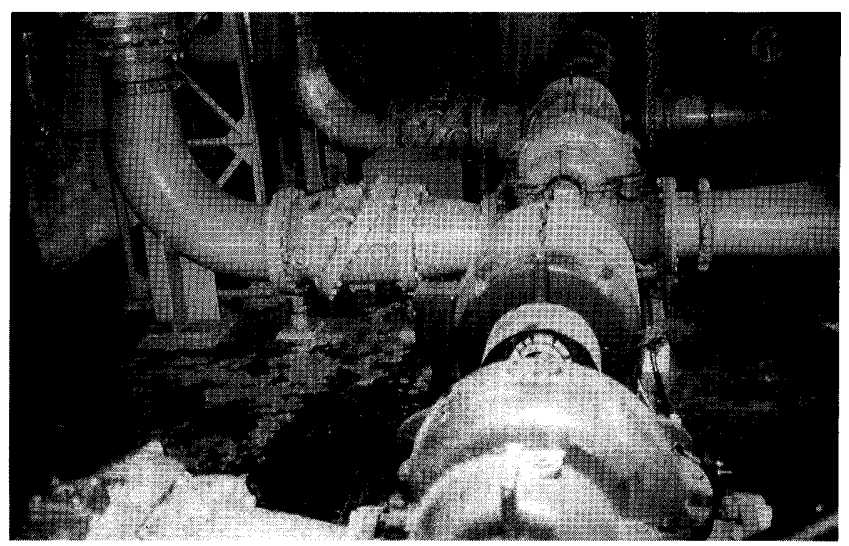

Figure 12.--Interior of water-pumping plant located near the Hayward fault in Oakland. Note pipe supports.

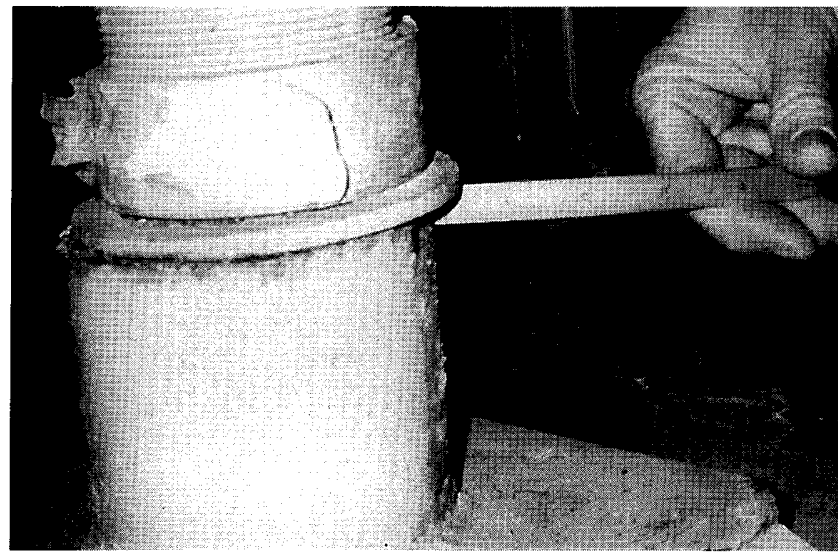

Figure 13.-Detail of gradual lateral displacement of pipe support shown in figure 12 , due to ground creep in area of the Hayward fault. 
on local soil conditions, planning and design can be done to minimize earthquake vulnerability. Maps that locate geologic faults with respect to street names are useful in retrofitting existing facilities and water-distribution systems.

The locations of breaks in the piping of water-distribution systems were useful in determining previously unknown minor geologic faults and areas of soil peculiarities. The records of these locations kept by many utilities on distribution-system maps have proved to be a great aid in the design and planning of future hazard mitigation.

\section{DESIGN AND CONSTRUCTION OF EQUIPMENT AND FACILITIES}

We observed a wide variation in the earthquake performance of structural facilities and operating equipment. In this section, we describe the earthquake performance of utility facilities and equipment in varying environments, noting the lessons that can be learned by designers and constructors.

\section{STRUCTURAL FACILITIES}

Utilities should assess the vulnerability of systems, equipment, and waterlines in masonry buildings. As an example, one significant private-waterline break occurred in Hollister as a direct result of the structural failure of an unreinforced-masonry building. This failure occurred when the building housing the International Order of Odd Fellows (IOOF) collapsed into an adjacent State office building, severing a 4-in.-diameter fire-sprinkler connector and causing significant water damage in the State office building. These buildings were located in downtown Hollister, on the east branch of the Calaveras fault.

We noted that one two-story reinforced-masonry building which was located about two blocks from the IOOF building and also located on the east branch of the Calaveras fault sustained only superficial cracks in the facade and interior walls and ceilings.

Utilities should assess their warehouse and storage buildings for vulnerability to earthquake damage. Warehouse contents should be restrained so that the horizontal motion of the Earth will not cause them to fall off shelves or topple over. In the Hollister area, two tiltup concrete warehouses and one metal-frame warehouse were significantly damaged when their contents toppled northward and knocked down much of the north walls of the buildings.

\section{EQUIPMENT ANCHORAGE}

Utilities should ensure that all equipment is positively anchored. Note that the anchor clip for the electronics cabinet shown in figure 14 provides a more secure restraint than that provided by a friction clip. The seismic-restraint straps shown in figure 15 anchor the underside of temporary office trailers to the ground. An example of a system-monitoring panel that is insufficiently restrained to prevent lateral motion at the top of the panel is shown in figure 16. Additionally, electrical and communications conduit should have enough slack that it will not stretch or break because of differential lateral motion between the conduit support and the panel.

During any disaster, communications within a utility are vitally important. Thus, utilities should ensure that communication equipment is properly anchored to lessen its vulnerability.

\section{TANKS}

In regard to their performance during and after an earthquake, both reinforced-concrete and steel tanks have advantages and disadvantages. For both types of tanks, however, the 1989 Loma Prieta earthquake made the following points clear:

- Tanks should be easy to inspect periodically.

- Damage to the tanks should be easy to identify after an earthquake.

- Damage to the tanks should be easy to reliably repair after an earthquake.

In particular, steel tanks require careful periodic inspection and maintenance to ensure that leg anchorage to the foundation and tension-bar adjustment and connections are maintained.

For example, earthquake-induced ground and water motion significantly damaged a concrete tank in the Purisima Hills Water District (figs. 17, 18). This wire-wound posttensionedconcrete tank was constructed in 1964 by alternate pours of the vertical panels. The earthquake caused the collapse of the col-

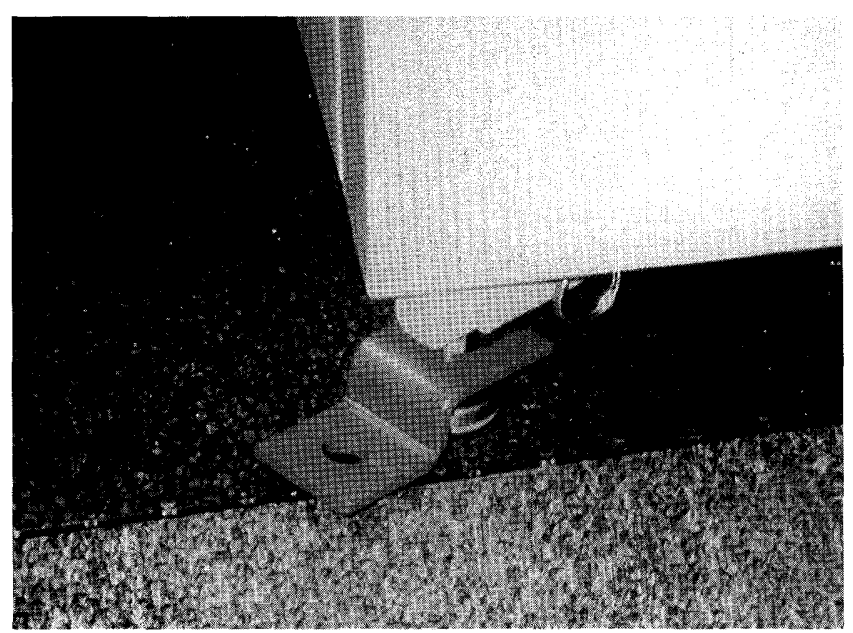

Figure 14.-Typical anchor clip for an electronics cabinet, use to prevent it from overturning. 


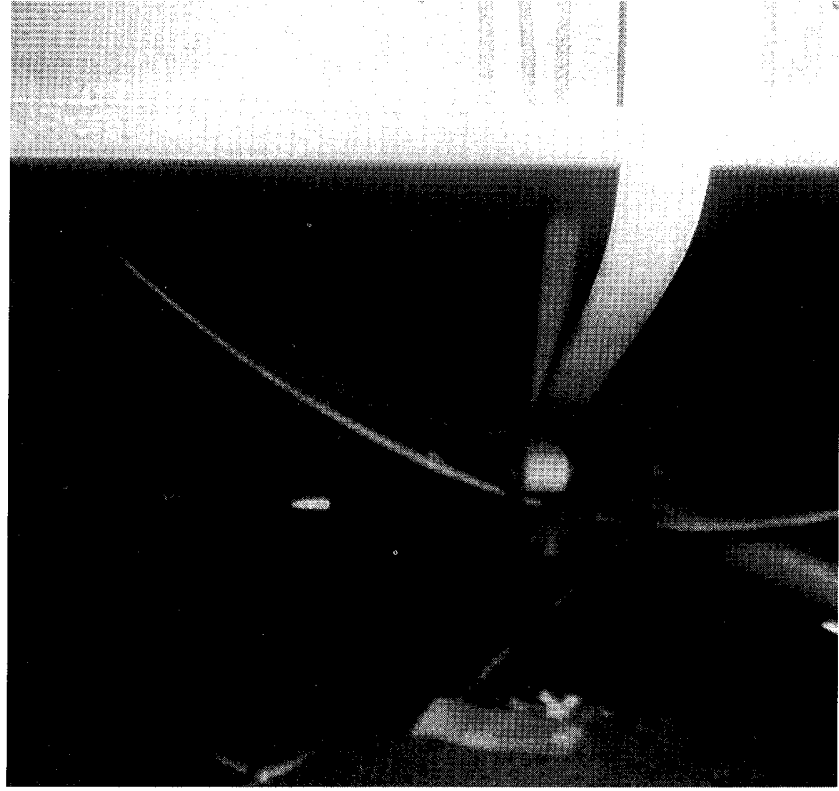

Figure 15.-Seismic-restraint straps anchoring underside crossbeams of a temporary office trailer to ground.

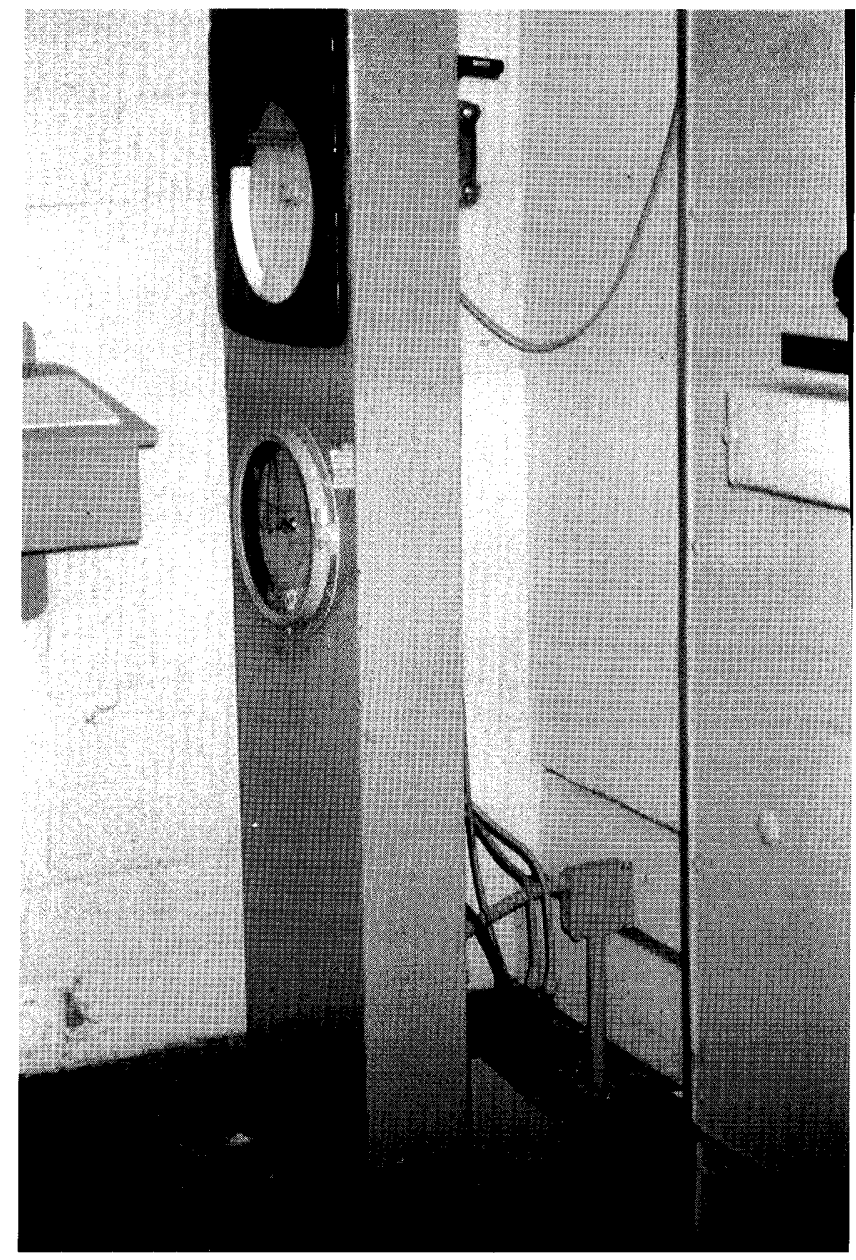

Figure 16.-Typical monitoring panel with no lateral restraint at top.

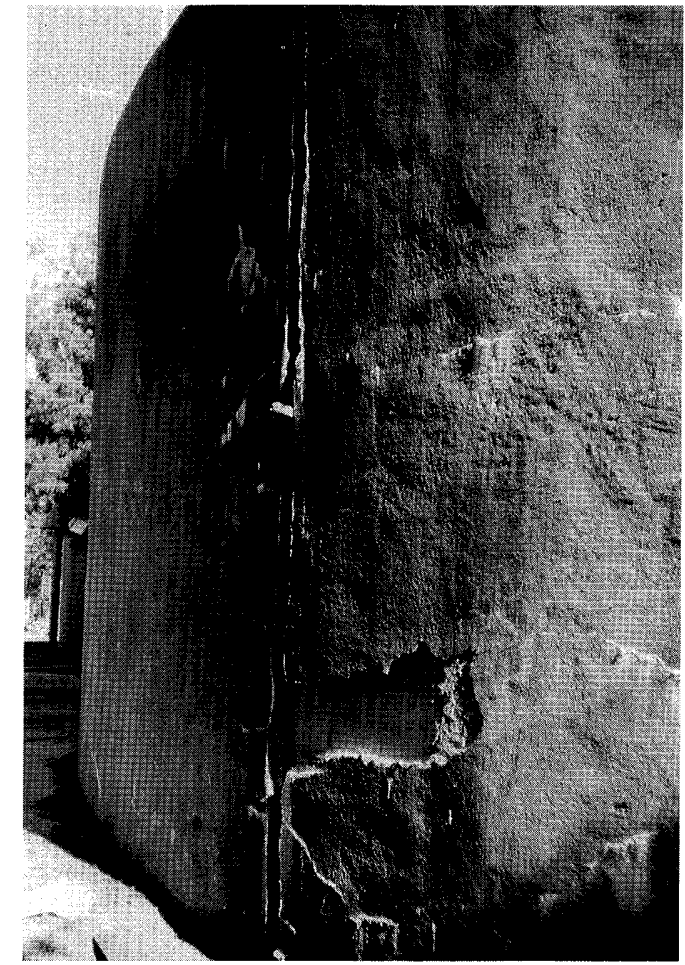

Figure 17.-Wire-wound posttensioned-concrete tank in the Purissima Hills Water District. Tank was constructed in 1964 by alternating pours of vertical panels.

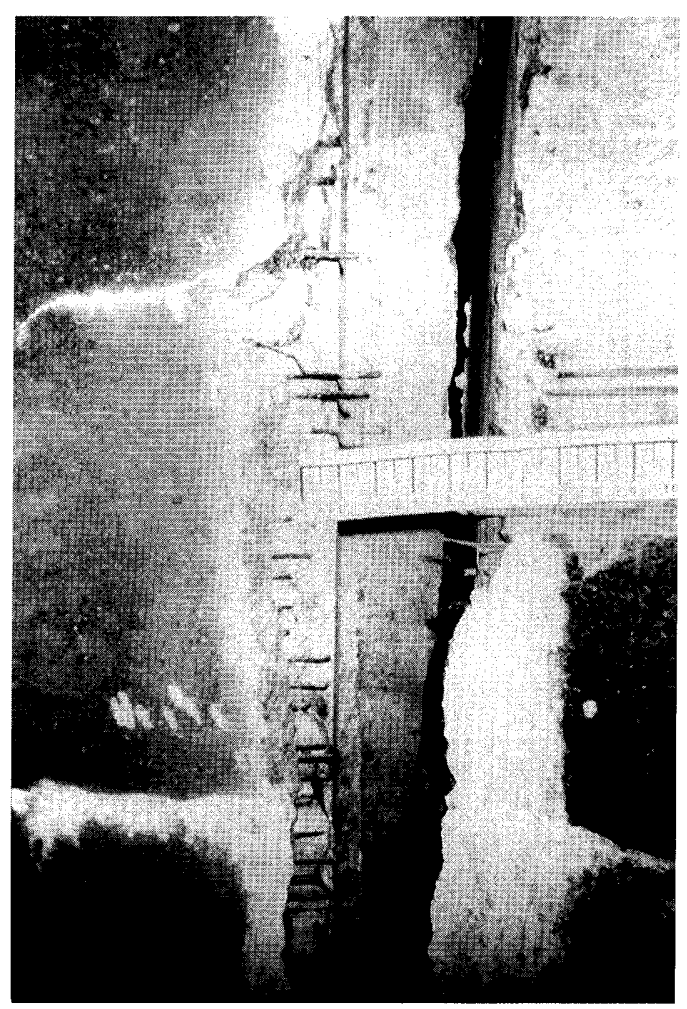

Figure 18.-Water tank shown in figure 17 completely lost its contents because of collapse of the column-supported roofslab and opening of vertical panel join. 
umn-supported roof slab and the rupture of a panel joint. The entire 1.1 million gal of water in the tank was lost.

Because tanks are susceptible to significant motion of their contents and support pad, the flexibility of the waterline connections to the tank is vitally important. Flexible connections should be provided that will allow relative motions of at least 6 in. (vertically and in both horizontal directions) between the tank and the waterlines (fig. 19).

\section{SUMMARY}

The implementation of these lessons learned will be difficult and costly in both time and material; however, the utilities that implement them will have made a significant investment in earthquake-disaster mitigation that will pay dividends both in financial costs and in public satisfaction after the next large earthquake. In geographic areas of low seismic risk, where seismic retrofit is much more difficult to justify, the appropriate seismic upgrades can commonly be performed during normal refurbishment.

\section{ACKNOWLEDGMENT}

We acknowledge the considerable contributions from the following members of other postearthquake-damage-reconnaissance teams, all of whom are members of the American Society of Civil Engineers, the American Water Works Association, or the Earthquake Engineering Research Institute: LeVal Lund, Donald Ballantyne, and Anshel Schiff. We especially thank the utility managers of the American Water Works Association, California/Nevada section: B.J. Miller, Norman Lougee, Brian Whitaker, Ronald Grasser, John Jones, and Richard McMillan.

\section{REFERENCES CITED}

American Public Health Association, 1989, Standard methods for the examination of water and waste water (17th ed.): Washington, D.C., American Water Works Association, 1,193 p.

Benuska, Lee, ed., 1990, Loma Prieta earthquake reconnaissance report: Earthquake Spectra, v. 6, supp. 90-01, 448 p.

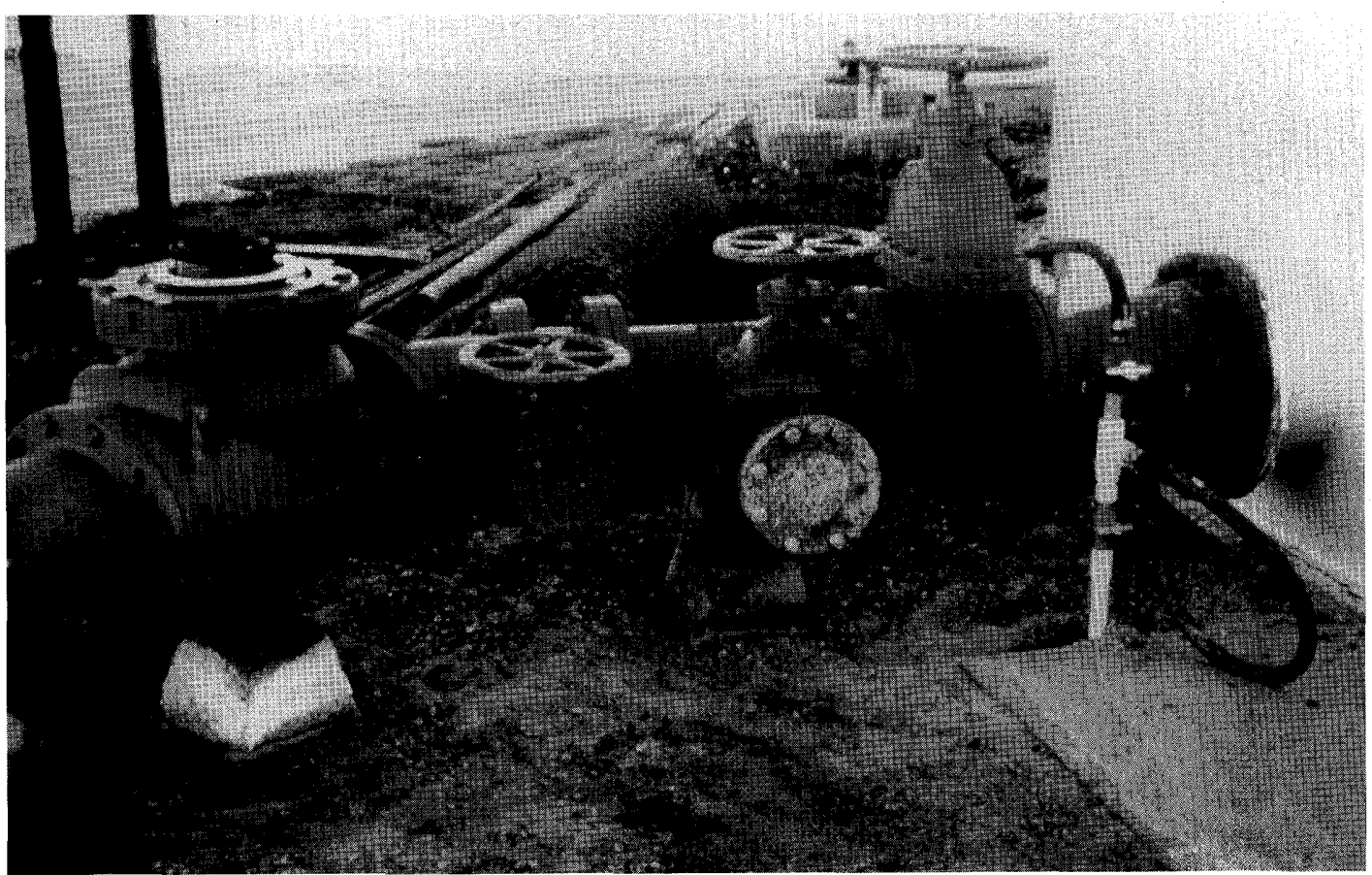

Figure 19.-Pipe connections to water tanks should be flexible enough to allow at least 6 in. of differential movement (both horizontal and vertical) between tank and piping. 
Francisco Bay region about what transportation services would be available to them the next Monday morning. All participating agencies contributed materials, which the MTC took the responsibility of reproducing and assembling into press kits along with additional maps, basic regional travel data, and telephone numbers to expedite use by the media. The maps were even provided in computer-disk format so that newspapers could more easily print them.

After that first week, these special TOCC coordinating meetings were held weekly to facilitate the exchange of information on service adjustments and to keep everyone apprised of evolving funding and planning issues. All the participants were extremely cooperative and responsive.

This process has pointed to the fact that no amount of previous planning could have precisely anticipated the transportation consequences of the earthquake. The flexibility afforded by regular communication enabled the region to easily adapt its response as travel patterns shifted.

\section{OPERATIONS DURING THE RECOVERY PERIOD}

After Monday, October 23, the MTC produced a daily summary of key regional travel indicators. Earlier, the MTC had published only annual data for transit operators and semiannual counts for the San Francisco-Oakland Bay Bridge and the Caldecott Tunnel. The transit agencies and bridge and ferry operators transmitted data to the MTC by telephone, facsimile machine, or in person after the end of the morning commute period. The report, published each afternoon, updated the daily totals for the previous day and included that morning's commute. The report had wide distribution and was the principal summary used for discussion at the special weekly coordinating meetings.

Although these reports were adequate for general trend analysis, it was up to each transit operator to monitor specific transit services at the route level and make adjustments as required. Any service adjustments were reported to the MTC so that public information could be updated.

In addition to the basic travel data, several surveys were mounted to gather more detailed information about how travelers adapted their behavior. Owing to the immediacy of the need and the uncertainty in the early weeks about the date when the San Francisco-Oakland Bay Bridge would reopen, several agencies organized independent but complementary surveys. These surveys were coordinated through weekly meetings sponsored by the University of California, Berkeley's Institute of Transportation Studies. MTC staff conducted a survey of passengers on all of the newly established emergency ferry services. The Bay Area Rapid Transit (BART) district administered an onboard survey of its patrons (Cambridge Systematics, Inc., 1991). Caltrans conducted vehicle-occupancy counts and license-plate surveys at the three bay bridges and other locations and followed up with a mailout travel survey. The university conducted a regionwide telephone survey about general travel behavior
(Transportation Center, 1990-91). Golden Gate Transit conducted a survey of its patrons, and the Bay Area Council conducted a survey of employer response.

The analysis was somewhat hampered by a lack of detailed preearthquake data. Occupancy counts on routes other than the San Francisco-Oakland Bay Bridge and the Golden Gate Bridge have been rare. No general travel data had been collected since the MTC is 1981 survey, although BART conducted a patron survey in early 1987.

After the first weekend press conference, it was clear that the changing requirements necessitated frequent updates for the public through the major media. It was agreed that Caltrans' and the MTC's public-information offices would be the central coordinating point, but it was left to each operating agency to develop and disseminate its own detailed materials to the press and public. Caltrans published a "Commuter Guide," and the MTC published an updated guide with maps showing the locations of new or changed services. The public-information officers of these two and other agencies met several times, but facsimile and telephone contact were the principal means of keeping everyone informed.

With the initial financial backing of the MTC, RIDES for Bay Area Commuters opened a regional 800 hotline on October 24 to answer requests for information on ride sharing and public transportation. The first such regional transportation hotline, it proved particularly effective as a supplement to the printed materials and media announcements. The hotline was discontinued shortly after the San Francisco-Oakland Bay Bridge reopened.

\section{OBSERVATIONS AND RECOMMENDATIONS}

\section{COORDINATION AND CENTRAL DECISIONMAKING}

Although the informal coordinating structure described earlier worked well, it was complicated by two factors. First, coordination was more complex because of the multiplicity of actors. There was no central decisionmaking body because each agency's management was limited by the authority granted by its respective policy board. There was a tacit understanding that Caltrans was the dominant actor, but otherwise, decisions were made independently, and there was no definitive agreement on central decisionmaking authority. Nonetheless, cooperation was excellent, and no major policy conflicts occurred.

\section{UNCERTAINTY ABOUT THE AVAILABILITY OF FUNDING}

After the earthquake, there was continual uncertainty about the availability of funding from Federal and State sources, especially for such nontraditional emergency func- 
tions and public-information programs on transportation alternatives. Even though the U.S. Congress and the California Legislature acted quickly to establish emergency funds, 7 weeks after the earthquake, it was still unclear how much of which funds could be committed for which purposes, with any degree of confidence that the expenditures would be subsequently upheld as reimbursable. This uncertainty in resources somewhat hampered decisionmaking on emergency-service provision. Of the two issues of multiple actors and funding uncertainty, funding uncertainty is clearly the major obstacle to more effective planning. The regular coordinating meetings continued as long as they were needed, but the decisions that could be made at those meetings were severely constrained by questions about funding.

\section{PUBLIC-TRANSPORTATION RESOURCES IN THE SAN FRANCISCO BAY REGION}

Because of its longstanding commitment to public transportation, the San Francisco Bay region was able to marshal a substantial array of transit-service alternatives. The variety and depth of public transportation services already in place allowed a comprehensive and flexible system of rail, bus, and water transport, complemented by new highway high-occupancy-vehicle facilities, which were put in place virtually overnight. Without a strong local transit funding base, some degree of redundancy, expansion capacity, and widespread use of public transportation, such a response might not have been possible.

\section{DIVERSIFICATION OF REGIONAL TRANSPORTATION SYSTEMS}

Air-quality, traffic-congestion, and land-use issues have long been the impetus for expanding the region's public-transportation system. The earthquake reminded us of the fragility of a regional economy dependent on bridges, tunnels, and landslide-prone highways. In investments, it is well established that diversification is the best protection against unanticipated setbacks. Similarly, beyond the immediate need for repair or replacement of facilities, a long-term need exists for Federal and State support to continue the expansion of regional public-transportation facilities in all major corridors, so as to diversify the region's transportation system and give it the ability to withstand shocks to parts without catastrophic damage to the whole.

\section{EMERGENCY PLANS}

All seismically vulnerable transportation systems should be immediately evaluated, and priorities established for dealing with them. Alternatives to these facilities should be identified and enhanced as needed to provide emergency capacity. Generalized regional contingency plans should be outlined for the most likely disaster scenarios. Management, opera- tions, and planning exercises should parallel the frequent disaster-response exercises.

\section{FORMAL COORDINATION PROCEDURES}

More formal understanding should be established of the respective roles and authorities of the various agencies. Where necessary, statutory changes might be required to achieve more effective coordination through a clearer delineation of powers. Emergency-communication arrangements among affected agencies should be upgraded and tested on a regular basis. Funding issues should be worked out in advance so that no question remains about the availability of resources. Flexibility in the use of funds is the paramount concern; decisions on how best to use resources should be delegated to the appropriate regional coordinating body, rather than by mode or funding agency.

\section{TRANSPORTATION-SYSTEM MONITORING}

The regular monitoring of travel in major regional corridors should be continued on a scaled-back basis. A continuing, low-level regional-travel-data-monitoring program should be established to provide reasonably current trend data at all times.

\section{PUBLIC INFORMATION}

Marketing and public information should be continued on a regional basis. A regional telephone information service should be continued, and a general regional public-transportation marketing and awareness program should be established to inform travelers of their alternatives.

\section{PREDISASTER PLANNING}

Effective response to future, more severe disasters could be limited by a lack of planning. No disagreement exists that this earthquake was merely a hint of what awaits the region when the major faults slip again closer to the San Francisco Bay region's urban center. The ability to effectively manage that catastrophe will not be limited by the dedication or resourcefulness of our citizens and institutions, which were superlative in this earthquake, but rather by the lack of adequate previous consideration of the issues raised above.

\section{LESSONS LEARNED AND CURRENT PRACTICES}

Since the initial evaluation reported above, there have been several activities to enhance future emergency-response capabilities:

1. Caltrans has completed a survey of routes State-wide for designation as "lifeline" routes to supply regions with emer- 
gency relief. Funding and priorities for improvements to those routes are being explored.

2. San Francisco Bay region public-transit operators have agreed on a general approach to evaluating and mitigating hazards in their systems (Metropolitan Transportation Commission, 1992), as well as responding to an earthquake (Metropolitan Transportation Commission, 1994).

3. San Francisco Bay region ferry operators have agreed on a specific plan to provide emergency services on San Francisco Bay (Metropolitan Transportation Commission, 1996).

4. The State has relinquished a radio frequency for use by transit agencies during emergencies. The MTC has helped the agencies procure and install radio equipment for baseto-base communications using that channel.

5. The Association of Bay Area Governments (ABAG) and Caltrans have completed a project that maps the region's transportation facilities against the known seismic hazards. The complete report (Association of Bay Area Governments, 1997) will be the focus of workshops to be hosted in the various corridors within the San Francisco Bay region in order to bring the transportation providers and emergency response community together in each corridor to encourage further planning at subregional/corridor levels.

6. The Bay Area Partnership's Planning \& Operations Committee and the Transit Coordinating Council endorsed the Trans Response Plan (TRP) in October 1997. The TRP defines procedures for developing and implementing a comprehensive multimodal transportation response to a regional disaster and coordinates this effort within the overall Standardized Emergency Management system (SEMS) implemented by the California Office of Emergency Services (OES). A "coordination team" that includes the U.S. Department of Transportation, the OES, Caltrans, and the MTC would convene to establish regional priorities for emergency response and recovery efforts.
7. As of September 1996, a new regional telephone number has been established for multimodal transportation information. Although that system, called TravInfo, has not yet been sized for the volume of calls which would result from a major earthquake, it could be expanded quickly. In addition, the TravInfo project provides a central electronic data base of traffic and transit information that can be used for preearthquake planning and postearthquake monitoring.

8. The MTC is leading an effort to better coordinate multiagency earthquake response ("regional emergency multimodal response plan"). The first multiagency tabletop planning exercise was held in November 1996. Multiagency planning exercises are now planned on an annual basis.

9. The State OES has implemented a Response Information Management System (RIMS) to track resources and response information among the County Operational Areas. The RIMS reporting can be communicated by using the Operational Area Satellite Information System (OASIS) throughout the State.

\section{REFERENCES CITED}

Association of Bay Area Governments, 1997, Riding out future quakes; pre-earthquake planning for post-earthquake transportation system recovery in the S.F. Bay Region, Oakland, Calif.

Cambridge Systematics, Inc., 1991, BART user/non-user panel survey analysis - phase 1: report prepared for San Francisco Bay Area Rapid Transit District.

Metropolitan Transportation Commission, 1992, Model operator contingency plan: Oakland, Calif.

1994, Regional emergency [transit] management plan: Oakland, Calif.

1996, Regional Ferry Contingency Plan: Oakland, Calif.

Transportation Center, 1990-91, Studies on the Loma Prieta earthquake: Berkeley, University of California. 


\title{
LIFELINES
}

\section{TRANSPORTATION SYSTEMS-AIRPORTS}

\author{
By Anshel J. Schiff, Precision Measurement Instruments and Stanford University; \\ and \\ Luis Cusa, Los Angeles Department of Airports
}

\section{CONTENTS}

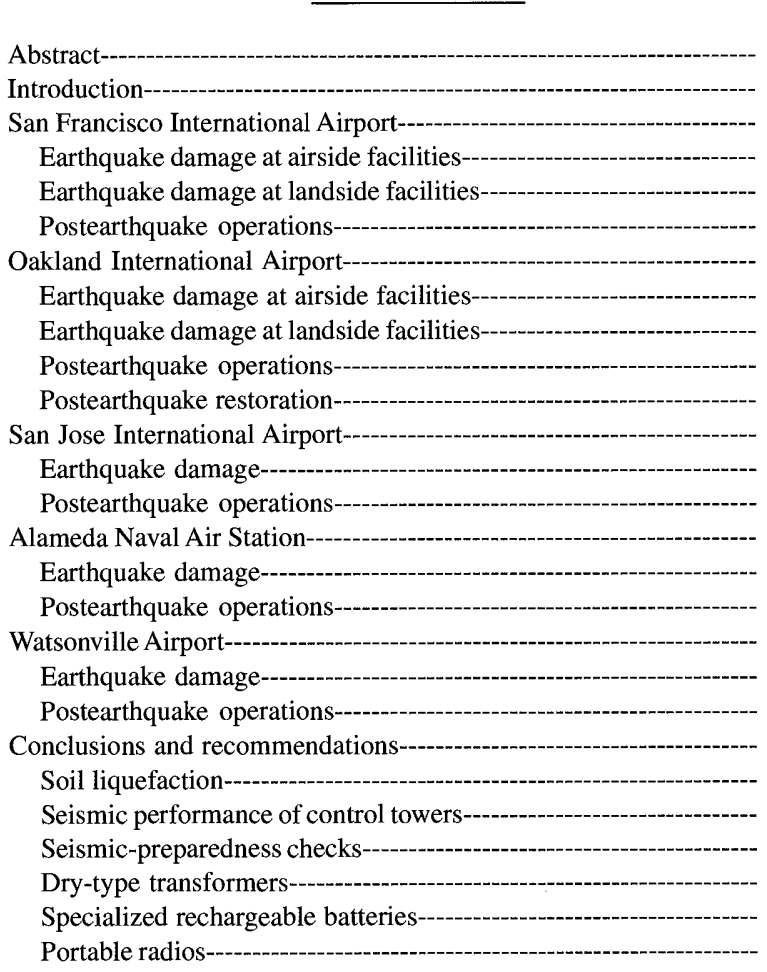

Page

A103

103

104

104

104

104

105

106

106

106

106

106

107

107

107

107

107

107

107

108

108

108

108

108

109

109

109

ABSTRACT

Runway damage was caused by soil liquefaction at Oakland International Airport and the Alameda Naval Air Station (ANAS). At the airport, 3,000 ft at one end of the runway was unusable until cracks across the runway were repaired. ANAS could not be used until massive repairs were completed.

Windows in the control towers at San Francisco International Airport and Oakland International Airport were damaged. Because of the high ambient-noise level outside of the control tower due to arriving and departing aircraft, the loss of the windows at San Francisco International Airport severely disrupted operations. Dispatchers in the control tower could not hear or be heard because of noise, and repeated transmissions slowed operations by half.

One of several engine generators at San Francisco International Airport did not start and the movement of an unanchored transformer at San Jose International Airport almost disrupted power there. Much of the equipment at airports, such as jetways and baggage handling equipment, is not provided with emergency power, and so the loss of commercial power can slow or interrupt airport operations.

The terminal area at Oakland International Airport sustained minor structural damage. A building used by freight forwarders at San Francisco International Airport was severely damaged and subsequently demolished. Damage to the suspended ceiling in the North Terminal at San Francisco International Airport caused massive water leaks in the fire sprinkler system.

\section{INTRODUCTION}

A reconnaissance team investigated the San Francisco Bay region's three commercial airports in San Francisco, Oakland, and San Jose. The Alameda Naval Air Station (ANAS), located in the east bay just south of the San Francisco-Oakland Bay Bridge, and the Watsonville Airport were also investigated by means of telephone interviews. No strong-motion-recording instruments were located at any of the airports. Because of the unique soil conditions at most of the airports, it would be inaccurate to characterize airport ground motions by using nearby seismic records. Peak accelerations at bedrock near all the airport sites, except Watsonville, were less than $0.1 \mathrm{~g}$, but soil conditions at the airports amplified ground motions.

The reconnaissance team visited officials at all three commercial airports on November 9, 1989. All airport managers reported that the response of their staffs to the earthquake was outstanding. Most offduty staff quickly returned to each airport and responded to contingencies as they arose. All three airports reported minor damage and (or) problems that affected, or could have affected, facility operations. Many of the shortcomings noted below are being addressed, even though they did not cause problems in the earthquake. One 
important purpose of postearthquake investigations is to identify things that either failed or did not operate as expected; little is generally said of the many operations, facilities, and equipment that worked well. The reconnaissance team came away from this investigation with the understanding that the airport authorities did a conscientious job in preparing for the earthquake.

Airports are generally divided into two parts: airside facilities and operations and landside facilities and operations. The airside facilities include the runways, Federal Aviation Administration (FAA) facilities, control tower, and other facilities in some restricted areas of the terminal building. Landside facilities include access roads, garages, and passenger areas within the terminal building.

The most significant earthquake damage was reported at Oakland International Airport, where soil liquefaction damaged 3,000 ft at the end of their only regular runway, as well as part of an adjacent taxiway. Soil liquefaction also severely damaged both runways at ANAS, which remained closed to air operations through December 1989. For various reasons, San Francisco International Airport was closed for 13 hours. For each airport, this section briefly describes the facility, identifies the reported damage, and discusses the earthquake's impact on various aspects of operations, concluding with general comments and observations.

\section{SAN FRANCISCO INTERNATIONAL AIRPORT}

San Francisco International Airport has two sets of parallel runways that intersect each other, with air traffic of about 1,300 commercial flights per day and an annual passenger flow of 31 million. The annual freight flow through the airport is $570,000 \mathrm{t}$. About 31,000 employees work at the airport.

The airport is located about $50 \mathrm{~m}$ from the epicenter, and the peak acceleration recorded near the airport was $0.29 \mathrm{~g}$.

\section{EARTHQUAKE DAMAGE AT AIRSIDE FACILITIES}

One window of the control-tower cab fell out, along with a radar monitor. Ceiling panels, light fixtures, and fiberglass acoustic insulation fell in the control-tower cab, making it difficult to operate the facility. Typewriters, computer monitors, two of the three remaining radar monitors, and an additional monitor used in training fell from their supports and were inoperable. None of this equipment was anchored to desktops or stands. At the time of the reconnaissance team's visit, the 184-ft-tall steel support structure of the control tower was being evaluated by using $X$-ray inspection methods. Four minor injuries occurred to personnel in the tower when objects fell on them. Damage to the elevator in the control tower made it inoperable for 3 to 4 days.
Despite a significant shift, possibly due to liquefaction, in the support structures for the lights that mark the runway approach and extend into the bay, the lights remained operational. All navigational equipment was unaffected, except for one of the instrument landing system's antennas adjacent to runway 28R, which was knocked down. The antenna was straightened, aligned, and put back into service. Fuel-storage tanks and piping systems were undamaged.

\section{EARTHQUAKE DAMAGE AT LANDSIDE FACILITIES}

Damage in the terminal areas was cosmetic and determined by each terminal's design. In the North Terminal, which was severely damaged, about 80 percent of the lightweight acoustic ceiling panels fell; they were supported on a wirehung T-bar framing system. Large, molded, monolithic ceiling elements, also supported by wires, swung more than $1 \mathrm{ft}$ and were cracked by their impacts with structural support columns; none of the ceiling elements fell. Fire-suppression sprinkler heads that protrude through the ceiling were damaged by the motion of the suspended ceiling, resulting in the release of large volumes of water, which was 4 to $6 \mathrm{in}$. deep in boarding area $\mathrm{F}$. Television flight monitors in several locations toppled from their supports above public-seating areas, but no one was hit. Wet floors became quite slippery, but no one was injured. The only injury reported was to an airline employee, who was found under an overturned check-in counter and could not move her legs. Water damaged a United Airlines' reservation computer located in the basement of the North Terminal. In the International Terminal, about 15 percent of the ceiling panels fell, and minor water damage was reported. Only a few ceiling panels fell in the South Terminal.

A dry-type transformer, part of a unit substation, sustained a temporary short, which activated a protective circuit; it was reset, and the substation was put back into service. Then, 10 days later, this transformer caught fire from damage attributed to the earthquake. A two-story building, which had been temporarily used for airline cargo operations and at the time of the earthquake was being used as office space by freight-forwarding companies, was severely damaged and subsequently demolished. Workers continued to find damage that did not affect operations for several months after the earthquake. For example, a pipe hanger was broken, and a small suspended transformer in an out-of-the-way location that was unanchored to its support had shifted.

\section{POSTEARTHQUAKE OPERATIONS}

After the earthquake, one or two aircraft on final approach were flagged off to allow the reconnaissance team to inspect the runways. Normal flight operations were stopped immediately after the earthquake disrupted control-tower ac- 
tivities. A few flights were allowed to depart about 2 hours after the earthquake because they were loaded and no airtraffic problems were reported. Although the tower was physically capable of operating, it was closed because not enough controllers were available to safely operate it. About $1 \frac{1}{2}$ hours after the earthquake, the airport was officially closed; private cars were not allowed into the airport until the next morning. Most passengers at the airport at the time of the earthquake took airport buses or taxis to the city or to airport hotels; 500 to 1,000 passengers stayed at the airport's South Terminal overnight, some using cots provided by the local American Red Cross. Blankets and pillows were supplied by some airlines, and food was supplied by the airport's food concessionaire. Two airport hotels, the AMFAC and the Hyatt Regency, were damaged and evacuated, leaving relatively few rooms available in the airport area. The airport was officially reopened and flight operations resumed at 6:00 a.m. P.s.t. October 18. Initially operations were at about 50 percent of their normal level, partly because of the extremely high noise level in the tower with the missing window. Installation of a temporary plexiglass panel improved the situation on October 19, making the tower fully operational. It took several days for airlines to resume normal schedules because aircraft and crews had been diverted and had to be repositioned.

Commercial power was lost shortly after the earthquake and was restored $2 \frac{1}{2}$ hours later. All but 1 of the 14 diesel gen-

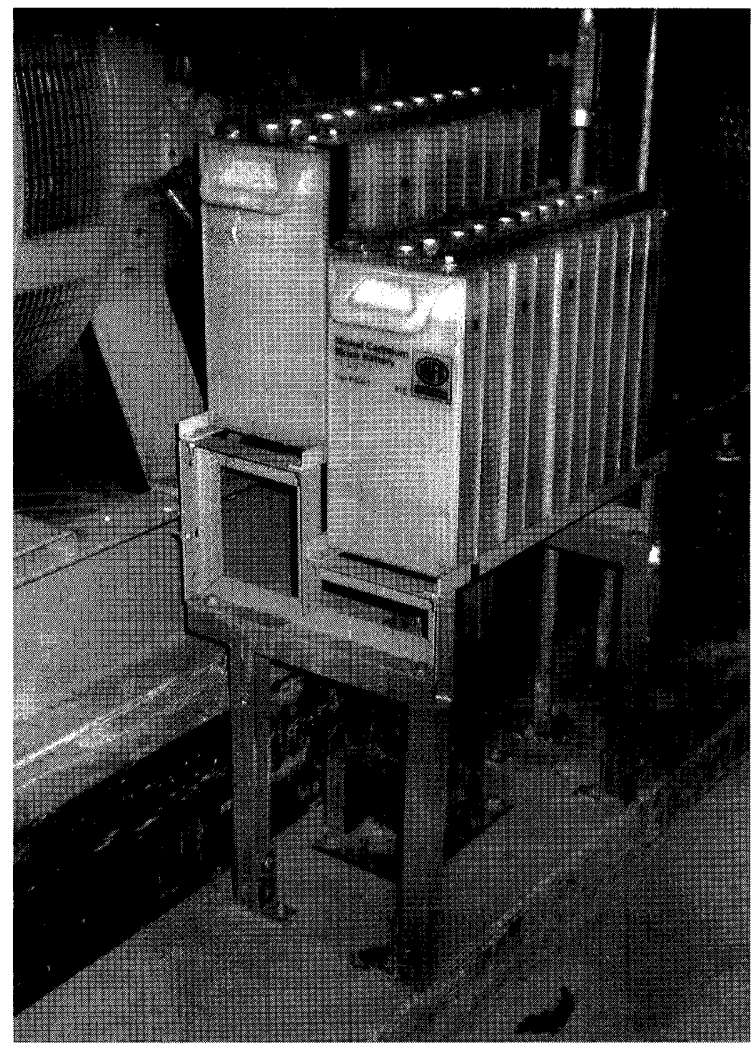

Figure 1.-Emergency-power generator with unsecured batteries. erators used to provide emergency power to airport facilities started automatically. That unit failed to start because the contacts of the relay that senses a power outage were burned; this relay is not used during normal periodic testing of the generators, and visual inspection did not detect the problem. The unit was started manually without difficulty. The diesel generator used to provide emergency power for communications was inspected by the reconnaissance team. The unit was mounted on well-designed, heavy-duty vibration isolators that had snubbers to prevent excessive motion. It appeared that the unit hit the snubbers during the earthquake. Batteries for starting the unit were supported on a stand about $3 \mathrm{ft}$ above the floor and, except for a $1 / 2$-in.-high lip at the edge of the rack, were unrestrained (fig. 1). None of the batteries fell from its support during the earthquake. The FAA had one or more generators, which provided power to control tower instruments. Emergency power for the tank farm, which supplied fuel to aircraft, was supplied by the tank-farm operator. Emergency power was not provided to the jetways normally used by passengers to disembark from planes; instead, mobile stairways were used to unload planes on the ground while commercial power was unavailable.

Because the airport does not use uninterruptable power supplies, a short interruption of power occurs before the emergency generators start. Repeaters, which are transmitters located around a site to ensure that radio communication can be picked up anywhere on the site, shut down because of the power outage and had to be reset manually. This resetting required that sites around the airport be entered, at some of which entry was delayed because access keys were unavailable. The temporary loss of some of the repeaters apparently did not cause any problems. The room currently used for airport emergency operations had, some time ago, been converted from a conference room. The lighting for this room had not been transferred over to circuits that are provided with emergency power, and so it became dark shortly after the earthquake.

Elevators in the terminals were shut down by automatic seismic switches; none of the elevators was damaged, and all were restored to service in about 2 hours. Non-coin-operated telephones within the airport are on a Centrex system, which runs through the central office of the telephone company. Although the equipment was undamaged, airport personnel assumed that the system was not working because of a very long delay (as long as several minutes) in getting a dialtone. Radiocommunication channels became saturated, but they were manageable. Had damage been more severe, or had there been more minor or major incidents, such as additional personal injuries or a fire, saturation of radio communication would probably have interfered with the emergency response. Additional frequencies have since been added to the system.

\section{OAKLAND INTERNATIONAL AIRPORT}

International Oakland Airport has two runways and two FAA-certified control towers, one at the commercial airport and 
one at the adjacent general-aviation airport. The commercial airport has about 100 flights per day, with about 4 million passengers per year; annual freight flow through the airport is $200,000 \mathrm{t}$. The main airport runway is $10,000 \mathrm{ft}$ long and parallels the bay shoreline; it is normally used for commercial aviation. A second runway that is $6,200 \mathrm{ft}$ long is now used primarily for general aviation, although it can also be used for commercial aviation. The main runway is built on hydraulic fill, from 5 to $10 \mathrm{ft}$ thick, which was placed over young bay mud. The entire runway is of similar construction. The hydraulic fill is primarily poorly consolidated sand, and so it is particularly vulnerable to soil liquefaction in an earthquake. The older part of the airport is built directly on bay mud, rather than sand.

The airport is located about $56 \mathrm{mi}$ from the epicenter and the peak accelerations recorded near the airport ranged from 0.19 to $0.29 \mathrm{~g}$.

\section{EARTHQUAKE DAMAGE AT AIRSIDE FACILITIES}

About 3,000 ft at the north end of the 10,000-ft-long main runway, the adjacent taxiway, and the dike that borders the bay were severely damaged by soil liquefaction. Cracks across the runway were as much as $1 \mathrm{ft}$ wide, and long cracks in the ground parallel to the runway were as much as $10 \mathrm{ft}$ deep. In a few places, vertical offsets across the runway were as large as $1 \mathrm{ft}$. Sand boils on the runway and adjacent to the runway were as long as $40 \mathrm{ft}$ in diameter. Abundant soil liquefaction occurred because the soils are especially susceptible. The control tower associated with the general-aviation field lost three windows, yet it continued to operate. One window was cracked in the commercial control tower.

\section{EARTHQUAKE DAMAGE AT LANDSIDE FACILITIES}

Soil liquefaction between two terminal buildings damaged two major structural columns that support the crosswalk between the terminals. The damage to these columns was probably due to relative motion between the two terminals, one of which is two stories high and relatively stiff, and the other a relatively flexible, taller structure. The rupture of a 16-in.-diameter water main caused the collapse of a service road.

\section{POSTEARTHQUAKE OPERATIONS}

Airport officials immediately shut down operations after the earthquake to allow runway damage to be evaluated. Flights were then diverted to the adjacent general-aviation runway, which is FAA certified. Within $1 \frac{1}{2}$ hours, flights were shifted back to the main runway, which had been shortened to 7,000 ft. The passenger terminals were evacuated until their safety could be evaluated. The damaged columns affected only the walkway between terminals. The airport did not lose commercial power, and so it did not have some of the problems at other airports in the San Francisco Bay region.

The damaged columns that support the interterminal walkway were shored up as a safety precaution, and the road under the walkway was closed to ensure that the shoring would not be damaged. The walkway remained in use for passenger traffic in the terminal.

Communication problems at the airport affected ground operations. Ground operations (police and maintenance workers) shared one radio frequency, which quickly became overloaded. The airport has two authorized frequencies and is adding a second repeater so that the second frequency can be used. Cellular telephones were added during the reconstruction to alleviate this problem. A problem was also reported in communicating with crews who were cleaning up minor damage to the terminal. Normally, pagers are used to contact crews, who then use courtesy telephones to get their messages. Airport telephones on a Centrex system were effectively nonfunctional because their circuits were overloaded, and so runners were used to communicate with the cleanup crews. A problem in communicating with passengers when they were outside of the terminal was similar to the experience at the Burbank Airport after the 1987 Whittier Narrows, Calif., earthquake. At Oakland International Airport, some car-mounted megaphones were used, but more were needed.

\section{POSTEARTHQUAKE RESTORATION}

At the time of the earthquake, crews were resurfacing the main runway. An emergency change order was issued, and restoration of the runways began almost immediately, because crews and equipment were already on site. The plan was to do a partial restoration before the Thanksgiving rush and then complete the work before the Christmas rush. Extensive testing verified the absence of any concealed cavities below the runway. The repairs involved removing about $5 \mathrm{ft}$ of soil on each side of the cracks, replacing it with engineered fill, and compacting the new materials. During the repair, the usable length of the runway had to be adjusted; at times, it was as short as $6,200 \mathrm{ft}$, but by December 25 it had been extended to $8,500 \mathrm{ft}$. The remaining $1,500 \mathrm{ft}$ and the damaged taxiway were repaired after the award of competitive bids. Total repair costs for the airport were about $\$ 7$ million.

\section{SAN JOSE INTERNATIONAL AIRPORT}

San Jose International Airport has three runways, which range in length from 4,800 to $8,900 \mathrm{ft}$. It has about $400 \mathrm{com}$ mercial flights per day, and the annual passenger flow is 20 million. The annual freight flow through the airport is 7,500 t. About 2,350 employees work at the airport. 
The airport is about $13 \mathrm{mi}$ from the epicenter, and the peak accelerations recorded near the airport ranged from 0.1 to $0.2 \mathrm{~g}$.

\section{EARTHQUAKE DAMAGE}

A window in the control tower fell out, and an overhead air-conditioning unit and fiberglass soundproofing panel fell into the control-tower cab. A 5-gal drinking-water bottle also caused some damage in the tower when it fell over. Within the terminal, a few ceiling panels fell from their Tbar supports. A signal lead that connected the base-station transmitter to its antenna broke because inadequate slack in the connection allowed motions of the antenna to overstrain the lead. A small dry-type transformer associated with the emergency-power generator came in contact with its cabinet and arced, but it remained functional.

\section{POSTEARTHQUAKE OPERATIONS}

Apart from a few minutes of interruption while the runways were being inspected, airport operations were not disrupted by the earthquake. Commercial power to the airport was lost shortly after the earthquake and was restored about $51 / 2$ hours later. The emergency-power generator started and operated as intended. Because the fuel-tank farm was not supplied with emergency power, aircraft and airport vehicles, such as police cars, could not be refueled. With the closing of San Francisco International Airport and the loss of part of the runway at Oakland International Airport, authorities considered diverting flights to San Jose International Airport. However, without the ability to refuel, many planes would not have been able to take off if they had landed.

Soon after the earthquake started, the two police dispatchers evacuated their small office in the terminal, but they continued to work outside of the building adjacent to their office. They used a hand-held radio and repeaters to maintain communications. The public-address system could not be accessed from outside of the dispatching office, and so officers evacuated the terminal by walking through. Because the basestation transmitter was out of service, the hand-held radio was also used after the dispatchers returning to their office.

\section{ALAMEDA NAVAL AIR STATION}

ANAS consists of an airport, port facilities, and berthing facilities. The airport has two runways, 7,200 and $8,000 \mathrm{ft}$ long, and a terminal building. The berthing facilities can accommodate 11 ships; 6 ships were berthed at the time of the earthquake. A squadron of six mine-countermeasure MH53E helicopters is based at ANAS, along with more than 20 other aircraft of various sizes, the largest of which is a DC 9.

The airport is located about $60 \mathrm{~m}$ from the epicenter, and the peak acceleration recorded at the airport was $0.29 \mathrm{~g}$.

\section{EARTHQUAKE DAMAGE}

Much of ANAS is built on fill, and substantial soil liquefaction occurred at the site. Both runways of the airport were closed because of severe damage, which consisted of 5- to 8-in.-wide cracks and surface ripples. About $4,000 \mathrm{ft}$ of one runway appeared to be undamaged. Part of the terminal building was condemned because of structural damage. Piers as well as railroad tracks on the piers were damaged. The water- and gas-distribution systems at ANAS were severely damaged, and both water and gas services were disrupted, but electric power remained available.

\section{POSTEARTHQUAKE OPERATIONS}

Helicopter pads remained operational and were used for emergency and relief operations to California Interstate Highway 880, Watsonville, Oakland, and Santa Cruz. The sixhelicopter squadron based at ANAS made 52 earthquakerelated flights. The Air National Guard also used ANAS in its earthquake-related activities.

About $4,000 \mathrm{ft}$ of one runway was opened 10 days after the earthquake for emergency purposes only and was restricted to lightly loaded aircraft. This runway was used to relocate many of the aircraft to the general-aviation field of Oakland International Airport. One runway was reopened at the end of December 1989, and the second was completed in mid-January 1990. Cracks were excavated, filled, and compacted, and the runway was resurfaced.

ANAS was without water for 8 days and without gas for 2 weeks. The telephone system was saturated, and so it was difficult to make calls.

\section{WATSONVILLE AIRPORT}

Watsonville Airport has two 4,000-ft-long, lighted, paved runways. It is the only airfield in Santa Cruz County that is open to the public, serves general aviation, and is "uncontrolled," in the sense that it lacks a control tower. The airport has three approaches with instrument support. Both local and a nondirectional beacon are located at the airport, and a very high frequency omnidirectional ranging unit, which serves Watsonville Airport, operates near Salinas.

The airport is located about $10 \mathrm{mi}$ from the epicenter, and the peak acceleration recorded near the airport was $0.29 \mathrm{~g}$.

\section{EARTHQUAKE DAMAGE}

Shortly after the earthquake, electrical power was lost. The airport did not have emergency-power generators. Aircraft there for the day could not leave because of the loss of runway lights. The only damage to the airport or its facilities was to some hangar doors, which fell from their support rails. 


\section{POSTEARTHQUAKE OPERATIONS}

Damage to highways and bridges led to the closure of all roads into Watsonville. California Highway 152, a mountain road with limitations on vehicle size, was reopened within 24 hours. Watsonville Airport was used to bring relief supplies and personnel into the area. During the days after the earthquake, air traffic increased significantly, and the FAA was asked to supply a temporary control tower. On October 19, 1989, two FAA vans established a control tower run by two or three people from the Monterey Airport control tower. Military aircraft, primarily large helicopters and C130 transport planes, brought in personnel and heavy supplies, including water. Groups of engineers were brought in daily on C130's to assist in the inspection and tagging of buildings in the area. About 25 military flights occurred daily, and many flights of small private aircraft delivered clothes and food. Airport officials reported that 125 tons of earthquake-relief supplies was flown from San Jose's Reid-Hillview Airport to Watsonville in more than 300 flights made by light planes on the weekend of October 28-29. Traffic during the days after the earthquake peaked at several hundred flights a day. The FAA removed the control tower on October 24, 1989. The airport also added emergency-power generators.

\section{CONCLUSIONS AND RECOMMENDATIONS}

\section{SOIL LIQUEFACTION}

The most significant impact of the earthquake on airports was the damage to the runways at Oakland International Airport and ANAS and the closing of San Francisco International Airport for 13 hours. None of these events interfered with or placed demands on the emergency response. The earthquake revealed system weaknesses, but because ground shaking was moderate at these sites, it did not overwhelm the systems or significantly disrupt service.

Soil liquefaction threatens long-term disruption of airports in future earthquakes. The intensity and duration of ground shaking in the earthquake at airports and in other parts of the San Francisco-Oakland area was just above the threshold for liquefaction of highly susceptible soils. Liquefaction will probably recur at Oakland International Airport in future earthquakes that generate an equal or greater intensity and duration of ground shaking. Earthquakes of similar magnitude on the Hayward or San Andreas fault nearer Oakland are expected to cause much more severe and extensive liquefaction, both in areas that liquefied in the 1989 Loma Prieta earthquake and in areas not affected by the earthquake.

\section{SEISMIC PERFORMANCE OF AIRPORT CONTROL}

The emergency-response community generally assumes that airports will play an important role in the emergency response and recovery stages after a major earthquake in a metropolitan area. The response of city-administered parts of the airports performed well, with the exceptions noted above. The control towers did have problems. Control-tower windows have failed after at least four earthquakes in California: the 1971 San Fernando earthquake, the 1987 Whittier Narrows earthquake and its aftershock, and the 1989 Loma Prieta earthquake. Control-tower operations were also disrupted by fallen ceilings, light fixtures, and sound proofing. The 1989 Loma Prieta earthquake caused extensive, yet avoidable, damage to important equipment; for example, radar monitors were not anchored. This damage occurred in "earthquake country," caused by ground shaking considered moderate relative to levels anticipated for an expected great earthquake. In other parts of the United States, where seismic provisions are not part of the building codes, the emergency response will play an even greater role, and airports may be a vital element in the emergency response. During severe weather, which is much more common in other parts of the United States, the loss of control-tower windows could prevent a control tower from being used. The loss of function of basic monitoring equipment would almost certainly reduce the efficiency of airside operations. On the basis of California's experience, the performance of control towers in a severe earthquake will probably be poor.

\section{SEISMIC-PREPAREDNESS CHECKS}

A large airport is a combination of many complex, interdependent organizations, not unlike a moderate-size city. For example, 50,000 people work at Los Angeles International Airport; the airport has its own fire and police departments and a complex communication system. Airports are constantly evolving, with various facilities either being changed, upgraded, or expanded. Because of the complexity of their system components, as well as complex system interactions, airports should periodically conduct seismic-preparedness checks of the facility to locate and identify system components that might cause problems in an earthquake. Of particular concern are backup systems and operations, which are used only under unusual circumstances, such as a loss of commercial power. In light of the importance of backup systems and the experience after the 1989 Loma Prieta earthquake, it would be desirable to actually shut off the commercial power every few years to test how the backup-power systems and operations perform. Because larger airports operate around 
the clock, the timing of such a test would have to be carefully planned and coordinated with all the airport users to ensure that the level of disruption would be acceptable. Such a test would help identify potential problems in controlled circumstances, rather than in the aftermath of a disaster.

\section{DRY-TYPE TRANSFORMERS}

Dry-type transformers were damaged at two airports. Transformers are a component of a unit substation, which is a collection of power equipment that converts distribution voltages $(2.4-21 \mathrm{kV})$ to service voltages of $480 \mathrm{~V}$ or less. The transformer can be of the dry type (the windings, which are exposed to the air, are contained in an electrical cabinet, which commonly has ventilation grates on the sides and top to enhance air circulation for cooling) or the wet type (the transformer windings are in a sealed tank that contains oil, and the tank may have radiators for enhanced cooling). Typically, the electrical cabinet is anchored to the floor slab; however, the transformer winding within the cabinet may not be anchored to the cabinet. Earthquake motions may cause the transformer winding to rock and come in contact with its enclosure, activating protective circuits, damaging the winding, or even causing a fire. This disruption can cause a temporary or long-term loss of power to the equipment connected to the unit substation. Inspection of these units can be difficult because the cabinet doors must be opened, requiring that electrical power to the unit be shut off.

\section{SPECIALIZED RECHARGEABLE BATTERIES}

Adequate supplies of specialized rechargeable batteries should be provided for critical equipment. The use of rechargeable flashlights and specialized battery packs for radios is especially common. At one site, the rack for recharging the radio batteries was not connected to the emer- gency power supply, and so, if the power outage had lasted longer, radios would have become inoperable, a situation that would have been a severe drawback to operations. Also, the flashlights were sealed units, and so standard D cells could not be substituted when the rechargeable cells had run down. At one site, two sets of radios and few spare battery packs were on hand. Normally, at every shift change, the incoming shift takes freshly recharged batteries from the charger and the outgoing shift inserts its batteries for recharging. After the earthquake, both shifts were on duty, and so most battery packs were being used, and few were being charged. This arrangement would be unacceptable in an event that required a longer response.

\section{PORTABLE RADIOS}

Airport managers should have portable radios, which would allow them to get an early assessment of an earthquake's impact and help them in initial planning. Airport managers and dispatchers reported that official information on the severity, extent, and impact of the earthquake was unavailable for several hours. If they had been equipped with a portable radio capable of receiving audio signals from television stations, they could have gotten the information they needed to determine what actions to take during the recovery. Although the television coverage of the 1989 Loma Prieta earthquake was unique, probably because of the concentration of news media in the area for the World Series, we can expect extensive coverage of future metropolitan earthquakes. The bias in media coverage to spectacular photogenic situations was clear in this earthquake. The failure of the San Francisco-Oakland Bay Bridge, the fire in the Marina District of San Francisco, and the collapse of the Cypress Avenue viaduct in Oakland dominated the news, and there were no reports about Watsonville for hours. Earthquake-preparedness training should also include cautions on the interpretation of media coverage. 


\title{
TRANSPORTATION SYSTEMS—SEAPORTS
}

\author{
By Charles R. Farrar, Los Alamos National Laboratory; \\ and \\ A. Claude Griffin, Greiner, Inc.
}

\section{CONTENTS}

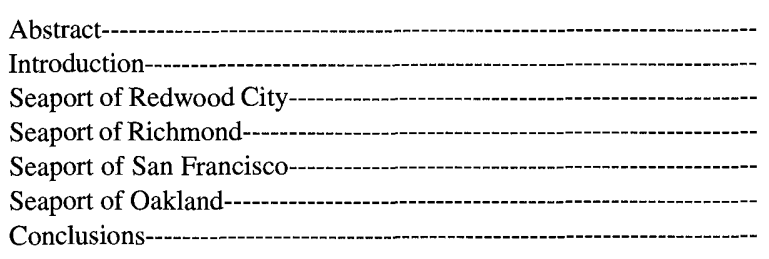

Page A111

111

111

112

115

117

119

\section{ABSTRACT}

There are four major commercial seaport facilities in the San Francisco Bay area: the Seaport of Redwood City, the Seaport of Richmond, the Seaport of San Francisco, and the Seaport of Oakland. Their primary lifeline function is to provide the initial or terminal transportation point for a variety of goods being imported to or exported from the San Francisco Bay area and other parts of the United States. First, we describe these seaport facilities, followed by a summary of the earthquake damage sustained, which is reported on an individual basis. In this summary, the seaports have been broken down into five parts: navigational channels, piers and wharves, cargo-handling equipment, cargo-storage areas, and interfaces with the inland transportation systems. The earthquake damage varied considerably for these different facilities. We discuss the steps taken to mitigate the effects of this damage and to bring the seaports back into operation, as well as the influence of the earthquake damage to other interfacing lifelines, such as power, water, natural gas, and communication systems, on the seaport operation immediately after the earthquake and on the long-term recovery of seaport facilities. Finally, we summarize the emergency-response plans that had been developed before the earthquake, their effectiveness, and the modifications to these plans that were made as a result of the earthquake.

\section{INTRODUCTION}

This section summarizes the postearthquake investigation of the major seaports in the San Francisco Bay region.
The reconnaissance team investigated the Seaports of San Francisco, Richmond, and Redwood City on November 20 and 21, 1989, and the Seaport of Oakland on November 28, 1989. The locations of these seaports are shown in figure 1.

Investigators attempted both to interview the engineers responsible for maintenance and operation of the port facilities and to inspect the actual damage to the facilities, so as to obtain the following information:

- Description of each seaport facility

- Description of the earthquake damage

- Description of the damage's impact on users of each seaport

- Description of the methods to restore service

- Description of obstacles to the restoration of service

- Description of the effects of earthquake damage to other lifelines on the operations of each seaport

- Description of the emergency plans of each seaport facility and their usefulness

\section{SEAPORT OF REDWOOD CITY}

The Seaport of Redwood City is located at the south end of San Francisco Bay, on the west side where Redwood Creek flows into the bay, as shown in Figure 1. This seaport, which was the one nearest the earthquake epicenter (approx $39 \mathrm{mi}$ ), is the smallest facility that was visited. A layout of this facility is shown in figure 2. Cement, scrap metal, and salt are the primary goods shipped from this seaport. The seaport handled $488,000 \mathrm{t}$ of freight in 1988. Tanks for petroleum products are also located at this seaport, along with a public marina and restaurants. The seaport was constructed on bay mud, with the wharves supported by both concrete and wood piles. The Seaport of Redwood City is responsible for all the maintenance of its facilities and has a one-person, inhouse maintenance crew. All the commercial wharves are accessible by both rail spurs and roadways.

\section{EARTHQUAKE DAMAGE}

Although this seaport was located closest to the epicenter of the earthquake, it sustained the least damage of the seaports 
in the San Francisco Bay region. Total damage was estimated at $\$ 260,000$, consisting primarily of broken waterlines, damaged batter piles, and separation of the concrete ramp at Wharf 1 from the pier. The seaport was never closed, and the earthquake damage had no adverse effect on the operation of the facility. Waterlines were repaired within a week after the earthquake. Other repairs to the seaport were contracted out.

There was only a temporary interruption in electrical and telephone service; both services were restored within 8 hours after the earthquake. Traffic was jammed on the major highways that service the seaport for most of the evening of the earthquake. There were no reported effects from earthquake damage to other lifelines.
EMERGENCY-RESPONSE PLAN

The Seaport of Redwood City had no formal emergencyresponse plan for an earthquake. When the investigation was made in November, 1989, the business manager said that they did not intend to develop such a plan at that time.

\section{SEAPORT OF RICHMOND}

The Seaport of Richmond is located at the northeast end of San Francisco Bay near the entrance to San Pablo Bay, approximately $65 \mathrm{mi}$ from the earthquake epicenter (fig. 1).

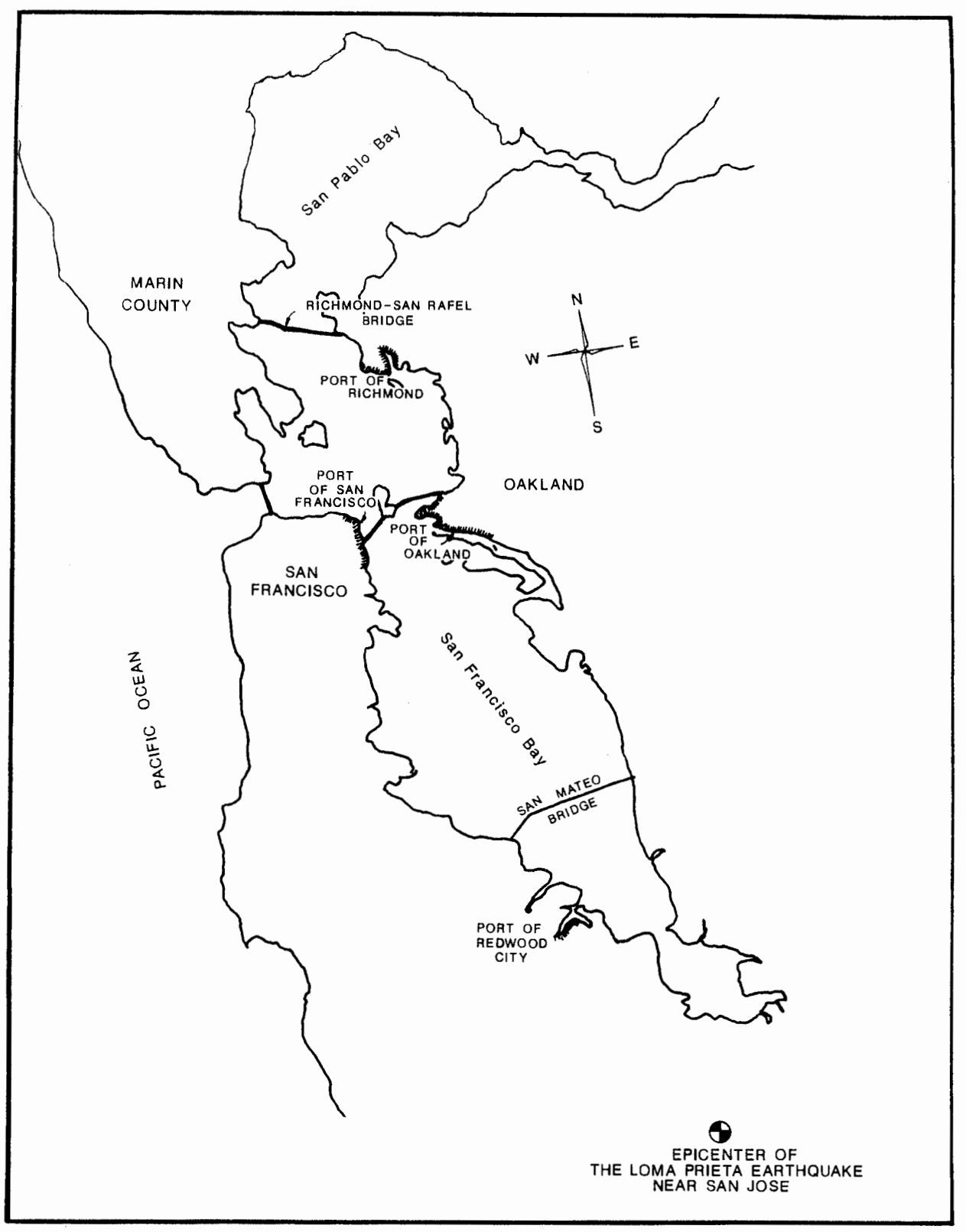

Figure 1.-San Francisco Bay region, showing locations of seaports. 


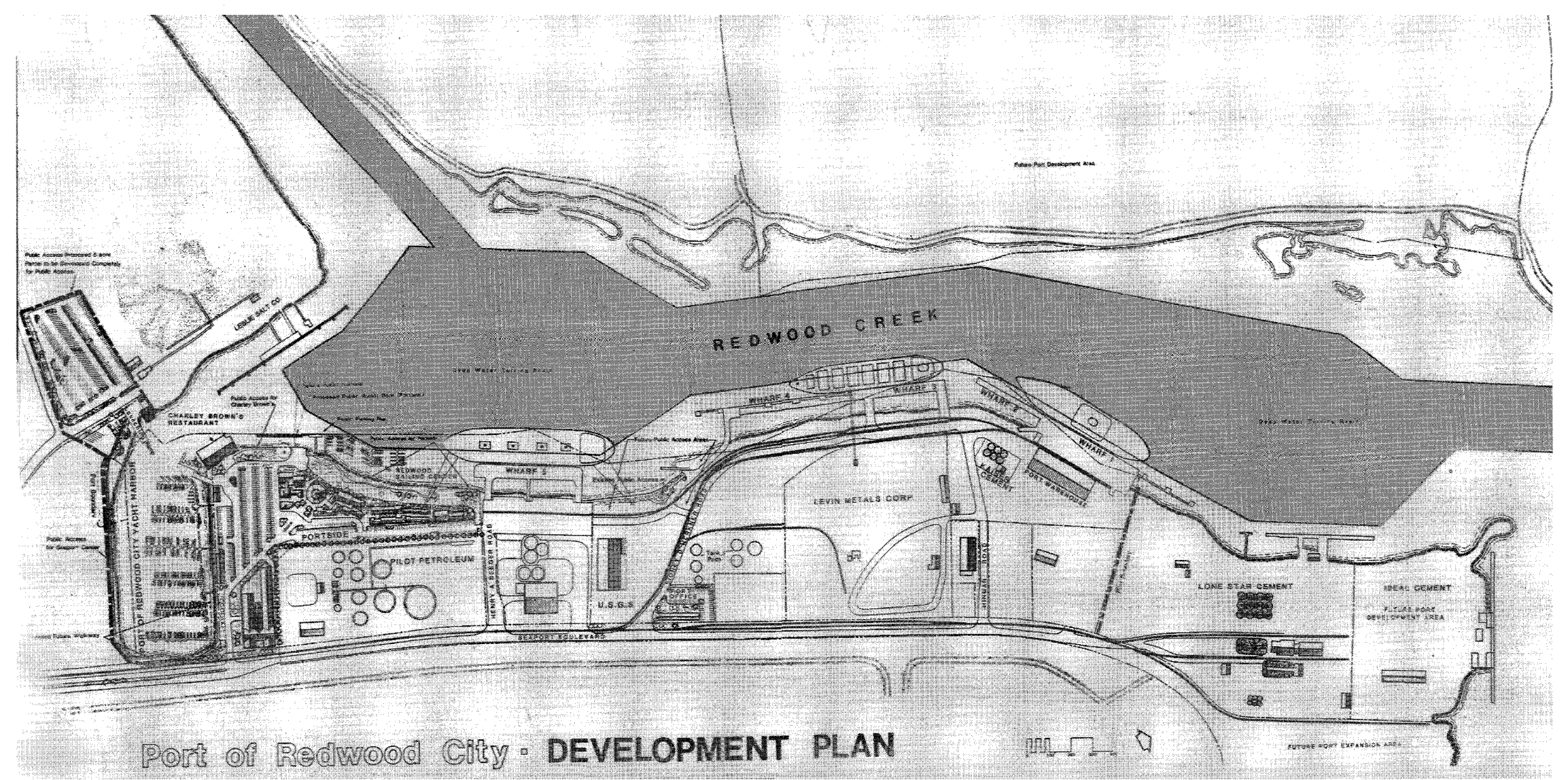

Figure 2.-Layout of the Seaport of Redwood City. U.S.G.S., U.S. Geological Survey. 


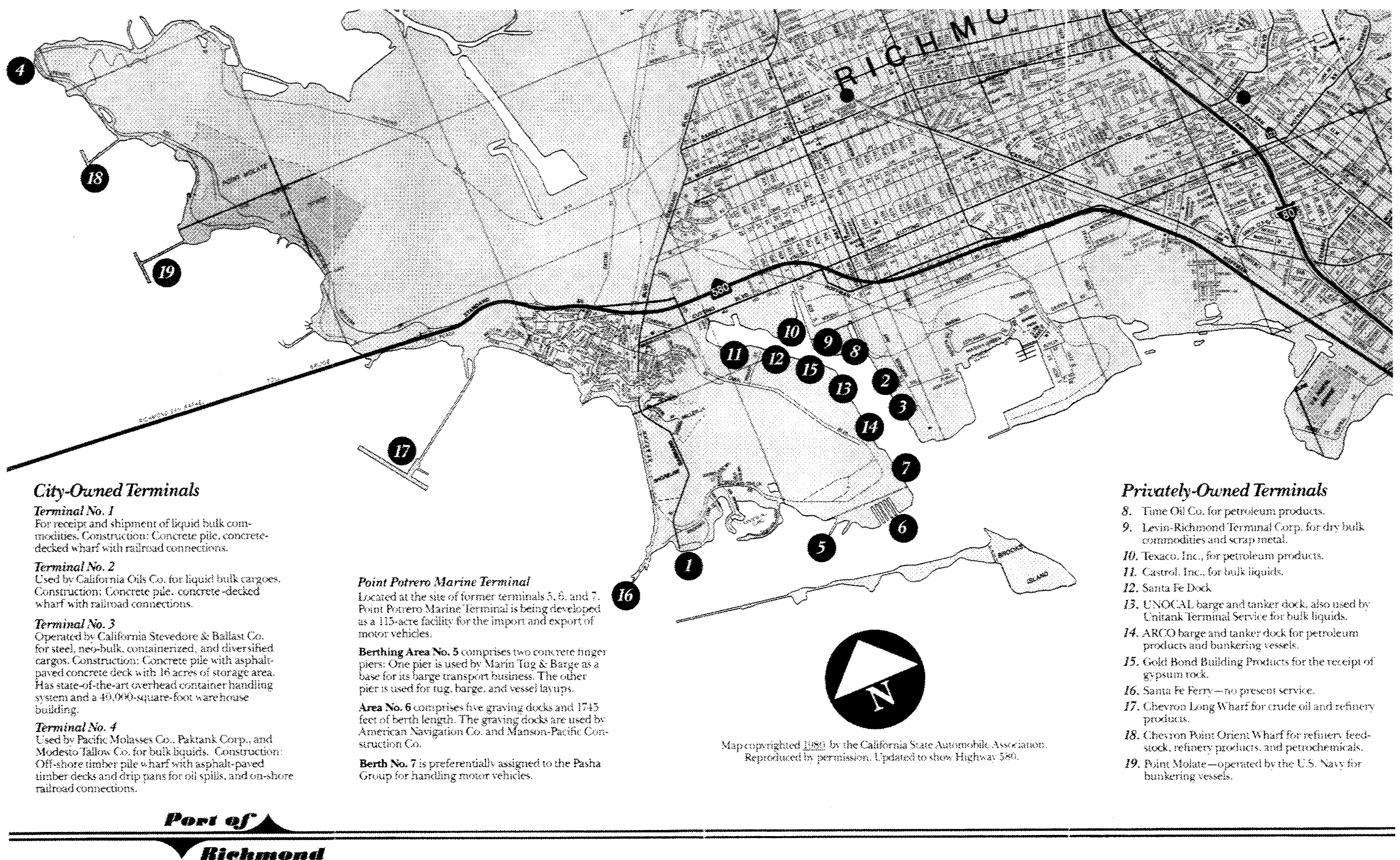


This seaport handles the most cargo (18 million tons per year) of any seaport in the San Francisco Bay region and is the primary seaport in the region for petroleum products and liquid bulk cargoes. Most of the terminals at the seaport are privately owned, and other seaport properties are leased to tenants under various maintenance agreements. The seaport facility is mapped in figure 3, along with a summary of the various activities, owners, and tenants at those facilities. Parts of the seaport are constructed on rock, and other parts on fill. A staff of two engineers and one maintenance person maintains the seaport.

\section{EARTHQUAKE DAMAGE}

The primary earthquake damage sustained by the Seaport of Richmond was a ruptured gasoline-storage tank at the Unocal terminal (Terminal 13, fig. 3). Fuel from this tank was contained by the surrounding berm. Some liquefaction occurred at the undeveloped areas on fill south of Terminal 3. Sand boils erupted at Terminal 3, and waterlines were broken at the Ford Motor Co. plant located on fill east of Terminal 3.

Unloading of cargo was delayed for 24 hours because of the gasoline leak. The fire department shut off power to the terminals because they feared that sparks might ignite fumes from the spilled fuel. Also, a ship that had arrived to unload automobiles was sent to deep anchorage until the gasoline was cleaned up. The other reported damage had no effect on the operation of facilities at the terminals where it occurred.

Because damage was sustained exclusively by privately owned terminals, the Seaport of Richmond was not involved in restoration of services. Within 48 hours after the earthquake, the entire seaport facility was functioning normally. There was no damage to other lifeline services. To help with the commuter problems that resulted from closing of the San Francisco-Oakland Bay Bridge, the Seaport of Richmond added facilities for additional ferries at Terminal 3 . These facilities began operating on Monday, October 23; they would have been operating on Thursday, October 19, but a floating-dock facility had to be added because of the low freeboard of the ferries relative to freight vessels that are normally moored at this terminal. Before the San Francisco-Oakland Bay Bridge was reopened, the new ferry service transported 400 to 500 passengers a day on the 45 -minute, 8 -mi trip to the Ferry Building at the Seaport of San Francisco.

\section{EMERGENCY-RESPONSE PLAN}

Engineers at the Seaport of Richmond stated that they had no emergency-response plans for earthquakes, because the seaport is under the jurisdiction of the City of Richmond and the city has charged the fire department with emergency response.

\section{SEAPORT OF SAN FRANCISCO}

The Seaport of San Francisco extends for $7 \mathrm{mi}$ along the west side of San Francisco Bay, from west of Aquatic Park to India Basin (fig. 1). The seaport is located approximately 60 $\mathrm{mi}$ from the earthquake epicenter. Activities at this seaport are diverse and include import and export of general cargo, primarily in container form, ship repair, passenger and cruise ships, a fishing industry, and tourist attractions. A total of 3 million $t$ of general cargo pass through this seaport annually. Annual revenues from the seaport in 1988 were estimated at $\$ 38$ million. Figure 4 shows that most of the San Francisco waterfront is constructed on fill. Most of the seaport is constructed on fill behind seawalls; the parts of the piers extending past the seawalls are supported on piles of concrete, timber, or concrete-encased timber. The central parts of the piers were built on fill to accommodate rail spurs, but today the piers are served primarily by trucks. The Seaport of San Francisco has an 11-person engineering staff, 4 inspectors, and a maintenance crew of approximately 70 people.

\section{EARTHQUAKE DAMAGE}

At the time of the investigation in 1989, engineers at the seaport estimate that repairs of earthquake-related damage would cost $\$ 8$ million to $\$ 10$ million. Tenants sustained additional damage, for which the seaport is not responsible. As with the other seaports in the San Francisco Bay region, the tenants' responsibility for repair and maintenance of their facilities differs under different lease agreements. The primary cause of damage was liquefaction of the fill materials, which resulted in settlement of the parts of the piers supported by fill relative to those supported by piles. Settlement continued for several weeks after the earthquake. Sand boils erupted at Pier 45 (sand boils result from the upward flow of water caused by the excess pore-water pressure associated with liquefaction). Because of significant structural damage at different places along the waterfront, some buildings were condemned. Structural damage included cracked concrete walls and displaced asphalt decks in the warehouses on Piers 45 and 48, caused by settlement of the underlying fill; cracking and collapse of unreinforced clay-tile walls in an office building on Pier 70; and buckling of columns in the clock tower above the Ferry Building, where the offices for the Seaport of San Francisco are located. The Agriculture Building adjacent to the Ferry Building was closed because of differential settlement. Other damage at the seaport included many broken waterlines, many broken batter piles, cracked concrete decks above piers, and damage to five container cranes.

Significant damage was sustained by the 17 -story clock tower above the Ferry Building, but this damage had only a limited effect on the operation of the seaport. Both the clock tower and the Ferry Building had survived the 1906 San Francisco earthquake. The clock tower's primary structural ele- 


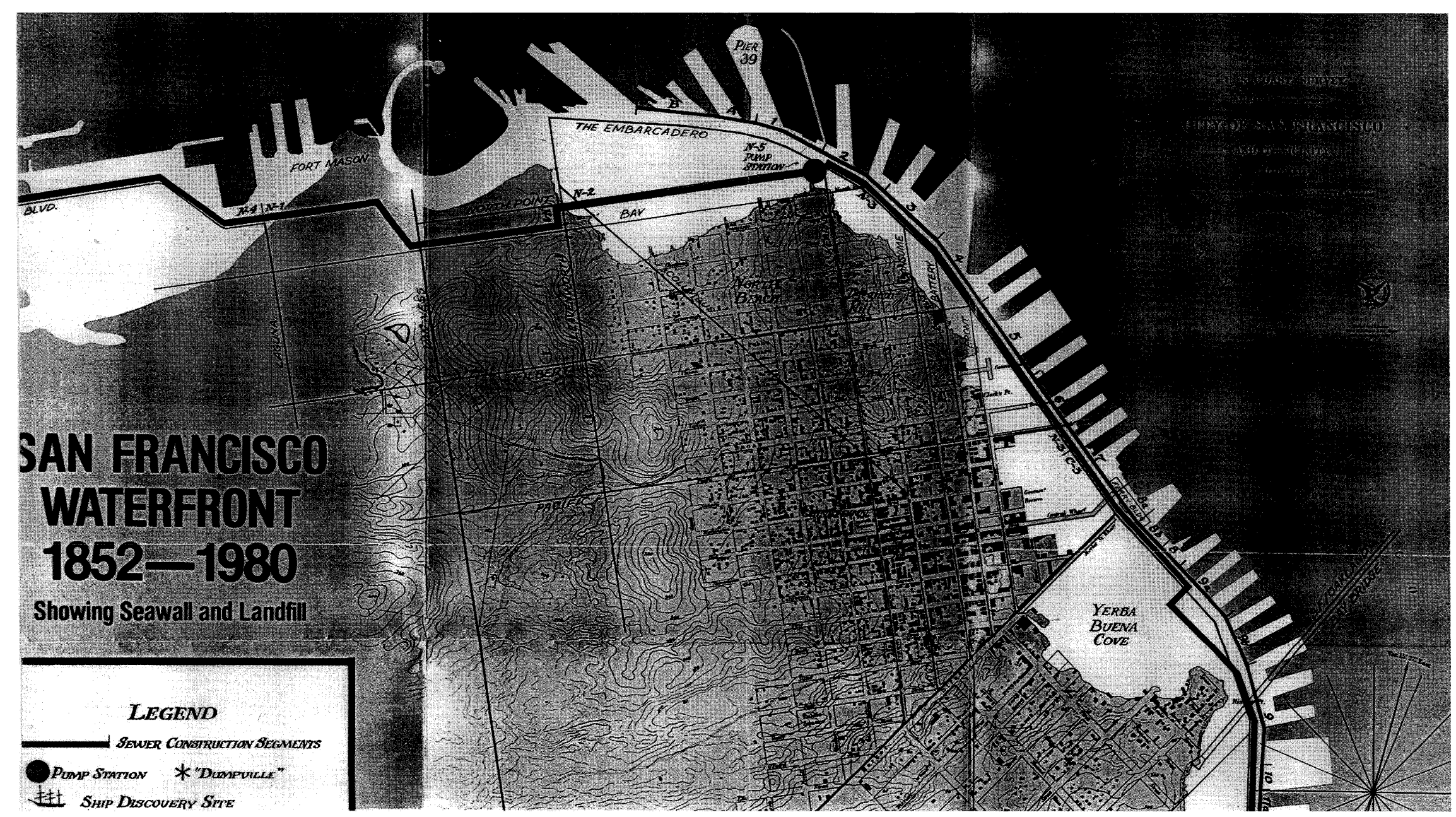


ments are four laced columns, each of which consists of two channel sections tied together with riveted plate laces on either side. Diagonal tie rods with turnbuckles are used to provide lateral stability. At the 13th level, two of the columns had buckled. The damaged sections were cut out, and temporary splices were added. At several levels, the tie rods were noticeably deformed, but without knowing their previous condition, it was difficult to determine whether the earthquake caused this deformation.

Commercial freight operations at the Seaport of San Francisco were largely unaffected by the earthquake damage. Two damaged container cranes were jacked back onto their rails, and a contractor replaced the damaged steel plates on the cranes' legs. Meanwhile, standby cranes were brought into service, and ships were being unloaded by Thursday, October 19. Commercial fishing was probably the most adversely affected business because two warehouses located on Pier 45 that were used for transportation and processing of fish were closed as a result of earthquake damage. Grain elevators near the south container terminal had to be closed until damage to a drag-conveyor bridge structure could be repaired. The Seaport of San Francisco lost revenue from businesses in the tourist sections of the seaport, which, as part of the lease agreements, pay the seaport a percentage of their profits. At the time of this investigation, a month after the earthquake, these businesses continued to have reduced tourism as a result of the earthquake.

Waterlines and gaslines were repaired within a week after the earthquake. The Seaport of San Francisco did not have enough plumbers to accomplish the repairs that fast, and so additional plumbers were provided by a private contractor and by the City of San Francisco. Temporary repairs to the differential settlement problems were handled by constructing asphalt ramps over cracks in the existing pavement. Inhouse maintenance people did these repairs, and there was no difficulty in obtaining repair material. Offices in buildings that sustained significant structural damage were moved to other locations. Fish processing, which was normally handled in a warehouse on Pier 45, was moved to Pier 33.

Telephone service was never lost at the Ferry Building, but the lines were jammed because of the volume of calls. Loss of electrical power to Pier 45 caused problems for the fish-processing businesses, which had to rent generators to prevent thawing of their freezers. The Pacific Gas \& Electric Co. (PG\&E) had turned off commercial power because of a concern that gas leaks might cause fires. Electrical power was restored by 2:00 p.m. P.s.t. October 19. Damage to the San Francisco-Oakland Bay Bridge resulted in an increased use of ferries by commuters, and additional temporary ferry terminals were set up at Pier 1. These terminals began operating on Monday, October 23.

\section{EMERGENCY-RESPONSE PLANS}

A month after the earthquake, the engineers at the Seaport of San Francisco stated that they had no formal emer- gency-response plans for earthquakes. The citywide emergency-response plan includes the seaport. As a result of the 1989 Loma Prieta earthquake, utility-shutoff manuals have been distributed to maintenance personnel and local fire stations.

The fireboat Phoenix, which is under the jurisdiction of the seaport (and which the City of San Francisco had previously been planning to put out of service as a cost-saving measure) was instrumental in putting out the fires in the Marina District.

\section{SEAPORT OF OAKLAND}

The Seaport of Oakland occupies $19 \mathrm{mi}$ of shoreline on the east side of San Francisco Bay (fig. 1). The seaport is located approximately $55 \mathrm{mi}$ from the earthquake epicenter. A detailed layout of the seaport is shown in figure 5. Both Oakland International Airport and the seaport are under the jurisdiction of the Port of Oakland; however, this section focuses exclusively on the seaport. Container freight is the primary item handled by this seaport. At the time of the earthquake, the seaport had 25 container cranes, which handle 14 million $t$ of cargo annually. Most of the seaport is constructed on fill behind dikes of sand and rock, with pile-supported wharves over the dike faces. All of the terminals are served by rail spurs and trucks. Some terminals are leased to private concerns with varying maintenance agreements; others are used as needed by customers, with the seaport providing the maintenance. A 25-person engineering staff and a 70-person maintenance crew maintain the seaport.

\section{EARTHQUAKE DAMAGE}

Initially, earthquake damage at the Seaport of Oakland was estimated at $\$ 75$ million. Damage occurred primarily at the Seventh Street Complex and the Middle Harbor; the Inner and Outer Harbors were relatively undamaged. As at the Seaport of San Francisco, the primary cause of damage was liquefaction of the fill and the resulting settlement and spreading of areas on fill relative to areas supported by piles. The many broken waterlines and fire lines washed the fine material from the soil, causing both settlement and uplift of the asphalt pavement at numerous places throughout the seaport. Concrete batter piles were broken at the Seventh Street Complex terminals and at the Matson Terminal; a cross section of these terminals is shown in figure 6 . The piles support a concrete deck covered by $3 \mathrm{ft}$ of sand through which utility lines run; 3 in. of asphalt pavement covers the sand. The damage to piles at this terminal resulted from the inertial forces generated by the large mass supported on top of these piles. A horizontal ground acceleration of $0.29 \mathrm{~g}$ and a vertical ground acceleration of $0.07 \mathrm{~g}$ were measured at Terminal 25 of the Outer Harbor; a horizontal acceleration of $0.45 \mathrm{~g}$ was measured on the wharf at Terminal 25. Wood piles with concrete 
followers were broken at the Middle Harbor, resulting in condemnation of a building that was supported on these piles; the piles broke at the wood-concrete interface. Throughout the seaport, damage to the piles and settlements of the fills were discovered over a period of 1 year after the earthquake. A container crane derailed at the Middle Harbor, and the $100-\mathrm{ft}$ gauge distance between the rails increased as much as 4 in. A total of 23 container cranes sustained damage estimated at $\$ 500,000$. At the Seventh Street terminals, the crane rails that were on fill settled as much as 12 to $15 \mathrm{in}$. relative to the crane rail on piles, making the container cranes inoperable. The rail spur serving Terminal 40 was out of service because of horizontal and vertical displacement of the rails on fill relative to the part of the spur supported by piles. Significant settlement and separation of the truck-access road to Terminals 35 through 38 at the Seventh Street Complex occurred as a result of liquefaction.

The Seventh Street Complex was shut down. Half of the complex was temporarily repaired and back in service by March 1990; permanent repairs to the other half were

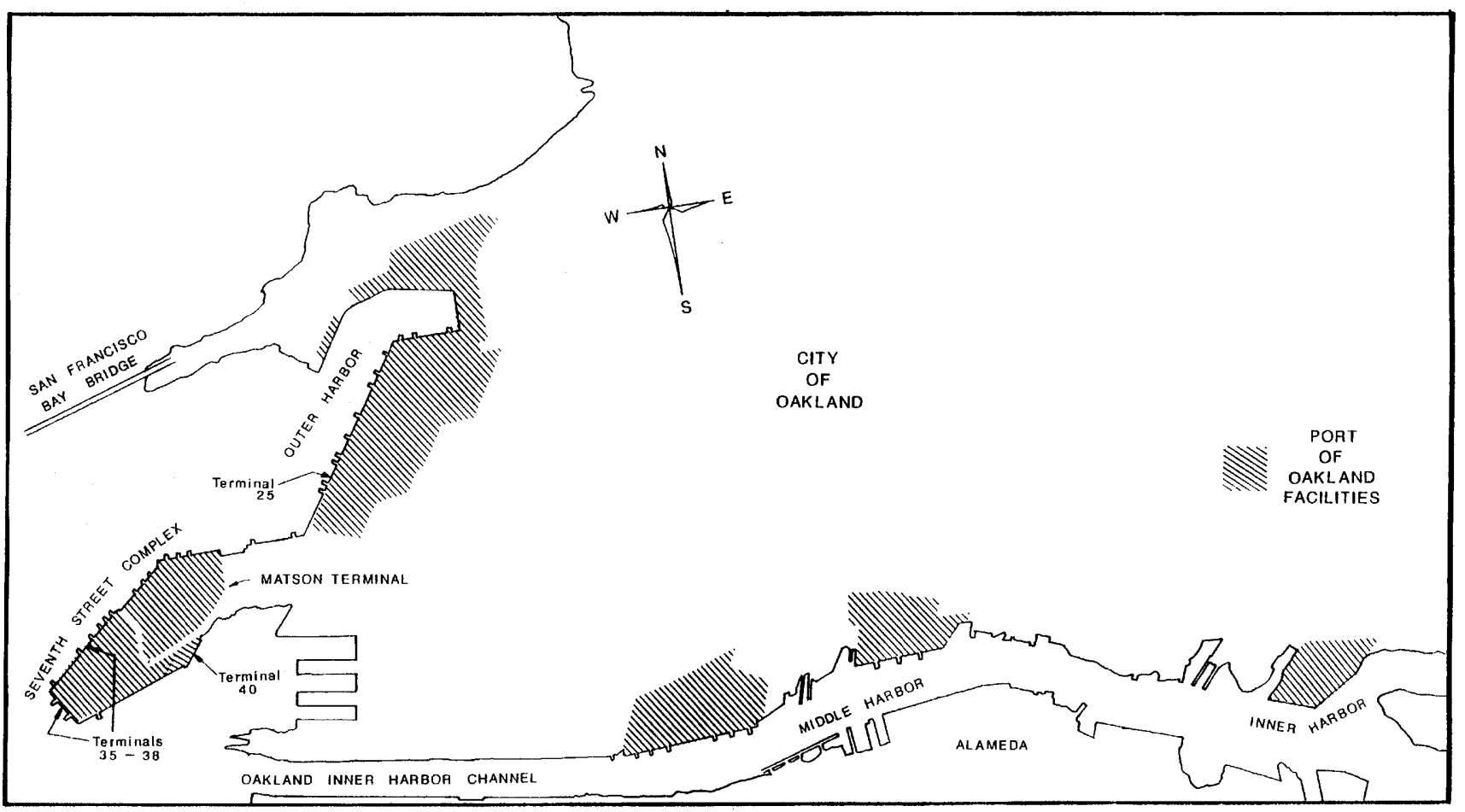

Figure 5.-Seaport of Oakland and facilities.

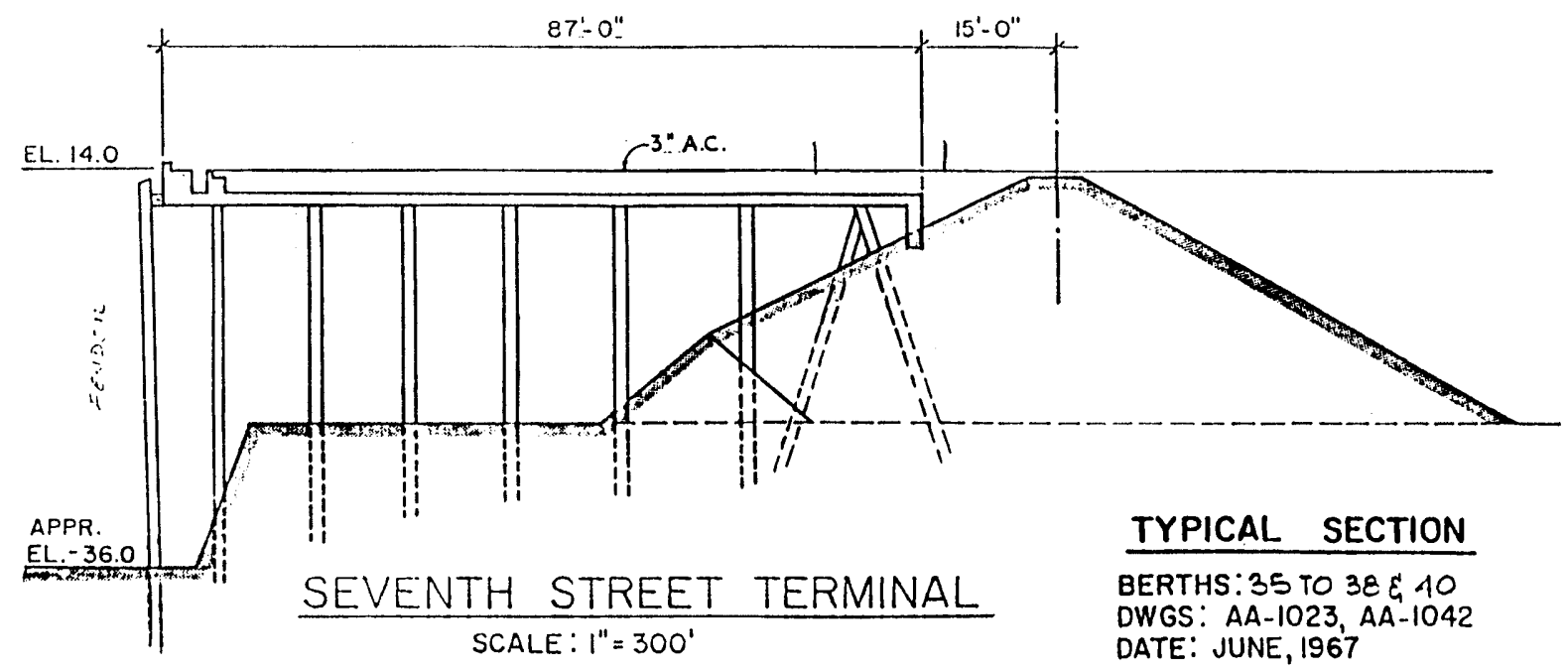

Figure 6.-Typical cross section of the Seventh Street Terminal at the Seaport of Oakland. 
completed by June 1991. Except for the crane at the Middle Harbor that derailed and the cranes on the damaged rails at the Seventh Street Terminal, all other container cranes remained operable. The derailed crane was repaired and operable within a day after the earthquake despite the increased gauge length of the rails. Although settlement and uplift of the pavement occurred throughout the staging areas for container freight, this damage did not hinder the overall operation of these facilities.

Repairs to the seaport were done by outside contractors. Temporary repairs consisted of placing asphalt at the locations of large discontinuities in the pavement. Waterlines for which the seaport was responsible were repaired within 2 weeks; waterlines maintained by the City of Oakland were repaired within a week after the earthquake. Permanent repairs to the crane rails at the Seventh Street Complex entailed the removal of the settled crane rail originally constructed on a grade beam supported by fill. This rail was replaced by a rail supported by a beam on piles and tied into the wharf to provide further earthquake resistance. The Matson Terminal, which does its own maintenance, appeared to be replacing the pavement on most of its property.

Damage to other lifelines had no direct impact on the Seaport of Oakland. Electrical power was lost temporarily, but there were no problems with gaslines. Fire lines ruptured, but no fires were reported, and so this damage did not adversely affect the seaport. One obstacle to repair of the seaport is the absence of reliable bench marks for surveying. Because the bench marks were determined to have moved as a result of the earthquake, a level circuit was brought in from remote sites not disturbed by the ground motion.

\section{EMERGENCY-RESPONSE PLANS}

The seaport had no formal emergency-response plan for earthquake damage, but it did have an emergency procedure and call lists of contractors and equipment suppliers. A for- mal emergency response manual is now in place and undergoing its second revision.

\section{CONCLUSIONS}

Extensive earthquake damage to seaport facilities can be expected from settlement and soil liquefaction.-Seaports in the San Francisco Bay region were constructed before modern engineered-fill procedures were in use, and so the 1989 Loma Prieta earthquake caused extensive damage from differential settlement and soil liquefaction. Much more extensive and severe problems can be expected in future earthquakes if ground motions are more severe or last longer.

The use of different foundation types within a given structure increases the potential for earthquake damage.-Differential settlement of pile-supported parts of the terminal relative to the parts supported by fill caused structural damage to buildings and equipment that straddle the different foundation systems. Container cranes and their rails are particularly susceptible to damage from differential settlement. Future seaport designs should have a consistent foundation system under a structure, and structures should not be supported directly on fill or be founded on fill.

Damage to piles can be reduced by avoiding terminal designs that place excessive mass on top of the piles.-The batter piles under Terminal 40 at the Seaport of Oakland, which support a 3-ft-thick layer of sand on top of a concrete slab, were severely damaged. This damage could possibly have been mitigated if an alternative method of running utility lines was developed that did not require the sand layer, thus reducing the mass (and inertial forces) supported by the piles.

Improved planning should reduce damage in future earthquakes.-The Seaport of San Francisco's plan to distribute utility-shutoff manuals to maintenance personnel and local fire stations is an inexpensive precaution that could prevent additional damage immediately after future earthquakes. 
THE LOMA PRIETA, CALIFORNIA, EARTHQUAKE OF OCTOBER 17, 1989:

PERFORMANCE OF THE BUILT ENVIRONMENT

LIFELINES

\section{TRANSPORTATION SYSTEMS-PASSENGER RAILWAYS AND BUSLINES}

By Stuart D. Werner, Seismic Systems \& Engineering Consultants; and

Anshel J. Schiff, Precision Measurement Instruments and Stanford University

\section{CONTENTS}

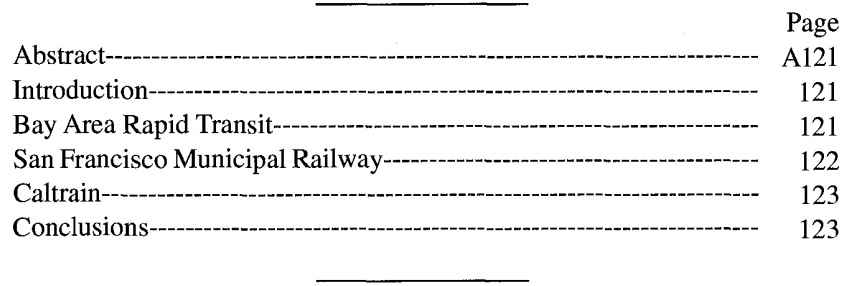

ABSTRACT

This paper describes the effects of the earthquake on the following vital railways and (or) buslines in the San Francisco Bay region: the Bay Area Rapid Transit (BART) system, the San Francisco Municipal Railway (Muni), and Caltrain. The BART and Caltrain systems are rail based, and the Muni system includes both railways and bus, trolleys, streetcars, and cable cars. For each system, we provide an overview and describe the earthquake damage, the immediate postearthquake operations, and the operations during the recovery period. All of these systems were nearly undamaged; the primary disruptions to the systems were for postearthquake inspection (for several hours after the earthquake) and a loss of electrical power.

\section{INTRODUCTION}

Three rail-based transportation systems have been investigated in the earthquake-affected area: the Bay Area Rapid Transit (BART), the San Francisco Municipal Railway (Muni), and Caltrain. The Muni system includes buses, trolleys, streetcars, and cable cars.

\section{BAY AREA RAPID TRANSIT}

Since the early 1970's, the BART system has provided a vital rail-transportation link for the east bay and the city of San Francisco. The system consists of three lines: (1) a single line that serves San Francisco and extends from Daly City in the south to the Embarcadero area of downtown San Francisco; (2) two single-bore transbay tubes along the bottom of San Francisco Bay that connect San Francisco to Oakland and the east bay; and (3) three separate lines in the east bay that branch from Oakland and extend northward to Richmond, southward to Fremont, and eastward to Concord. The BART system contains $71.5 \mathrm{mi}$ of track and 34 stations, which are equally divided between elevated, surface, and subway sections. The system is served by 570 cars, which are self-propelled from $1-\mathrm{kV}$ d-c power provided over a third rail. Three facilities in the east bay provide operational maintenance for these cars; in addition, a new facility in Daly City was opened shortly after the earthquake.

The Pacific Gas \& Electric Co. (PG\&E) provides traction power for the operation of BART trains and conventional power for station operations, lighting, and communications. The traction power is obtained from PG\&E through seven special substations that are distributed throughout the BART system. These substations have PG\&E transformers that convert $115-\mathrm{kV}$ to $34.5-\mathrm{kV}$ power; BART's power-distribution system distributes this $34.5-\mathrm{kV}$ a-c power to 34 locations, where it is converted to $1-\mathrm{kV}$ d-c power and then supplied to the rails. Power for BART station operations, lighting, and communications comes from PG\&E's regular power-distribution system. Batteries provide backup power for station lighting.

BART has earthquake alarms along its track routes that alert BART's central-operations facility when ground shaking exceeds $0.1 \mathrm{~g}$. Central operations then notifies the train operators by radio, and the trains are either stopped, if they are in a station, or directed to proceed at a slow speed to the next station, where the passengers are unloaded.

\section{EARTHQUAKE DAMAGE}

Although no significant structural damage was reported anywhere in the BART system, some minor damage did occur in the transition structure between the transbay tubes and the West Oakland Station, and at several stations in the east bay. The transbay tubes sustained minor water seepage but no structural damage. In San Francisco, the most serious problem resulted from the loss of electrical power to sump pumps that 
are routinely used to remove water which enters the subway between the Civic Center and Powell Street Stations in downtown San Francisco, from an underground stream at that site. Because of the power outage, water began to fill the sump at the Powell Street Station. The water rose to within 2 in. of the top of the rails before generators were obtained from the San Francisco Department of Public Works to operate the pumps.

\section{IMMEDIATE POSTEARTHQUAKE OPERATIONS}

Immediately after the earthquake, electrical power was lost in San Francisco to one of the seven PG\&E feeds that supply BART with traction power for its trains. Power was also lost to several stations in San Francisco.

The loss of traction power affected the trains in San Francisco that were between stations at the time of the earthquake, as well as trains in the transbay tubes. Limited traction power for trains in downtown San Francisco was transmitted from the east bay through the third rail, enabling BART to slowly move one train at a time to the next station, where the passengers could disembark. However, passengers on one train near the Powell Street Station in downtown San Francisco had to exit through the tunnel to the station.

Eastbound trains in the transbay tube and trains in the east bay and in San Francisco south of the downtown area were able to proceed to the next station. However, a single train in the transbay tube was heading westbound into San Francisco at the time of the earthquake. This train was stopped in the tube for about 20 minutes, until trains at the Embarcadero Station in San Francisco (the station closest to the west end of the tube) could be repositioned. After this repositioning, the train proceeded through the tube to the station, where its passengers disembarked.

Emergency batteries prevented the BART stations in San Francisco that lost their primary PG\&E power from going dark. Temporary power outages occurred at the Coliseum and Fremont Stations in the east bay, and radio communication to some of the trains was briefly lost. However, BART's train operators have backup mobile radios, which they used until normal communication was restored.

BART officials reported that all passengers in San Francisco were unloaded from the trains within about 30 minutes after the earthquake. BART's earthquake-alarm system functioned properly, although it was superfluous because personnel in BART's central-operations facility felt the shaking and were aware that a major earthquake had occurred. After evacuating all passengers, BART was shut down because of the power outage and the need to inspect the system for earthquake damage.

Traction power was restored at the damaged San Francisco BART substation about $4 \frac{1}{2}$ hours after the earthquake, allowing trains to operate and speeding inspection. Electrical power to stations was restored about 6 hours after the earthquake. Limited train service started at about 2:00 a.m. P.s.t.
October 18 and gradually increased as various BART lines and stations were returned to service. Normal rush-hour service was started at about 5:00 a.m., and all stations were reported to be operating by $8: 30 \mathrm{a} . \mathrm{m}$.

\section{OPERATIONS DURING THE RECOVERY PERIOD}

Until the damaged San Francisco-Oakland Bay Bridge was reopened on November 17, 1989, BART and a transbay ferry system that was initiated after the earthquake were the only direct modes of transportation between the east bay and San Francisco. To meet its increased transportation demands during this period, BART initiated 24-hour daily service. BART's daily ridership soon increased from a preearthquake level of 218,000 passengers to a postearthquake peak of 357,000 passengers-a 64-percent increase. This substantially increased demand began to overload BART's existing maintenance facilities, temporarily leading to less frequent and shorter trains. To alleviate this problem, BART accelerated the start of operations at a new maintenance facility in Daly City, and the maintenance backlog was soon reduced.

Since the reopening of the San Francisco-Oakland Bay Bridge, BART's daily ridership has stabilized at a level that is about 20 percent greater than its preearthquake ridership. Therefore, although its 24-hour service has been discontinued, BART's weekday service now begins 1 hour earlier than it did before the earthquake, and its rush-hour schedule has been extended for an extra hour each afternoon. In addition, 26 additional cars and two additional train sets operate during each peak period.

\section{SAN FRANCISCO MUNICIPAL RAILWAY}

The Muni system serves San Francisco with several different types of transportation systems, including light-rail trains, trolleys, cable cars, electric-powered buses, and diesel-powered buses. The system has 78 routes throughout the city, which are served by 540 diesel buses, 345 trolleys, 12 streetcars, 130 light-rail vehicles, and 37 cable cars.

Muni relies on PG\&E's electrical power for propulsion of its trains, operation of its stations, and operation of signal lights in its underground tunnels. Should power be lost, Muni has no backup power for these vital functions. Emergency diesel generators are available only for the Metrocom radios and the data-acquisition computers in Muni's central-control facility. Emergency lighting for this facility is provided by a battery-powered backup system.

\section{EARTHQUAKE DAMAGE}

The earthquake did not directly damage Muni's facilities, its overhead power-distribution system, or its tracks. The 
only significant damage to Muni's physical plant occurred in a pre-1906 building that was of secondary importance to Muni's overall operations.

\section{IMMEDIATE POSTEARTHQUAKE OPERATIONS}

All of Muni's electric-powered vehicles (its trolleys, light-rail trains, cable cars, and electric-powered buses) were unable to function because of the power outage in the downtown San Francisco area immediately after the earthquake. Also, because of Muni's lack of backup power, its station power and signal lights in the downtown area went out. Several trains were stranded in tunnels and underground stations, and passengers had to be evacuated by train crews, station agents, and available supervisors and managers, with flashlights providing the only source of lighting. The evacuation was completed within about 45 minutes, probably because the trains happened to be near stations at the time of the earthquake.

Except for the power outage, no disruptions to Muni operations after the earthquake, and no injuries or accidents were reported. In addition, backup-power generators that operated fuel pumps at the Wood's Diesel Division parking and service area allowed diesel-powered buses to continue operating. Diesel and gasoline fuels were also provided to other city vehicles until power was restored by PG\&E.

\section{OPERATIONS DURING THE RECOVERY PERIOD}

About 60 percent of Muni's service was restored within 1 day after the earthquake. Passengers who normally used Muni's electrical-powered buslines to downtown San Francisco rode to stations outside of the downtown area, where they had to transfer to diesel-powered buses that continued to downtown destinations. Commercial power was fully restored 2 days after the earthquake, when all of Muni's normal operations resumed. Muni modified its normal bus routes to accommodate passengers who used ferryboats to commute to San Francisco from the east bay.

Muni did not sustain major financial losses due to the earthquake. Costs to repair earthquake damage were minimal, and revenue losses due to decreased ridership immediately after the earthquake were at least partly counterbalanced by (1) the use of monthly passes by about 60 percent of its normal passengers and (2) additional passengers coming in from the ferries.

\section{CALTRAIN}

Caltrain runs commuter trains on the Southern Pacific Railroad tracks between San Jose and San Francisco. The system is $47 \mathrm{mi}$ long, has 24 stops, and is served by 20 diesel locomotives and 73 cars.

\section{EARTHQUAKE DAMAGE}

No significant damage to the Caltrain system was reported; minor damage consisted of a few fallen bricks from one of the tunnel linings. The tracks south of San Jose, which are not part of the commuter-train rail system, buckled and were repaired within 2 days after the earthquake.

\section{IMMEDIATE POSTEARTHQUAKE OPERATIONS}

In accordance with Caltrain's policy for earthquakes of $M \geq 5.0$, all trains in operation during the earthquake proceeded slowly to the next station, where all passengers disembarked. The Caltrain system was then shut down for inspection, also in accordance with Caltrain's earthquake policy. This inspection was completed within 5 hours, and service was resumed at about 10:00 p.m. on the night of the earthquake.

When Caltrain trains resumed operation after the earthquake, they maintained a maximum speed of $20 \mathrm{mi} / \mathrm{h}$ because of the possibility of aftershocks. In addition, train schedules were reduced because many of Caltrain's crew members live in Santa Cruz, where damage to roads prevented them from reporting to work.

\section{OPERATIONS DURING THE RECOVERY PERIOD}

During the week after the earthquake, Caltrain's daily ridership rose to a level 32 percent above preearthquake ridership. By early December, ridership stabilized somewhat but was still 10 percent higher than preearthquake levels. Caltrain added more cars to its scheduled trains to accommodate this increased ridership but added no new trains.

On October 23, 1989 (6 days after the earthquake), Caltrain began an emergency rail service south of San Jose, primarily to serve the Watsonville area. This service was terminated on November 10 because of a dispute between the State of California and the Southern Pacific Railroad over liability and insurance.

\section{CONCLUSIONS}

Almost no earthquake damage to any of the rail systems in the San Francisco Bay region was reported, although all the systems discontinued service for several hours after the earthquake to inspect for earthquake damage. The primary disruption of the BART and Muni systems was due to a power outage in San Francisco. The most significant disruption to Caltrain service after the earthquake was caused 
by the unavailability of crew members who lived in the stricken Santa Cruz area.

The importance of the BART system as a vital transportation link between San Francisco and the East Bay was demonstrated in this earthquake. Accordingly, we note the absence of any strong-motion-recording instruments within the transbay tubes. Although such instrumentation would not affect the performance or safety of the system, it would be invaluable for measuring characteristics of the motions in the tubes. Such measurements would be particularly helpful in interpreting any damage to the tubes that might occur during future earthquakes.

The BART system was particularly instrumental in meeting the increased transportation needs caused by the closing of the San Francisco-Oakland Bay Bridge. Muni and Caltrain played major roles in alleviating problems caused by the closing of elevated highways in San Francisco. 


\title{
LIFELINES
}

\section{RESIDENTIAL NATURAL-GAS PIPING AND APPLIANCES}

\author{
By Peter W. McDonough, Questar Corp.
}

\section{CONTENTS}

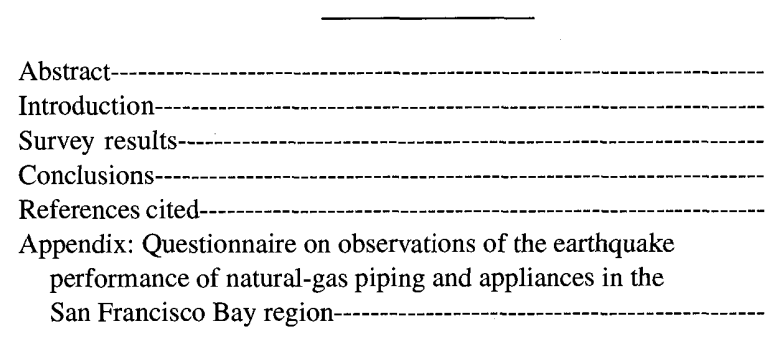

Page

A125

125

125

126

126

performance of natural-gas piping and appliances in the

San Francisco Bay region tions deal with these valves. Mountain Fuel Supply Co. personnel worked in three communities west of San Jose: Los Gatos, Mountain View, and Cupertino (fig. 1). Separate questionnaires were provided for each town. Of approximately 18,000 customers without gas in these areas, about 15 percent of total area customers, Mountain Fuel Supply Co. personnel visited approximately 4,500. A total of 22 completed questionnaires were returned, providing a sample of approximately 18 percent of affected customers.

An isoseismal map of the San Francisco Bay region is shown in figure 1.

\section{SURVEY RESULTS}

The results of the questionnaire are summarized in table 1. Significant observation about these results include the following:

1. In approximately 21 percent of the buildings where service valves had been closed, some type of downstream gas-pipe/appliance damage was reported, with no significant influence by recorded differences in ground acceleration of 0.21 to $0.53 \mathrm{~g}$.

2. Only in Los Gatos (fig. 1), where a modified Mercalli intensity (MMI) of VII was assigned, was most of the damage in old (approx pre-1950) buildings. The fact that damage was reported in a significant percentage of newer buildings in all three communities implies that gas-facility damage was largely independent of the greater structural damage anticipated in older buildings.

3. The most common type of damage observed was to unattached vent ducting. Although this damage would cause combustion products to enter the structure, it does not imply gas leakage. This and the second-most-common problem, water-heater movement, were also probably the easiest to mitigate (that is, provide adequate strapping of water heaters; use sheet-metal screws to attach sections of vent duct). Damage to piping not associated with water heaters was observed in no more than 9 percent of the buildings visited.

4. Natural-gas-caused fire damage was observed in no more than 1 percent of the buildings visited. These fires can be assumed to have been minor because the buildings continued to be occupied after the earthquake.

5. Very few earthquake shutoff valves were observed, 
Table 1.-Summary of survey results on buildings with service valves closed.

[All values in percent, except as noted. See figure 1 for locations]

\begin{tabular}{|c|c|c|c|}
\hline & Los Gatos & Cupertino & Mountain View \\
\hline Buildings with pipe/appliance damage---.--_- & 22 & 24 & 16 \\
\hline $\begin{array}{l}\text { Buildings with pipe/appliance damage } \\
\text { that were classed as "old." }\end{array}$ & 57 & 44 & 40 \\
\hline \multicolumn{4}{|l|}{ Damaged buildings with: } \\
\hline Damaged water heaters & 44 & 38 & 41 \\
\hline Damaged vent piping & 58 & 67 & 57 \\
\hline Damaged furnaces -- & 13 & 15 & 11 \\
\hline Damaged ranges-- & 1 & $<1$ & $<1$ \\
\hline Damaged meter sets/outdoor piping ------- & 5 & 4 & 4 \\
\hline Damaged interior piping & 4 & 7 & 9 \\
\hline Damage-related fires --- & $<1$ & 1 & 0 \\
\hline $\begin{array}{l}\text { Undamaged buildings with activated } \\
\text { earthquake valves. }\end{array}$ & $<1$ & 0 & 1 \\
\hline $\begin{array}{l}\text { Damaged buildings with activated } \\
\text { earthquake valves. }\end{array}$ & 0 & 0 & 6 \\
\hline $\begin{array}{l}\text { Damaged buildings with unactivated } \\
\text { earthquake valves. }\end{array}$ & 0 & 0 & 0 \\
\hline $\begin{array}{l}\text { Activated earthquake valves that could } \\
\text { not be reset. }\end{array}$ & 0 & 0 & 2 \\
\hline Modified Mercalli intensity & VII & VII & VII \\
\hline $\begin{array}{l}\text { Local peak ground accelerations at sites } \\
\text { in each city }(g) \text {. }\end{array}$ & $0.53,0.33$ & $\begin{array}{l}0.53,0.33 \\
0.22\end{array}$ & $\begin{array}{l}0.38,0.22 \\
0.21\end{array}$ \\
\hline
\end{tabular}

which apparently were activated from the ground accelerations of $\geq 0.21 \mathrm{~g}$ that were recorded.

\section{CONCLUSION}

These survey data may be useful in predicting the performance of typical residential gas piping and appliances during MMI VII shaking. Comparable epicentral intensities might be expected during moderate $(M \sim 5.5)$ earthquakes. These data also may point out where the most practical damage mitigation can be undertaken by homeowners.

The survey result showing that approximately 21 per- cent of the buildings with valves closed actually were damaged can also be read as that 79 percent of the buildings had valves which closed needlessly.

\section{REFERENCES CITED}

Boore, D.M., Seekins, Linda, and Joyner, W.B., 1989, Peak accelerations from the 17 October 1989 Loma Prieta earthquake: Seismological Research Letters, v. 60, no. 4, p. 151-166.

Stover, C.W., Reagor, B.G., Baldwin, F.W., and Brewer, L.R., 1990, Preliminary isoseismal map for the Santa Cruz (Loma Prieta), California, earthquake of October 18, 1989 UTC: U.S. Geological Survey Open-File Report 90-18, 24 p. 


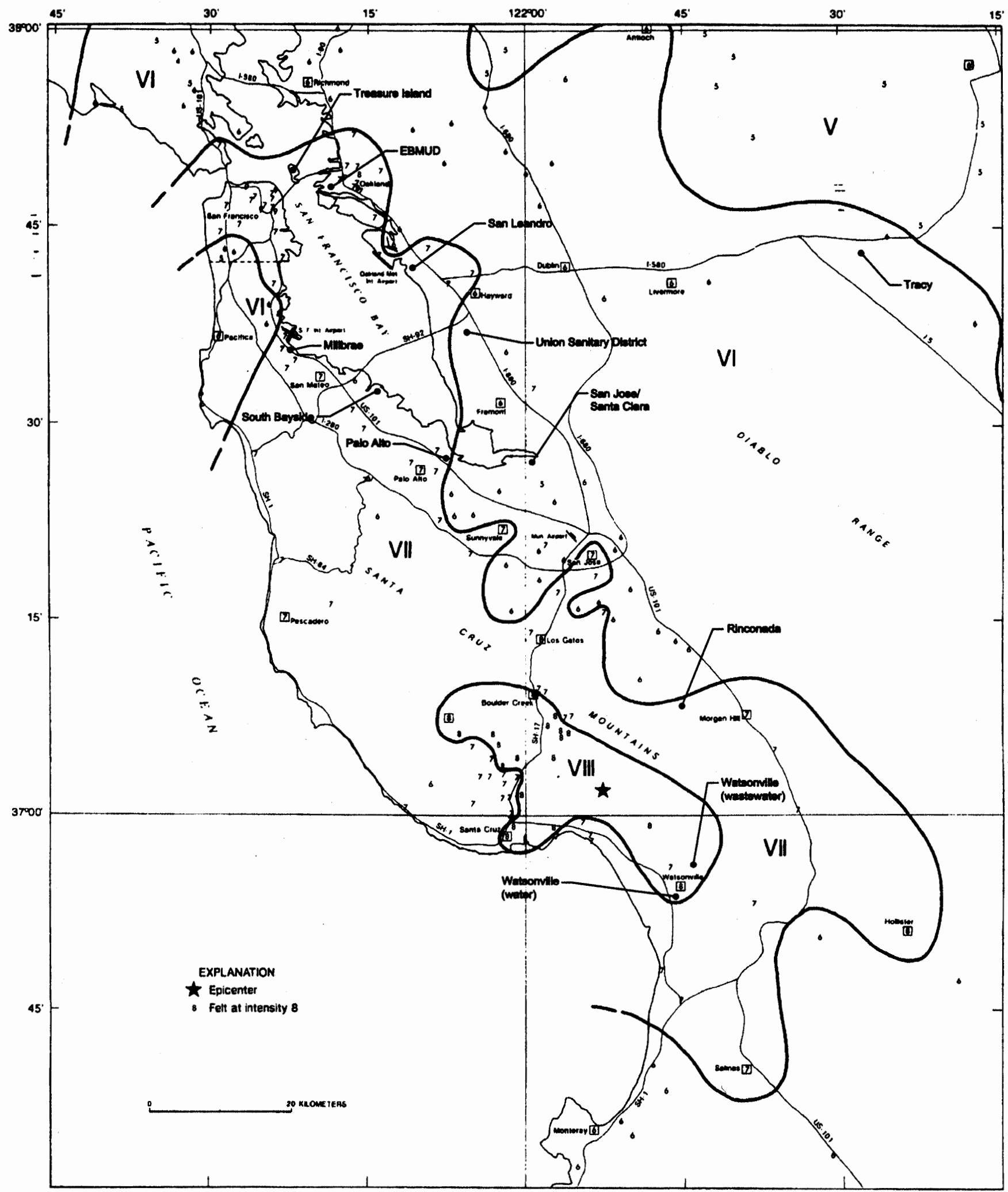

Figure 1.-San Francisco Bay region, showing locations of water- and wastewater-treatment plants and areas of modified Mercalli intensity (roman numerals). EBMUD, East Bay Municipal Utility District. From Stover and others (1990). 
APPENDIX: QUESTIONNAIRE ON OBSERVATIONS OF THE EARTHQUAKE PERFORMANCE OF NATURAL-GAS PIPING AND APPLIANCES IN THE SAN FRANCISCO BAY REGION

Town:

(Please give the best-estimate answer based on the buildings you personally visited.)

1. Of the buildings you found with fire cocks turned off, what percentage had some type of gas-pipe/appliance damage?

2. Of the buildings you found with gas-pipe/appliance damage, what percentage would you classify as old (built before 1950)? $\%$

3. Of the buildings with gas-pipe/appliance damage, what percentage had damaged water heaters?

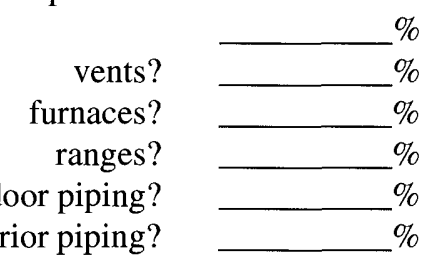

4. What percentage of the gas-related damage that you observed resulted in fires?

5. What percent of the buildings without pipe/appliance damage had earthquake valves that activated?

6. What percentage of the buildings with pipe/appliance damage had earthquake valves that activated?

7. What percentage of the buildings with pipe/appliance damage had earthquake valves that did not activate? $\%$

8. What percentage of the buildings with earthquake valves that activated had earthquake valves that could not be reset? 


\section{REPAIR PATTERNS FOR THE GAS-DISTRIBUTION SYSTEM IN SAN FRANCISCO}

By Douglas G. Honegger, Consultant

\section{CONTENTS}

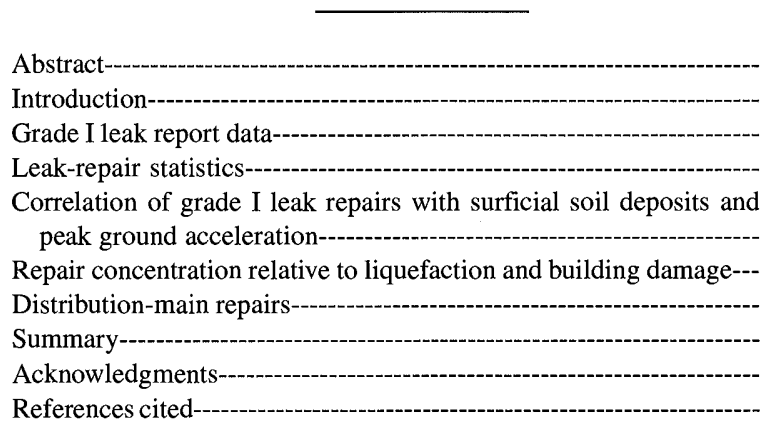

Page

A129

129

129

131

131

132

132

133

133

133

ABSTRACT

Leak-repair calls in San Francisco were tracked immediately after the earthquake. This information was subsequently obtained from the Pacific Gas \& Electric Co. and examined for possible correlation with other geologic, seismic, and structural information. Repair data were mapped with recorded peak ground acceleration, modified Mercalli intensity, building damage, near-surface soil types, and sites of liquefaction. Although the results obtained from this type of data representation are qualitative, they provide a convenient format for analyzing the various types of information. The maps indicate that soil characteristics are the best indication of where damage to the gas-distribution system can be expected in future earthquakes.

\section{INTRODUCTION}

After the earthquake, considerable interest was focused on the relatively small Marina District of San Francisco and on the damage sustained by the gas-distribution system there. However, virtually no detailed repair data are available on this system because the system was largely replaced in the weeks after the earthquake. Low-pressure steel and cast-iron gas-distribution lines were inserted with plastic lines operat- ing at higher pressure. This paper presents other gas-distribution-system damage in the city of San Francisco for which considerable information is available. Damage to the gasdistribution system in San Francisco was light, even including the loss of gas service in the Marina District, an observation consistent with earthquake magnitude and epicentral distance. Examination of data for the entire city is more useful for identifying regional weak spots in the system that may be important in the event of future large earthquakes. The data collected after the earthquake included leak-repair address, pipe material, and type of repair.

The data presented in this paper are in the form of various maps generated for the San Francisco area. The maps indicate the locations of grade I leak repairs performed by the Pacific Gas and Electric Co. (PG\&E) in the San Francisco Division of the Golden Gate Region; grade I leaks are indicated by the presence of a noticeable gas odor.

\section{GRADE I LEAK REPORT DATA}

Tracking of earthquake-related grade I leak repairs was accomplished by assigning a special billing account. PG\&E uses a standard leak-repair-reporting form; information is tracked by a computerized data base. PG\&E provided a summary of the leak-repair data base for their San Francisco Division for the period October 17-31, 1990. These data were incorporated into a data base and mapped to show the repair locations along with key site data. This data base is unusual in that no differentiation was made regarding existing damage from corrosion or other preexisting conditions. Gas-distribution systems typically have many existing leak conditions that are less serious and may not be readily locatable. Repair of these low-grade leaks is generally handled as a part of routine maintenance. Earthquakes can increase the rate of leakage at the locations of lower-grade leaks.

Leak-repair data are tracked according to the mapping grid established by PG\&E for the city of San Francisco. A standard plat reference scheme is used to refer to detailed system maps. Each rectangular plat map represents an area of $0.067 \mathrm{mi}^{2}$, with a north-south length of $1,700 \mathrm{ft}$ and an 
Table 1.-Summary of grade I leak repairs by material and function.

\begin{tabular}{|c|c|c|c|c|}
\hline \multirow{2}{*}{$\begin{array}{l}\text { Pipe } \\
\text { material }\end{array}$} & \multicolumn{2}{|c|}{ Mains } & \multicolumn{2}{|c|}{ Service connections } \\
\hline & $\begin{array}{l}\text { Number } \\
\text { of repairs }\end{array}$ & $\begin{array}{l}\text { Percentage } \\
\text { of total }\end{array}$ & $\begin{array}{l}\text { Number } \\
\text { of repairs }\end{array}$ & $\begin{array}{l}\text { Percentage } \\
\text { of total }\end{array}$ \\
\hline 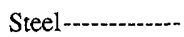 & 3 & 0.99 & 241 & 79.80 \\
\hline Cast iron--.-.-.- & 27 & 8.94 & 0 & \\
\hline Plastic--..-........ & 1 & .33 & 10 & 3.31 \\
\hline Copper-............. & 0 & 0 & 20 & 6.62 \\
\hline Total -........... & 31 & 10.26 & 271 & 89.73 \\
\hline
\end{tabular}

Table 2.-Summary of grade I leak repairs by material and repair code.

\begin{tabular}{|c|c|c|c|c|c|c|}
\hline \multirow{2}{*}{$\begin{array}{l}\text { Repair } \\
\text { code }\end{array}$} & \multicolumn{4}{|c|}{ Pipe material } & \multirow{2}{*}{ Total } & \multirow{2}{*}{ Percentage } \\
\hline & Steel & Cast iron & Copper & Plastic & & \\
\hline Bell-joint damage--------- & 1 & 19 & 0 & 0 & 20 & 6.62 \\
\hline Weld repair- & 1 & 0 & 0 & 0 & 1 & .33 \\
\hline Replace pipe section----- & 1 & 0 & 0 & 1 & 2 & .66 \\
\hline New clamp - & 5 & 5 & 0 & 0 & 10 & 3.31 \\
\hline 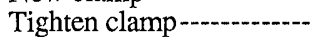 & 94 & 2 & 8 & 3 & 107 & 35.43 \\
\hline Tighten pipe joint & 45 & 0 & 0 & 0 & 45 & 14.90 \\
\hline Pipe-body damage- & 1 & 0 & 0 & 0 & 1 & .33 \\
\hline Other (permanent) & 21 & 1 & 2 & 6 & 30 & 9.93 \\
\hline Other (temporary) ----- & 75 & 0 & 10 & 1 & 86 & 28.48 \\
\hline Total - & 244 & 27 & 20 & 11 & 292 & -- \\
\hline Percentage-- & 80.79 & 8.94 & 6.62 & 3.64 & -- & -- \\
\hline
\end{tabular}

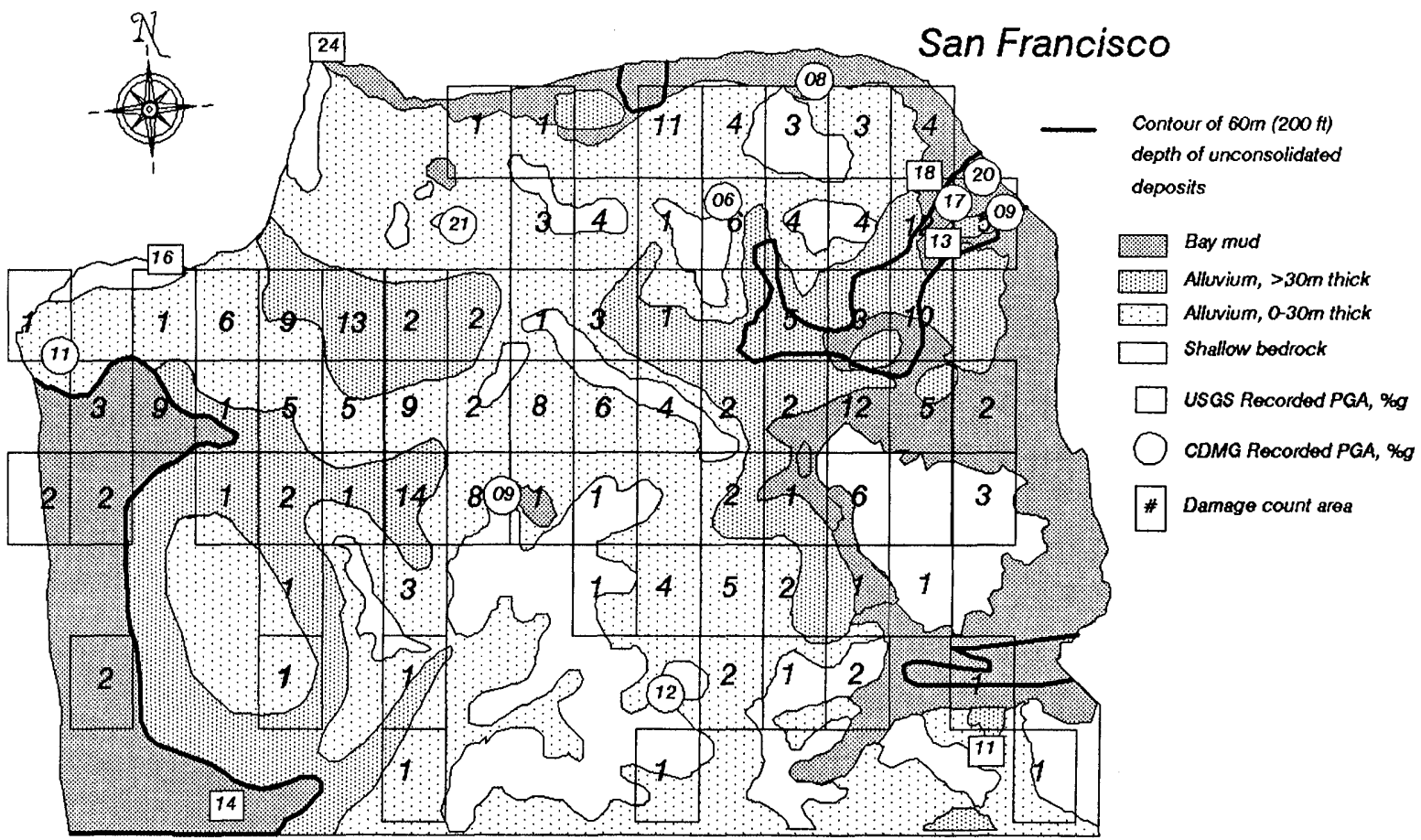

Figure 1.-Northern part of San Francisco, showing correlation of grade I leak repairs with surficial deposits and recorded ground motions. CDMG, California Division of Mines and Geology; PGA, peak ground acceleration; USGS, U.S. Geological Survey. 
east-west length of 1,100 ft. San Francisco city and County are covered by a total of 194 plat maps.

Site data mapped with the leak locations provided by PG\&E include recorded peak ground acceleration (Maley and others, 1989, Shakal, 1989), surficial soil deposits, building damage, modified Mercalli intensity (MMI) (Lew, 1990), and liquefaction occurrence (Benuska, 1990).

\section{LEAK-REPAIR STATISTICS FOR SAN FRANCISCO}

Leak repairs in San Francisco were predominantly minor. As listed in table 1 , nearly 90 percent of all repairs were on service lines. These lines, which are typically steel of less than 2 -in. diameter, provide gas from the distribution main to the customer's meter. Many of the distribution mains are of cast iron with bell-and-spigot joints. This fact is also reflected in table 1 , where 87 percent of the distribution-main repairs were made on cast-iron lines.

The types of repairs carried out are listed in table 2, which points out several interesting characteristics. First, nearly 39 percent of the repairs to steel lines were minor, requiring only tightening of bolts or pipe caps. The next-greater number of repairs, which were assigned to a "miscellaneous" category, were temporary; most temporary repairs required additional work to make them permanent. Both of these categories, which together represent nearly 70 percent of the total repairs to steel lines, can be considered as minor repairs. Cast-iron repairs, which were largely ( 70 percent) concentrated at bell joints, are considered major. Overall, minor repairs (tightening and other categories) accounted for 71 percent of all repairs.

\section{CORRELATION OF GRADE I REPAIRS WITH SURFICIAL DEPOSITS AND PEAK GROUND ACCELERATION}

A comparison of the locations of grade I leak repairs with surficial soil deposits and peak ground acceleration is shown in figure 1 . Some correlation is evident between higher numbers of repairs and the sites of deep alluvial deposits. When the exact addresses of repairs are examined, a qualitative trend is evident for higher incidences of repairs near the boundaries between different soil deposits. However, this trend is not evident in figure 1 because of grouping of the data according to plat-map boundaries.

As expected, no correlation is evident between the pattern of leak repairs and peak ground acceleration, possibly partly as a result of different concentrations of gaslines in the vicinity of seismic recording stations and the sparsity of seis-

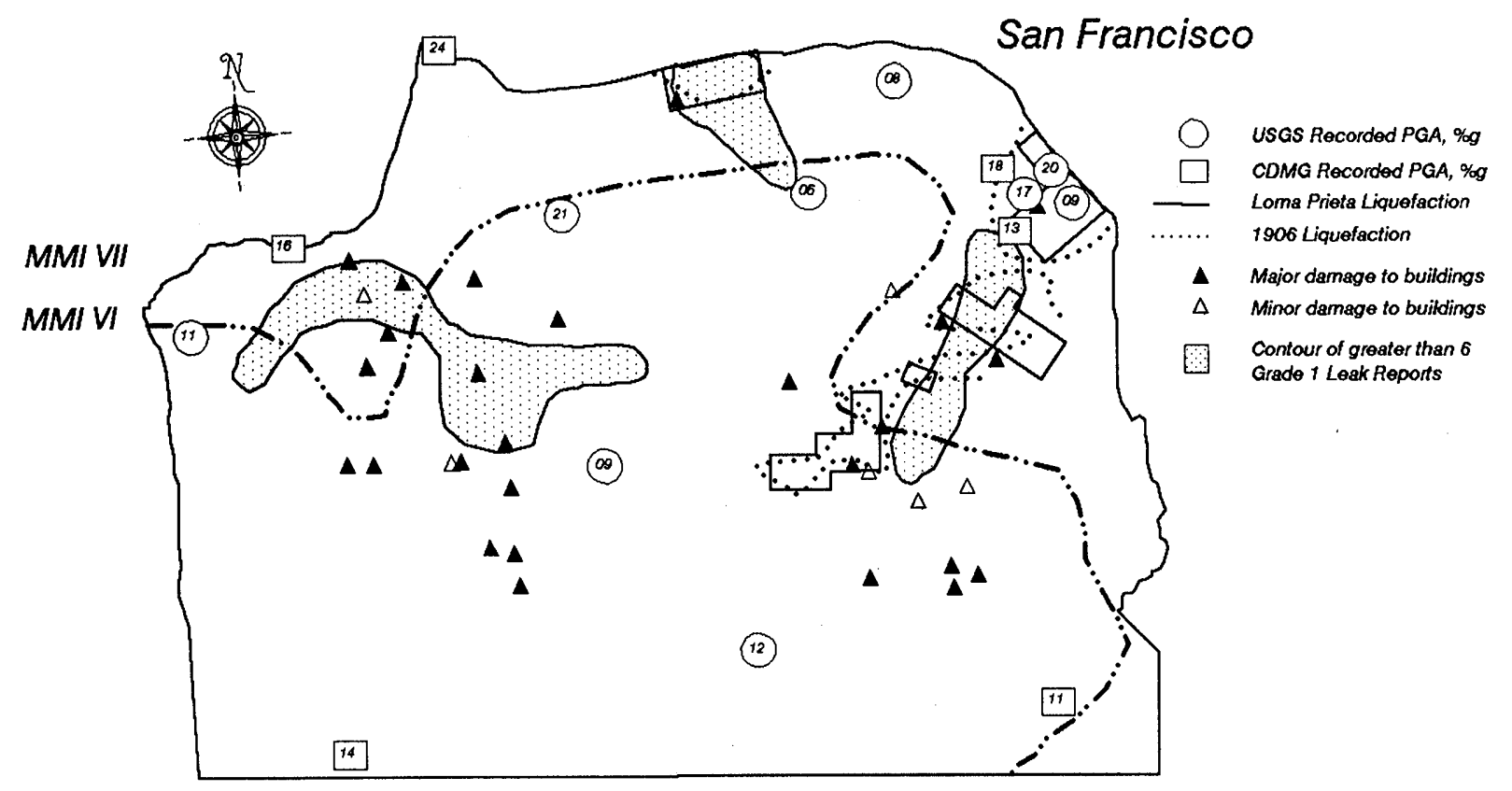

Figure 2.-Northern part of San Francisco, showing correlation of grade I leak repairs with areas of observed liquefaction and building damage. CDMG, California Division of Mines and Geology; MMI, modified Mercalli intensity; PGA, peak ground acceleration; USGS, U.S. Geological Survey. 
mograph stations. On the whole, the absence of correlation with peak ground acceleration is viewed as confirmation of the insensitivity of buried lifeline systems to ground shaking.

\section{REPAIR CONCENTRATION RELATIVE TO LIQUEFACTION AND BUILDING DAMAGE}

Most of the plat-map areas contain at least one occurrence of a leak repair, possibly as a result of the relatively large area used in mapping the city. An arbitrary selection of six leak repairs was used as a number distinguishing the limit between plat-map areas with high and low concentrations of repairs. These "high"-repair areas were mapped in figure 2 with locations of observed building damage, liquefaction, and MMI boundaries. The boundary of high-repair areas is qualitatively drawn to encompass individual repair locations within the plat map. A correlation between liquefaction zones and number of leaks is immediately apparent. Building damage and MMI do not appear to be so well correlated with pipe repairs: Only 41 percent of the repairs fall into the MMI VII zone. From the data mapped in figure 2, the MMI VII contour could have been drawn to more closely reflect severe building damage in the sand-dune deposits north of Golden Gate Park. Then, 92 percent of the high-repair areas and 64 percent of total repairs would have been contained within the MMI VII zone.

An interesting conclusion from this comparison is that preliminary MMI designations are not particularly reliable. Little is gained from preliminary MMI estimates, and unless MMI contours are drawn on the basis of thorough reconnaissance, they should be treated cautiously.

\section{DISTRIBUTION-MAIN REPAIRS}

As mentioned above, most of the repairs addressed service lines. Because of the few repairs to gas-distribution mains, the correlations made are only tentative. The distribution-main repairs by $P G \& E$ are mapped in figure 3 . The concentration of distribution-main repairs generally follows that for the total data base, with more repairs in the northeast quadrant of the city near Market Street. Nearly 50 percent of the distribution-main repairs are located north of Market Street and east of Leavenworth Street. Areas with distribution main repairs are mapped along with building damage, liquefaction, and MMI in figure 4. Distribution-main repairs correlate reasonably well with the sites of liquefaction during the 1906 San Francisco and 1989 Loma Prieta earthquakes. Except for this trend, the concentration of distribution-main repairs does not closely match that observed for service lines.

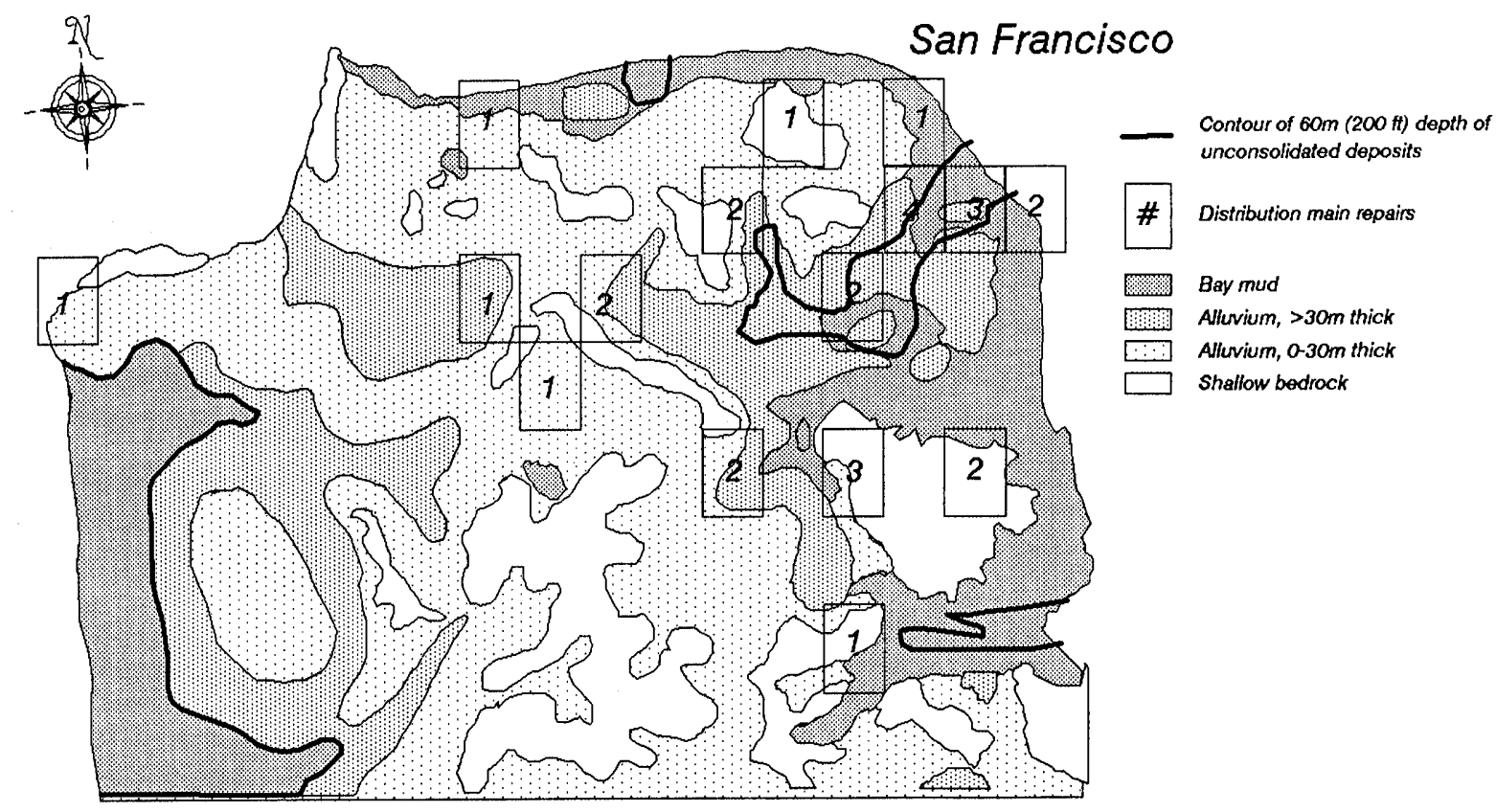

Figure 3.- Northern part of San Francisco, showing correlation of grade I distribution-main repairs with areas of surface deposits. 


\section{SUMMARY}

The concentration of gas-distribution-system damage in poor soils observed in San Francisco is typical of those observed in past earthquakes. Heavier damage in the Marina District was not unexpected, given what is known of the site conditions there. At the time of the earthquake, the gas-distribution system in San Francisco had a considerable amount of cast-iron pipe with bell-and-spigot joints; this type of pipe has a history of poor earthquake performance. Media coverage focused on the Marina District, where structural damage was most severe and a major fire occurred. Actual damage to the gas-distribution system as a whole was light.

\section{ACKNOWLEDGMENTS}

I am grateful for the assistance provided by PG\&E in obtaining details regarding their repair activities. Additional information on gasline performance was collected during postearthquake reconnaissance activities and specific investigations. Approval for the release of information by PG\&E was a result of related investigative work being conducted for Steven P. Burke. The grade I leak-repair summary for San Francisco was provided by Leslie Stevens. I deeply appreciate the time taken by Steve Phillips and Sergio Bruni to provide tours of the Marina District and describe PG\&E's response effort. Bob Moureau of PG\&E's San Francisco Division provided plat maps for the key areas where repairs were made. An excellent summary of PG\&E's overall response to the earthquake was presented by Phillips and Virostek (1990).

\section{REFERENCES CITED}

Benuska, Lee, ed., 1990, Loma Prieta earthquake reconnaissance report: Earthquake Spectra, v. 6, supp. 90-01, 448 p.

Lew, H.S., ed., 1990, Performance of structures during the Loma Prieta earthquake of October 17. 1989: National Institute of Standards and Technology Special Publication 778.

Maley, R.P., Acosta, A.V., Ellio, F., Etheredge, E.C., Foote, L.J., Johnson, D.A., Porcella, R.L., Salsman, M., and Switzer, J.C., 1989, U.S. Geological Survey strong-motion records from the Northern California (Loma Prieta) Earthquake of 17 October 1989: U.S. Geological Survey Open-File Report 89-568, 85 p.

Phillips, S.H., and Virostek, J.K., 1990, Natural gas disaster planning and recovery; the Loma Prieta earthquake: San Francisco, Pacific Gas \& Electric Co.

Shakal, A.F., Huang, M.J., Reichle, M.S., Ventura, C., Cao, T., Sherburne, R.W., Savage, M., Darragh, R.B., and Petersen, C., 1989, CSMIP strong motion records from the Santa Cruz Mountains (Loma Prieta), California earthquake of 17 October 1989: California Division of Mines and Geology, Office of Strong Motion Studies Report OSMS 89-06, 196 p.

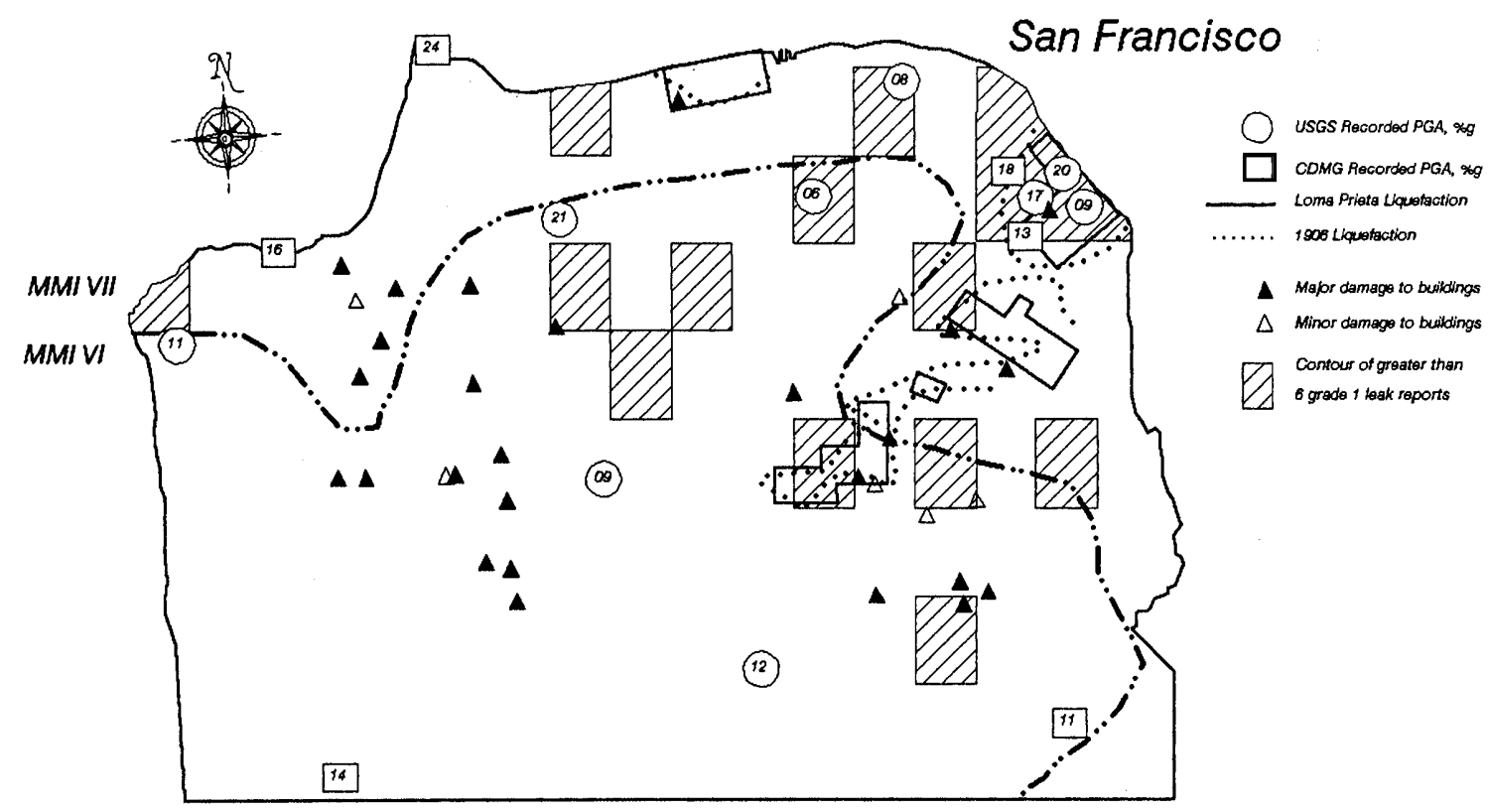

Figure 4.- Northern part of San Francisco, showing correlation of grade I distribution-main repairs with areas of observed liquefaction and building damage. CDMG, California Division of Mines and Geology; MMI, modified Mercalli intensity; PGA, peak ground acceleration; USGS, U.S. Geological Survey. 